Portland State University

PDXScholar

$1-1-2011$

\title{
Exploring Sense of Place of Community Gardens in Portland
}

\author{
Barbara E. Shields \\ Portland State University
}

Follow this and additional works at: https://pdxscholar.library.pdx.edu/open_access_etds Let us know how access to this document benefits you.

\section{Recommended Citation}

Shields, Barbara E., "Exploring Sense of Place of Community Gardens in Portland" (2011). Dissertations and Theses. Paper 307.

https://doi.org/10.15760/etd.307

This Dissertation is brought to you for free and open access. It has been accepted for inclusion in Dissertations and Theses by an authorized administrator of PDXScholar. Please contact us if we can make this document more accessible: pdxscholar@pdx.edu. 
Exploring Sense of Place of Community Gardens in Portland

by

Barbara E. Shields

A dissertation submitted in partial fulfillment of the requirements for the degree of

\author{
Doctor of Philosophy \\ in \\ Urban Studies
}

\begin{abstract}
Dissertation Committee
Carl Abbott, Chair

Ellen M. Bassett

Karen J. Gibson

W. Barry Messer

William Lang
\end{abstract}

Portland State University

(C)2011 


\begin{abstract}
The study examines social and physical connections and images that define the sense of place of three community gardens managed by the City of Portland. Most research on community gardens focuses on social group connections and their impact on community revitalization and empowerment. Few studies consider the impact of physical and social connections to community gardens from the perspective of individual gardeners in constructing their sense of place. No studies have yet examined the relationship between spatial images, space connections, and empowerment feelings related to community gardens. This study is intended to initiate a discussion on the empowerment experience of individual gardeners and their images associated with community gardens in the context of sense of place.
\end{abstract}

Thirty gardeners participated in the study. The use of the narrative photo storytelling method applied through de Certeau's practice of everyday life and narrative city approach enabled gardeners to express in their own terms connections to space and experience of empowerment achieved through community gardening.

The study proposes the concept of the Natural Realm as the context for sense of place of Portland Community gardens. Natural Realm deemphasizes the humancentric view of nature. 
Community gardeners most commonly experience empowerment by perceiving community gardens as sacred places where people feel well because they can grow healthy food, practice green domesticity, and learn from nature in a beautiful setting.

The study applies Rocha's ladder of empowerment to examine the relevance of individual and group action in fulfilling empowerment goals in the context of sense of place. Gardeners accomplish most of their empowerment goals through solitary efforts to maximize pleasurable activities and increase personal efficacy and satisfaction by optimizing physical and social connections in community gardens. 


\section{Acknowledgements}

This dissertation would have not have been possible without the generous contributions of the Fulton, Brentwood, and Johns gardeners who participated in my study. I am grateful to all the gardeners who spent the summer of 2009 with cameras trying to capture their most empowering images of Portland Community Gardens and shared with me their garden stories.

My special thanks goes to community garden managers William Cepurna, Robby Holmes, and Abby Corbet, who helped me understand the importance of volunteers in the Portland Community Garden Program. My appreciation also goes to City of Portland staff members Leslie Phol-Kosbau, John Iott, and Dan Franek, who spent many hours with me discussing the importance of the Community Garden Program.

I am especially grateful to the Chair of my Dissertation Committee, Carl Abbott, for his graciousness, charm, intellectual curiosity, and imagination in enabling me to explore sense of place of community gardens through a heuristic lens with the members of my committee: Ellen Basset, Karen Gibson, Barry Messer, and William Lang. 
Finally, I want to acknowledge my friends who inspired me with their endless words of support and excitement for the subject of my research. 


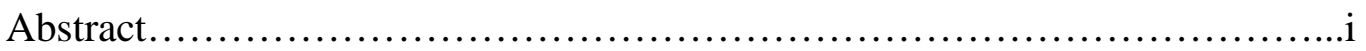

Acknowledgements ....................................................ii

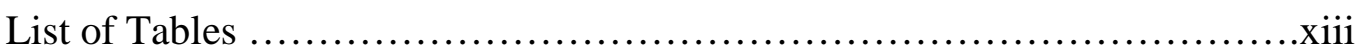

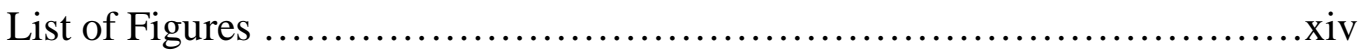

Chapter I

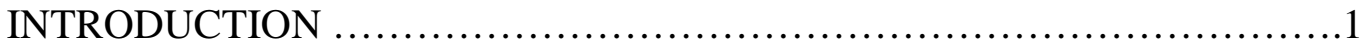

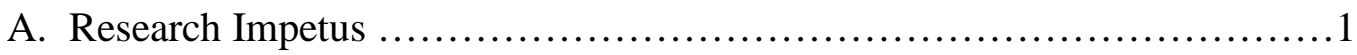

B. Purpose and Theoretical Framework ..................................4

C. Research Organization and Subjects.................................5

\section{Chapter II}

LITERATURE REVIEW .............................................. 7

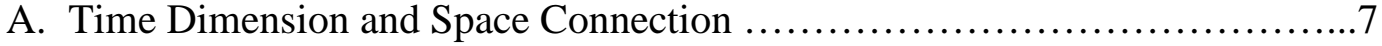

1. Sense of Place and Space Connections................................ 7

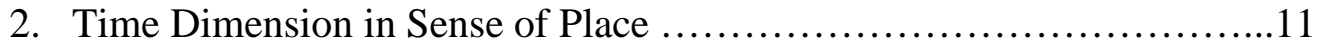

3. Community Gardens and Space Connections ........................12

B. Space Connections and Empowerment............................... 14

1. Concept of Empowerment.......................................14

2. Individual Empowerment in Community Planning and Development ....16

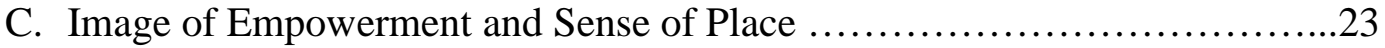

D. Link between Sense of Place, Empowerment, and Image .................25 
E. Link between Social Realm and the Practice of Everyday Life

F. Summary of Research Questions and Hypotheses

Chapter III

METHODOLOGY .33

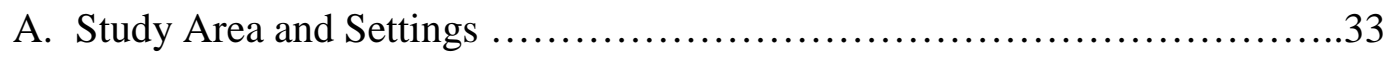

1. City of Portland Community Garden Program .........................33

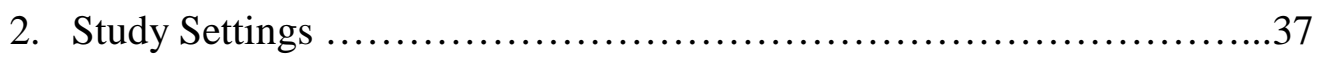

B. Data Collection ................................................42

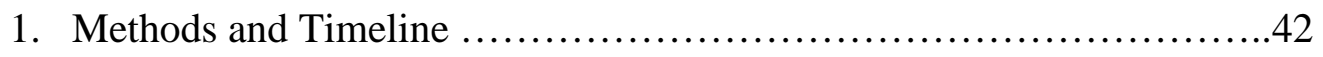

2. Field Observations ..........................................44

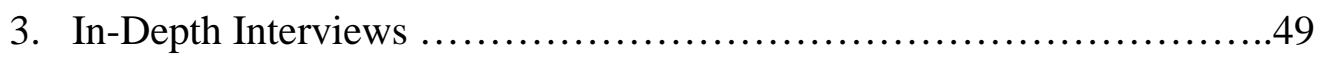

Chapter IV

SUMMARY OF FIELD OBSERVATIONS $\ldots \ldots \ldots \ldots \ldots \ldots \ldots \ldots \ldots \ldots \ldots \ldots . \ldots . \ldots \ldots 7$

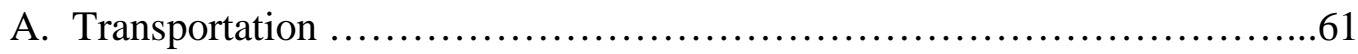

1. Space Connection in Transportation Phase .......................61

2. Social Realm in Transportation Phase ............................64

3. Transportation: Inter Garden Analysis ..........................65

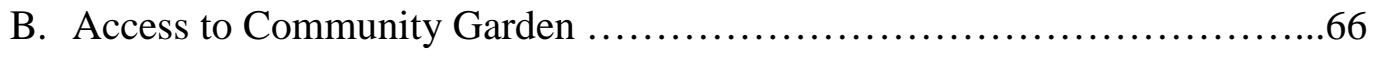

1. Space Connection in Access Phase ...............................66

2. Fence and Space Connections in Community Garden .................75

3. Access: Inter Garden Analysis . ...............................76 
C. Experiencing Garden Space

1. Garden Space Connections: Physical Factors..........................77

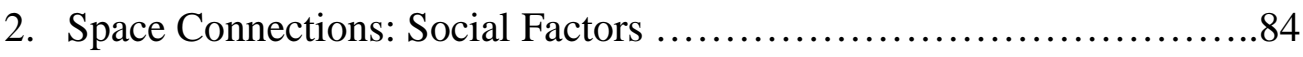

3. Social Realm........................................................93

D. Field Observations: Summary of Findings ............................... 101

1. Space Transformation and Dominant Connections in Community Gardens in Portland ................................................ 102

2. Social Realm in Community Gardens in Portland ....................103

3. The Role of the Agency (City of Portland) in the Practice of Everyday Life in Community Gardens in Portland 104

\section{Chapter V}

TIME AND SPACE CONNECTION IN COMMUNITY GARDENS .........107

A. Analysis of the Spatiotemporal Relationship in Community Gardens ......107 1. Physical versus Social Connections .................................108

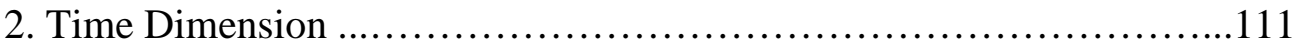

B. Time and Space Connection in Community Gardens: Summary of

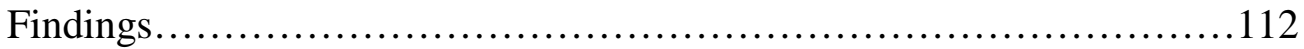

Chapter VI

COMMUNITY GARDEN EMPOWERMENT .............................116

A. Community Gardening Empowerment Goals ...........................117

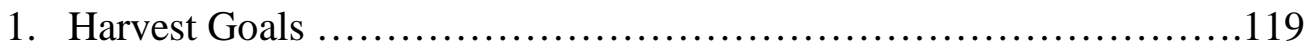

2. Non-Harvest Goals ............................................. 127 
B. Community Garden Empowerment Narratives .........................153

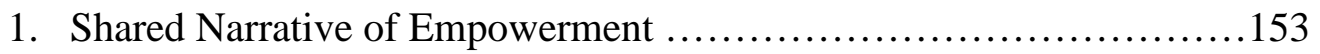

2. Fulton Empowerment Narrative: "The Beautiful Lifestyle" ............156

3. Brentwood Empowerment Narrative: "The Garden is Everything" ......158

4. Johns Empowerment Narrative: “The Community of Beauty and Food”.161

5. Garden Narratives: Summary of Findings...........................163

C. Individual and Group Action in Fulfilling Empowerment .................175

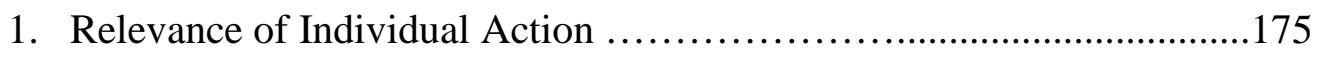

2. Relevance of Group Action ................................... 182

D. Community Garden Empowerment: Summary of Findings ................186

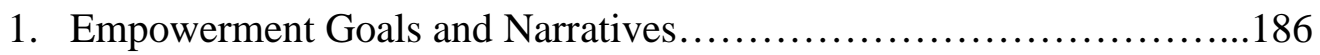

2. Empowerment and Space Connections ..........................187

3. Rocha's Ladder of Empowerment in the Community Garden Context ..188

4. Consumerism and Empowerment in Community Garden................191

\section{Chapter VII}

EMPOWERMENT AND IMAGE IN COMMUNITY GARDENS.............193

A. Types of Images in Community Garden ..............................194

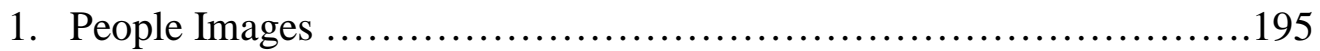

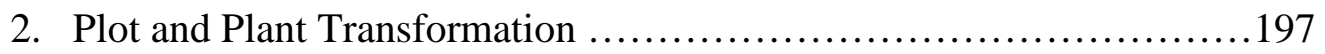

3. Influence of Surrounding Areas on Image Types .....................198

4. Types of Images in Community Garden: Summary of Findings .......200

B. Symbolic Representation of Community Garden Empowerment ...........200 
1. Food Harvest Empowerment Representations ......................203

2. Non-Food Harvest Empowerment Representations ....................204

3. Harvest Support Empowerment Representations ....................205

4. Beauty Empowerment Representations ............................206

5. Lifestyle Empowerment Representations ...........................210

6. Sanctuary Empowerment Representations .......................2215

7. Learning Empowerment Representations .............................219

8. Symbolic Representation of Empowerment in Community Garden: Summary of Findings........................................222

C. Empowerment Representations Across Gardens........................225

1. Fulton: "The Beautiful Lifestyle" Imagery...........................226

2. Brentwood: "The Garden is Everything" Imagery...................228

3. Johns: "The Community of Beauty and Food" Imagery ..............229

4. Empowerment Representations Across Gardens: Summary of Findings...................................................231

D. Empowerment and Image in Community Garden: Summary of Findings...232

1. Influence of Space Transformation on Empowerment Imagery.........232

2. Visual Images and Diversity of Empowerment.....................235

3. Importance of Photo Storytelling Method in Analyzing Sense of Place and Empowerment..............................................236

Chapter VIII

CONCLUSION: EXPLORING SENSE OF PLACE OF PORTLAND

COMMUNITY GADENS ............................................239 


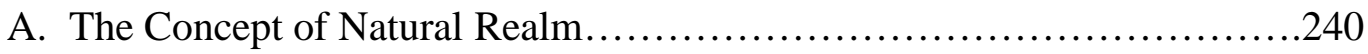

B. Time Dimension and Space Connection in Community Gardens..............240

C. Experiencing Empowerment in Community Gardens in

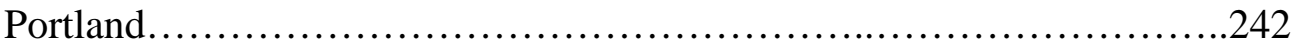

1. Community Garden Empowerment Shared Narrative..................242

2. Empowerment and Physical Space Connections........................242

3. Individual Empowerment in Community Gardening....................243

4. Community Gardening as a Reflection of Consumerism................244

D. Image of Community Garden Empowerment ...........................245

E. Imaging Future of Community Gardens in Portland .......................245

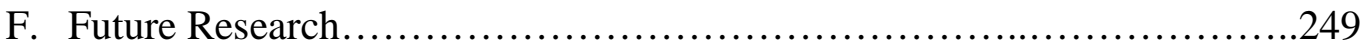

1. Towards Landscapes of Empowerment.................................249

2. Gardener Types................................................... 250

3. Class and Ethnic Dimensions in Community Gardening...............252

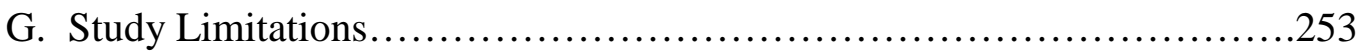

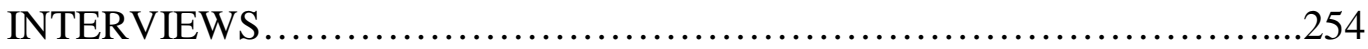

1. List of In-depth Interviews.......................................254

2. List of Interviews with Portland Community Garden Staff ............255

3. List of Interviews with Community Garden Managers..................255

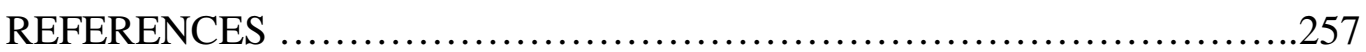

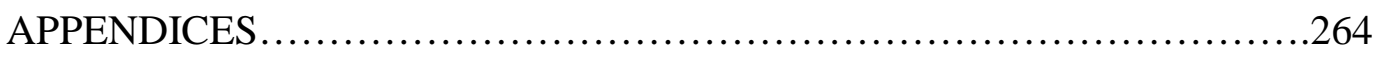

APPENDIX A. EMPOWERMENT IMAGES................................264 


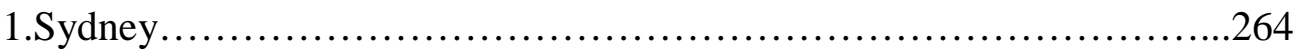

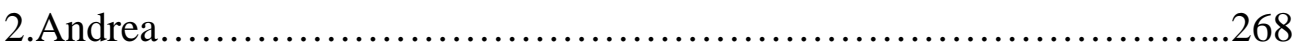

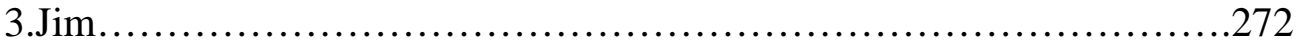

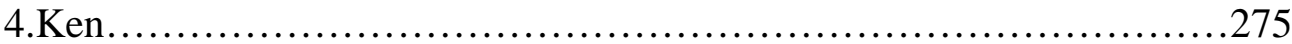

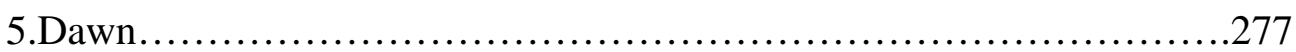

6. Perky ................................................................ 280

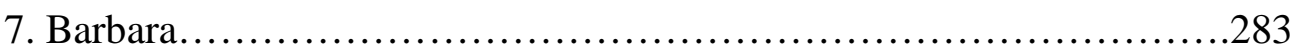

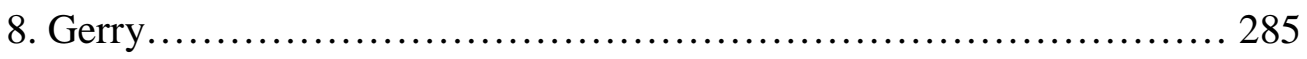

9.Florence........................................................ 288

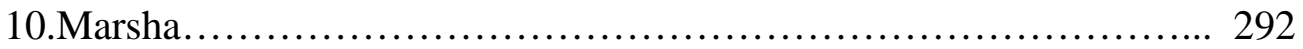

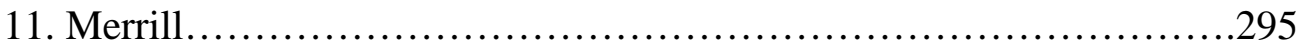

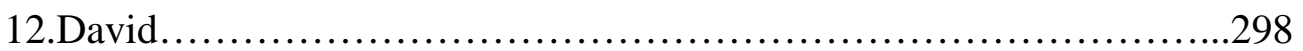

13. Lisa ............................................................... 301

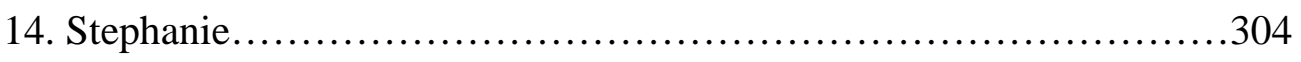

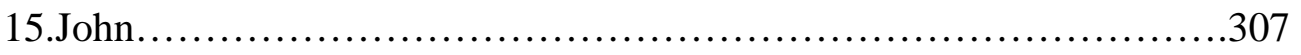

16.Melinda........................................................... 311

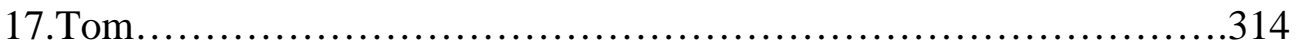

18. Heike.......................................................... 317

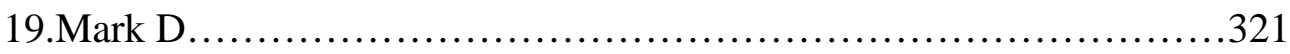

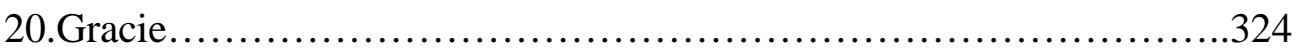

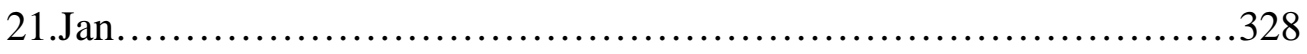

22. Bill........................................................... 331

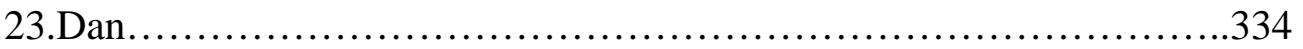

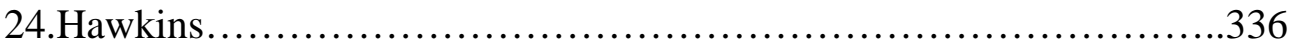


25.Wendy 338

26.Mark .341

27.Marguerite .344

28. Mary Anne. 346

29.Robby 349

30.Mike 352

B. MAPS 356

1. Fulton Community Garden Location .356

2. Brentwood Community Garden Location 357

3. Johns Community Garden Location.................................358

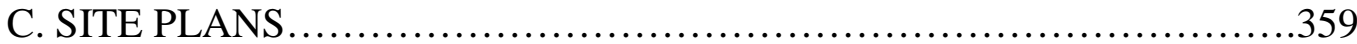

1. Fulton Community Garden Site Plan................................359

2. Brentwood Community Garden Site Plan.............................360

3. Johns Community Garden Site Plan...............................361

D.FIELD DATA COLLECTION ........................................ 362

1. Camera Script.................................................. 362

2. In-Depth Interview Script.........................................363 
List of Tables

Table III.1. Garden Sites: Summary of Physical Characteristics................41

Table III.2. List of Selected Gardeners...................................52

Table IV.1. Summary of Space Connections by Garden.........................59

Table IV.2. Summary of Interactions across Gardens .......................85

Table V.1. Time Dimension and Space Connection by Gardener...............107

Table VI.1. Empowerment Goals Summary..............................119

Table VI.2 Housing Types by Gardeners and Gardens.......................171

Table VI.3. Socioeconomic Data/Garden Vicinity.........................174

Table VI.4. Protecting Our Garden: Summary of Responses..................184

Table VII.1. Summary of Space Transformation Images.................... 195

Table VII.2. Summary of Symbolic Representations of Empowerment Goals...202 
List of Figures

Figure II.1. Research on Place: Field and Methodology......................8

Figure II.2. Empowering Processes and Outcomes across Levels of Analysis....15

Figure II.3. Individual Empowerment in Context of Rocha's Empowerment

Ladder.......................................................... 18

Figure II.4.Reserach Framework: Symbolic Meaning of Social Realms..........31

Figure II.5. Summary of Research Questions and Hypotheses.................32

Figure III.1. Johns Community Garden Location...............................39

Figure III.2. Fulton Community Garden Location..........................39

Figure III.3.Brentwood Community Garden Location.........................40

Figure IV.1.Community Garden Travel Story and Space Appropriation:

Analytical Approach................................................ 58

Figure IV.2. Community Garden Transportation

Choices..........................................................64

Figure IV.3. Transportation Choices across Gardens.........................65

Figure IV.4. Social Realms and Social Activities..........................95

Figure IV.5. Summary of Dominant Symbolic Representations of Social

Realms..........................................................99

Figure IV.6. Space Transformation and Dominant Connection in Portland Community Gardens ..................................................103

Figure V.1 Natural Realm Web Connections in Community Gardens. ..........114

Figure VI.1. Empowerment in Community Gardens.........................153

Figure VI.2. Non-Harvest Empowerment Goals and Themes..................156

Figure VI.3. Empowerment in Fulton Community Garden...................157

Figure VI.4. Empowerment in Brentwood Community Garden................159

Figure VI.5. Empowerment in Johns Community Garden....................162 
Figure VI.6. Empowerment across Gardens.............................164

FigureVI.7. Non-Harvest Goals and Themes across Gardens..................165

Figure VI.8. Space Connections and Empowerment across Gardens.............167

Figure VII.1. Percentage of Garden Images by Type..........................194

Figure VII.2. Distribution of Image Types across Gardens...................198

Figure VII.3. Distribution of Symbolic Representations of Empowerment

Goals..............................................................201

Figure VII.4. Hawkins, Johns Gardener, "The First Carrot,"

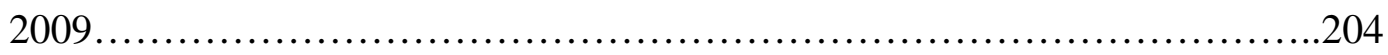

Figure VII.5. Andrea, Fulton Gardener, "A Bouquet of Sunflowers: Sharing

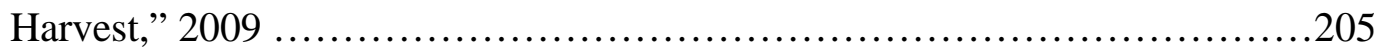

Figure VII.6. Robby, Johns Gardener, "Water in the Garden: It is something I do not take for granted,"

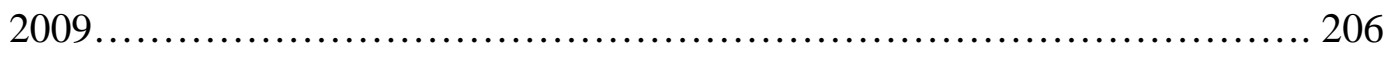

Figure VII.7. David, Fulton Gardener, “Art and Garden Beauty: Composition of Natural Shapes, Colors, and Structures," 2009..........................208

Figure VII.8. Merrill, Fulton Gardener, "Sharing the Beauty and the Bounty of the Garden,"

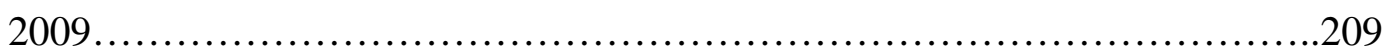

Figure VII.9. Stephanie, Brentwood Gardener, "Japanese Mustard Leaf: Beauty in the Garden,"

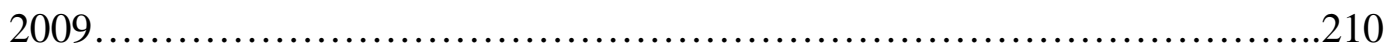

Figure VII.10. Mike, Johns Gardener, "The Prolific Garden: Summer Harvest,"

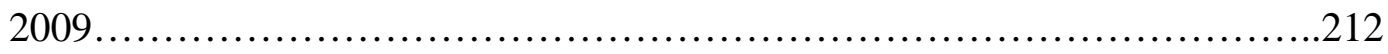

Figure VII.11. Mark, Johns Gardener, "Green Oasis in Rural Eden," 2009 .

Figure VII.12. Florence, Fulton Gardener, "The Place of Beauty: Family Space in

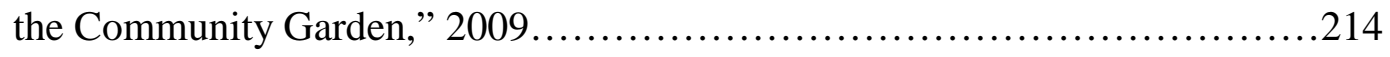


Figure VII.13. Gracie, Brentwood Gardener, "Raspberries: Luxurious Food and Celebration of Healthy Lifestyle," 2009.

Figure VII.14. Lisa, Brentwood Gardener, "Imperfect Patterns of Life," 2009

Figure VII.15. Florence, Fulton Gardener, "The Road to the Garden and Childhood Memories: O hushed October morning mild, Thy leaves have ripened to the fall,"'2009.

Figure VII.16. Gracie, Brentwood Gardener, "Working Together in the Community Garden: Growing Friendships,” 2009.

Figure VII.17. Dan, Johns Gardener, "First Year: Garden Panic,” 2009........221

Figure VII.18. Bill, Brentwood Gardener, "Accepting the Unexpected: Control and Pleasure in Garden and Life," 2009.

Figure VII.19. Symbolic Representations of Empowerment Goals by Number of Image

Types............................................................... 223

Figure VII.20. Distribution of Image Types by Empowerment Goals..........223

Figure VII.21. Fulton Representation of Empowerment Goals by Number of

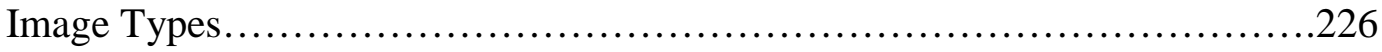

Figure VII.22. Fulton Distribution of Image Types by Empowerment Goals... .227

Figure VII.23. Brentwood Representation of Empowerment Goals by Number and Image

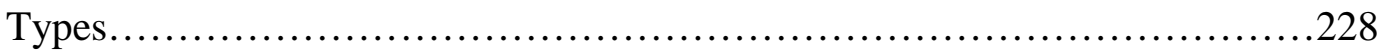

Figure VII.24. Brentwood Distribution of Image Types by Empowerment

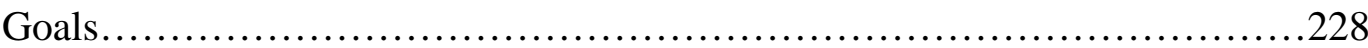

Figure VII.25. Johns Representation of Empowerment Goals by Number of Image Types.... .230

Figure VII.26. Johns Distribution of Image Types by Empowerment Goals .230

Figure VII.27. Dominant Image Types across Gardens .231 
Figure VII.28. People and Surrounding Area Images in Empowerment

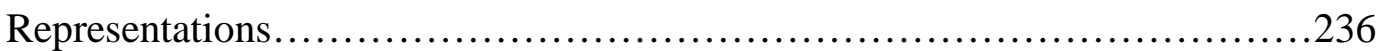

Figure VIII. 1. Towards Landscapes of Empowerment........................250

Figure VIII. 2. Gardener

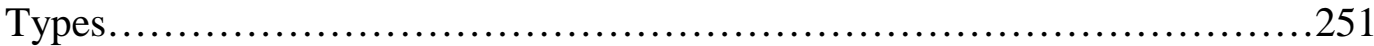




\section{INTRODUCTION}

\section{A. Research Impetus}

In a discussion on crisis in public spaces, urban community gardens occupy a prominent role as the reinvention of public green space. Green public spaces are considered the key to a livable urban environment. The beginning of the third millennium should mark an opportunity for increasing the quality of urban living by the creation of many new gardens (Cohen and Potter, 2000). With an increasing necessity for self-sufficiency, the benefits of gardens as providers of food are important. Community gardens should help to improve urban selfsufficiency, bring nature into the cities, and promote biodiversity.

In 2006, Community Greening Review asked some of the most accomplished researchers in the field of community greening to share their newest thoughts and insights about community gardens (Tidball and Krasny, 2006). As part of this discussion, Connie Nelson noted:

"One thing that is still an issue is sense of place. When you really talk to people about why they garden and what they do in the gardens, it is about place, it is about a relationship with place, it's about a relationship with plants, and it is about a relationship with other people. This is a quality I think that we want to have throughout the city in a variety of ways, and that's one of the areas that gardens contribute something more that designed traditional open spaces..." (Tidball and Krasny, 2009) 
Mark Francis, who participated in the same discussion, observed:

"I think that the movement has grown up to a point where it can take itself even more seriously and to contribute even in a larger way to the overall urban environment, beyond just places for individuals to have plot so they can grow vegetables. That's stereotype, and I think gardens have reached beyond that and they need to take that opportunity seriously..." (Tidball and Krasny, 2009)

The primary impetus of my study was to examine the factors that stimulate the formation of social and physical connections to community gardens that influence the sense of place and provide the context for community development. A better understanding of the factors that influence the formation of the sense of place of community gardens may help to explore the role of community gardens as public spaces in the third millennium.

How do people experience community gardens at the beginning of the third millennium? Do community gardens contribute beyond the stereotypical places to grow vegetables? Do community gardens influence effective bonds to places? Do the gardens help to inspire action to protect and improve places that are meaningful to gardeners?

Literature on public spaces emphasizes the importance of physical and social connections to public spaces to influence sense of place and stimulate community development (Carr, Francis, Rivlin, \& Stone, 1992). Sense of place components 
are all critical parts of person-environment transactions that foster the development of community in all of its physical, social, political, and economic aspects. In particular, affective bonds to places can help inspire action because people are motivated to seek, stay in, protect, and improve places that are meaningful to them (Brown \& Perkins, 1992). Sense of place has become a concern in the community development literature, focusing on people's connections to place (Manzo, 2005).

Prolific, but narrow, research on community gardens stresses the value of community gardens in community development but centers on the general benefits of community gardening, ranging from urban revitalization and environmental stewardship to food production, relaxation and education. An urban community garden is commonly defined as a collective venture that entails the formation of a social network (Glover, 2004), which voluntarily brings together collective resources to deal with neighborhood issues, notably urban decline and the criminal activity associated with it. The emphasis is on the formation of social connections rather than the importance of physical features (Glover, 2004; Jamison, 1985; Landman, 1993; Schmeltzkof, 1996; Schrieber, 1998; Kingsley \& Townsend, 2006; Pudup, 2008).

Manzo and Perkins argue that literature on space connections, sense of place, and place attachment focuses on individual feelings and experiences and has not placed these bonds in the larger context, in which planners operate (Manzo and Perkins, 2006). Community planning literature emphasizes participation and 
empowerment, but overlooks emotional connections to place. Although place connections are important in inspiring community development actions, research on place has not played an important role in the community planning and development processes. Much of the reason lies in the lack of interdisciplinary collaboration and in differences in perspective across research fields.

\section{B. Purpose and Theoretical Framework}

The main purpose of the study is to link the concept of sense of place with community development to examine the role of community gardens as public spaces. The study focuses on three aspects of sense of place that are important to community development: (1) the influence of time dimension on forming physical and social connections to community gardens: (2) the influence of social and physical connections on experiencing empowerment in community garden settings: and (3) the representation of empowerment images held in common by community gardeners.

De Certeau's spatial travel story (De Certeau, 1984) was applied to explore the relationship between sense of place, empowerment and image in the context of community gardening.

The narrative storytelling methodology that was applied in my research enabled gardeners to express in their own terms their connections to space and their experiences of empowerment achieved through community gardening. The temporal and thematic aspects of the narratives captured the impact of time 
dimension on forming social and physical connections to the garden with the contextual aspect of empowerment. The photo images provided an additional understanding of the empowering impact of community gardens in the context of storytelling.

C. Research Organization and Subjects

Chapter II contains a discussion of theoretical framework and research questions.

Chapter III discusses methods applied in the study.

Chapter IV contains a summary of field observations. It consists of two major parts: (1) discussion of the factors influencing the formation of physical and social connections to community gardens; and (2) discussion of the influence of space connection on social realms.

Chapter V contains analysis and findings related to the influence of the time dimension on forming space connections and sense of place. I propose that the Natural Realm connections that deemphasize the human role in nature and embrace the circular concept of time form the basis for the sense of place context. The Natural Realm is grounded around the garden cycle. Thus, the significant space transformations that influence the formation of relevant connections revolve around the cyclical concept of time, marked by the renewal of nature. 
Chapter VI contains an analysis and findings related to empowerment. The first part contains a discussion of multiple forms of individual empowerment in community gardens and the influence of the social realm and physical settings on the formation of individual empowerment goals. The second part focuses on the empowerment process, (i.e., the relevance of individual and group action in accomplishing the empowerment goals.)

Chapter VII contains an analysis of empowerment images. The first part of Chapter VII focuses on a discussion of the relationship between the community gardeners own practices and the formation of their space images. The second part of the chapter contains a discussion of community gardeners own images of space symbolizing empowerment feelings.

Chapter VIII consists of three parts: (1) a summary of key findings; (2) study implication for community development and planning; and (3) directions for future research on image and empowerment in the context of sense of place. 


\section{Chapter II. LITERATURE REVIEW}

The study focused on three dimensions of sense of place: (1) the influence of time dimension on forming physical and social connection to community gardens (i.e., whether physical connection to spaces play an important role in constructing sense of place in a short term, but less important in the long term); (2) the influence of social and physical connections on experiencing empowerment in community garden settings (i.e., whether and how space connections influence the feeling of empowerment and whether empowerment is achieved through individual or group action) and (3) the representation of empowerment images held in common by community gardeners (i.e., whether and how garden empowerment is represented in visual images held by community gardeners.)

\section{A. Time Dimension and Space Connection}

\section{Sense of Place and Space Connections}

The concept of sense of place emerged in the late 1960s as a focus for exploring the relationship between humans and the environment in a variety of fields, ranging from architecture, planning, and geography to environmental psychology and sociology. In the late 1970 s, the concept gained prominence among researchers in architecture and geography with the publication of works such as Relph's (1976) Place and Placeness; Tuan's (1977) Space and Place: The Perspective of Experience, and Norberg-Schultz's (1980) Genius Loci: Towards 
Phenomenology in Architecture. In the early 1990s, environment and behavioral researchers, such as Low and Altman (1992), dominated research on place.

In the first decade of the twenty first century, research on place continues to be informed by two major research traditions: phenomenology and environmental psychology and sociology. Human geography, architecture and planning researchers have focused on the term "sense of place" and favor phenomenological methods, whereas environmental psychologists and sociologists tend to use the term "place attachment" or "place identity" for place related research (Figure II.1).

Figure II.1. Research on Place: Field and Methodology

\begin{tabular}{|l|l|l|}
\hline Research Term & Research Field & $\begin{array}{l}\text { Research } \\
\text { Approach/Methodology }\end{array}$ \\
\hline Sense of Place & $\begin{array}{l}\text { Geography, architecture, } \\
\text { planning }\end{array}$ & Phenomenology/qualitative \\
\hline Place Attachment & Environmental psychology & $\begin{array}{l}\text { Positivistic/quantitative/ } \\
\text { psychometrics }\end{array}$ \\
\hline Place Identity & Sociology, social psychology & $\begin{array}{l}\text { Positivistic/quantitative/ } \\
\text { psychometrics }\end{array}$ \\
\hline
\end{tabular}

The phenomenological approach is concerned with presences or objects as they appear in consciousness. Objects are not of interest for their "objective," "real," or "existential" sense, rather the focus is on the meaning of the object precisely as it is given to an individual (Seamon, 1982).The phenomenologically grounded place research pioneers, such as Relph (1976) and Seamon (1997) suggest that 
place is not a formal concept awaiting a precise definition. Efforts to operationalize place-related concepts into constructs such as "place identity" eliminate the phenomenological essence of place as a psycho-socialenvironmental whole larger than the sum of its parts. Phenomenology focuses on the meaning and experience of places via a descriptive, qualitative discovery of things in their own terms, where place is an inseparable part of existence (Tuan, 1977). In contrast, environmental psychologists and sociologists focus their efforts to translate place terminology into social psychological concepts with "well established measures" that permit quantitative hypothesis testing (Stedman, 2002, 2003) and on developing constructs that can be operationalized (Low and Altman, 1992).

Regardless of the difference in semantics and methodological approaches, research on place centers on the three-component view of place: physical setting, human activities, and psychological processes, including image formations. Hidalgo (2001) examines how the physical and social dimensions of attachment vary across spaces that are different in size, ranging from house to city scale. Similarly, Stokols and Altman (1987) assert that environmental elements and physical context contribute to aesthetic place perception and image. Stedman (2003) and Riley (1992) examine how elements in the physical environment relate to sense of place and how humans interact with landscapes and form connections. Similarly, phenomenological researchers, Relph (1976) and Tuan 
(1977), stress the importance of social, physical, and symbolic aspects in forming sense of place.

A number of studies emphasize the dynamic nature of social and physical connections and meaning as part of sense of place development. The phenomenological perspective I applied in my study suggests that relationship to place is a dialectic process that forms the foundations of human being (Seamon, 1979; Relph, 1976). The research in sociology, psychology, geography, and design fields indicates that the relationship between physical and social connections is a dynamic process and the meaning of place is subject to change. The appropriation of space is the key phenomenological concept in exploring the dynamic nature of the connections people develop with space (Stedman, 2003). Appropriation purports that it is only by means of human activities (both mental and physical) that the world has become a truly human habitat, that objects and occurrences become human affairs (Graumann, 2003). Appropriation means making something one's own and taking it for one's use. Within the sociocultural context, appropriation means that what a person does is learned from others either by instruction or by doing as others do. On the other hand, it is through appropriating their environment that people acquire new skills and patterns of behavior to develop skills that enable them to deal with new environmental features and events. The dialectical meaning of appropriation means that people change by changing the environment. 


\section{Time Dimension in Sense of Place}

Research on place has recognized time dimension as one of the key elements in forming social and physical connections to place through place appropriation. Researchers rooted in both positivistic and phenomenological approaches agree that length and experience with the setting is a critical factor for exploring the relationship between the length of time and the influence of social connections in forming sense of place.

Sociologists and psychologists examining community attachment and identity have been replicating and modifying Kasarda and Janovitz (1974). The Kasarda and Janovitz community attachment model posits a systematic interaction between community attachment and length of residence. In that context, longterm residence emerges as a variable highly correlated with the strength of localized social attachment. McCool and Martin (1994) observe that recent immigrants may quickly form strong sentimental ties to a locale based largely on natural environmental factors such as landscape features. They argue that this is indicative of the tendency of newcomers to be attached to physical or landscape features of place, as opposed to social networks and local relationships.

Relph (1976) and Tuan (1977) argue that from a temporal perspective, the physical dimensions of places are most salient in the short term and are displaced in the long term by socio-cultural dimensions. Emotion links that all humans experience so that place can acquire deep meaning through "the steady accretion 
of sentiment" (Tuan, 1977, p. 33), which could imply that a length of time may be the key dimension in forming the "social sense of place," based on emotional and social connections to the place.

Both Tuan and Relph emphasize the dynamic nature of people's relationships to places. They claim that the physical dimensions of place play an important role in constructing sense of place in the short term, but are less important in the long term.

\section{Community Gardens and Space Connections}

Research on community gardens typically centers on the social connections to community gardens and their impact on revitalizing the surrounding areas.

Glover (2004) and Jamison (1985) explore community gardens as a social context in which the participants' willingness to share resources is enhanced by the social connections they make during their participation in the shared act of gardening. Landman (1993) and Schmeltzkof (1996) discuss how by converting dilapidated vacant lots into usable garden spaces, community gardeners renew their declining neighborhoods and turn neighborhood liabilities into assets. Community gardens provide opportunities for social interaction, through shared enjoyment of gardening (Schrieber, 1998).

Only a handful of studies have explored the impact of physical features of community places on forming connections to community gardens. Jamison 
(1985) argues that physical features and design of community gardens reflect an emphasis on either collective or individual activities in community gardens. The garden structures, design, and plants also reflect the country of origin of the gardeners and garden members (Ferris, 2001). Francis, Cashdan, \& Paxon emphasize the lack of significance of physical factors in commuity gardening (Francis, Cashdan, \& Paxon, 1984). They claim that community control of the decision making and development process is the primary incentive for people to get involved in the project and the design and physical arrangment of garden places is not a major factor, but it is secondary to the primary aspect of controlling the space. Community gardens are ephemeral places, "placeholders" for other uses (Schmelzkof, 1996), and therefore, typically, there is a limited incentive for major physical improvements (Lawson, 2005).

In summary, the existing community garden research has focused on the social realm and the impact of community gardens on revitalizing the surrounding area. It has not addressed the issue of how social interactions and physical connections shape the sense of place held by community gardeners and how time dimension influences the formation of space connections to community gardens.

\section{Study Question:}

How does the time dimension influence social and physical connection developed by gardeners?

Study Hypothesis: 
Physical dimensions of gardens play an important role in constructing sense of place in the short term but are less important in the long term.

B. Space Connections and Empowerment

1. Concept of Empowerment

Empowerment is a process by which people, organizations, and communities gain mastery of their affairs (Rappaport, 1987). Empowerment is a process in which efforts to exert control are central (Zimmerman, 2000). This definition suggests that participation with others to achieve goals, efforts to gain access to resources, and a critical understanding of the sociopolitical environment are the key components.

A theory of empowerment includes processes and outcomes (Zimmerman, 2000). It suggests that activities or structures may be empowering and that the outcome of such processes result in a level of being empowered. Empowering processes, which attempt to gain control, to obtain resources, and to critically understand one's social environoment, are fundamental. Empowered outcomes refer to operationalization of empowerment to study the consequences of people's attempts to gain greater control in their community or the effects of interventions to be empowered.

Empowered persons are the basis for developing responsible and participatory organizations and communities that form foundations for community 
development. At an organizational level of analysis, empowerment may include processes and structures that enhance member participation and improve organizational effectiveness for goal achievement. At a community level of analysis, empowerment may refer to collective action to improve the quality of life in a community and the connections among community organizations.

Figure II.2 summarizes empowering processes and empowered outcomes across the levels of analysis discussed by Zimmerman (2000). Each level of analysis is inherently connected to the others. Individual, organizational, and community empowerment are interdependent and are both a cause and consequence of each other.

Figure I I.2. Empowering Processes and Outcomes across Levels of Analysis

\begin{tabular}{|l|l|l|}
\hline \multicolumn{1}{|c|}{ Level of Analysis } & \multicolumn{1}{|c|}{ Empowering Process } & \multicolumn{1}{c|}{ Outcome } \\
\hline \multirow{2}{*}{ Individual } & Learning decision making skills & Sense of control \\
& Managing resources & Critical awareness \\
Working with others & Participatory behaviors \\
\hline Organizational & $\begin{array}{l}\text { Opportunities to participate in decision } \\
\text { making }\end{array}$ & $\begin{array}{l}\text { Effectively compete for } \\
\text { resources }\end{array}$ \\
& $\begin{array}{l}\text { Shared responsibilities } \\
\text { Shared leadership } \\
\text { organizations }\end{array}$ \\
& $\begin{array}{l}\text { Access to resources } \\
\text { Open government structure } \\
\text { Tolerance for diversity }\end{array}$ & $\begin{array}{l}\text { Policy influence } \\
\text { Residents' participatory } \\
\text { skills }\end{array}$ \\
\hline
\end{tabular}


The focus of my study was to analyze empowerment outcomes associated with community gardens at the individual level of analysis (Figure II.2, shaded area). An empowered person is expected to exhibit a sense of personal control, a critical awareness of the environment, and the behaviors necessary to exert control. Perceived control is the belief that one can influence decisions that affect one's life and accomplishment of goals. Critical awareness is the ability to analyze and understand the social and political environment. This includes the recognition of causal agents with authoritative power and their connection to issues of concern. Participatory behavior includes being a part of a collective action, involvement in voluntary organizations, or solitary efforts to influence the sociopolitical environment.

Empowered individuals possess some combination of a sense of control in accomplishing goals, a critical awareness of their sociopolitical environment, and an involvement in their community. One component does not necessarily lead to another, nor are they hierarchically ordered. Rather these components are found in varying degrees in different individuals (Zimmerman, 2000).

\section{Individual Empowerment in Community Planning and Development}

Empowerment suggests approaches for developing interventions and creating social change. It directs attention toward adaptation, competence, and natural helping systems. It includes the perspective that many social problems exist due 
to unequal distribution of, and unequal access to, resources. Community development deals directly with this process (Zimmerman, 2000).

Empowerment concepts involve both an individual (psychological) dimension and collective (political) dimension. Community development addresses both. Participants in community development develop skills integral to empowerment, ranging from self-help and mutual aid activities to increased involvement in neighborhood organizations. Participation in community neighborhood organizations is associated with psychological manifestations of individual empowerment, such as perceived personal competence, political efficacy, expectations of successful group problem solving, and a greater sense of civic duty.

Zimmerman provides the general conceptual framework for an empowerment theory, which can be tested in different contexts and fields (Zimmerman, 2000). Rocha's empowerment research focuses on the fields of planning and community development (Rocha, 1997). Rocha's ladder can be employed as a theoretical framework to measure the extent to which individual empowerment goals are achieved, either by the participation in group activities or through solitary efforts. Rocha's empowerment typology can be utilized by community development practitioners to gain a conceptual view of how empowerment is realized and by local governments to evaluate the methods used by community organizations. 
Under Rocha's ladder typology, four empowerment dimensions are examined:

locus, process, goals and power experience. For two types of empowerment (political and sociopolitical), the fulfillment of individual goals is achieved through the process of participation in collective group action. For three types of empowerment (atomistic, individual, and mediated) the fulfillment of empowerment goals is achieved by solitary and individual action. The locus of empowerment - the intended arena of change- also moves from individual to community. In political and sociopolitical empowerment, individual empowerment goals are likely to reflect the goals of the group. In a group type empowerment, the sense of control in gained by accomplishing goals by group actions. In an individual type empowerment, the accomplishment of goals is associated with individual action. Critical awareness relates to the individual assessment of the extent to which certain goals may be accomplished through individual and group action.

Figure II.3 reflects the relationship between the individual level of analysis of empowerment outcomes proposed by Zimmerman and the ladder of empowerment proposed by Rocha.

Figure II.3. Individual Empowerment in Context of Rocha's Empowerment Ladder

\begin{tabular}{|c|c|c|c|}
\hline $\begin{array}{c}\text { Empowerment } \\
\text { Type }\end{array}$ & $\begin{array}{c}\text { Empowerment Goal } \\
\text { and Focus } \\
\text { (Sense of Control) }\end{array}$ & $\begin{array}{c}\text { Empowerment } \\
\text { Process } \\
\text { (Critical Awareness } \\
\text { and Participatory } \\
\text { Behavior }\end{array}$ & $\begin{array}{c}\text { Dominant } \\
\text { Empowerment } \\
\text { Feeling (Power } \\
\text { Experience ) }\end{array}$ \\
\hline $\begin{array}{l}\text { Atomistic } \\
\text { Individual }\end{array}$ & $\begin{array}{l}\text { Increase in individual } \\
\text { coping skills } \\
\text { (vocational or physical }\end{array}$ & $\begin{array}{l}\text { Individual action; } \\
\text { strength is gained } \\
\text { through the support }\end{array}$ & $\begin{array}{l}\text { Feelings of power } \\
\text { gained via self- }\end{array}$ \\
\hline
\end{tabular}




\begin{tabular}{|c|c|c|c|}
\hline $\begin{array}{c}\text { Empowerment } \\
\text { Type }\end{array}$ & $\begin{array}{l}\text { Empowerment Goal } \\
\text { and Focus } \\
\text { (Sense of Control) }\end{array}$ & $\begin{array}{c}\text { Empowerment } \\
\text { Process } \\
\text { (Critical Awareness } \\
\text { and Participatory } \\
\text { Behavior }\end{array}$ & $\begin{array}{c}\text { Dominant } \\
\text { Empowerment } \\
\text { Feeling (Power } \\
\text { Experience ) }\end{array}$ \\
\hline & capacity) & from organization & control \\
\hline $\begin{array}{l}\text { Embedded } \\
\text { Individual }\end{array}$ & $\begin{array}{l}\text { Individual goal, sense } \\
\text { of control related to } \\
\text { participation in } \\
\text { organization External } \\
\text { elements are } \\
\text { understood to increase } \\
\text { control over the self } \\
\text { within existing } \\
\text { structures }\end{array}$ & $\begin{array}{l}\text { Recognition of } \\
\text { surrounding } \\
\text { environment but focus } \\
\text { on individual action }\end{array}$ & $\begin{array}{l}\text { Feeling of power } \\
\text { gained via } \\
\text { membership in } \\
\text { organization in } \\
\text { specific physical } \\
\text { setting }\end{array}$ \\
\hline $\begin{array}{l}\text { Mediated } \\
\text { Individual }\end{array}$ & $\begin{array}{l}\text { Individual goal is } \\
\text { accomplished with } \\
\text { expertise of } \\
\text { professionals }\end{array}$ & $\begin{array}{l}\text { Empowerment is } \\
\text { mediated by expert or } \\
\text { professional; Focus on } \\
\text { individual action } \\
\text { within group to obtain } \\
\text { service }\end{array}$ & $\begin{array}{l}\text { Feeling of power is a } \\
\text { result of negotiations } \\
\text { between client and } \\
\text { expert (helping and } \\
\text { receiving) }\end{array}$ \\
\hline $\begin{array}{l}\text { Sociopolitical } \\
\text { Group }\end{array}$ & $\begin{array}{l}\text { Individual and } \\
\text { community goals to } \\
\text { change power structure }\end{array}$ & $\begin{array}{l}\text { Critical awareness by } \\
\text { group and individuals } \\
\text { of relationship to } \\
\text { structures of power } \\
\text { and collective action } \\
\text { upon these structures }\end{array}$ & $\begin{array}{l}\text { Feeling of power } \\
\text { comes from } \\
\text { collective action to } \\
\text { accomplish group } \\
\text { and individual goals }\end{array}$ \\
\hline Political Group & $\begin{array}{l}\text { Individual and } \\
\text { community goals to } \\
\text { obtain resources for } \\
\text { group }\end{array}$ & $\begin{array}{l}\text { Group action aimed at } \\
\text { allocation of } \\
\text { resources; } \\
\text { Geographically } \\
\text { defined community }\end{array}$ & $\begin{array}{l}\text { Feeling of power } \\
\text { comes from } \\
\text { allocation of } \\
\text { resources, typically } \\
\text { to a specific } \\
\text { area/program }\end{array}$ \\
\hline
\end{tabular}

Rocha's ladder provides a method of determining the extent that individual empowerment goals are achieved either by the participation in group activities or through solitary efforts. The ladder was constructed from a review of the empowerment literature and was not intended to be an explicit guide to practice. 
One of the objectives of my study was to test Rocha's ladder of empowerment in the context of community gardens.

Even though the multifaceted nature of empowerment has been well documented in the literature, the range of empowerment experiences within particular settings has not been fully explored. Although, within a given context, setting members may have similar goals, they may experience different empowerment feelings (Zimmerman, 2000). The contextual embeddedness of empowerment recognizes that both physical and organizational settings influence the experience of empowerment. It is important, therefore, to understand how different contexts influence the experience of indiviudals.

The concept of community development is broadly employed to capture a variety of social, economic, and physical improvements meant to empower people. While there may be many neighborhood improvement projects that make urban living more fulfilling, an effective community development strategy requires attention to increasing the community's capacity to meet its needs. Many advocates describe urban gardens as community development because they serve so many community functions, such as social interaction, beautification, and education. However, the question is whether these programs actually empower individuals and communities over the long run. 
The leading research text on the phenomenon of community-developed gardens and open spaces, frequently referenced by community garden actvists and reseachers is Community Open Spaces by Francis, Cashdan, \& Paxon (1984). Francis, Cashdan, \& Paxon claim that community control of the decision making and development process is common in community gardening projects. Control is an important incentive for people to get involved in the project and to continue to work over time. Francis, Cashdan, \& Paxon find that control of the process has several benefits for community gardens because it increases the sense of attachment and helps groups develop their own management skills and leadership. Community gardening stimulates growth through knowledge acquisition and collaborative social action. Working together in community gardens empowers people to pursue political action to change their living conditions. This type of empowerment is classified as "political" according to Rocha's ladder of empowerment.

A more comprehensive review of literature on community gardens revealed that people participate in community garden projects for different reasons, ranging from food production for their own consumption to larger community development goals. Consequently, they experience community gardens at different levels (Glover, 2004; Amstrong, 2000; Francis, 1992). With that, I found Rocha's ladder of empowerment transformation useful in terms of analyzing the whole spectrum of feelings and connections associated with community gardens. 
Rocha does not specifically relate her concept of the empowerment ladder to sense of place (Rocha, 1997). Manzo and Perkins (2006) provide an informative discussion of emotional relationships with places, but their focus is mostly on the "embedded individual" and "political empowerment" in the context of place. I found this approach to be too narrow to be helpful in examining the full spectrum of empowerment types in the context of place. Manzo and Perkins argue that unique qualities and meanings of the specific physical settings in which community planning and development takes place can play a critical role in the community development process. Their analysis, however, does not link different types of empowerment with socially or physically based sense of place. Research that incorporates place experiences (physical and social connections) can provide an important model for an ecological approach to community-based planning. The approach employed in my study is to link the physical and social aspects of sense of place to the different types of individual empowerment.

\section{$\underline{\text { Research Question: }}$}

What types of empowerment are experienced by community gardeners? What is the impact of the physical setting of gardens on empowerment experienced by community gardeners?

The objective of my study was to test Rocha's ladder of empowerment in examing indivudual empowerment feelings achieved through community gardens. I focused on two contextual aspects of experiencing empowerment: (1) 
multiple forms of empowerment related to gardening activities, which assumes that people may have different goals and rely on different processes to accomplish them either by indivdual or group action; and (2) the impact of the physcial settings of gardens on empowerment feelings.

Hypothesis:

Community gardeners in Portland experience multiple forms of empowerment; mostly at the embedded individual and/or mediated empowerment levels

\section{Image of Empowerment and Sense of Place}

Image of sense of place consists primarily of the collection of symbols reflecting physical settings, activities, and human and social processes rooted in the setting (Relph, 1976). People attribute meanings to landscapes and, in turn, become attached to meanings (Relph, 1976; Tuan, 1977). A given setting will contain as many different meanings as there are people using the setting (Meinig,1979; Relph, 1976).

Relph (1976) points out that the image consists of all the elements associated with the experience of individuals or groups and their intentions towards that place. Insofar as these intentions are specific, such images may be considered by others to be narrow and biased. But for those who hold them, they are complete and constitute reality of that place. Boulding (1956) argues that the basic bond of any society or organization is a "public image," ( i.e., an image of the essential characteristics, which are shared by the individuals participating in the group). 
Every single image begins in the mind of an individual and only becomes public as it is transmitted and shared. A significant part of any social activity involves the transmission and protection of its public images, which are shared by the members of the group.

A public image is transferred from generation to generation through the production of "transcripts" (Boulding, 1956). In non-literate societies, the transcript takes the form of verbal rituals, legends, poems, and ceremonials, the transmission of which is always one of the principal activities of the group. With the invention of printing, the photograph, the recorder, and the film, the transcript has progressed to the point where a relatively large part of image can be recorded directly. There are still parts of the image, however, that are transcribed in symbolic forms. People still do not have an effective and direct means of transcribing emotions of feelings except through channels of symbolic representations.

Although much of the community garden literature ties the meaning of community gardens to empowerment, there appears to be a complete absence of research linking visual images and empowerment to the sense of place in community gardens. A few researchers have employed visual images to explore the concept of sense of space associated with natural areas. Ryan explored the relationship between place attachment and environmental attributes within natural areas (Ryan, 2005) using a photo questionnaire. Mazumdar's study focused on the symbolic meaning of architectural elements on creating ethnic enclaves 
(Mazumdar, 2000). Nowell, Berkowitz, Deacon, \& Foster-Fishman used photographic imagery to understand how the environmental characteristics and social dynamics of neighborhoods, as places, have meaning for residents (Nowell, Berkowitz, Deacon, \& Foster-Fishman, 2006).

\section{$\underline{\text { Research Question: }}$}

What visual images do community gardeners use to represent their feeling of empowerment?

Hypothesis: No hypothesis.

D. Link between Sense of Place, Empowerment, and Image

De Certeau's spatial travel story (de Certeau, 1984) was utilized heuristically to help understand the relationship between sense of place, empowerment, and image in the context of community gardening.

De Certeau (1984) claims that the there is only one dominant mode in space appropriation, which is a foundation for the practice of everyday life: spatial tactics by which people transform places into spaces. De Certeau defines "place" as an instantaneous configuration of positions that implies stability. A "space," in contrast, is an intersect of mobile elements; it is actuated by the ensemble of movements deployed within it. Any geometrically defined area is transformed 
into a space by its users. In de Certeau's "tactical model," spatial tactics are the way people appropriate places (i.e., transform places into spaces).

De Certeau distinguishes a few elementary forms of spatial practices. First, he makes a bipolar distinction between "map" and "itinerary." Second, he outlines the procedure for delineation or "marking boundaries." The description of places oscillates between either seeing a "map" (knowledge of an order of places) or "touring" (spatializing actions). The "map" is a stage on which elements of diverse origin are brought together from the tableau of geographical knowledge. The "tour" articulates spatial practices and is a memorandum of prescribing actions outlining how to find the "route" to a particular place. Spatial stories (stories about "places") traverse and organize places.

The space and place transformations occur by crossing boundaries between places. From the distinction that separates a place from its exteriority to the distinction that localizes objects, from a home to a journey, from the functioning of the urban network to that of the rural landscape, there is no spatiality that is not organized by the determination of frontiers. By considering the role of stories in delineation of boundaries, one can see that the primary function is to authorize the establishment, displacement, or transcendence of limits.

In The Practice of Everyday Life, de Certeau depicts life as a constant, subconscious struggle against the institutions trying to assimilate the everyday 
person (De Certeau, 1984). De Certeau's focus is on exploring the ways that ordinary human behavior resists institutional control (i.e., the ways in which people individualize mass culture and organizational and legal systems to adjust them to their everyday lives). De Certeau argues that through the abundance of everyday activities, ordinary people subvert the rituals and representations that institutions seek to impose upon them. De Certeau identities two types of behavior, the strategic and the tactical as the key components of his theory of the practice of everyday life. He describes institutions as "strategic" and ordinary people as "tactical."

A "strategy" is an entity that is recognized as an authority. It manifests itself physically on its sites of operations (headquarters) and its products (laws, language, rituals, commercial goods, art, and inventions). A strategy represents a significant investment in space (land, infrastructure, and buildings) and time (its own history and traditions). A strategy is relatively inflexible because it is embedded in its spatial or institutional localization. The goal of a strategy is to perpetuate itself through the things that it makes. Its concerns are mass production and the homogenizing of its audience. Besides creating its products, it may work by developing its market through creating uniformity and need. Uniformity is beneficial to a strategy. Therefore, it is engaged in the work of systematizing and imposing order. 
A strategy is capable of defining itself as producer as opposed to user, and has only indirect contact with its audience. Its input from users may come from polls, focus groups and case studies, while its contact with the outside world might come in the form of advertising and public relations campaigns.

De Certueau's “tactical” model describes individuals or groups, which are fragmented in terms of space and maintain no specific site of operations (no headquarters). With no ownership of dedicated resources, a tactic manages to be more flexible compared to a strategy. A tactic depends on loopholes: it will infiltrate but will not try to take over. A tactic does not seek to win or take over but it seeks to fulfill its needs behind an appearance of conformity. A tactic expects to have to work on things in order to make them its own, or to make them "habitable." Unlike the strategy, a tactic lacks the centralized structure and performance that would enable it to set itself up as a competitor to other forms of activity.

The spatial image, the picture of the individual's location in space is the primary dimension of the image of man (Boulding, 1956). DeCerteau claims that the practice of everyday life, the active transformation of space, enables and empowers ordinary people to fulfill their goals (De Certeau, 1984). Ordinary people work to transform space to meet their needs and to make space habitable to them. Through space transformation, people develop connections and create images that reflect their empowerment experience. In that context, the spatial 
travel story, the practice of everyday life, may be seen as the landscapes of empowerment - the landscapes that reflect the practice of ordinary to transform the space to fulfill their needs.

E. Link between Social Realm and the Practice of Everyday Life

Research work done by Lofland (1998), Lofland (2006), Spradley ( 1979), and Schensul (1999) provided the major guidance for structuring my fieldwork research and analyzing the collected data.

Lofland emphasizes the importance of field research methods (empirical/field methods) in determining the type of social realms in urban spaces (Lofland, 1998). Whether any actual physical space contains a realm at all and, if it does, whether that realm is private, parochial, or public is not the consequence of a culturally or legally given designation, but is often a matter of conflict and/or negotiation. The private realm is characterized by ties of intimacy among primary group members within households and personal networks. The parochial realm is synonymous with a sense of commonality among acquaintances and neighbors who are involved in interpersonal networks. The public realm is the world of strangers.

Concrete places often exist on a continuum between private and public, private and parochial, and parochial and public (Lofland, 1998). Also, just as the spatial 
definition is subject to conflict, equally so is the understanding of the location of the spatial boundary. The realm type is not defined by the physical space in which it is located but by the relational forms that dominate within. A private realm exists when the dominating relational form found in some physical space is intimate. A parochial realm exists when the dominating relational form is communal. The public realm is the world of strangers. Realms, as social territories, come into being only in actual physical territories. Whether any actual physical space contains a realm and the type of realm it contains is always a matter to be discovered empirically.

The primary objective of the field observation phase was to explore how social realms in community gardens were conceptualized (i.e., what cultural meanings people use to organize the behavior and interpret their experience in forming social realms in the gardens). Understanding the type of realm in the community garden was the first step in defining the context for the sense of place formation for individual members and identifying the types of linkages among the gardeners. The findings of this phase were used to gain a better understanding for in depth interviews.

I applied a concept of domain analysis to explore the system of meanings people used to mark private, parochial, and public realms in community gardens. Schensul (1999) defines a cultural domain as a set of items, behaviors, beliefs, or events defined by a group, a basic unit of meaning that shapes how people 
conceptually organize their worlds. All cultural meaning is created by symbols (Spradley, 1979). A symbol is an object or event that refers to something. My field research focus was on the type of symbols that defined the meaning of social boundaries in community gardens (i.e., the part of community garden cultural domain that shapes the territorial aspect of spaces).

As previously discussed, I applied de Certeau's concept of "bounded spatiality” to identify the factors that lead to the formation of social realm meanings in community gardens (De Certeau, 1984). Figure II.4 summarizes my approach to the exploration of social realms in community gardens in the context of everyday life.

Figure II.4. Research Framework: Symbolic Meaning of Social Realms

\begin{tabular}{|c|l|l|l|}
\hline Spatial Symbol & Private Realm & Parochial Realm & Public Realm \\
\hline Event/Activity & $\begin{array}{l}\text { Meaning of } \\
\text { Private Realm }\end{array}$ & $\begin{array}{l}\text { Meaning of } \\
\text { Parochial } \\
\text { Realm }\end{array}$ \\
\hline Object & $\begin{array}{l}\text { Meaning of } \\
\text { Public Realm }\end{array}$ \\
\hline
\end{tabular}




\section{F. Summary of Research Questions and Hypotheses}

Figure II.5. Summary of Research Questions and Hypotheses

\begin{tabular}{|c|c|}
\hline Research Questions & Hypotheses \\
\hline $\begin{array}{l}\text { Time Dimension and Space Connections } \\
\text { 1. How does the time dimension influence } \\
\text { social and physical connection developed } \\
\text { by gardeners? }\end{array}$ & $\begin{array}{l}\text { Physical dimensions of gardens play an } \\
\text { important role in constructing sense of } \\
\text { place in the short term but are less } \\
\text { important in the long term. }\end{array}$ \\
\hline $\begin{array}{l}\text { Space Connection and Empowerment } \\
\text { 2. How do space connections influence the } \\
\text { feeling of empowerment of gardeners? } \\
\text { What is the impact of the physical setting of } \\
\text { gardens on empowerment experienced by } \\
\text { community gardeners? } \\
\text { Do community gardeners experience } \\
\text { empowerment through individual or group } \\
\text { action? }\end{array}$ & $\begin{array}{l}\text { Community gardeners in Portland } \\
\text { experience empowerment mostly at the } \\
\text { embedded individual and/or mediated } \\
\text { empowerment levels. }\end{array}$ \\
\hline $\begin{array}{l}\text { Image of Empowerment in Sense of Place } \\
\text { 3. What visual images do community } \\
\text { gardeners use to represent their feeling of } \\
\text { empowerment? }\end{array}$ & $\begin{array}{l}\text { No hypothesis. } \\
\text { A photo storytelling method was used to } \\
\text { enrich data and to add depth and provide } \\
\text { further insights into sense of place. }\end{array}$ \\
\hline
\end{tabular}




\section{CHAPTER III. METHODOLOGY}

\section{A. Study Area and Settings}

\section{City of Portland Community Garden Program}

The data for the study were collected in 2009. The City of Portland managed 32 community gardens in 2009. Most of Portland's community gardens are located in city parks or on other types of city property, created through partnership with the Bureau of Environmental Services and the Water Bureau. The Community Garden program offers over 1,000 plots for gardening. The program charges a fee for each plot [seventy five dollars per regular plot (400 square feet), thirty eight for half plots (200 square feet), and twenty dollars for raised garden plots (32 square feet)].

Both the design of the garden space and the rules and guidelines for gardening activities focus on individual behavior in the garden.

Community gardens managed by the City of Portland are typically divided into a number of plots of uniform size arranged in a chess-board fashion (Appendix C). Walkways crisscross the entire site and allow access to the sides and backs of plots. Wider paths serve as main avenues for pedestrian traffic. Common areas are typically minimally developed and contain a sign board, a bulletin board, picnic table and benches, water faucets and tool sheds. 
The chess-board pattern of plots give the gardens the appearance of a residential neighborhood. That is, each plot has a certain autonomy: plot boundary lines are marked on the site plan, plots are numbered, and the names of individual gardners are assigned to the plots. Several raised beds are available in some gardens. All three community gardens selected for my study reflect these general design principles (Apendix C).

The Portland Community Garden Handbook (2008) contains a set of rules and guidelines for behavior in the community gardens managed by the City of Portland. The rules specify how to be a "perfect" gardener, what to grow, how to maintain paths, how to take care of gardening tools, how to treat dogs in the garden, how to water, and how to organize a work party.

The city requires the gardeners to maintain their plots. Consistently weedy or abandoned-looking plots were considered for cancellation. Excessive trash, "unsightly structures," and encroachments on paths or community spaces are prohibited.

The City also specifies that gardeners must start tending their plots by May 1 . Each gardener should tend the garden plot weekly, if not daily. Organic gardening is expected and no herbicides are permitted. Crops are for home use only, not commercial purposes, and have to be legal. Trees and other plants that shade other plots are not allowed in the garden. Gardeners are to use the pathways without going through the plots of other gardens and harvest only from their assigned 
plots. Gardens have to be cleaned and cover-cropped or mulched around perennial plants by October 31 .

The "residential subdivision" plot pattern emphasizes the individual practice of gardening. The rules and regulations target mainly individual behavior in tending plots. Each plot was about the same size and shape and each gardener was provided access to resources: water, shed, and compost. The registered gardeners had to pay a fee and follow the rules to avoid forfeiting the plot.

The garden rules (Portland Community Gardens: A Handbook, 2008) specify that each gardener is expected to help with work parties to maintain communal garden projects, and related events at least six hours per year. Between June and September 2009, only one work party was arranged in the three community gardens that were part of my project, at Johns Garden. Six gardeners attended the party. One social BBQ was arranged at Brentwood. Fulton had a limited tradition in organizing work parties but in the summer of 2009 a group of three or four volunteers was working diligently in the "rose garden" part of Fulton, trying to convert this weedy and dry corner with neglected rose bushes into a thriving rose garden.

Community garden managers are the key implementers of the guidelines (PohlKosbau, 2009a). The garden managers are volunteers, elected by the gardeners. One of their main roles is to provide clarification of the guidelines and help 
gardeners to resolve conflicts in the garden. The community garden managers who were interviewed as part of my research pointed out that their capability to implement the garden rules was limited because of lack of time to investigate the conflicts ( Cepurna, 2009b; Holmes, 2009b; Corbet, 2009a, Decker, 2009b).

During my informal field interviews, many community gardeners whom I interviewed felt that the implementation and the enforcement of the garden rules should have been carried out by city staff. The Community Garden Program staff consisted with one full time person (program manager) and two part time support staff. Given the size of the program (32 gardens and over 1000 plots), the small city staff was not able to address and investigate all conflicts in a timely manner (Iott, 2009a; Iott, 2009b; Franek, 2009).

The City of Portland does not require that participants in community gardens live in close proximity to the garden. The 2008 survey (414 respondents) conducted by the City of Portland indicated that most gardeners (70\%) live less than a mile from their community garden (City of Portland Community Gardens Office, 2008). On average, respondents spend 3-5 hours per week in their gardens spring, summer, and fall, and 1-2 hours per week in the winter. According to the survey, the most frequent reasons for participating in community gardens were the lack for garden space at home, better quality of produce, and a general enjoyment of gardening. The results of the survey indicated that there is a wide range of experience among community gardeners: almost $60 \%$ of respondents have been gardening for over 10 years; approximately $11 \%$ of gardeners have been gardening less than 3 years. 


\section{Study Settings}

\subsection{Study Sites}

Three community gardens were selected for the study: Brentwood Community Garden in Southeast Portland, Fulton Community Garden in Southwest Portland, and Johns Community Garden in North Portland. The primary selection criteria for the three gardens focused on (1) the surrounding land use pattern, including access to the garden; (2) the year the garden was established; and (3) the size of the garden.

\section{(1) Surrounding Land Use Pattern}

As previously discussed, empowerment is context specific. It takes on different forms for different people in different contexts. The contextual embeddedness of empowerment recognizes that although people may experience the same physical and orgnizational setting, their feeling of empowerment depends upon their connection to place.

The selected gardens provided significant differences in their surrounding land use areas and the presence/absence of significant landmarks (Appendix B). The Johns garden is located in North Portland, in close proximity to the St. Johns Bridge. The backdrop of the bridge provides a spectacular landmark and point of reference for the surrounding area. The vicinity of the Brentwood garden does not offer any spectacular views. The garden is in a mostly residential area and 
borders on a large tract of vacant property owned by the Portland School District. A prominent chain link fence topped with barbed wire provides a distinctive separation between the garden and the surrounding areas. The area occupied by the Fulton garden is marked by major transportation corridors: Barbur Boulevard to the north and I-5 to the south. Residential areas, including single-family houses and apartments are located east and west of the garden site.

One of the objectives of my study was to determine how a fence (or its absence) contributes to the formation of sense of place, feeling of empowerment, or images held in common by community gardeners.

The three gardens selected for the study have varying degrees of connection to the surrounding areas. Fulton Community Garden is fully accessible to the public by unobstructed access through the surrounding street network. Chain link fences with locked gates surround Johns Community Garden, which consists of two parts, separated by a public road. A chain link fence, with barbed wire on top, and two gates with locks secure Brentwood Community Garden. Most community gardens managed by the City of Portland are noticeably separated from the sidewalk and surrounding properties by chain link fences. Access is restricted and available only through a gate, which is usually locked. 
Figure III.1. Johns Community Garden Location, Source: City of Portland www.portlandonline.comp/parks; retrieved

October 2010

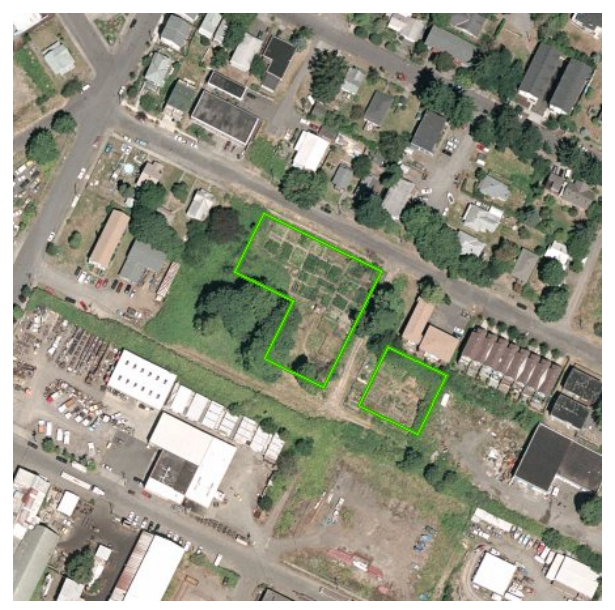

Figure III.2. Fulton Community Garden Location, Source: City of Portland www.portlandonline.comp/parks; retrieved October 2010

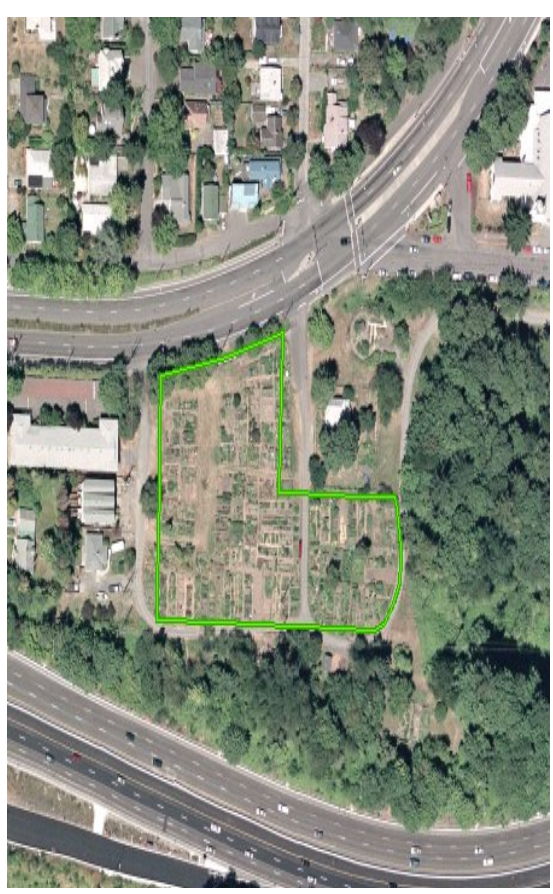


Figure III.3. Brentwood Community Garden Location, Source: City of Portland www.portlandonline.comp/parks; retrieved October 2010

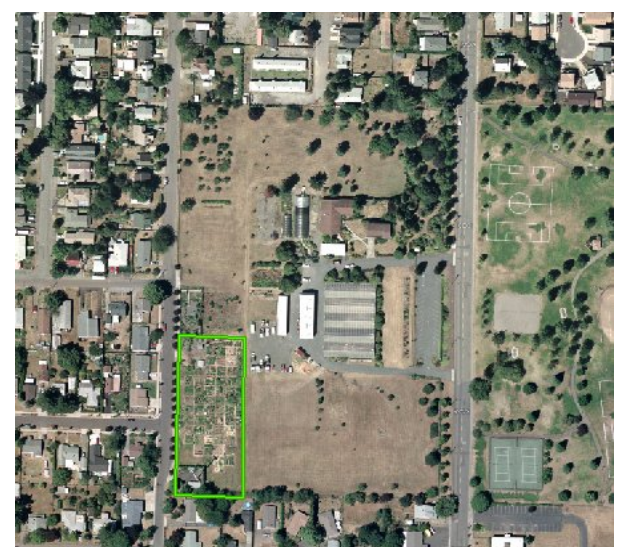

(2) Year Established

Both Fulton and Johns are among the oldest community gardens in Portland. The selection of these gardens for the study provided a good opportunity to find gardeners who have been gardening for an extensive period and compare their sense of place with the sense of place formed by the gardeners with a shorter gardening tenure.

\section{(3) Garden Size}

All three gardens are larger than the average community garden in Portland. The size of the garden was an important factor in finding volunteers who were willing to participate in my study. The focus of the field observation phase was to explore the social realm in the three community gardens and select thirty gardeners for in-depth interviews. The size of the garden provided a better 
opportunity for a wider selection of gardeners. In summary, selecting the three gardens provided a good opportunity to explore whether the physical setting matters in experiencing the feeling of empowerment and whether the length of membership in the garden influences the gardeners' connections to the garden spaces.

As part of the selection process, I reviewed City of Portland Garden Office materials, interviewed Garden Office employees, and talked to members of the Friends of Community Gardens. I also visited all community gardens managed by the City of Portland in 2008 .

Table III.1 provides a summary of the physical characteristics of community gardens selected for the study. Appendices B and C contain maps and pictures of the gardens reflecting the location and surrounding land uses.

Table III.1. Garden Sites: Summary of Physical Characteristics

\begin{tabular}{|c|c|c|c|c|c|}
\hline $\begin{array}{l}\text { Garden/ } \\
\text { General } \\
\text { Location }\end{array}$ & $\begin{array}{c}\text { Year } \\
\text { established }\end{array}$ & $\begin{array}{l}\text { Size } \\
{[\mathrm{ac}]}\end{array}$ & $\begin{array}{l}\text { Number } \\
\text { of } \\
\text { Plots }\end{array}$ & Access & $\begin{array}{l}\text { Surrounding Land Use } \\
\text { Pattern } \\
\text { Landmarks }\end{array}$ \\
\hline $\begin{array}{l}\text { Brentwood } \\
\text { SE } \\
\text { Portland }\end{array}$ & 1996 & 1.25 & 75 & $\begin{array}{l}\text { Fence with } \\
\text { barbed wire } \\
\text { and locked } \\
\text { gates }\end{array}$ & $\begin{array}{l}\text { Adjacent to vacant Portland School } \\
\text { District property (former Green } \\
\text { Thumb program site); adjacent to } \\
\text { Metro demonstration garden; } \\
\text { barbed wire on top of the fence } \\
\text { separating the garden from the } \\
\text { surrounding properties; residential } \\
\text { properties across the street. }\end{array}$ \\
\hline $\begin{array}{l}\text { Fulton } \\
\text { SW } \\
\text { Portland }\end{array}$ & 1974 & 2.19 & 103 & No fence & $\begin{array}{l}\text { Cluster of single-family houses in } \\
\text { vicinity of the garden; located } \\
\text { between two major transportation }\end{array}$ \\
\hline
\end{tabular}




\begin{tabular}{|l|l|l|l|l|l|}
\hline & & & & & $\begin{array}{l}\text { corridors: Barbur and I-5; high } \\
\text { level of traffic noise; access from } \\
\text { Barbur. }\end{array}$ \\
\hline $\begin{array}{l}\text { Johns } \\
\text { N Portland }\end{array}$ & 1974 & .97 & 53 & $\begin{array}{l}\text { Fence with } \\
\text { locked gate }\end{array}$ & $\begin{array}{l}\text { Surrounded by mixed residential } \\
\text { (single-multi, new-old), walking } \\
\text { distance to neighborhood } \\
\text { commercial; Johns bridge } \\
\text { dominant landmark. }\end{array}$ \\
\hline
\end{tabular}

\section{B. Data Collection}

\section{Methods and Timeline}

The following methods were used to collect original data: (1) exploratory interviews with City of Portland staff, community garden managers, and members of the Board of Friends of Community Gardens; (2) field observations of the three selected gardens; and (3) in-depth interviews of 30 gardeners selected from the three gardens. A secondary data source was background information about the gardens obtained by reviewing City of Portland documents, web site information, local newspapers, and neighborhood and garden newsletters.

In 2009, the Community Garden Office staff consisted of one full time community garden manager and two part- time employees. I interviewed all three employees as part of my research. I had three interviews with the program manager and five interviews with the support staff. My interviews with the program manager focused on general garden regulations and garden program implementation. My interviews with the support staff focused on specific 
activities related to the garden design, work parties, maintenance schedules, educational classes, and enforcement of community garden rules.

In my study, I used photography to enhance the storytelling method. The photo narrative storytelling methodology enabled me to link the phenomenological approach to sense of place with the contextual embeddedness of empowerment. Phenomenology developed as a form of attention to individual consciousness and concern for the ways that individuals construct their social lives and their knowledge of the everyday social world. The narrative storytelling methodology that was applied in the study allowed gardeners to express in their own terms their connections to space and experience of empowerment achieved by community gardening. The temporal and thematic aspects of narratives captured the impact of the time dimension in forming social and physical connections. The photo images provided an important insight to explore space connections in forming space images related to empowerment.

The study consisted of four phases. Phase I (May - June 2009) focused on exploratory interviews. The main objective of the exploratory interviews was to select three gardens for field observations. Phase II (May - September 2009) focused on field observations and selection of 30 gardeners for in-depth interviews. Phase III (October-December 2009) involved in-depth interviews of the selected gardeners. The field data collected in 2009 were analyzed JanuaryJuly 2010 (Phase IV). 


\section{Field Observations}

The focus of the field observation phase was to explore the social realm in the three community gardens and select 30 gardeners for in-depth interviews. Field observations were conducted between May and September 2009. A detailed observation schedule was developed for each garden to compare daily and weekly activities. The schedule for each garden contained weekday and weekend morning, afternoon, and evening activities. On average, five to six field observations were conducted per week. The length of each observation ranged from one to two hours.

\subsection{Gaining Access}

In my study, the "field" was comprised of three community gardens in different parts of Portland. The major focus of this phase of my research was to determine the meaning of the full spectrum of social realms of community gardens. Therefore, it was important to observe the gardens from both areas outside the garden and areas inside the garden to get an understanding of the type of activities. The Brentwood garden and Johns garden areas are secured by chained link fence and access to the garden is obtained only through the locked gates. The gates are unlocked by applying codes given by garden managers only to registered gardeners. Fulton garden does not have a perimeter fence and is freely accessed by the public.

I observed Brentwood and Johns from the public streets in front of the gardens. Most of the time, a sidewalk location was adequate to observe the activities inside and outside the garden fence. If the gates were left unlocked, I entered 
the garden areas to observe the gardener's reaction to a "stranger." A fence does not secure the Fulton garden and this allows for unrestricted access by people who are non-registered gardeners. During my Fulton garden observation, I was freely roaming inside the garden.

\subsection{Types of Observation}

Data were collected by both direct nonparticipant and participant observation.

\section{(1) Nonparticipant Observation}

The first phase of my field observation involved the exploration of the public realm in community gardens and this approach was a logical one in the preliminary data collection. My objective was to gain an understanding of how the people in the community gardens react to strangers. At this phase of the field observation, it was important not to reveal my identity. It was beneficial to the study to disguise my identity to get observations that are more reliable.

\section{(2) Participant Observation}

The second phase of my field observation involved participant observation. In discussing participant observation, Savage (2000) describes a range of roles in the process of field observation. A participant observer is defined as full participant, participant as observer, observer as participant, or complete observer. I was neither a complete participant nor a complete observer. The role of participant as observer demands that the researcher be a participant in one of the social groups in the research setting, and appears as such to persons outside of 
that group. For most of my field research, I did not participate as a member of any group, so this role did not apply to me. My role was observer as participant. In Savage's view, I utilized a moderately participative observation. My participation was participation in the sense that I was present in the scene of the garden as a social being, watching, observing, and talking to the people.

\subsection{Field Interviews}

John Lofland (2006) notes that the bulk of analysis in most field studies is based on talk of informants because language is the key to understanding most human interactions. In my research, I applied intensive interviews and informal interviews. From May to October 2009, I conducted 72 informal interviews and 13 intensive interviews (total 85 field interviews).

Informal interviewing involves asking questions during the course of naturally occuring activities (Lofland, 2006). Questioning of this kind is often called "casual interviewing," because it relates to the immediate context of the interview (questions in situ). The informal interviews were suited to the main objective of my research, which involved decoding symbolic meanings of objects and actions and clarifying behaviors. Typically, I would ask gardeners about specific actions and behavior in the gardens. Why was certain produce placed in basket next to the shed? Why don't gardeners sit at picnic tables? Why are certain tools placed on picnic tables? Have they seen any strangers in the garden? What did the stranger look like? How did they build/use sturctures on their individual plots? 
My intensive interviews dealt with actions that occurred outside the immediate context of the interview. Typically, during my intensive interviews I focused on patterns of behaviors I watched during my field observations. The intensive interview approach was useful in developing follow up questions that were incorporated into my in-depth interviews. How many people do gardeners see typically in the garden? How do people typically use common spaces? How often do gardeners meet other gardeners outside the garden space? Is is difficult to unlock the gate?

\subsection{Observation Phases}

The field observation phase took place between May and October 2009. Between May and June, my field observation was focused on general exploration of the garden places and the surrounding areas. The general objective during these months was to understand better the development pattern of the surrounding land uses, the activities in the areas immediately bordering the gardens, and the activities inside the garden. Between mid June and July, I gathered information about each garden's routine and organization and observed different social interactions in and around the garden.

For the convenience of my data collection, I divided the information into three categories: place, people, and events (Schensul, Schensul, \& LeCompte, 1999). 
The place observations focused on individual plot arrangements, design of communal places in the garden, and the upkeep of the area bordering the garden space. The people observations included the way gardeners arrived to the garden, how they accessed the garden, and the type of activities in the garden territories. The events observations included going to social gatherings and work parties arranged by community garden managers.

As my next step, I organized my observations into the factors that defined more specifically the social realm of gardens. In August, I began to give special attention to objects and activities related to the factors I identified in the first phase of my study in July. In September, my focus was on identifying follow up questions pertaining to the garden activities that I was not able to understand fully either by direct field observations or by field interviews. The follow-up questions were included into my in-depth interview script (Appendix D.2).

I used three notebooks: a jotting book, a field notebook, and a memo book. The jotting book was always at hand, and I took short notes openly during my observations. Sometimes I elaborated on the observations made in my field notes while in the garden. In the memo book, I wrote my reflections on each day of observation. In that book, I kept notes about the significant observations, new ideas, missing observations, and things to be done next. I always tried to make sure that I finished writing the detailed observation and memo each day. 


\section{In-Depth Interviews}

\subsection{Selection Process}

Between May and June 2009, I compiled a list of 51 volunteers how expressed interest and agreed to participate in my study. The primary criterion for the selection was the time dimension, i.e., the length of the membership of the gardener in the specific garden. My objective was to have a diversified group of people with varied lengths of experience in the community garden. As part of my initial contact, I explained to each participant that she/he would be given a disposable camera to take pictures of the garden and that my interview would involve a photo storytelling component to enhance their narrative and illustrate feelings related to community gardens.

All cameras were distributed between July 1-July 10. I applied two methods of distribution: (1) group meetings and (2) individual drop offs. In each garden, I arranged for two group meetings to discuss the scope of the project and provide the cameras. Several participants were not able to come to the group meetings and asked for individual meetings. Each camera was marked with the name of the participant and the time of pick up. I also explained that my objective was to collect the cameras in the last week of October 2009. Each of the selected gardeners was asked to take up to 27 pictures with the disposable cameras. A general script for passing out the cameras was given to each participant at the time of camera pick up. Appendix D.1 contains the camera script used. 
Between the second and third week of October, I contacted all 51 participants to collect the cameras and schedule interviews. I typically left 2-3 phone messages, sent an email, and asked garden managers to contact some of the gardeners who did not have access to email. By November 1 2009, I was able to collect back 37 cameras. Despite my efforts, 14 out of 51 people who initially agreed to participate in the study did not return the cameras. Nine of the 14 people, who did not return the cameras were apologetic and explained that because of family illness, lack of time, or lack of focus they were not able to use the cameras and participate in my study. Three people mentioned that they lost the cameras. One person did not respond to my phone calls and email messages.

I finalized developing pictures the first week of November. At that time, I discovered that seven of 37 cameras did not contain pictures (all exposures were black and did not have any images). Based on my follow up discussion with the participants who returned the cameras with no developable pictures, it was unclear whether the disposable cameras were deficient or the participants did not properly operate the cameras. Each of the remaining thirty gardeners took all of the twenty-seven pictures available in their disposable cameras. Thus, by the beginning of November 2009, the total number of pictures taken by the thirty gardeners was 810 . 
During the selection and interview process, I discussed the confidentiality aspect of the study and explained that in accordance with the Human Subjects Research Review Committee (HSRRC) approval, the participants would be identified only by first names and garden affiliation. Table III. 2 (page 54) contains names of all thirty gardeners who participated in in-depth interviews.

As previously discussed, the primary criterion for the selection was the length of the membership in the specific garden. I assumed that the length of membership in the garden would be the most important time dimension in experiencing community gardens. Later, in late July and August, after I had already passed out the cameras to the 51 participants, I became aware that community gardeners recognized four aspects of the length of their experience in community gardens: (1) length of membership in the garden; (2) years lived in the area; (3) years of gardening experience; and (4) weekly visits to the garden. A summary table contains all selected gardeners (Table III., next page ) and the four aspects of time dimension that emerged during the in-depth interviews with the thirty gardeners. 


\begin{tabular}{|c|c|c|c|c|c|}
\hline \multicolumn{6}{|c|}{ Table III.2 List of Selected Gardeners } \\
\hline & & \multicolumn{4}{|c|}{ TIME DIMENSION } \\
\hline & GARDENER & $\begin{array}{l}\text { Years } \\
\text { In } \\
\text { Garden }\end{array}$ & $\begin{array}{l}\text { Years } \\
\text { In } \\
\text { Area }\end{array}$ & $\begin{array}{l}\text { Years } \\
\text { Total } \\
\text { Gardening }\end{array}$ & $\begin{array}{l}\text { Visits } \\
\text { per } \\
\text { week }\end{array}$ \\
\hline & Fulton & & & & \\
\hline 1 & Sydney & 1 & 23 & 46 & $2-3$ \\
\hline 2 & Andrea & 2 & 25 & 20 & 1 \\
\hline 3 & Jim & 2 & 20 & 44 & $5-6$ \\
\hline 4 & Ken & 3 & 3 & 50 & 4 \\
\hline 5 & Dawn & 3 & 3 & 45 & $3-4$ \\
\hline 6 & Perky & 4 & 40 & 60 & $2-3$ \\
\hline 7 & Barbara & 4 & 9 & 5 & $4-5$ \\
\hline 8 & Gerry & 4 & 9 & 5 & $3-4$ \\
\hline 9 & Florence & 5 & 6 & 38 & $4-5$ \\
\hline 10 & Marsha & 10 & 37 & 60 & $3-4$ \\
\hline 11 & Hugo & 10 & 17 & 70 & $4-5$ \\
\hline 12 & David & 11 & 25 & 20 & $3-5$ \\
\hline & Brentwood & & & & \\
\hline 13 & Lisa & 1 & 13 & 16 & $2-3$ \\
\hline 14 & Stephanie & 3 & 7 & 3 & $2-3$ \\
\hline 15 & John & 4 & 24 & 10 & $3-4$ \\
\hline 16 & Melinda & 4 & 7 & 30 & $5-7$ \\
\hline
\end{tabular}




\begin{tabular}{|l|l|l|l|l|l|}
\hline 17 & Tom & 5 & 62 & 20 & $6-7$ \\
\hline 18 & Heike & 5 & 7 & 30 & 3 \\
\hline 19 & Mark & 6 & 38 & 12 & $5-7$ \\
\hline 20 & Gracie & 6 & 19 & 7 & $2-3$ \\
\hline 21 & Jan & 7 & 40 & 20 & $4-5$ \\
\hline 22 & Bill & 12 & 13 & 47 & $5-6$ \\
\hline & Johns & & & & \\
\hline 23 & Dan & 1 & 9 & 1 & 2 \\
\hline 24 & Hawkins & 1 & 3 & 1 & $3-4$ \\
\hline 25 & Wendy & 1 & 1 & 3 & $1-2$ \\
\hline 26 & Mark & 2 & 3 & 15 & $5-6$ \\
\hline 27 & Marguerite & 3 & 3 & 60 & $5-6$ \\
\hline 28 & Mary Anne & 3 & 3 & 20 & $5-7$ \\
\hline 29 & Robby & 3 & 3 & 10 & $5-6$ \\
\hline 30 & Mike & 3 & 20 & 50 & $5-7$ \\
\hline
\end{tabular}

For most community gardeners, the length of the membership in the specific garden did not seem to be an important factor in the overall experience. They frequently pointed out that their actual gardening experience extended far beyond their experience in the community garden and influenced their community garden practice. Regardless of their tenure in the garden, some gardeners who had been living longer near the garden were more likely to be influenced by their general connection to the area where the garden was located. Frequency of the visits to the garden was another factor that emerged as an important aspect of the "length of time" in the community garden. Some people were able to come to the 
garden more often than others (e.g., retirees) were but other people had to fit their visits to the garden into their overall work schedules.

\subsection{Interview Process}

The in-depth interviews were conducted between October 2009 and December 2010.

The interviews were structured to collect personal narratives from individuals who were community gardeners. The interviews consisted of two parts: Photo storytelling: the gardeners were asked during the first part of the interview to describe the feelings and experiences related to each picture; and Follow-up/open ended questions (Appendix D.2).

I used the term photovoice to acknowledge participants as the authors of the photographs, and photo storytelling to describe the process by which the photographs were subsequently discussed during the first part of the interviews. During the last several years, interest in photography as a tool for research and action has gained new energy under the heading of "photovoice." Caroline Wang (1997) coined this term to describe a method of using photography to capture "voices that ordinarily would not be heard and to broadcast them into the halls of decision making power." Several photo-related methods were developed to capture the "ordinary voices" ((Nowell, Berkowitz, Deacon, \& Foster-Fishman, 2006; Rudkin, 2007; McIntyre, 2003). 
Using the disposable cameras was considered challenging by the gardeners, as most of them were used to operating digital cameras. This challenge was a source of uncertainty and frustration to some gardeners who felt that the inferior technology and their lack of prior practice would negatively impact the quality of the pictures and they would not adequately represent their feelings. To overcome this challenge, many gardeners tended to take more than one picture of the same aspect of the garden to make sure that they captured the images that were important to them. Once I collected the cameras and developed the pictures, I needed to sort through all the images to eliminate the redundant takes.

The interviews were conducted in November and December 2009. The gardeners were asked during the first part of the interview to describe the feelings and experiences related to each picture or group of pictures. At the end of the first part of the interview, each gardener was asked to select up to four pictures that she or he considered the "most important" in the story.

The moment of selection of the most important pictures was distressing to the majority of gardeners. After spending part of their summer and fall with the disposable cameras trying to capture their feelings as accurately as possible and with as many takes as they felt were needed to reflect their experience and illustrate their stories, it was difficult to decide what pictures were "the most important" to them. Ultimately, all the gardeners chose those pictures that conveyed multilayered meanings and influences of gardens in their lives. Thus, 
their definition of "important pictures" was associated with the highest number of meanings and representations of empowerment through community gardens.

Eighteen gardeners were able to select their "three most important" pictures. Eleven gardeners selected "the four most important pictures," and one gardener felt that "two most important pictures" were sufficient to summarize their feelings and experiences related to the community garden. Thus, the collection of "the most important pictures" selected by the thirty gardeners consists of one hundred pictures. The most important pictures selected by the gardeners typically carried more than one meaning. 


\section{CHAPTER IV. SUMMARY OF FIELD OBSERVATIONS}

De Certeau's spatial travel story was used as a heuristic lens for understanding the experience of the gardeners. De Certeau claims that spatial practices by which people transform places into spaces are a foundation for the practice of everyday life. "Space" is a collection of "maps" and "tours." A "map" is a static description of a place. The "tour" articulates spatial practices outlining how to move from one place to another.

The place-to-space transformations occur by crossing boundaries between places. People vary in the ways they transform places into spaces. These variations in individual space appropriation are called "spatial tactics" (activities and objects). According to de Certeau, the most the most important tactics are those that mark out/delineate the boundaries in space transformation. A "spatial story" is a collection of tactics to mark the most important transformation phases and boundaries (traversing/ "tour" and organizing "map").

Based on my field observations, field interviews, and in-depth interviews, a car, a fence, and an individual plot are the most important tactics of the "community garden spatial story." Most individual stories revolve around driving to the garden, accessing the garden, and cultivating one's own plot.

The main objective of the field observation phase of the study was to explore two aspects of the relationship between space connections and sense of place: (1) factors influencing the formation of physical and social connections to community 
gardens; and (2) influence of space connections on social realms. Field observation findings presented in this chapter formed the foundation for exploring the three research questions discussed in Chapter II.

Figure IV.1 contains a summary of the analytical approach used in the study.

Figure IV.1. Community Garden Travel Story and Space Appropriation: Analytical Approach

\begin{tabular}{|c|l|l|}
\hline SPACE TRANSFORMATION & $\begin{array}{c}\text { SPACE TRANSFORMATION } \\
\text { TACTICS: FACTORS } \\
\text { INFLUENCING PHYSICAL } \\
\text { AND SOCIAL CONNECTIONS }\end{array}$ & SOCIAL REALMS \\
\hline TRANSFORMATION PHASES & $\begin{array}{l}\text { Physical factors: objects and } \\
\text { physical features of places }\end{array}$ & $\begin{array}{l}\text { Prevailing type of } \\
\text { realm: public, } \\
\text { parochial, private }\end{array}$ \\
$\begin{array}{c}\text { (TRANSPORTATION, } \\
\text { ACCESS,GARDEN SPACE) }\end{array}$ & $\begin{array}{l}\text { Social factors: behavior, } \\
\text { activities, events }\end{array}$ & $\begin{array}{l}\text { Symbolic } \\
\text { representation of social } \\
\text { realm }\end{array}$ \\
\hline
\end{tabular}

Space appropriation community gardening involved three major transformation phases:

1) Transportation from the place of residence to the garden;

2) Access to the garden; and

3) Activities in the garden.

The analysis and discussion of each transformation phase is framed in the context of travel story tactics and the social realm boundary marking. The tactics 
include physical objects, physical place features of places, activities, behaviors, and events. The social realm discussion focuses on the tactics that denote public, communal, and private boundaries during each transformation phase.

Table IV.1 contains a summary of responses obtained during the in-depth interviews. The responses were arranged into four groups: (1) dominant space connection, (2) most important place in the garden; (3) most enjoyable aspects of community gardening; and (4) least enjoyable aspects of community gardening.

Table IV.1. Summary of Space Connection by Garden

\begin{tabular}{|c|c|c|c|c|c|}
\hline SPACE CONNECTIONS & Fulton & Brentwood & Johns & $\begin{array}{l}\text { Total } \\
\#\end{array}$ & $\begin{array}{l}\% \text { of } \\
\text { Total }\end{array}$ \\
\hline Number of Gardeners & 12 & 10 & 8 & 30 & 100 \\
\hline \multicolumn{6}{|l|}{ I. Dominant Connection } \\
\hline 1.Physical & 10 & 7 & 6 & 23 & 77 \\
\hline 2.Social & & 3 & & 3 & 10 \\
\hline 3.Both (social and physical) & 2 & & 2 & 4 & 13 \\
\hline \multicolumn{6}{|l|}{ II. Most Important Place } \\
\hline 1.My plot only & 6 & 8 & 5 & 19 & 63 \\
\hline 2. My plot and other parts of garden & 2 & & 2 & 2 & 6 \\
\hline $\begin{array}{l}\text { 3. All garden space/no preference for } \\
\text { any particular spot }\end{array}$ & 2 & 2 & & 4 & 13 \\
\hline 4. Surrounding areas only & 1 & & & 1 & 3 \\
\hline 5. My plot and surrounding areas & 1 & & 1 & 2 & 6 \\
\hline & & & & & \\
\hline
\end{tabular}




\begin{tabular}{|c|c|c|c|c|c|}
\hline SPACE CONNECTIONS & Fulton & Brentwood & Johns & $\begin{array}{l}\text { Total } \\
\#\end{array}$ & $\begin{array}{l}\% \text { of } \\
\text { Total }\end{array}$ \\
\hline \multicolumn{6}{|l|}{$\begin{array}{l}\text { III. Most Enjoyable Aspects of } \\
\text { Community Gardening }\end{array}$} \\
\hline $\begin{array}{l}\text { 1.Land cultivation (physical touch; } \\
\text { all senses) }\end{array}$ & 10 & 4 & 6 & 20 & 66 \\
\hline \multicolumn{6}{|l|}{ 2. Social activities } \\
\hline Meeting new people in garden & 4 & 1 & 0 & 5 & 17 \\
\hline $\begin{array}{l}\text { Enhancing existing social networks } \\
\text { outside garden }\end{array}$ & 4 & 2 & 0 & 6 & 20 \\
\hline $\begin{array}{l}\text { 3. Watching natural cycle/miracle of } \\
\text { growth and renewal/meditation }\end{array}$ & 5 & 6 & 3 & 14 & 46 \\
\hline $\begin{array}{l}\text { 4. Contemplation of spiritual earth- } \\
\text { plant-animal connections and } \\
\text { patterns }\end{array}$ & 2 & 2 & 1 & 5 & 17 \\
\hline \multicolumn{6}{|l|}{$\begin{array}{l}\text { IV. Least Enjoyable Aspects of } \\
\text { Community Gardening }\end{array}$} \\
\hline \multicolumn{6}{|l|}{ 1.Personal preference/choice } \\
\hline $\begin{array}{l}\text { Dislike for some aspects of land } \\
\text { cultivation }\end{array}$ & 1 & 1 & 3 & 5 & 17 \\
\hline Distance to garden & 1 & 2 & 2 & 5 & 17 \\
\hline \multicolumn{6}{|l|}{$\begin{array}{l}\text { 2. Garden space: interactions with } \\
\text { fellow gardeners }\end{array}$} \\
\hline $\begin{array}{l}\text { Gardening styles (weeding, plant } \\
\text { selection, composting) }\end{array}$ & 4 & 3 & 1 & 8 & 27 \\
\hline $\begin{array}{l}\text { Disrespecting other plots and } \\
\text { comfort of gardeners(stepping on } \\
\text { plants; unauthorized harvest; } \\
\text { unauthorized use of compost bins; } \\
\text { smoking, garbage) }\end{array}$ & 2 & 4 & 0 & 6 & 20 \\
\hline
\end{tabular}




\begin{tabular}{|l|l|l|l|l|l|}
\hline SPACE CONNECTIONS & Fulton & Brentwood & Johns & Total & $\%$ of \\
Total & & & & & \\
\hline $\begin{array}{l}\text { Lack of coordination of group } \\
\text { activities (social and garden } \\
\text { maintenance) }\end{array}$ & 0 & 2 & 3 & 5 & 17 \\
\hline Lack of care for communal areas & 0 & 2 & 3 & 5 & 17 \\
\hline $\begin{array}{l}\text { 3.Surrounding Areas } \\
\text { Unauthorized harvest }\end{array}$ & & & & & \\
\hline Traffic/parking & 3 & & & 3 & 10 \\
\hline Presence of fence/locked gate & & 3 & 1 & 4 & 13 \\
\hline Dogs & 4 & & & 4 & 13 \\
\hline
\end{tabular}

\section{A. Transportation}

Community gardening involves a trip to the garden. Most of the gardeners live a certain distance from their community gardens. The city does not require the gardeners to live in proximity to the garden. The choice of transportation to a community garden influences the gardening experiences and the formation of both social and physical connections.

\section{Space Connection in Transportation Phase}

\subsection{Physical Factors}

The car was the primary mode of transportation and an indispensible appendage of community gardening (Figure IV.2). Its role extended beyond the primarily 
transportation function. It served as a tool shed, pantry, and living room (i.e., it provided a connection to and an extension of home outside the place of residence for most of the gardeners interviewed for the study).

Many gardeners chose not to store their own favorite gardening tools in the garden shed because this could lead to unauthorized use of their tools by other gardeners who might have not take proper care of them. The car was frequently used to transport tools to the garden. The car was also convenient for hauling produce from the garden and taking compost. City gardening rules did not allow the gardeners to set up a shared composting heap because there are not enough volunteers to tend to the composting process. The gardeners are encouraged to set up their own composting bin on their individual plots, as part of the gardening cycle. For many gardeners this was not a good option, because it took up precious space on the plot, which was typically used for growing produce. Consequently, the car became a necessity for hauling debris from individual plots out of the garden. From late June to late October, the car was used to haul out harvested crops. During tedious hours of weeding, some gardeners liked to listen to a car radio or DVD player. The car served as a shelter during a rain. It was where people temporarily hid, rested, and ate.

Walking was the second most popular way to get to the garden. Gardeners tended to walk to the garden for less labor-intensive tasks, like watering, incidental weeding and harvesting, or simply to "check in" and see the overall progress in 
the garden. Some gardeners incorporated walking to the garden as part of their daily routine, as part of their fitness program, their lifestyle choice, or a form of daily meditation. Walking to the garden was typically a solitary activity, a form of connecting to nature, or a private time to have a moment of reflection amid busy city life. The gravel road perimeter road linking Fulton Garden with the nearby Fulton Community Center, and the combination of unimproved and gravel streets in the vicinity of Johns Garden created a romanticized version of simple, bucolic, rural life, a road to a "green oasis," a quiet place on earth.

Bicycling was not perceived either as the most convenient or as a recreational mode of transportation to the garden. It was used occasionally by some of the gardeners for incidental gardening maintenance and hauling a limited amount of vegetables. Although bus stops were conveniently located near all three gardens, using local transit was not appealing as part of the community gardening experience. It is difficult to carry produce, compost, or gardening tools on the bus.

Most of the gardeners relied on more than one transportation mode. Driving and walking were the two most popular ways to get to the garden. Given the usefulness of the car in the community gardening process, it was surprising that not everybody used cars as part of the community gardening routine. Only seven gardeners (23\% of thirty who participated in the study) did not use a car to get to the garden (Figure IV.2). Half of the people who participated in the study liked to 
walk to the garden. Seven gardeners rode bicycles. Only one of the thirty gardeners rode a bus to the garden.

Figure IV.2. Community Garden Transportation Choices

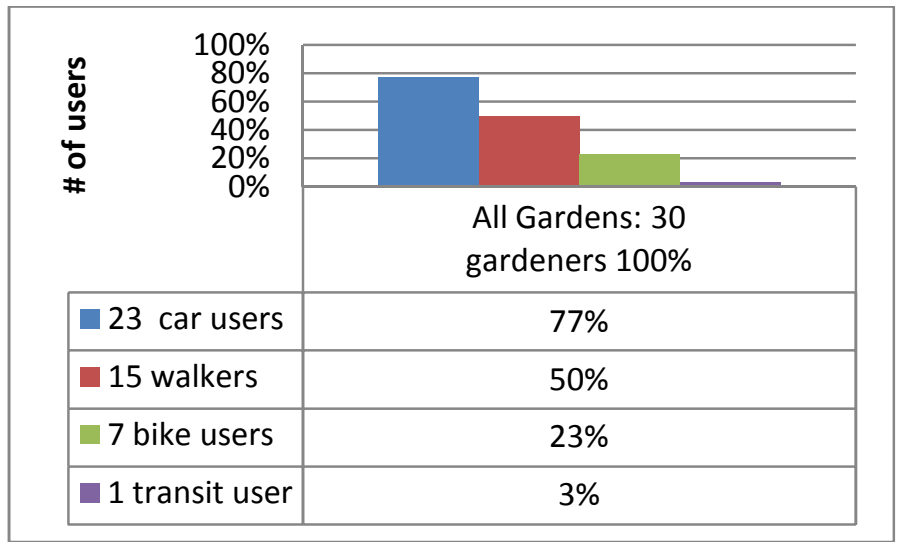

\subsection{Social Factors}

Getting to the garden, for the most part, was a solitary activity. Most of the time gardeners walked or rode a bicycle alone. Carpooling was sporadic. When it occurred, it typically involved two people getting together for a short, ad hoc trip to the garden, mainly to harvest or to do some spot watering or incidental maintenance.

2. Social Realm in Transportation Phase

\subsection{Dominant Type of Social Realm in Transportation Phase}

The transportation phase was dominated by the public realm connections. It occurred outside the garden area and involved occasional interactions with 
strangers. Driving alone, bicycling, or taking a bus to the garden did not allow for any type of extensive, social interactions outside the garden.

\subsection{Symbolic Representations of Social Realm}

Driving the car was the most typical way to get to the garden. The car symbolized (for most of the gardeners, reluctantly) a trip to the community garden.

3. Transportation: Inter Garden Analysis

Figure IV.3. Transportation Choices across Gardens

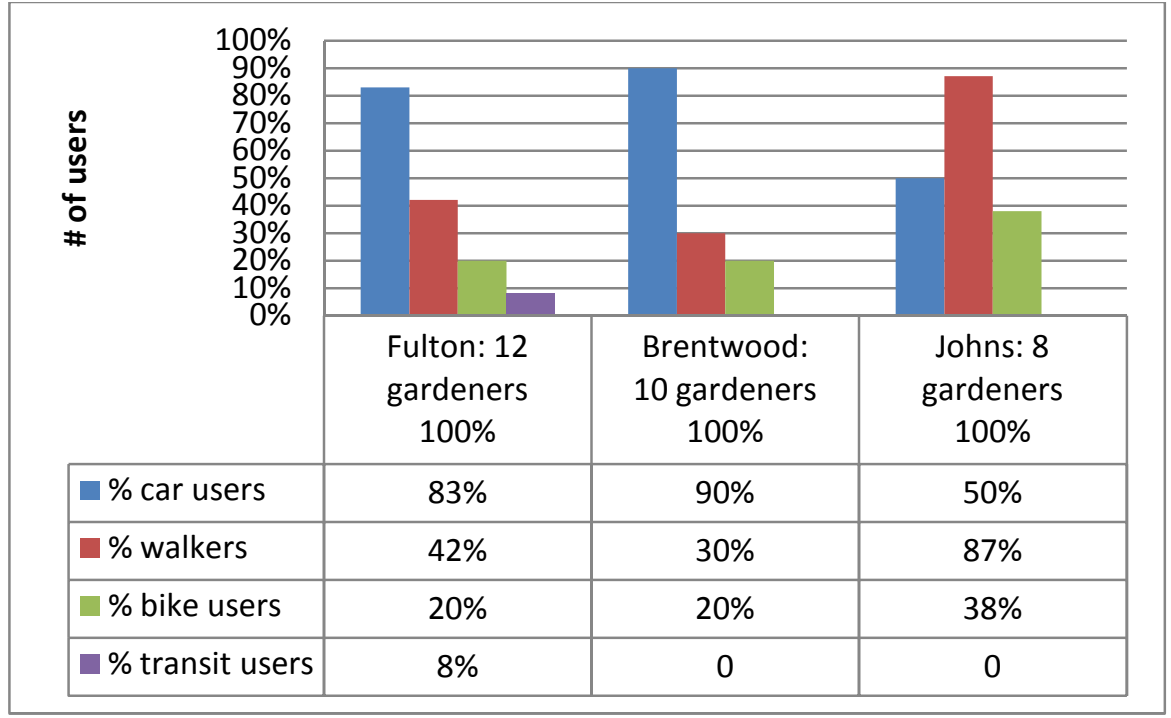

Johns was the least car-oriented garden. Johns gardeners mostly walked to the garden (Figure VI.3). Brentwood was the most car-oriented garden. Most of the Brentwood gardeners drove to the garden. Fulton gardeners represented the most diversified group in transportation choices. Most of them used cars, but walking was the second most popular way to get to the garden among the Fulton 
gardeners. The lack of fence at Fulton allowed gardeners to park their cars on the perimeter road, as close as possible to their individual plots. Some of them chose to park their cars in the middle of the communal grassy areas. As a result, the communal areas at Fulton were appropriated partly as a parking lot, partly as a home backyard, where the activity centered on the connection between the car and the individual plot in the garden.

Driving a car was the most favorable transportation choice for most of the gardeners mostly because it met more than just one need. It was a mobile tool shed and the living room in bridging the community garden plot with the residence for most of the gardeners. This "bridging" function was most visible in Fulton. Fulton did not have a fence around its perimeter and the road and the communal areas provided an opportunity to park the car as close as possible to one's plot. Walking was the second preferred choice of transportation to the community garden. It was either a choice of lifestyle (Johns), where people incorporated walking to the garden as part of their overall lifestyle philosophy or part of necessity or recreation (Fulton), when sometimes it was more practical to walk then drive, because of the traffic congestion.

\section{B. Access to Community Garden}

1. Space Connection in Access Phase

\subsection{Physical Factors}


The presence of the fence was the obvious physical marker of boundary separating the garden space from the surrounding areas. The three gardens selected for the study had varying degrees of access from the surrounding areas. Fulton Community Garden was fully accessible to the public by unobstructed access via the surrounding street network. Chain link fences with locked gates surrounded Johns Community Garden, which consisted of two parts. A chain link fence, with barbed wire on top and locked gates, secured Brentwood Community Garden.

Most of the gardeners participating in the study related to the question of fence and safety in community gardens at two levels: (1) personal safety; and (2) safety and security of garden harvest.

\section{(1) Personal Safety in Community Gardens}

At Fulton, which was not separated by a fence from the surrounding areas, most of the people felt safer in the presence of other people, including fellow gardeners, other people walking on the road, or people living near the garden. At Brentwood and Johns, a fence might have enhanced the feeling of safety, but was not considered the critical factor in personal safety. Only one gardener out of thirty gardeners (in-depth interviews) believed that a locked gate and fence was a condition to feel safer in the community garden.

The following comment from Jan, a Brentwood gardener, reflects an ambivalent relationship between community gardeners and fences: 
"It is something I love and hate. We have a fence around our garden. I hate the fact that we need the fence and people just cannot respect the boundaries property, but our fence works. I do not like to have a boundary and a barrier... it seems to be sad that as human beings we cannot respect each other; the neighborhood is not respectful of the garden.

It is a mixed blessing; I hate to fuss with the lock, in and out is a pain. I am never empty handed when I go in and out of the garden, you always carry something, to haul your produce, your favorite tools, it is a pain, I do not lock the gate behind me, if somebody is in, they need to get out quickly, I latch the gate but I do not lock them.” Jan (Brentwood Gardener, 2009)

The combination of the fence and the locked gate made it quite inconvenient for many gardeners to enter the garden. The numbers on the locks were small and difficult to operate for people with less nimble fingers. It was also difficult to operate the lock with limited light, at dusk, when many gardeners typically leave the garden. The gate locks needed to be operated with two hands. Given the level of inconvenience, some people chose not to lock up the garden upon entering the garden area. During my field observation phase, I discovered that, typically, if only one or two gardeners were present in the garden, they kept the gate locked. Once the number of gardeners increased to three, the gate was left unlocked. 
If the garden gate was unlocked, it created an opportunity for non-registered gardeners to sneak into the garden and explore the area. The "non- registered" gardeners were typically people who were passing by the garden and were curious about the activities on the other side of the fence. On several occasions, I watched children who made a game of annoying gardeners by trying to decipher the code to the gate lock and enter the garden, upon irritation of the gardeners who were present in the garden.

(2) Harvest Safety and Security in Community Garden

For most of the gardeners, fences were important to protect the quality and quantity of the harvest and were not typically associated with personal safety. Most gardeners detested the ritual of locking and unlocking the gate, but it was also considered as a necessary measure to ensure the safety and security of their crops.

Gardening for food harvest was the primary reason for most of the community gardeners. Any trace of vandalism in the garden aimed to destroy defenseless plants and potential food source was considered as a senseless and wicked activity by community gardeners. In August 2009, one of the community gardens in southeast Portland was vandalized (Brettman, 2009). Sombody pulled out plants, broke wooden trellises and turned on water spigots full blast. The 
Oregonian reported several versions of this incident througout the rest of the summer.

The vandalism story was a common discussion starter for many people I met in the three community gardens and often came up during my informal interviews. Typically, at some point in our discussion, the gardner I was talking to would ask me whether I heard about the outrageous act of vandalism that occurred in the southeast Portland community garden. The August incident perpetuated a wave of cautionary emails from city staff to garden managers and to all gardeners reminding them about locking up the garden gates. The August incident also resulted in more zealous adherence to the locking up routine and watchful anxiety in scanning the surrounding areas for criminally minded strangers.

Several stories (informal interviews) of vandalism that were shared with me by other gardeners did not involve the level of malicious behavior that was displayed in the much-publicized occurrence in the southeast Portland garden. At Johns, somebody took tomato cages from one of the plots but did not take the tomato plants. This courteous thief did not hurt any of the plants and was content only with the cages. At Fulton, somebody picked all peaches from the peach trees grown by one of the gardeners on his plot. On several occasions, at Fulton, I watched bicyclists getting off at Barbur Boulevard to nibble on fresh raspberries. Other Fulton gardeners encountered middle- aged women walking 
out of the surrounding subdivisions, bags in their hands, heading toward some of the garden plots to harvest the ripening tomatoes.

At Brentwood, an unknown person was consistently harvesting ripening tomatoes from one of the plots and took vegetables from the communal basket, placed in front of the shed. The vegetables were collected as part of the Produce for People Program. The Produce for People program was run by the city and is aimed to provide fresh produce for the for hunger relief agencies in Portland. Although, it was not clear who was taking the food from the Produce for People basket (a stranger or a fellow gardener), the basket was moved into the locked shed to eliminate or reduce the temptation of unauthorized taking of produce from the basket.

Community gardeners found some consolation in thinking that all unauthorized harvest from their plot was linked to people who were hungry and in desperate need of food. There was no evidence to support this wishful thinking. One Brentwood gardener mentioned that somebody dug out one tomato plant from his plot in early May. He had nourished this plant for several months under a plastic cover and was anxiously waiting for the first early spring fresh tomatoes, when somebody took the whole plant away just before the much anticipated harvest moment. A Johns gardener told a story of several ornamental mums that were dug out of her plot. These stories did not evoke the image of a hungry person in desperate need of food and there was no clear evidence that the damage 
was done by non-registered gardeners. On some occasions, registered gardeners shared the code to the garden with their friends and family to ask them for help in maintaining their plot or sharing some produce with them.

Either way, most gardeners recognized that the fence and the locked gate were insufficient measures to protect the gardens from all forms of vandalism and unauthorized taking of their garden harvest. They also realized that the people on the both sides of the fence could do the damage: non-registered strangers and registered gardeners. Fences could provide a protection against dogs or unsupervised children who tended to run exuberantly over the plots or incidentally step on the patches of fragile plants, but were not believed as the ultimate measure to protect garden harvest from unauthorized taking.

Most of initial informal interviews were related to the issue of safety in the garden. I was curious about how people who work in community gardens can recognize "strangers." It was easier to detect strangers in Brentwood or Johns, because, typically, they did not have a code to the gate. Since the Fulton Garden did not have a fence, it was not at first obvious to me who was the stranger. In the first phase of my observations it was important to me to find out how people would react to me as a "stranger." It allowed me to develop a list of observations related to the importance of the fence on forming social realms in community gardens. I have used my initial list of observations during informal and in-depth 
interviews. For example, most typically the first question people would ask me was "Which one is your plot?"

\subsection{Social Factors}

Fences and locks were not ultimately associated with the division between the public and communal realm, as they did not "weed out" strangers who could, on occasions, enter the garden area. Community gardeners relied on their observations of other people to detect a stranger in the garden and determine the source or reason for the alarm.

(1) Behavior: The Stranger in the Community Garden

Community gardeners used several indicators to determine the stranger in the garden. The gardeners were watching for a set of behaviors when they saw the person unknown to them in the garden setting. During my in-depth interviews, I asked each gardener how they could recognize a stranger in the garden. The following list of "stranger in the community garden indicators" was developed based on the data I collected during the interviews.

$\checkmark$ The gardener must have a gardening tool in his or her hand. People come to the garden to work and the gardening tools symbolize soil cultivation.

$\checkmark$ The gardener must have a "focused" look and go directly to the assigned plot upon entering the garden. New gardeners often have a site map in their hands indicating the location of their plots. 
The gardener does not roam around leisurely and examine the garden; the gardener comes to work and stays most of the time near the individual plot.

$\checkmark \quad$ If needed, the gardener may go to the shed for tools.

$\checkmark$ If the gardener decides to take the break, she or he typically stands up, walks around the garden, or sits either on a chair near the plot or, sometimes on the communal bench. This signals the time when gardeners might wish to socialize.

$\checkmark$ The gardener standing near his or her plot or walking to the shed may be ready for social interaction with other gardeners.

(2) Activity: "Which one is your plot?"

In addition to the above behaviors that might have signified the presence of non registered gardeners, community gardeners tended to ask all new people "which one is your plot?" Not having an immediate answer to this question could imply that the person was not a registered gardener. Detecting a stranger in the garden did not lead to any hostile action, it just allowed the gardener to assess the level of alert and decide upon the need for alarm.

In my first weeks of garden observations, I met many outgoing people who generously devoted time to my research and were willing to talk to me about their experiences in the garden. This was the best opportunity to ask questions related to my reflections on gardening and increase my comprehension of the common perspectives shared by the gardeners. Later, during my in-depth 
interview phase, I had an opportunity to discuss these "stranger-in-the-garden" clues to confirm or clarify my field observations.

In sum, most of the gardeners believed that fences and locks were not exclusively associated with the division between the public and communal realm. The presence of fence was one of the symbolic representations of the boundary between the public and parochial realm but was not the ultimate barrier between the two realms. It was possible that strangers may sneak inside the garden despite the diligent locking and unlocking gate.

I learned from my in-depth interviews, that ultimately, the gardeners relied on the behavior of the person entering the garden area and looked for the clues for alarm.

\section{Fence and Space Connections in Community Garden}

Securing and protecting harvest is of vital importance. Balancing a garden's commitment to being a public resource with its need for being a safe environment is an ongoing challenge for many community gardeners. A fence and a locked gate are the most commonly applied physical objects to form a physical barrier at the gardens.

The study suggested that for most of the gardeners, fences were important to protect the quality and quantity of their harvest but were typically not associated with the personal safety of the gardeners. Any trace of vandalism in the garden 
aimed to destroy defenseless plants and potential food sources was considered as a senseless and wicked activity. The ritual of locking and unlocking the gate was detested by most of the gardeners who were part of the study but considered as a necessary measure to ensure the safety and security of their crops.

\section{Access: Inter Garden Analysis}

All of the gardeners distinguished between their personal safety and the security and safety of the garden harvest. The set of "stranger in the garden"clues were typical for all the gardens, regardless of the presence of fence and locked gate. The "clues" defined the "normal appearances" of the registered gardeners. Although the gardeners did not rely on the presence of the fence to discern the division between the public and communal use, the study suggested that the presence the fence and locked gate could have influenced gardeners' connections to community garden spaces.

The gardeners in Fulton, which had unlimited public access, experienced conflicts with dogs and cars that could lead to unpleasant, if not life threatening situations. While open access to the area was the cause of a threat to personal safety, it also stimulated people to explore areas near the garden. Half of the Fulton gardeners interviewed for the project (in-depth interviews) considered the areas outside their own plots as most important places in the garden (Table IV.1). In contrast, $80 \%$ of Brentwood gardeners regarded their own plots as the most important places in the 
garden. At Johns, 63\% of gardeners believed that their own plots are most important.

The fence dilemma seemed also to be associated with the least enjoyable aspects in the garden At Fulton, 33\% gardeners believed that meeting new people in the garden was the most enjoyable activity. At Brentwood, only $10 \%$ gardeners stated that meeting new people was the most enjoyable activity in the garden but nine Brentwood gardeners believed that their least enjoyable experience was related to dealing with other people in the garden. Nobody at Johns indicated that meeting new people was their most enjoyable activity, but only one person was bothered by other people's gardening styles and the lack of upkeep of individual plots.

\section{Experiencing Garden Space}

\section{Garden Space Connections: Physical Factors}

Based on my field observations, filed interviews, and in-depth interviews, I learned that typically, gardeners related to the garden physical layout at two levels: (1) the importance of their own plot; and (2) the relationship of their own plot to "the other parts of the garden.” The other parts of the garden included, typically, communal areas. 
1.1. The Spirit of Individualism in Community Gardens: "Which one is your plot?"

The presence of each new registered gardener was validated by the key question: "Which one is your plot?" It assured that the stranger who came to garden has the right to be there. Nineteen out of the thirty gardeners $(63 \%)$ who participated in the in-depth interviews considered their plot as the most important place in the garden (Table IV.1). Only five people (17\%) did not regard their own plots as the most important places in the garden: some of them liked the entire garden area and did not focus on any specific part of the garden; others preferred the areas surrounding the garden and the garden area was not an important part of their experience.

The diversity of approaches and creativity in tending individual plots could be either a source of enjoyment or aggravation for gardeners if their gardening philosophy was substantially different from the gardening style of the other gardeners. As previously discussed in Chapter III, the City of Portland Handbook contains a set of rules and guidelines that aimed to rein in some of the creative approaches in individual plot appropriations (Portland Community Gardens: A Handbook, 2008).

\subsection{The Quandary of Communal Areas: "We come here to work!"}

Communal areas in community gardens are frequently referred by the gardners as "the other parts of the garden." The main objective of gardening for most of the 
registered gardeners was food production on individual plots. The rules and regulations of the city further reinforced this objective by imposing specific rules adopted to guide the gardening practice and behavior in the gardens. With that in mind, gardeners appraised communal areas at two levels of importance: (1) to what extent the communal area supported the individual aspect of gardening; and (2) to what extent the communal area enhanced cultivation of the individual plot. Typically, communal areas were associated with group recreation and entertainment, the two aspects of community gardening that were considered "optional" because they went beyond the "necessary" activity of land cultivation for productive use.

Through my informal interviews, intensive interviews, and in-depth interviews I learned that support for "necessary" activities in community gardens was associated with a tool shed, a path connecting the individual plot with the tool shed, and a water source. These primary communal infrastructure improvements supported land cultivation in the garden. Water was a necessary condition for any type of agricultural activity. Each gardener was likely to use the tool shed for storing his or her own tools or use communal tools. The shed gate and walls also served as the bulletin board that contained vital information pertaining to all registered gardeners. The shed was typically locked and combinations codes were expected to be kept secret (Portland Community Gardens: A handbook, 2008). The route between the gate, the shed, and the individual plot defined the typical boundaries of the communal area for each gardener. 
Picnic tables, benches, and demonstration projects belonged to the secondary level of importance and their level of appreciation could have varied among gardeners, depending upon how these structures enhanced their primary gardening goals. The "enhancing" value of the secondary garden infrastructure was typically associated with recreational or learning aspect of garden improvements. Picnic tables and benches installed by the City provided an area for rest and relaxation for several gardeners, if these structures happened to be placed a few feet away from individual plots, preferably in the shaded areas. Gardeners tended to relax close to their individual plots and frequently brought their own chairs or built benches on the edge of plots. Demonstration projects typically included a display of structures or plants that aimed to educate gardeners on a variety of gardening techniques related to sustainable gardening practices (eco roofs, composting bins, rain water circulation cistern, and small fruit orchard demonstration projects).

I learned through my field interviews and in-depth interviews that gardeners used several criteria to assess the usefulness of the optional garden infrastructure:

(1) Time. A trip to the community garden involved some time and preparation. It required careful planning regarding to balance the time in the garden to keep up with the demands of the crop cultivation, personal schedule, and rules and regulations governing community gardening. 
During my initial phase of field observations, I frequently heard from the gardeners that they were pressed for time because they did not live in the immediate vicinity of the garden. During my in-depth interviews, $17 \%$ of the people said that a trip to the garden is the least enjoyable aspect of their gardening and they would prefer to have their own garden near their place of residence.

"If the garden had been in my backyard I could have opened the door, but I have to walk. It is not a huge walk but it is not convenient, I get muddy, I have to go home to change and clean up after watering. It is the inconvenience of it. In the morning it was a hassle.” Dan (Johns Gardener, 2009)

(2) Location. A gardener first arriving at the garden tended first to his or her own plot. If the plot was situated closer to the communal area, the gardener could use the communal area. Nevertheless, for the most part, it was unlikely that any gardener would modify their typical route to include the picnic table and bench for resting and taking breaks. Gardeners tended to take breaks from work near their own plots and convert a portion of an adjoining path into a temporary leisure area. If a garden technique demonstration area (i.e., eco roof, rainwater cistern, demonstration orchard) happened to be close to the major shed-gate route, a gardener was likely to stop by and explore this part of the garden. 
During my field observations, I did not see many people using the communal areas. Based on this observation, I included a question in my in-depth interviews that specifically asked participants about their beliefs related to the low usage of communal areas.

(3) On- Site Conveniences. A number of gardeners mentioned the lack of toilet facilities as a reason for their reluctance to use the communal recreational areas for ad hoc relaxation.

"I sometimes bring my granddaughter but there are no restroom facilities in the garden. The community center is locked on weekends. I see people squatting in the woods. It is not convenient if you have food and drink, not convenient for people to hang around.” Marsha, Fulton Gardener (2009).

(4) Group activities. Gardeners were likely to believe that the communal areas were more appropriate for organized group events of pleasurable nature, such as potlucks and barbeques. Although the lack of organized group activities was the most disappointing and least enjoyable aspect of community gardening for five of the thirty gardeners (17\%) who participated in the study (in-depth interviews) (Table IV.1), most of the gardeners felt that their schedule could prevent them from participating in organized group activities.

(5) Maintenance. Five of the thirty gardeners (17\%, in-depth interviews) considered the lack of care for communal areas as the most distressing part of 
their experience in the community garden (Table IV.1). The garden rules specified that paths in the garden must be flat and at least 2.5- 3 feet wide and each gardener needed to keep paths clear and free from weeds and compost (Portland Community Gardens: A Handbook, 2008). Each gardener was expected to help with work parties, garden projects, and related events at least six hours per year.

Most gardeners focused on the primary function of the communal areas in supporting their goal of food production and the secondary function of the communal areas did not seem to be that important because it was not directly related to the primary goal of gardening. Since communal areas were not considered as the primary activity area, they tended to be neglected by most gardeners, who devoted most of their maintenance attention to the paths near their plots. Thus, the upkeep of communal areas was the left for the work party. These behaviors are similar to those observed and discussed during my interviews with community garden managers (Holmes, 2009a; Cepurna, 2009b, Corbet, 2009b) and city staff (Iott, 2009c).

Between June and September 2009, only one work party was arranged in the three community gardens that were part of my project, at Johns Garden. Six gardeners attended the party. One social BBQ was arranged at Brentwood. Fulton had a limited tradition in organizing work parties (Decker, 2009) but in the summer of 2009 a group of three or four volunteers was working diligently in 
the "rose garden" part of Fulton, trying to convert this weedy and dry corner with neglected rose bushes into a thriving rose garden.

\section{Space Connections: Social Factors}

Table IV. 2 contains a summary of my field observations related to people-topeople interactions in the gardens. Based on the field observations, I identified four types of people-to-people interactions.

(1) No interactions. This category contains single gardeners who never made any contact during my observations. They typically remained close to the plots, either working or relaxing (reading books, painting, knitting, listening to ipods). $72 \%$ of all interactions in the gardens fall into this category.

(2) Two-people interactions. This category contains a number of interactions between two people. I could include short conversations (1-3 minutes) or longer discussions (up to 10 minutes). $23 \%$ of all interactions fall into this category.

(3) Three-people interactions. This category contains a number of interactions involving three people (3\% of all interactions).

(4) More than four people. This category contains a number of interactions involving more than 3 people. It typically included 4-5 people involved in a discussion (2\% of all interactions). 
Table IV.2. Summary of Interactions across Gardens

\begin{tabular}{|c|c|c|c|c|c|}
\hline \multirow{2}{*}{ Garden } & \multicolumn{5}{|c|}{ Interactions } \\
\hline & $\begin{array}{l}\text { No } \\
\text { interactions }\end{array}$ & $\begin{array}{l}\text { 2-people } \\
\text { interactions }\end{array}$ & $\begin{array}{l}\text { 3-people } \\
\text { interactions }\end{array}$ & $\begin{array}{l}\text { 3> people } \\
\text { interactions }\end{array}$ & $\begin{array}{l}\text { All } \\
\text { inter } \\
\text { actio } \\
\text { ns }\end{array}$ \\
\hline \multicolumn{6}{|l|}{ Fulton } \\
\hline$\#$ of interactions & 108 & 43 & 7 & 3 & 161 \\
\hline $\begin{array}{l}\% \text { of total Fulton } \\
\text { interactions }\end{array}$ & $67 \%$ & $27 \%$ & $4 \%$ & $2 \%$ & $\begin{array}{l}100 \\
\%\end{array}$ \\
\hline \multicolumn{6}{|l|}{ Brentwood } \\
\hline \# of interactions & 123 & 35 & 5 & 2 & 165 \\
\hline $\begin{array}{l}\% \text { of total Brentwood } \\
\text { interactions }\end{array}$ & $75 \%$ & $21 \%$ & $3 \%$ & $1 \%$ & $\begin{array}{l}100 \\
\%\end{array}$ \\
\hline \multicolumn{6}{|l|}{ Johns } \\
\hline$\#$ of interactions & 53 & 15 & 1 & 0 & 69 \\
\hline $\begin{array}{l}\% \text { of total Brentwood } \\
\text { interactions }\end{array}$ & $77 \%$ & $22 \%$ & $1 \%$ & $0 \%$ & $\begin{array}{l}100 \\
\%\end{array}$ \\
\hline All Gardens & & & & & \\
\hline \# of interactions & 284 & 93 & 13 & 5 & 395 \\
\hline$\%$ of total interactions & $72 \%$ & $23 \%$ & $3 \%$ & $2 \%$ & $\begin{array}{l}100 \\
\%\end{array}$ \\
\hline
\end{tabular}


The data collected during my field observations indicated that the social realm is dominated by single people working alone in the garden.

These observations were later confirmed by my in-depth interviews. Fourteen out of the thirty gardeners $(47 \%)$ who participated in the study believed that behavior of other gardeners was the least enjoyable aspect of the community garden (Table IV.1). Only five people (17\%) indicated that meeting new people in the garden was the most enjoyable activity in the garden. In contrast, all land cultivation activities, including soil preparation, weeding, watering, and harvesting were considered the most enjoyable activities and twenty gardeners held this view. Fourteen gardeners (47\%) said that either watching and contemplating the natural circle and miracle of growth and renewal and contemplating earth-plant-animal connection were the most enjoyable aspects of activities. Land cultivation, experiencing the natural cycle of growth and renewal, and contemplating the nature connections were solitary activities and did not lead to the formation of vibrant social connections in the community garden.

Typically, gardeners assessed social activities in the community garden at three levels of experience: (1) pleasure, (2) annoyance, and (3) threat.

\subsection{Pleasurable Experiences in Community Garden}

(1) Verbal connections 
Small talk/casual social interaction, helping with garden maintenance, sharing garden harvest, experience, beauty and poetry were considered the most enjoyable experiences in the garden that involved some form of verbal social interaction with other gardeners. Gardening is hard work and the sympathetic and supportive gardening companions were an important factor in forming social connections: they could help with garden chores; they listened to the garden success stories, and shared their harvest and experience. They were a necessary condition for experiencing a sense of accomplishment in the garden.

\section{(2) Visual social connection}

Visual connection included watching other people in the garden and their behavior without engaging in any direct conversation with them. Several people found the presence of groups of people (i.e., friends, married couples) inspirational and stimulating in the way that they were interacting with each other. Their behavior was a source of enjoyment for other people who were watching them from a distance. This included spouses taking care of their disabled partners, young parents with children, and multigenerational families coming to the garden and working together. Visual communication also included watching other people's "imprints" in the garden: artful arrangements of plants and garden structures, plant supports, benches, chairs, composting bins, and weekly poetry postings. 
(3) Non -verbal and non -visual social connection

The garden space was believed to be a reservoir of positive social energy. The awareness that people who came to the garden cared about plants signified a general goodness of spirit, which was felt by some gardeners. This special bond involved the positive energy connection they felt once they entered the garden area. The cumulative human energy that was transformed into the garden was the primary social connection, because it was associated with people and their good will to take care of the plants. Several gardeners felt that they did not need to maintain any verbal connection with the rest of the gardeners but they felt connected through the positive human energy that was accumulated in the garden space and provided a special bond and connection.

"Sitting on the bench, in the corner, next to the pear trees, just take a moment, breath it in...Just appreciate the area; more than my garden plot the whole garden, everybody's plots. All the positive energy that was put into it, it is very sacred space to many people, just to be around this space. It is not a malicious space, it is where nurturing people come and nurture. When you see somebody to some extent you know that it is a decent person because you at least know that to that extent they have so much care in order to plant and water. It is the positive energy people put to the space I can feel it. No need to talk to anybody. It is still positive experience." Hawkins (Johns Gardner, 2009). 
Only five gardeners $(17 \%)$ indicated that the pleasurable social activity was the most important aspect of their community gardening (in-depth interviews). Four out of twelve Fulton gardeners (33\%) believed that social activities in the garden were their most enjoyable aspect of community gardening (Table IV.1). In contrast, nobody from Johns indicated that meeting new people was the most enjoyable activity, as they tended to meet people outside the garden, at other social venues in the Johns neighborhood. Thus, the community garden was not seen as the primary place for developing social connections in the neighborhood by the Johns gardeners. One Brentwood gardener (10\%) indicated that that meeting people at the community garden was the most enjoyable aspect of community gardening.

\subsection{Annoyance Experiences}

(1) Gardening styles of fellow gardeners

Gardeners differed in the way they chose to cultivate their own plots. Most gardeners who joined the community gardening program grew vegetables and small fruit and might have not appreciated other gardeners who did not like growing vegetables or did not keep their plots properly maintained and free from weeds. Non -vegetable and neglected plots were a source of annoyance because they signified lower productivity of land that could have been used for food production. 
During my field observation phase it was not obvious to me that gardening styles of other community gardeners were annoying. Most of the time people were talking about their positive experience during my informal interviews. However, most of the people were more inclined to discuss annoyances during the in-depth interviews. The analysis contained in this section is based mostly on the data obtained during the in-depth interviews.

\section{(2) Disrespecting other plots and comfort of gardeners}

Stepping on plants, smoking in the garden, loud conversations, listening to a car radio, and unauthorized harvest from either the communal area or an individual plot were other sources of annoyance for the community gardeners. Nine of ten Brentwood gardeners (90\%) were annoyed by the behavior of other people in the garden, mostly by disrespecting the plots by others (Table IV.1). Eight

Brentwood gardeners ( $80 \%$ ) believed that their own individual plot was the most important part of the garden. (As discussed in Chapter VI, most of the Brentwood gardeners associated assess to individual plots with individual sanctuaries. The community garden plot provided a sense of stability and a sense of belonging. It was a symbol of sustenance, endurance, and rootedness - the gardeners' own safe territory amid their mobile and fragile life. In that context, any activity that might have desecrated this special area was perceived as a negative aspect of communal gardening.) 
Six out of Fulton gardeners (50\%) found other people in the garden annoying, mostly because the other gardeners did not maintain their plots properly (Table IV.1, summary of in-depth interviews). One (13\%) Johns gardener found that gardening styles of other people should be changed to increase productivity in the garden. While Johns gardeners were mostly annoyed by the lack of maintenance and care for communal areas in the garden, nobody at Fulton was annoyed by the lack of upkeep of communal area. Fulton gardeners enjoyed meeting new people in the community garden, but they did not associate social activities with the communal areas, and therefore, were not bothered the low maintenance of the communal areas. For most of the Johns gardeners, the garden was not the primary social venue but they liked to see the communal areas better maintained and developed to improve their feeling of comfort in the garden. Two of the ten Brentwood gardeners (20\%) were bothered by the lack of care for communal areas and one gardener believed that meeting people in the garden was the most enjoyable aspect of community gardening.

\subsection{Threats in Community Gardens}

\section{(1) Personal safety}

The presence of other people was the key factor in experiencing the feeling of safety. At Fulton, which had unlimited public access, several gardeners believed that the presence of other people, either gardeners or non- gardeners, made them feel safer because they could rely on other people to get help in case of emergencies. At Brentwood and Johns, with limited public access, the gate 
tended to be left unlocked when the number of gardeners increased to at least three people.

"We had tomato cages stolen earlier in the year. It did not make me feel good but it did not make me feel unsafe. More than anything, it aggravated me... Five tomato cages were stolen from my plot. "Hawkins (Johns Gardener, 2009).

(2) Harvest security and safety

For most gardeners, fences were important in protecting their quality and quantity of their harvest and are not typically associated with personal safety. The ritual of locking and unlocking the gate was detested by most of the gardeners but considered as a necessary measure to ensure the safety and security of their crops. Social interactions related to watchful observations and reminders of vandalism influenced formation of social ties in the garden. The concern for harvest safety and security and the elimination of potential threats were the basis or trigger for group interactions.

(3) Lack of support for the community garden program

As part of my in-depth interviews, I asked each gardener what she/he would do if the garden were to be redeveloped. Community gardens maintained by municipalities are fragile and ephemeral places and may be subject to either redevelopment pressure or budget cuts to reduce gardening program services and benefits. In his study on attachment to natural places, Ryan (2003) claims that 
place connections may be most apparent in the face of negative change. He found that the responses to hypothetical negative changes related to natural areas fell into two categories around the themes of emotional responses and environmental activism. The emotional response was associated with the personal loss and feeling sad. The environmental activism manifests itself in taking environmental action to protect a special place.

A detailed analysis of this question, contained in Chapter VI, revealed that seven out of thirty gardeners (23\%) indicated that they had already participated in an organized action to protect the garden and would be part of any action again to protect the garden. Twelve gardeners (40\%) felt strongly that they would either participate or organize an action to protect the garden and the program, if needed. Six gardeners (20\%) felt that they would be sad and would look for another opportunity to garden. They would look for another agency or private property owners to lease garden space to grown vegetables or move to a different house with more access to sun. Six gardeners (20\%) felt that they would be horrified and depressed and either would not know what to do or "let it go" because it would not be possible for them to find another opportunity to grow vegetables.

\section{Social Realm}

\subsection{Dominant Types of Social Realms in Community Gardens}

(1) Individual Realm 
The private realm experience was related to the individual or couples coming to the garden and tending their plot without any extensive interaction with other people. Tending and cultivating one's own plot was the most enjoyable activity for twenty of the interviewed gardeners (67\%) (in-depth interviews). Data collected during my field observations indicates that $72 \%$ of all "interactions" involved people who never made any contact with anybody at the time when I was in the garden.

\section{(2) Communal realm}

The communal realm experience involved interaction with fellow gardeners and was associated with both the most enjoyable and the least enjoyable activities in the community garden. Meeting people in the garden was considered the most enjoyable by six gardeners. Gardening styles of other gardeners and disrespectful behavior of other gardeners were considered as the least enjoyable activities in the community garden by fifteen gardeners (50\%). Data collected from my field observations indicated that $23 \%$ interactions involved interactions with two people and only 3\% interactions involved three people. Gatherings and informal discussions made up only $2 \%$ of all interactions observed by me.

\section{(3) Public realm}

The public realm experience relating to interactions with strangers involved experiencing pleasure (small talk), annoyance (disrespectful behavior/unauthorized produce taking) and threat (personal safety and garden 
vandalism). Seven Fulton (58\% of in-depth interviews) gardeners indicated that interaction with strangers (including driving and dog walking) were the most unpleasant experiences and some of them considered a direct threat to personal safety in the community garden. Three Brentwood gardeners (30\%) believed that the locked gate and the fence provide some measure of personal safety and harvest security.

In summary, the analysis of my field observations, informal interviews, intensive interviews, and in-depth evidence provides evidence that the private realm was mostly associated with pleasurable activities; the communal realm could involved both pleasure and annoyance experiences; and the public realm might have entailed pleasure, annoyance, and threat experiences. Figure IV.4 shows the relationship between social realms and connections in community gardens.

Figure IV.4. Social Realms and Social Activities in Community Gardens $\square$ Presence of prevailing type of activities

\begin{tabular}{|l|l|l|l|}
\hline Type of Social Realm & $\begin{array}{l}\text { Pleasurable } \\
\text { Activities }\end{array}$ & $\begin{array}{l}\text { Social Interactions } \\
\text { Related to Annoyance }\end{array}$ & $\begin{array}{l}\text { Social } \\
\text { Interactions } \\
\text { Related to } \\
\text { Threat }\end{array}$ \\
\hline Private & & & \\
\hline Communal & & & \\
\hline Public & & & \\
\hline
\end{tabular}


The study suggested that the range of general patterns involving pleasure, annoyance, and threat related social activities might have influenced the formation of social realms in the three community gardens.

\subsection{Symbolic Representations of Social Realms in Community Gardens in Portland}

The individual plot was the universal symbol of private realm in the community gardens. The shed, the path, the table, and the Produce for People basket were the central elements of the community gardens representations of public and communal realms. The shed was the key symbol of the communal realm in community gardens. The public realm was not universally symbolized by one object in the three gardens.

\section{(1) Tool Shed}

The shed was the most commonly recognizable feature in all three community gardens. Most gardeners might have not ventured to the communal areas with picnic tables, but they were likely to use the shed, either to store their tools or read announcements. The tool shed was the symbol of the community garden and the communal realm. The city rules required that gardeners keep the combination to the shed locks secret. Only registered gardeners had access to the tool shed to store garden tools. The bulletin board provided a common ground for all gardeners and was the primary source of information in the garden. It was 
a symbol of "community" in the community garden. Occasionally, the shed area might have served as an ad hoc communal gathering area, but most of the time, paths were the spaces for social interaction in the community garden.

"The shed is one of the most important communal areas to me , because it has tools. It is a reminder that I have access to tools to learn how to use them and maintain the garden, shovels, wheel borrows..." Tom (Brentwood Gardener, 2009).

(2) Path

The paths connecting the plots and the shed were recognized as social interaction area. When a gardener took a break and was ready for a social interaction, he or she stepped into the path. Assuming a standing position in the path might have shown a desire to talk to fellow gardeners and signaled the conversion from the private to the communal realm. Squatting and bending position signaled the private use on the individual plot.

During my field observations, I became aware that most of the two-people interactions took place on the paths. In my intensive interviews and in-depth interviews, I asked why paths appeared to be the most social place in garden. Most of the gardeners felt that there was no need to use the picnic table/bench area for ad hoc social conversations and that the paths were conveniently located next to their plots. 


\section{(3) Picnic Table}

The picnic table was the symbol of "sharing" in the garden. The willingness of gardeners to share their crops, knowledge, and gardening wisdom was legendary equally so in all three gardens. The picnic table symbolized sharing produce and good will through gardening. Here, the gardeners left their plants, seeds, garden tools, and harvest to share with other people. The picnic table symbolized "authorized" taking: whatever was left on the table was up "for grabs" by other people.

"Our picnic table is very important to me. People put things on the table to share with everybody. Sometimes we like to go and have our sandwiches there. It is nice to have it in a central location so we see it. It is next to the shed. It is a nice hangout place for us" Heike (Brentwood Gardener, 2009).

(4) Produce for People Basket/Bucket

Produce for People is a program run by the City of Portland. It links Portland Community Gardens with local emergency food agencies. Volunteer gardeners set aside a plot or donate their excess produce for the program.

"It warms my heart... Produce for People, in the shed, I warms my heart to know that we can provide fresh organic vegetables to people who 
really need. It is sharing bounty; we are able to share the bounty with other people I do not know; it is being connected with people I do not know... Even if I do not have money to give, I can give food, it is fundamental, it you think about it there is nothing more powerful that giving food to people." (Jan, Brentwood Gardener, 2009).

Most of the gardeners were acutely sensitive to the possibility of wasting fresh garden produce and welcomed all opportunities to avoid the waste of food and share it with others in need. Typically, the Produce for People basket/bucket was placed in the heart of the garden (i.e. next to the shed) or inside the shed. The produce in the basket was designated for the families in need and it was not meant to provide produce for the registered gardeners. Taking produce from the basket by community gardener, or anybody else, was considered an "unauthorized taking," in contrast to taking produce from the table, which symbolized the general concept of sharing with everybody. Several volunteers delivered Produce for People donations to the local emergency food agencies. Figure IV.5 summarizes the differences across the gardens related to the symbolic representations of social realms.

Table IV.5 Summary of Dominant Symbolic Representations of Social Realms $\square$ presence of symbolic representation

\begin{tabular}{|l|c|l|c|l|l|l|}
\hline \multirow{2}{*}{ OBJECT } & \multicolumn{2}{|c|}{ Fulton } & \multicolumn{2}{c|}{ Brentwood } & \multicolumn{2}{c|}{ Johns } \\
\cline { 2 - 6 } & Communal & Public & Communal & Public & Communal & Public \\
\hline
\end{tabular}




\begin{tabular}{|l|l|l|l|l|l|l|}
\hline \multirow{2}{*}{ OBJECT } & \multicolumn{2}{c|}{ Fulton } & \multicolumn{2}{c|}{ Brentwood } & \multicolumn{2}{c|}{ Johns } \\
\cline { 2 - 7 } & Communal & Public & Communal & Public & Communal & Public \\
\hline Shed & & & & & & \\
\hline Path & & & & & & \\
\hline Table & & & & & & \\
\hline Produce for People & & & & & & \\
\hline
\end{tabular}

Fulton was most "endowed" in the range of symbolic representations of social realms. The paths and the table symbolized both communal and public realms. The shed was considered "communal" but the Produce for People basket symbolized the public realm. At Brentwood, the shed, the paths and the table were mostly used by registered gardeners and associated mostly with the communal realm. The Produce for People basket, placed inside the shelf, was a symbol of the public realm, the connection between the garden and the unknown people in need of fresh produce. Johns had only two symbols of the communal realm: the shed and the path. There was no picnic table at Johns, and the garden did not participate in the Produce for People program.

At Fulton, a path and a picnic table symbolized the "gathering place" in both communal and public realms. The picnic table was the universal symbol of "sharing" in community gardens. At Fulton, it included both sharing with strangers and fellow gardeners. Fulton had unlimited access and both registered gardeners and strangers were invited to share the bounty of the garden. It signalized "authorized" produce taking, in contrast to "unauthorized" produce 
taking from individual plots by strangers and fellow gardeners. Internal paths were also used by strangers, registered gardeners, and were associated with both public and communal realms.

At Brentwood and Johns, a path and a picnic table symbolized the communal realm because both gardens had limited access and, typically, did not encourage non -registered gardeners to visit the garden. At Brentwood, the picnic table symbolized the communal realm because the garden was locked most of the time and was not accessible to strangers. Johns did not have a picnic table in its communal area.

The Produce for People basket. symbolized the public realm at Fulton and Brentwood, the two gardens that participated in the Produce for People program. Johns did not participate in the program.

D. Field Observations: Summary of Findings As previously discussed in Chapter II, de Certeau's spatial travel story was used heuristically to explore the experience of the gardeners in two ways:

(1) To understand the relationship between space transformation and space connections in community gardening practices;

(2) To understand the relationship between the city ("agency") and the gardeners ("tactics) in forming spatial connection. 
1. Space Transformation and Dominant Connections in Community Gardens in Portland

Community gardeners recognized three major types of space transformation in their gardening practices that influence the formation of their connection to the gardens: (1) transportation to the garden; (2) access ;(3) garden space.

Figure IV.6 summarizes the relationship between the community garden transformation phases and formation of relevant/dominant connections in the practice of everyday life in community gardens, i.e., it captures the "community garden spatial travel story" that justifies the space and place conversions through marking out boundaries of the primary gardening activities.

The car, the fence, and the individual plot are the three key elements defining boundaries in the space transformation phases. Most gardeners are likely to: (1) drive to the garden. (2) enter the garden through the gate, and (3) focus their attention mostly on their individual plots. Gardeners usually assess the activities and space connections in the garden in the context of their own plots. 
Figure IV.6. Space Transformation and Dominant Connection in the Practice of Everyday Life in Portland Community Gardens

\begin{tabular}{|c|c|c|}
\hline Space Transformation & $\begin{array}{c}\text { Dominant Physical } \\
\text { Connections: } \\
\text { Objects /Physical Features }\end{array}$ & $\begin{array}{c}\text { Dominant Social Connections: } \\
\text { Behavior/Activity/Event }\end{array}$ \\
\hline Transportation & car & driving, walking \\
\hline Access & fence, locked gate & $\begin{array}{c}\text { ritual of locking/unlocking gate; } \\
\text { watching and talking to strangers } \\
\text { for clues }\end{array}$ \\
\hline Garden Space & $\begin{array}{c}\text { own plot, } \\
\text { other parts of the garden } \\
\text { (communal areas/other plots) }\end{array}$ & $\begin{array}{c}\text { pleasure, annoyance, and threat } \\
\text { experiences }\end{array}$ \\
\hline
\end{tabular}

\section{Social Realm in Community Gardens in Portland}

The private realm experience in community gardens was related to individuals or couples coming to the garden and tending their plot without any extensive interaction with other people ( $72 \%$ of all interactions). The communal realm experience involved interaction with other fellow gardeners (28\% of all interactions) and was associated with both the most enjoyable and the least enjoyable activities in the community gardens. The public realm experience involved direct interactions with strangers (incidental and sporadic exchange of greetings and causal comments about the weather and joy of gardening were the most typical exchanges observed by me). Based on my field observations, field interviews, and in-depth interviews, I was unable to determine the actual number of conversations between the strangers and registered gardeners. 
3. The Role of the Agency (City of Portland) in the Practice of Everyday Life in Community Gardens in Portland

De Certeau notes that ordinary human behavior resists institutional control of the agency and people typically make spaces habitable to themselves. The study suggests that community gardeners resist the institutional control of the City of Portland in two ways (1) by not conforming to regulations related to individual plots; (2) by converting formal recreational spaces (designed by the city) to nonrecreational uses.

\subsection{Use of Individual Plots}

As previously discussed (Chapter III), the city's design of community gardens focuses on individual plots. All gardeners are subject to the same rules aimed to control gardening activities (upkeep of plots, times of cultivation, size of supportive structures, watering, use of organic fertilizers, and harvest only for personal use).

Nineteen of the thirty gardeners $(63 \%)$ who participated in the study believed that their own plot was the most important place in the garden and most of their activities revolved around the appropriations of individual plots to express their creativity and diversity of their gardening goals. Their expression of creativity involved growing plants (trees and bushes) that were not allowed by the garden rules. Some gardeners constructed structures (fences around the plots) that 
violated the garden rules. Frequently, communal paths adjacent to the plots were converted into private recreational areas, which was against city regulations. In short, they appropriated their own plots to make them feel comfortable in the garden but did not conform to the city guidelines.

De Certeau argues that the objective of the agency is to homogenize its audience by creating uniformity. A strategy is relatively infexible because it is embedded in its spatial or institutional localization. Thus, the uniform design standards applied by the city to develop and manage the gardens were symptomatic of the "strategy" aimed to impose order and control and resulted in reinforcing the inividual use of community garden plots through the homogenized design and management.

\subsection{Use of Communal Areas}

As previously discussed in this chapter, the gardeners made the communal spaces "habitable" by appropriating picnic tables mostly for harvest display and storage and converting walkways to recreational uses. Picnic tables and benches were the central feature of "formal" recreational areas in community gardens designed by the city but they were not used for recreational uses by the gardeners most of the time. Only gardeners who happened to have their own plots near the picnic tables frequently appropriated the communal space and treated it as an extension of their own plots. 
Gardeners typically relaxed by sitting in their own chairs and benches near their plots or by walking on the paths. The areas designated for "recreational communal use" were underutilized because gardeners came to the garden to work and stayed close to their plots. As a result, paths were the most popular social gathering areas and places for ad hoc socializing. Picnic tables were mostly associated with the "sharing in the community garden". They were used for sharing plantings and harvest with both strangers and fellow gardeners.

De Certeau notes that ordinary human behavior resists institutional control and people typically make spaces habitable to them behind the appearance of conformity. Through field observations and in-depth interviews, I learned that a number of gardeners viewed the picnic areas and paths as "underutilized " areas of the garden that should have been converted into "productive use" (i.e. land cultivation) but did not voice their ideas to city staff. Ultimately, most of the community gardeners converted the communal areas to "productive use" by appropriating them for harvest sharing (placing surplus seeds, vegetables, and fruit for communal and public sharing) and considered paths as their primary "recreational" areas for ad hoc socializing. While to a casual observer a picnic table under a fruit tree was a symbol of relaxation, seemingly in conformance with its formal designation, most of the gardeners tended to turn the picnic tables into the harvest related activities, and convert the paths to their own recreational areas. 


\section{CHAPTER V. TIME AND SPACE CONNECTION IN COMMUNITY GARDENS}

This chapter contains an analysis and findings related to the influence of time on social and physical connections to community gardens.

My hypothesis was that physical connections in community gardens would play an important role in constructing sense of place in the short term but would be less important in the long term.

A. Analysis of the Spatiotemporal Relationship in Community Gardens

During my in-depth interviews, I asked each gardener what they believed was

their primary connection to the garden. Twenty-three gardeners (77\%) felt that the physical connection was their primary connection (Table V.1). Four gardeners (13\%) considered both social and physical connections as equally important.

Three (10\%) gardeners said that their primary connection was social.

Table V.1. Time Dimension and Space Connection by Gardener

\begin{tabular}{|l|l|l|l|l|l|l|l|l|}
\hline & & \multicolumn{3}{|c|}{ TIME DIMENSION } & \multicolumn{3}{c|}{ CONNECTION } \\
\hline & Gardener & $\begin{array}{l}\text { Years } \\
\text { In } \\
\text { Garden } \\
\text { In }\end{array}$ & $\begin{array}{l}\text { Years } \\
\text { Area }\end{array}$ & $\begin{array}{l}\text { Years } \\
\text { Total } \\
\text { Gardening } \\
\text { per } \\
\text { week }\end{array}$ & $\begin{array}{l}\text { Visits } \\
\text { Phys. }\end{array}$ & Soc. & Both \\
& $\begin{array}{l}\text { Fulton (12 } \\
\text { gardeners) }\end{array}$ & & & & & & & \\
\hline 1 & Sydney & 1 & 23 & 46 & $2-3$ & X & & \\
\hline $\mathbf{2}$ & Andrea & 2 & 25 & 20 & 1 & X & & \\
\hline $\mathbf{3}$ & Jim & 2 & 20 & 44 & $5-6$ & $\mathrm{X}$ & & \\
\hline $\mathbf{4}$ & Ken & 3 & 3 & 50 & 4 & $\mathrm{x}$ & & \\
\hline $\mathbf{5}$ & Dawn & 3 & 3 & 45 & $3-4$ & $\mathrm{x}$ & & \\
\hline $\mathbf{6}$ & Perky & 4 & 40 & 60 & $2-3$ & $\mathrm{x}$ & & \\
\hline $\mathbf{7}$ & Barbara & 4 & 9 & 5 & $4-5$ & $\mathrm{x}$ & & \\
\hline
\end{tabular}




\begin{tabular}{|c|c|c|c|c|c|c|c|c|}
\hline & & \multicolumn{4}{|c|}{ TIME DIMENSION } & \multicolumn{3}{|c|}{ CONNECTION } \\
\hline & Gardener & $\begin{array}{l}\text { Years } \\
\text { In } \\
\text { Garden }\end{array}$ & $\begin{array}{l}\text { Years } \\
\text { In } \\
\text { Area }\end{array}$ & $\begin{array}{l}\text { Years } \\
\text { Total } \\
\text { Gardening }\end{array}$ & $\begin{array}{l}\text { Visits } \\
\text { per } \\
\text { week }\end{array}$ & Phys. & Soc. & Both \\
\hline 8 & Gerry & 4 & 9 & 5 & $3-4$ & & & $\mathrm{x}$ \\
\hline 9 & Florence & 5 & 6 & 38 & $4-5$ & & & $\mathrm{x}$ \\
\hline 10 & Marsha & 10 & 37 & 60 & $3-4$ & $\mathrm{x}$ & & \\
\hline 11 & Merrill & 10 & 17 & 70 & $4-5$ & $\mathrm{x}$ & & \\
\hline \multirow[t]{3}{*}{12} & David & 11 & 25 & 20 & $3-5$ & $\mathrm{x}$ & & \\
\hline & \# in Garden & & & & & 10 & & 2 \\
\hline & \% in Garden & & & & & $83 \%$ & & $17 \%$ \\
\hline 13 & Lisa & 1 & 13 & 16 & $2-3$ & $\mathrm{x}$ & & \\
\hline 14 & Stephanie & 3 & 7 & 3 & $2-3$ & $\mathrm{x}$ & & \\
\hline 15 & John & 4 & 24 & 10 & $3-4$ & $\mathrm{x}$ & & \\
\hline 16 & Melinda & 4 & 7 & 30 & $5-7$ & $\mathrm{x}$ & & \\
\hline 17 & Tom & 5 & 62 & 20 & $6-7$ & & $\mathrm{x}$ & \\
\hline 18 & Heike & 5 & 7 & 30 & 3 & $\mathrm{x}$ & & \\
\hline 19 & Mark & 6 & 38 & 12 & $5-7$ & $\mathrm{x}$ & & \\
\hline 20 & Gracie & 6 & 19 & 7 & $2-3$ & & $\mathrm{x}$ & \\
\hline 21 & Jan & 7 & 40 & 20 & $4-5$ & $\mathrm{x}$ & & \\
\hline \multirow[t]{4}{*}{22} & Bill & 12 & 13 & 47 & $5-6$ & & $\mathrm{x}$ & \\
\hline & \# in Garden & & & & & 7 & 3 & \\
\hline & $\%$ in Garden & & & & & $70 \%$ & $30 \%$ & \\
\hline & Johns & & & & & & & \\
\hline 23 & Dan & 1 & 9 & 1 & 2 & $\mathrm{x}$ & & \\
\hline 24 & Hawkins & 1 & 3 & 1 & $3-4$ & $\mathrm{x}$ & & \\
\hline 25 & Wendy & 1 & 1 & 3 & $1-2$ & $\mathrm{x}$ & & \\
\hline 26 & Mark & 2 & 3 & 15 & $5-6$ & $\mathrm{x}$ & & \\
\hline 27 & Marguerite & 3 & 3 & 60 & $5-6$ & & & $\mathrm{x}$ \\
\hline 28 & Mary Anne & 3 & 3 & 20 & $5-7$ & & & $\mathrm{x}$ \\
\hline 29 & Robby & 3 & 3 & 10 & $5-6$ & $\mathrm{x}$ & & \\
\hline \multirow[t]{6}{*}{30} & Mike & 3 & 20 & 50 & $5-7$ & $\mathrm{x}$ & & \\
\hline & \# in Garden & & & & & 6 & & 2 \\
\hline & $\%$ in Garden & & & & & $75 \%$ & & $25 \%$ \\
\hline & & & & & & & & \\
\hline & ALL & & & & & 23 & 3 & 4 \\
\hline & $\%$ of All & & & & & $77 \%$ & $10 \%$ & $13 \%$ \\
\hline
\end{tabular}

\section{Physical versus Social Connections}

The analysis of interviews and field observations presented in Chapter IV indicated that community gardeners did not engage with the community garden 
space in terms of "social" and "physical" connections, but saw the "community garden" as the embodiment of symbiotic relationships between flora, fauna, and human groups.

Social, people-to-people connections were relatively insignificant and less pleasurable in the context of community gardens. Only five gardeners (17\%) indicated that the pleasurable social activity was the most important aspect of their community gardening (Figure IV.2). Six gardeners (20\%) believed that the behavior of other gardeners (disrespecting plots and comfort of gardeners) was the least enjoyable experience. Eight gardeners (27\%) were annoyed by the gardening styles of other gardeners.

Social interactions related to helping out with garden maintenance and sharing harvest and gardening experience were typically associated with pleasurable social activities in the garden. These included verbal connection (small talk), visual connection (watching other gardeners' behavior and imprints of their activities), and experiencing positive energy accumulated in the garden space.

Visual and non-verbal connections were an important part of garden "people" connections but they did not lead to direct social involvement. Many gardeners watched other people and their work without any verbal engagement. Observing other people's imprints in the garden, (i.e., their artful arrangements of plants and garden structures) were one of the most enjoyable activities in the garden. 
Cultivation of individual plots, experiencing the natural cycle of growth and renewal, and contemplation of nature were solitary activities and did not lead to the formation of the vibrant social realm in community gardens. During my field observations from May 1 to October 31, 2009, I did not usually see more than three people working in different parts of the garden. Weekend mornings, weekend afternoons, and early evenings were the times I could see up to twelve gardeners working in the garden at the same time.

As previously discussed in Chapter IV (Figure IV.2), the physical transformation of one's own plot was the most enjoyable activity in community gardens ( $66 \%$ of gardeners). It included land cultivation activities, preparing soil for planting, seeding, watering, weeding, harvesting, and watching the cycle of nature.

The gardeners' connection with the garden space was not limited to cultivating land and tending plants. Watching the natural cycle of life, the miracle of growth and renewal, meditation of ephemeral life forms, and the contemplation of the natural web of life were also considered enjoyable activities. My analysis of indepth interviews (Chapter IV, Figure IV.2) indicates that most community gardeners defined themselves in the context of the people-plant-animal-land web connections, which involved the physical transformation of earth and appreciation of direct physical touch. The people-plant-animal-land connections were the most enjoyable activity for twenty (67\%) gardeners. Fourteen gardeners (46\%) believed 
that watching the "natural cycle of nature", renewal of life and energy, meditation of ephemeral life forms, and the cyclical contemplation of seasons was their favorite activity in the garden. Contemplation of spiritual earth-plant-animal connections and patterns was the most enjoyable activity for five $(17 \%)$ of the gardeners.

The garden was believed to be a reservoir of positive energy associated with the people who came to the garden to take care of plants. Although only five gardeners $(17 \%)$ believed that the "contemplation of spiritual earth-plant-animal connections and patterns" (Figure IV.2) was their favorite aspect of community gardening, the awareness of accumulated goodness of spirit that was felt by most fellow gardeners and provided a tacit understanding of the spiritual ties binding the people, plants and animals.

\section{Time Dimension}

During the in-depth interviews, it became apparent that that the time dimension, measured in chronological years, was not relevant in influencing the connections to community gardens (Figure V.1). Regardless the length of time in the area, length of membership in the garden, total years of gardening, and frequency of visits to the garden, $77 \%$ of the gardeners believed that "physical connection" was their primary connection. As discussed above, the "physical connections" meant gardeners' relationship with flora, fauna, and land. 
In the community garden narrative, the cyclical concept of time constituted the primary time dimension. Gardeners associated the concept of "present time" with the natural cycle and renewal. Past memories and future expectations were connected with the circular meaning of time and played an important part in experiencing empowerment. The relationship between the circular meaning of time and empowerment is discussed in detail in Chapter VI. The "past" in community gardening was about past memories of cultivating plants from childhood, connecting with home and parents, and remembering children, spouses, and friends. Individual plots were reservoirs of memories of the past. Gardeners reflected on their first exposure to gardening, and who or what was the primary impetus or reason to start cultivating land. Frequently, special objects or flowers commemorated past events. These spatial memories were materialized through cyclical land cultivation.

B. Time and Space Connection in Community Gardens: Summary of Findings

This study finds that the circular time dimension in community gardens, reflective of the natural life cycle, is fundamental in influencing nature-based space spatiotemporal connections that are different from the physical/social dichotomy. Gardeners define the "physical" aspect of gardening as a symbiotic web of plants, earth, and animals co-existing in the same garden space. "Land" includes earth, water, air, and temperature, the traditionally recognized elements of the physical environment. The "social" aspect of gardening, although 
acknowledged as important by many gardeners, is not considered as the primary connection. In this view, humans are the only link in the connections between plants, animals, and land. Gardeners do not engage with the community garden space in terms of "social" and "physical" connections. Instead, they viewed the "community garden" as the embodiment of the symbiotic relationships between flora, fauna, and human groups. In the context of community garden, people-topeople connections are relatively insignificant.

Community gardeners relate to the concept of time in a circular way, reflecting the influence of the natural cycle of life renewal. Thus, the linear concept of time does not appear to be relevant in the context of community garden.

As the result of my analysis of community garden connections, I developed the concept of Natural Realm to capture the uniqueness of the spatiotemporal connections in these community gardens. Natural Realm connections to garden spaces deemphasize the human-centric view of nature and redefine the context for forming relevant connections in community gardens. This prevailing naturecentered connection recognizes that the recycling of nutrients and energy in nature is a function of many species and that human survival is dependent on preserving all existing species and allowing them a place to live. Figure V.1 captures the concept of the Natural Realm connections in community gardens, discussed above. 
Figure V.1. Natural Realm Web Connections in Community Gardens

"social" (people-to-people) connections

"physical" (non-people-to-people) connections

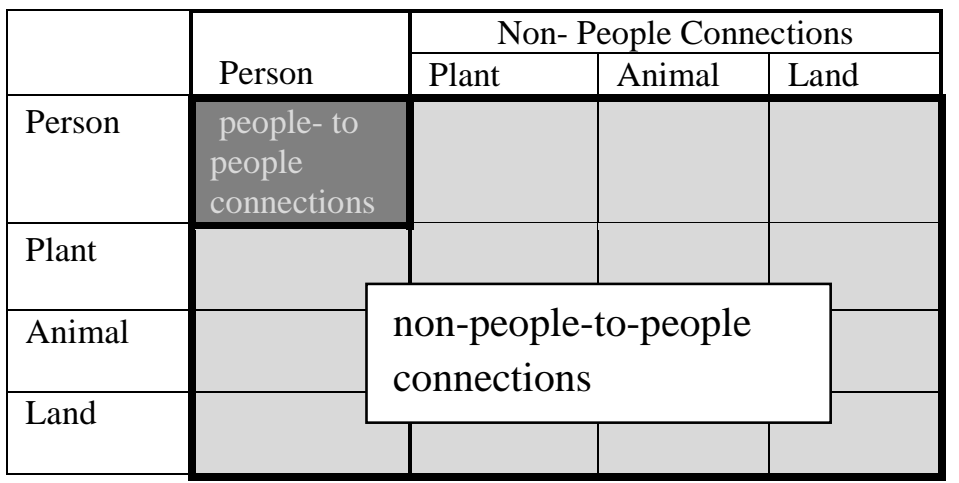

In summary, my analysis of space connections in community gardening does not support my hypothesis that physical dimensions of gardens play an important role in constructing sense of place in the short term but are less important in the long term. The study finds that regardless of the gardener's length of the membership in the community garden, physical connections are believed to be the most important in forming connections to community gardens. Gardeners tend to define "physical" connections as non-people-to-people connections that could include any combination of people-plant-animal-land connections (Figure V.1). In that context, the non-people to people connections, defined as "physical," dominated the Natural Realm experience in community gardens.

The Natural Realm is grounded in the garden cycle and tending plots for food production. The significant space transformation that influences the formation of relevant connections revolves around the cyclical concept of time, marked by the 
renewal of nature. Thus, community gardeners relate to the concept of time in a circular way, reflecting the influence of Natural Realm connections.

In the community garden narrative, the cyclical concept of time constitutes the primary time dimension. Circular time, associated with the natural circle and renewal, is considered "present time" in community gardening. Both past memories and future expectations are connected with the circular meaning of time. 


\section{CHAPTER VI. COMMUNITY GARDEN EMPOWERMENT}

This chapter focuses on three aspects of experiencing empowerment in community gardening: (1) multiple forms of empowerment related to gardening activities, which assumes that people may have different goals in the same settings; (2) the impact of social realm and physical setting of community gardens on empowerment feelings; and (3) the relevence of individual and group action to accomplish individual goals.

My hypothesis was that, given the entire spectrum of "empowerments" suggested by Rocha's ladder, community gardens may empower people at different levels - gardeners may choose to partcipate in a group action to fullfill certain empowerment goals or choose to rely on individual action to fullfill other goals. Based on my preliminary observations and discussions with city staff and garden managers, it seemed that people who participated in the city garden program might have experienced community gardens at the "embedded individual" and/or "mediated" empowerment levels.

Both embedded and mediated empowerment recognize the importance of the surrounding environment and conceptualize individuals within the larger context affecting their circumstances. The settings include both the physical setting and the organizational context. Mediated empowerment recognizes the importance 
of an expert or professional. The Portland Community Garden Program provides physical settings (individual plots) in the larger context (community garden spaces) and is managed by the City of Portland (organizational context with experts). According to Rocha, participation in the program is fundamental in experiencing both embedded and mediated empowerment. Therefore, I hypothesized that community gardeners who signed up for a plot in a community garden program would experience "embedded empowerment" and /or “mediated empowerment."

The first part of Chapter VI contains a discussion of multiple forms of individual empowerment in community gardens and the influence of the social realm and physical settings on the formation of individual empowerment goals. The second part of the chapter focuses on the empowerment process itself (i.e., the relevance of individual and group action in accomplishing the empowerment goals).

\section{A. Community Gardening Empowerment Goals}

Empowerment is broadly defined as both outcome and process by which people gain mastery of their affairs and control of their life. During my in-depth interviews I asked each gardener in a series of follow up questions to gain an understanding how people perceive the importance of the community garden in gaining "mastery of their affairs and control of their lives:" (1) how did the 
garden changed her/his life? (2) why does she/he do community gardening? (3) what is community gardening worth to she/he?

The main impetus for community gardening for most of the registered gardeners was food production. Once this primary goal was satisfied, gardeners could reflect on other aspects of community gardening.

"I feed myself from the garden. It started as an economic thing, and then became a health thing, a lifestyle, and a social thing, everything...

Participating in your project has given me an opportunity to reflect on the importance of the community garden in my life. The garden is an enormous part of my life, it changed everything, and it made my eyes open to many new aspects of life..." (Gracie, Brentwood Gardener, 2009).

The study reveals that community gardeners experienced empowerment at two levels: (1) by growing and harvesting plants; and (2) by experiencing empowerment feelings not directly related to food production in community gardens.

Figure VI.1 contains a summary of empowerment experienced by community gardeners across the gardens. Most of the gardeners believed that access to community gardens empowered them in several ways. 
Table VI.1. Empowerment Goals Summary

\begin{tabular}{|c|c|c|c|c|c|c|c|c|}
\hline \multirow{3}{*}{$\begin{array}{c}\text { Empower } \\
\text { ment } \\
\text { Goal }\end{array}$} & \multicolumn{8}{|c|}{ GARDENS } \\
\hline & \multicolumn{2}{|c|}{$\begin{array}{c}\text { Three } \\
\text { Gardens } \\
\mathbf{3 0} \\
\text { gardeners }\end{array}$} & \multicolumn{2}{|c|}{$\begin{array}{c}\text { Fulton } \\
12 \\
\text { gardeners }\end{array}$} & \multicolumn{2}{|c|}{$\begin{array}{c}\text { Brentwood } \\
10 \\
\text { gardeners }\end{array}$} & \multicolumn{2}{|c|}{$\begin{array}{c}\text { Johns } \\
8 \text { gardeners }\end{array}$} \\
\hline & 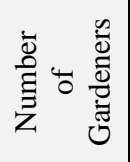 & 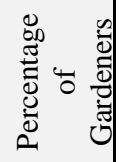 & 离 & 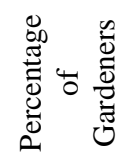 & 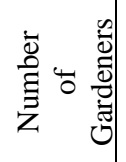 & 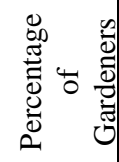 & 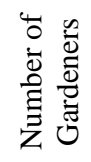 & 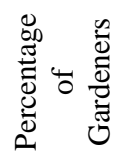 \\
\hline \multicolumn{9}{|l|}{ Harvest } \\
\hline $\begin{array}{l}\text { Food } \\
\text { quality }\end{array}$ & 25 & $83 \%$ & 8 & $66 \%$ & 10 & $100 \%$ & 7 & $88 \%$ \\
\hline $\begin{array}{l}\text { Food } \\
\text { quantity }\end{array}$ & 22 & $73 \%$ & 7 & $58 \%$ & 10 & $100 \%$ & 5 & $63 \%$ \\
\hline $\begin{array}{l}\text { Nonfood } \\
\text { harvest }\end{array}$ & 4 & $13 \%$ & 4 & $33 \%$ & 0 & $0 \%$ & 0 & $0 \%$ \\
\hline $\begin{array}{l}\text { Harvest } \\
\text { support }\end{array}$ & 19 & $63 \%$ & 7 & $58 \%$ & 6 & $60 \%$ & 6 & $75 \%$ \\
\hline \multicolumn{9}{|l|}{$\begin{array}{l}\text { Non- } \\
\text { Harvest }\end{array}$} \\
\hline Lifestyle & 24 & $82 \%$ & 8 & $66 \%$ & 8 & $80 \%$ & 8 & $100 \%$ \\
\hline Sanctuary & 17 & $56 \%$ & 4 & $33 \%$ & 8 & $80 \%$ & 5 & $63 \%$ \\
\hline Beauty & 25 & $83 \%$ & 9 & $75 \%$ & 9 & $90 \%$ & 7 & $88 \%$ \\
\hline Learning & 20 & $66 \%$ & 5 & $41 \%$ & 9 & $90 \%$ & 6 & $75 \%$ \\
\hline
\end{tabular}

\section{Harvest Goals}

Garden harvesting was one of two major sources of empowerment in community gardens (Table VI.1). Community gardeners experienced harvest-related empowerment in four ways: (1) satisfaction from growing safe and nutritious food; ( 2) satisfaction from growing enough food to feed themselves, their family, friends, and other people who are less fortunate; (3) pleasure of growing plants to feed animals, both wild animals in the garden and animals at home or to share non food plants with other people; and (4) appreciation of available land 
resources and community garden infrastructure to support their primary goal of food production.

"Food production" was not a universal expression used by the gardeners, as most of them distinguished between "food quality" and "food quantity." Twenty-five of $(83 \%)$ the thirty gardeners experienced empowerment feelings related to the ability and opportunity to produce their own vegetables and fruit. Twenty-two (73\%) gardeners were empowered by producing enough food to feed them and share fresh-garden grown or home processed food with other people. The "food quality" related empowerment varied across the three gardens. "Food quality" and "food quantity" were equally important to Brentwood gardeners (all of them felt empowered by growing enough good quality food). In contrast, Fulton and Johns gardeners felt more empowered by producing high quality food and were slightly less focused on food quantity.

\subsection{Food Quality}

Satisfaction from growing safe and healthy food was the primary feeling of empowerment related to the harvest goals. Twenty-five (83\%) gardeners believed that the safe food was their primary source of accomplishment. The feeling of empowerment came from the ability to control both the source of growing and handling food products.

The City of Portland requires that community gardeners apply organic food growing techinques and encouraged sustainable forms of agriculture (Portland Community Gardens: A Handbook, 2008). 
The thirty community gardeners who particpated in the project were a small contignent but testimony to the growing awarness that government regualations did not assure food safety and local control over the food production had became one of the biggest social concerns. As food sources and food handling and processing are becoming more distant, consumers have scant knowledge of where their food comes from, how it is produced, and under what conditions.

The community gardeners interviewed for the study tended to see their ability to control and grow nutritious and healthy food as a "luxury" not a "right." Availabilty of fresh raspberries or blueberries, just a drive away, was associated with the concept of affluent life. Snacking on fresh asparagus and carrots, growing purple potatoes and heirloom tomatoes was believed to be a status symbol and an indicator of luxurious lifestyle fullfilled by maintaining a community garden plot in a sunny location. The image was one of a fashonable and healthy lifestyle achieved by controlling one's source of food. Portland community gardeners tended to associate the "rich and famous" lifestyle with the ability to have a spoonful of fresh raspberries rather than circling the globe. They related luxury with health and healthy eating habits; the concept of affluence and good fortune in life was tied to the place and the ability to control own food. 
"Eat local, eat organic... those were the things I never thought about before I had my garden. I would go to the surplus groceries, to find dented cans cereal boxes and I would buy the cheapest things I could get...Having all the raspberries I want to eat is an incredible luxury to me; like buying a BMW or Mercedes. It became the most important thing in my diet. It is an incredible luxury. It shifted my all perception of myself that I can get also luxurious things in my life and it was pretty significant..." (Gracie, Brentwood Gardener, 2009).

The fear of unhealthy food was the primary motivation to undertake control over food growing and processing in community gardens managed by the City of Portland. Access to one's own plot and producing food with one's own hands in a community garden was associated with good fortune rather than a political statement in the community food security system.

"The produce we are growing in the garden is my own food. Otherwise, I would not be able to eat that well...I like to be able to grow food using traditional methods; organic gardening; look for new healthy methods to grow vegetables... The interactions with other people, they opened my mind; I think about different aspects of gardening, more traditional methods I never thought about... So many different ways to garden, more traditional things, people use different things I did not know. I like 
gardening with my own hands, it is nice to do that..." (Heike, Brentwood Gardener, 2009).

\subsection{Food Quantity}

Twenty-two (73\%) gardeners believed that growing enough food for their own consumption and sharing it with others was a source of satisfaction (Table VI.1). The feeling of empowerment came from the ability to produce enough food and satisfy the primary need for sustenance.

In community gardens, the feeling of "food quantity" related empowerment came either from the ability to grow enough food for one's own consumption or to share it the people who were "less fortunate."

Sharing the produce from the garden with those people who were less fortunate was seen as a rewarding experience for all gardeners who particpated in the study. A picnic table, a symbol of "garden sharing" epitomized the gardeners' willingness to share the harvest from their plots with people who did not have access to fresh vegetables and fruit. As discussed in Chapter IV, the picnic table played an important role in the community gardening culture. The gardeners offered their oversupply of plants, seeds, garden tools, and crops to share with other people. (This symbolized "authorized" taking: whatever was left on the table was up "for grabs" by other people, in contrast to "unauthorized" taking by 
freelance pickers who happened to pick vegetables from individual plots without authorization).

Most of the gardeners relied on their own social networks to distribute the oversupply of produce. First, they shared it with friends, neighbors, coworkers, and local hunger relief agencies. Given the fragility of fresh produce, it made more sense to use individual connections to avoid food waste. The availability of the City-run Produce for People program was an important aspect of food production to community gardeners because it provided a secondary level of assurance that the oversupply of fresh food would not be wasted. The Produce for People program links the community gardens with local emergency food agencies. Volunteer gardeners set aside a plot or donated their excess produce for the program. Typically, the Produce for People basket was placed in the heart of the garden next to the shed.

Most of the gardeners were acutely sensitive to the possibility of wasting fresh garden produce and welcomed all opportunities to avoid the waste of food and share it with others in need.

"Even if I do not have money to give, I can give food, it is fundamental, if you think about it, there is nothing more powerful that giving food to people... My community plot gives me more food that I need. I constantly give stuff away. I can get by with one third or a quarter of space I have just 
to feed me, but I love to give away. I have not always been making money, but I can always give my produce to the food emergency services... Produce for People - it warms my heart to know that we can provide fresh organic vegetables to people who really need it, it is sharing bounty; we are able to share the bounty with other people I do not know; it is being connected with people I do not know...I give something locally because I would like to know that it is not wasted. It is very rewarding it is going directly to the people who truly need it, the food you get from a food bank is not very nutritious, as a society are not aware of that there is so much horrible food; empty calories, white flour products. People can survive but not thrive. It is nothing better than locally and organically grown produce, the counteraction to pasta and cheese. It is hard for a food bank to have fresh food available" (Jan, Brentwood Gardener, 2009).

\subsection{Non-Food Harvest}

Non-food harvest included growing plants with the goals extending beyond food production for human consumption. It took into account (1) symbiotic relationships between the human and non-human garden users; and (2) human need to enjoy and share non-food garden harvest (flowers and ornamental shrubs). Four of thirty gardeners (Table VI.1) believed that growing flowers that attract beneficial insects (pollinating bees) and feeding birds and other animals was one of the most important aspects of community gardening. The goal of sharing the space together with animals and plants and enhancing garden 
productivity by planting flowers was a source of empowerment feeling. Sharing flowers with other people was also considered another satisfying aspect of harvest sharing in community gardens.

Although only four gardeners felt empowered by their efforts in the community gardens to enhance the general biodiversity of the urban area, this belief was reflective of a growing movement in urban ecology that successful conservation of the world's biodiversity must include urban and urbanizing landscapes.

The non-food harvest empowerment was most important to Fulton gardeners (Table VI.1). In her interview, Andrea (2009) said having her own community garden plot allowed her to grow sunflowers. Andrea does not have enough sun on her home yard and was never able to grow sunflowers around her house. She also brought bunches of sunflowers and shared it with the students and teachers at the school where she worked. The concept of sharing the harvest from her plot in the community garden with other people and animals was important to her.

Sunflowers symbolized both sharing produce and beauty in the garden. "Harvest" meant also non - food produce grown in the garden.

\subsection{Harvest Support}

Nineteen (63\%) gardeners felt fortunate to be able to get a plot in a community garden along with the garden infrastructure to support their primary goal of food production (Table VI.1). 
Access to one's own plot, a tool shed, and water source provided by the city were believed to be empowering resources that were vital to support food production in community gardens. Johns gardeners appeared to be most appreciative of access to a community garden with the garden infrastructure - six of the eight Johns gardeners felt empowered by the opportunity to cultivate a plot in the community garden. Seven Fulton gardeners and six Brentwood gardeners expressed appreciation for the availability of public land and infrastructure for individual agricultural production through the gardening program managed by the city (Table VI.1).

"It is water, watering station above my garden, without water nothing is possible. If we did not have water, it would be a much different task growing. It is something I do not take for granted; we do not have to pay for it other than our fees for the year, a very important picture for me..." (Holmes, Johns Gardener, 2009).

\section{Non-Harvest Goals}

Non-harvest goals were fulfilled by experiencing empowerment that was perceived by community gardeners as not directly related to food production but enhancing their overall experience and the land cultivation activities directly related to food production. Community gardeners experienced non -harvest related empowerment in four ways: (1) by incorporating community gardens into 
their lifestyle; (2) by developing spiritual ties with garden spaces; (3) by experiencing beauty in garden spaces; and (4) by learning in community gardens.

\subsection{Lifestyle}

Twenty four (82\%) community gardeners considered gardening and trips to community gardens as an integral part of their "lifestyle" (Table VI.1) Four descriptions of "lifestyle" emerged during the interview process.: (1) community garden as a "green oasis"; (2) community gardening as fitness and recreation; (3) community gardening as an element of "new domesticity"; and (4) community gardening as part of a luxurious life.

\section{(1) Community Gardening as a "Green Oasis"}

This concept of "lifestyle" placed the activity of community gardening in the context of community connections and choice of living. It reflected a romanticized, retooled version of the "communal" life, combining the villagelike quality of urban life with the contemporary neotraditional design concept and "green living." A community garden was seen as a "green oasis" that stimulated and epitomized the sort of Gemeinschaft relations, based on direct face-to-face connections, where everyone knew one another and was comforted by slow pace of life.

In that view, community gardens were not the major focal point for interactions but rather were part of a neighborhood space dedicated to growing plants. They 
were a place for meditation - a link and transition between village-like urban life that offered the best of the worlds: the green, quiet area for solitary work and contemplation within walking distance of neighborhod points of actvities (bars, restaurants, libraries, stores, medical offices). This meaning of lifestyle attempted to bridge the American love-hate relationship with the cities to by linking the "green oasis of community garden" with the surrounding happy houses with happy people within walking distance of a café or cinema in the nearby neighborhood.

The "green oasis" aspect of the community gardening lifestyle experienced by several community gardeners embraced this small town village concept and updated it with a community garden within walking distance of the Main Street area, which was mostly lined with local pubs and vegan eateries. The empowerment feelings came from experiencing a lifestyle where a community garden was part of the walkable and diversified neighborhood. The closeness and availability of the community garden was considered a neighbrohod asset and an attraction in finding a place to live.

Several gardeners, mostly from the Johns garden felt empowered by being able to practice community gardening in the area that resonated with the Portland lifestyle, described above. 
"I was looking for a neighborhood where I can go to a vegan restaurant, I can take a bus, since I do not have a car, and I have to have a community garden. The community garden was part of my package... We were looking for the area with a community garden, after a while you know what you want; we moved 30 times, I can get by with a really small place to live but I need a place to go, I you have a community garden you have a place to go..." (Marguerite, Johns Gardener, 2009).

Mary Anne, another Johns gardener, moved to the St. Johns neighborhood three years ago. The community garden was one of the deciding factors to live in the area.

"One of the reasons I moved to the house I lived now is because it was a community garden down the street. I was just driving around the area, I discovered St. Johns, and I knew immediately that I would like to live here. There was something about small town atmosphere, it is very walkable, a little old fashioned; something about it, a gut feeling, when I drove on Lombard, it is difficult to explain... We have beautiful views, park, industrial mix, the river, the bridge... "(Mary Anne, Johns Gardener, 2009).

To Mark, another Johns gardener, the surrounding houses symbolized the city life; the garden area was a reminiscent of bucolic rural life in the city. 
"I like this picture because, it is representative of the houses and the area I always liked. They sit above the road; they look down at the garden. I like the character of the garden that it is on the slope... the overall garden. The majority of the gardens are relatively flat; this one is hilly, with the houses above, it is a story you can made up of the people who live there, what they see from their windows; it triggers your imagination of a happy and cheerful life..." (Mark, Johns Gardener, 2009).

\section{(2) Community Gardening as Fitness and Recreation}

This concept of "the community garden lifestyle" equated the use of a community garden plot with "your own backyard" in a residential subdivision. People who appropriated community garden plots into their everyday routine enjoyed the availability and access to community gardens and used their plots and the surrounding areas for relaxation and entertainment. The community garden that functioned as a "back yard," typically had more permanent accommodations to support relaxation and entertainment. It served as a place to bring family and friends for leisurely meal under the sun umbrella, to read a book, to teach children and grandchildren about nature, and to interact with both strangers and fellow gardeners. The feeling of empowerment came from the ability to enjoy and combine outdoor recreation with social interaction, food production and relaxation. In this view, the community garden was a "place to go," to meet people, to socialize, or to gain physical strength. 
"It is my lifestyle, it gives me strength I gain from it, clears my mind, the power to control my life... Now and then I have some physical ailment, my back, my foot, something, I think I cannot go to the garden but when I actually go there and start working I am not in pain and when I leave the garden it comes back; it is almost that my pain is left outside the garden...for that amount of time my focus is really on my garden and my pain is gone. If I am not well, a good thing to me is to go to the garden, and then I do not feel pain..." (Gracie, Brentwood Gardener, 2009).

Sydney (2009) captures the feeling of comfort and safety in an informal recreation area at the Fulton Community Garden.

"The little oasis area, the gardens around me, under the tree... "This is our garden oasis where five of us share vegetables..." (Sydney, Fulton Garden, 2009).

A plastic chair and a potting table under an old pear tree marked Sydney's most important place in the garden. Here, Sydney could come and sit if she needed to take a break from gardening. The table was also used for sharing tools and vegetables. The table was located just several feet from her plot. It was her first season in the garden and she watched the garden from here; it became her vantage point for contemplation and quiet time. Occasionally, she had her sandwich here. 
The "pear tree oasis" was an important observation point to watch the action in the garden. This informal resting place was mostly used by the immediate five gardeners; this was the area Sydney felt comfortable: it was under the tree, it provided the shade; it was close to her plot. It was also the space for sharing. It was a safe place. The safe place was marked by other people's presence: an old plastic chair, a potting table, and a bench.

\section{(3) Community Gardening as "New Domesticity"}

Most of the community gardeners prided themselves on processing vegetables and fruit and depending on their own produce. The shelves lined with cans of tomatoes, zuchinis, asparagus, pumpkins were a source of enjoyment and empowerment. One of the gardeners I interviewed for the study grew chickens in her own backyard and used produce from the garden to feed them. Several others were providing vegetables to friends who grew rabbits. In general, however, the theme of "domesticity" was moslty related to the ability and enjoyment of processing fruit and vegetables.

Wendy, a Johns gardener, reflected the "domesticity" empowerment achieved through gardening.

\footnotetext{
"This is the first time I have canned tomatoes. Before I canned jam, I did not have the equipment for canning, we had so many tomatoes...The
} 
community garden gave me the opportunity to do that..." (Wendy, Johns Gardener, 2009).

(4) Community Gardening as Luxurious Life

Growing purple potatoes and exotic berries was a hobby, joy, and passion. Sharing interesting and unique vegetables or pictures of garden products with coworkers and friends provided an identity, social distinction, and confidence in establishing new relationships.

Growing her own food was a matter of pride, accomplishment, luxury, and identity for Melinda, one of the Brentwood gardeners.

" I just do not grow anything, I grow unique things..., I research what to grow, I grow purple carrots; I like to read about plants, I like to learn about them, I have my criteria what to choose for growing. I enjoy reading about it; it is a matter of pride...My friends have fancy careers, they talk about it. I have my gardens, my purple tomatoes, my green tomatoes; it gives me something to talk about at potlucks. It is my life..." (Melinda, Brentwood Gardener, 2009).

Growing vegetables was Melinda's entertainment, her fun, and her sense of accomplishment and distinction. It provided a context for her social interactions. 
(5) Summary of Lifestyle Themes

The importance practicing the "new domesticity" was the most commonly expressed feeling of empowerment in the context of "lifestyle" in the three gardens. The new domesticity embodied elements of new "green philosophy" in life: eating healthy food and producing sustainably instead of consuming rampantly. Most of the community gardeners prided themselves on processing their own vegetables and fruit. They were dependent on their own produce. Shelves and pantries full of canned vegetables were the source of enjoyment and power to control the source of food in the cycle of "green living."

For the most of the gardeners, the "lifestyle" included some aspects of the four concepts described above. The "new domesticity" could have been coupled with the "luxurious lifestyle" or recreation. The recreational aspect of community gardening and "luxurious food production" augmented the "green oasis". It was a concept of luxury achieved by controlling one's source and quality of food.

Growing one's own food was indicative of "richness" and "health."

The "recreational" lifestyle equated the use of a community garden plot with one's own backyard in a residential subdivision. The feeling of empowerment came from the ability to enjoy outdoor recreation with social interaction and food production for consumption. The "green oasis" lifestyle embraced the villagelike quality of urban life where an individual plot in an urban garden symbolized 
a link and transition between rural and urban life. A community garden was not seen as the major focal point for an interaction but rather as a part of neighborhood space dedicated to growing fruit and vegetables, within walking distance to urban conveniences.

\subsection{Sanctuary: Community Garden as Sacred Place}

Seventeen gardeners $(56 \%)$ said that community gardens were "sacred places" to them (Table VI.1).

Community gardeners who participated in the study considered the community gardens as "sacred places" for three major reasons: (1) as places to feel the spirit and energy in nature; (2) as places to reconnect with their past, mostly childhood memories; and (3) as a "well being" or "feeling well" place.

\section{(1) Experiencing Energy Flow and Spirit in Community Gardens}

The feeling of the spirit and energy that equated God with Nature, held by some of the gardeners, evoked the concept of pantheism, calling humanity into religious communion with the natural world.

Gardeners who participated in the study described their spiritual connections to the community gardens in several ways. Hawkins, a Johns gardener, associated the garden beauty with the positive energy he experienced there. 
"I just appreciate the whole area of the garden; more than my garden plot .The whole garden, everybody's plots are important to me. All the positive energy that was put into it, it is a very sacred space to many people, just to be around this space..." (Hawkins, Johns Gardener, 2009)

A small sculpture of a blue bird perching on a PEACE sign was placed on Melinda's plot at Brentwood. It symbolized her private space, a sanctuary where she came to reflect and meditate. Through her private sanctuary in the community garden, Melinda shared her respect for all creatures. Here, a PEACE sign, with a perched bird, represented her philosophy in living in harmony and beauty with nature. Nasturtiums signified sharing the beauty and bounty with people and animals. Humming birds and bees loved them for nectar and her friend rabbit liked to eat them. They were pretty and could be used for salads. The seeds could be made into capers. Gardening was also about "giving it back to the nature. Melinda grew the plants that were enjoyed by birds and bees and placed a birdbath on her plot to provide water for birds. The garden was her way of being respectful of nature and aware that people should share their space with other living creatures.

"I respect other lives to live: grasshoppers, aphids, humming birds, frogs, spiders, and lady bugs... I like flowers in the garden, I love flowers, you can eat them, it is a dual purpose, it is pretty and it is edible; potato and squash flowers blooms are pretty; they are also edible... I plant bee balms 
for bees and humming birds...I see frogs in my compost bin..." (Melinda, Brentwood Gardener, 2009).

To Lisa, a Brentwood gardener, spirituality meant being close to the soil, where the air meets the earth, the border, the boundary, the ability to touch soil and connect with the Spirit of Nature.

"The ground, it does not matter where...everywhere in the garden. I come to the garden to reconnect with earth...to feel the unveiled presence, the Energy, the Spirit of Place... You cannot quite capture the illusive element of natural world, you can feel but you cannot see the details you cannot really harness feeling the presence not feel the shape, it is indefinable form it is the spirit of things, life's creative force, it is veiled..." (Lisa, Brentwood Gardener, 2009).

For Marsha, a Fulton gardener, walking to the community garden was part of her daily meditation. Her experience was about the anticipation of her daily journey to the garden, the changes in the garden, the area around the garden, the gravel path, and the diversity of plants. The light and shade, warm and cold weather, plants and animals created an ongoing pleasure of experiencing nature at many different levels. 
"I see people walk here and their demeanor change; I see them walk on the path around the garden; I seem them pray, I see a rosary in their hands... I lose track of time, it is like yoga breathing experience; I walk over the sky, come to the garden, and there is the element of surprise; garden is different than the day before I am always fascinated how plants look, a variety and shapes, a number of patterns in nature, how many shapes and patterns you can have in nature, if you cut vegetables, cabbage or cucumber it looks like lobster, I am fascinated how the patterns repeat in nature...Discovering new things when you arrive, discovering different things in the garden, all it is important to me. Take your walk, and you see a different picture every day, it changes daily (Marsha, Fulton Gardener, 2009).

(2) Reconnecting with the Past in Community Gardens

The study discovered that several gardeners, who felt connected with the spirit(s) of nature, energy, and the cycle of life, also felt empowered by connecting their present experiences with their past experiences. This was related mainly to childhood memories. Thus, they associated community garden spaces with the cycle of life at the universal energy level, and the individual life cycle in the context of the natural cycle.

Community gardens were repositories of memories of happy and safe childhood places, of parents who were avid gardeners, and of friends and events from the 
past. A gravel road to the garden, a line of trees along the road, a view of the mountain, a flower planted in the plot, a small object tucked away, were all reminders of the life cycle in nature and memories of safe places and past relationships with people and places.

During her interview, Florence referred to the line from Robert Frost's poem to illustrate her nostalgic feelings about changes in her life. The poem related to the road connecting the Fulton Community Center parking area with the gravel road to the community garden. It suggested a tranquil and bucolic country setting despite the constant, roaring sound of the nearby freeway. The country road symbolized the connection between past and present. The road to the garden was about the expectation of getting closer to the garden, the place she is transforming for her family. Getting closer to the garden meant getting closer to home in Oregon. The garden space was becoming Florence's new concept of home. The road represented her transition from New England to her new place in Portland. It reminded Florence about her childhood in New England, coming back home from a boarding school in New York. The country road took her home, to her parents' house.

"It is fall; the color the shadows, the nut trees. I am from New England and it gets red in Fall. The shadows, the sky, it is fall in the garden. It is time to harvest. It is country, a touch warm, sun is out; trees are turning red, a nip of frost, just like in Robert Frost' poem...It is fall in the garden, 
it is time to harvest, it is country, a touch warm... It is safe on the road, the country is quiet. Looking at the picture, one tries to forget the roaring noise of the freeway, we are on the freeway here..." (Florence, Fulton Gardener, 2009).

My research suggests that community gardens served as an important public space for people in "transition" - they functioned as a link between the gardeners' past and present life by weaving the images from the past into the life in a different place. Past images were incorporated into the everyday practice in community gardens. The feeling of empowerment came from experiencing safety associated with childhood memories and a happy life in one's past.

\section{(3) "Well- Being" in Community Gardens}

Regardless of the level of transcendental relationship with the community garden, the gardeners who believed in the sacred qualities of community gardens, also pointed out the overall "good feeling" they experienced in the garden.

To many Portland community gardeners, "well -being" meant having their own space and the feeling of being connected or "rooted" in the place.

"My plot is the most important place in the community garden. I can walk down the street and the closer I get to it the better I feel and I open the gate 
....and I am not quite there, I walk down the path and I physically step into my garden....and it is wonderful. I think about my garden a lot. As I get closer, I can feel it. I go to my space to be there...I did a lot of therapy in my garden. The going to the garden...being in my little space, something about it makes me feel really good and secure, even though I have not been gardening for that long I feel I know what I am doing there, because it is my place..." (Mary Anne, Johns Gardener, 2009).

To Jan, a Brentwood gardener, the community garden plot provided a sense of stability and a sense of belonging. Jan changed her apartment three times in the last six years. The asparagus she planted in her garden six years ago had grown stronger each year and provided her sense of connection with the area. It was an indication of sustenance, endurance, and belonging. Her plot was important was because it represented her sense of belonging and stability - and her own territory amid mobile life.

"I moved three times since I got the garden. What was nice is that I knew that the garden is there, it grounded me, and it centered me. I was moving around, I knew I might be here and there, but I will not lose the investment in my garden; it is perennial, and it takes a major investment, it takes several years. I have established asparagus here; I will not give it up readily. I could move, but I am happy here. It is my history for the last six or seven years, I know, where I fertilized, I know my crop rotation, I am 
settled, I am grounded there...The garden provided a sense of connection, I could always count on it. You can move in your living situation, but the garden provided the grounding for me, sense of security, moving is so disruptive, to know that I have my own space is to know that I have control over my life...I do not have to wait for a boss to improve my work, I do not have to have anybody's approval, the control, the independence, I do not need anybody's feedback to control my own space, to control my little patch of earth, a little bit of artwork, I choose what shape to make, I choose what to plant where..." (Jan, Brentwood Gardener, 2009)

(4) Summary of Sanctuary Themes

"Feeling well" in the community garden was the most commonly expressed empowerment feeling in describing spiritual aspects of community gardening. While some gardeners saw community garden spaces as places to experience spiritual unity with nature and reflect on their individual life in the context of the natural cycle, for the most part, their experiences suggested the restorative qualities of community gardens and their influence on the general well being of the gardeners.

\subsection{Beauty}

Twenty-five (83\%) gardeners believed that beauty was one of the most important empowering experiences in the garden (Table VI.1). Community gardeners 
experienced beauty-related empowerment in three ways: (1) by converting individual plots into objects of art and beauty in the garden "green oasis;"( 2) by sharing garden experiences and harvest with other people; and (3) by associating aesthetic values of food production with sustenance of garden harvest.

\section{(1) Beautiful Conversion of a Garden Plot}

The act of converting a garden plot into an object of beauty was a powerful experience. The garden area and the vicinity of the community garden provided a backdrop and background for the gardeners' own, individual art achieved through the transformation of a plot. The natural beauty of the garden green area, combined with other gardeners' creativity and the collection of other artfully arranged plots, was a source of joy and satisfaction among community gardeners. In that context, unkempt plots were an unwelcome disturbance to the overall experience of transforming one's plot into an object of beauty. The areas surrounding the garden, the dirt road lined with trees, the view of sky, bridge, mountain, or river enhanced the feeling of empowerment achieved by sensing beauty.

My study suggests that Portland community gardens associated the concept of beauty in garden landscapes with the spontaneity of nature.The act of converting a garden plot into an object of beauty was an active and mysterious experience that could not be entirely controlled by people. In community gardens, a 
beautiful and spontaneous landscape, the act of converting a garden plot, to weave it into the coherent "garden quilt," was an act of beauty and connecting people with nature. The act of conversion was beautiful, because it involved sensory experiences (smell, sound, shape, color, texture, and temperature) in the active act of land conversion.

To David, a Fulton gardener, his plot in community garden was an ever -changing object of art in progress; David was looking for a perfect expression of beauty. The natural cycle in the garden and the change in vegetation and landscape provided a context for his art making in the garden. The beauty of the garden, its texture, colors, sunflowers and roses created a background for his art.

"The spaces mesh together: it is urban and rural; it is an oasis in the city; it is natural art; an oasis of natural beauty, defined by sky, trees, and mountains." Gardening is about composing art "All the variety of flowers; it is like painting with plants...My personal plot, with all the variety, an artistic view of the plot I try to arrange this in a way to make it a composition, it is like a painting, it is capturing the moment of beauty...I have a tremendous variety of plants, probably over 200 species, as I keep all my plants, it is a hodgepodge here. I have gorgeous roses here... The big view of all magnificent flowers is, their composition gives a good sense of space... I like to get a big picture of the garden, I like a view of the overall area, lots of my pictures are "big pictures" of the whole area, 
basically a forest park; trees around the garden give so much character to the area... I love the sky; sky shows are tremendous, the clouds, the evening, and the open space around me, the country side, and the open country feeling..." (David, Fulton Gardener, 2009).

(2) Beauty of Sharing the Garden

The act of sharing the garden with others was one of the conditions of experiencing beauty in the community garden. "Sharing the garden" with others (family, friends, neighbors, coworkers, and strangers) was the ultimate and fundamental step in the community garden cycle. The gardening cycle was not complete without sharing the bounty. The production cycle had to be validated by the act of sharing. Sharing vegetables and home processed food was an emotional and bonding experience to many community gardeners.

"Sharing the garden" was not limited to food products and flowers, it included gardening tools, plant starts, garden art, knowledge of gardening wisdom. Sharing art in community gardens involved converting a plot into an object of art by arranging plants, placing whimsical art objects, and displaying poetry. Sharing art and beauty with other gardeners was part of the non-verbal communication in the community garden. Garden plots, converted into objects of art, were personal and individual imprints that were much admired by the other gardeners. They could lead the gardeners to an impulse for initial and direct 
contact that was predicated on uniqueness and fascination by other people's expressions of beauty.

The communal and occasional public realm in community gardens created the necessary space for sharing and receiving. To Jim, a Fulton gardener, a plot in the community garden meant a closer connection to community to share the beauty of life with other people. This was the first time in his life that Jim posted a poem in any public space. Poetry symbolized the spiritual aspect of the nurturing power of the garden. Sharing poetry was about sharing spiritual meaning of life with other people. The community garden space was "the right time and right place" to start "giving back.

"My plot is close the road, I put a few poems...I have never posted any poetry before. Now I can share poetry. It seems right to me ...Poetry goes with gardening; ties it together for me, it is nurturing the spirit and the body ..." (Jim, Fulton Gardener, 2009).

(3) Beauty of Garden Harvest: Usefulness and Aesthetics

The beauty of the garden was to be able to grow beautiful and useful plants. "Beauty" must be "useful." The shape, texture, color, and smell of vegetables produced with one's own hands were beautiful. "Beauty" was experienced by growing wholesome vegetables and being able to harvest them. The change of energy that came from growing plants and harvesting them defined the concept 
of "harvest beauty." Beauty was both the physical attributes of the plants, their "prettiness," and the plants' usefulness in sustaining the primal human need. Beauty must be "purposeful," in that it is tied to the ultimate goal of food production.

The feeling of empowerment came from equating garden productivity with aesthetics and beauty. Plants that were not productive were not considered "beautiful." Each plant in the garden had to be multifunctional. At the very least, it had to satisfy some level of sustenance for either humans or animals in the garden. Plots that were not properly cultivated (weeds, lack of productive plants) were not considered "beautiful" and were a source of agitation in the community garden.

"The composition of the picture, the color in it, it is a beautiful very beautiful day. It is a sense of beauty, of mystery of life, a sense of nature, cycle of life, I have the kale, onions, of the stuff going on here, all the nature, and in the corner it is me, it is the straw path I created in my garden. It is the reminder of my space in the garden..." ( Mary Anne, Johns Gardener, 2009).

(4) Summary of Beauty Empowerment Themes

Converting one's plot into an object of art in the green oasis of the community garden was the most common theme in expressing beauty empowerment feelings 
in all three community gardens. Converting garden plots into productive use was the most enjoyable activity in the community gardens and formed the basis of experiencing a sense of spontaneous beauty.

The context of the garden, defined as "green oasis" by most of the gardeners, influenced the experience of spontaneous beauty.

\subsection{Learning}

Twenty gardeners $(66 \%)$ believed that learning in community gardens was empowering (Table VI.1). The analysis of the interview data suggested that community gardeners experience empowerment feelings related to learning at three levels: (1) by increasing their knowledge of garden cultivation techniques; (2) by relating the natural garden cycle to human life; and (3) by appreciating gardening as a way to acquire or improve professional skills.

\section{(1) Improving Garden Cultivation Techniques}

Improving the knowledge of gardening techniques could be by one's own practice in the garden or by watching and interacting with the fellow gardeners who happen to be in the garden in the same time. The presence of garden demonstration projects (rainwater cistern, eco roofs, composting bins) were appreciated by both novice and advanced gardeners because the projects offered the opportunity to learn different types of gardening techniques at a gardener's convenience. Community gardening involved careful management of time because it took place outside of one's residence. Given the time limitations, 
community gardeners focused first on tending their own plots. If a demonstration project happened to be near their plot, or on the way from the gate to the shed, it was likely that a gardener would benefit from its presence. Gardeners absorbed gardening knowledge from the demonstration projects at their convenience as time allowed.

Brentwood gardeners frequently mentioned the water cistern as a source of learning in the community garden.

(2) Learning from Nature and Garden Cycle

The garden teaches people to embrace differences and temper their desire to control life by embracing the joy of the gardener's unpredictable events.

To Bill, a Brentwood gardener, the garden reminded him about the pleasure of spontaneity in life. Bill's objective of converting land through controlling the area of cultivation was contrasted with his pleasure of spotting a volunteer plant that was not planted by him. It was a reminder that one needs to be able to balance controlled and unplanned events in life and gardening.

"Watching volunteer plans is one of my favorite things..." (Bill, Brentwood Gardener, 2009). 
Nature taught people to accept and enjoy changes in life. The garden was a place where people could learn how to embrace a difference and ceded their desire to control life by accepting unpredictable events in the garden and in life.

"I have not been to the garden for a while I was a little surprised, it was a lovely surprise, my butternut squash was ready. I put the ladder, but it did not climb, it was not orderly, I am very orderly in my garden, the squash took over the other part of the garden, not where I wanted it to grow, on the ladder. It just further reminded me how my life has changed so much this year, with Mark and me opening my shop, one of the best years in my life. Having my squash go everywhere made me smile. The garden was one of the areas that I lost control of and it did not bother me that much.... (Mary Anne, Johns Gardner, 2009).

\section{(3) Learning for New Business Ventures}

Several community gardeners who participated in the study viewed their work in the community gardens as a way to learn or practice their skills. Their objectives were to set up their own businesses or hone their skills to enhance their employment opportunities in the food industry, urban agriculture, edible landscaping, or health and horticulture counseling. Their participation in the community gardening program was their first step in learning about gardening techniques, general land cultivation, and building a new set of skills. They used their garden plots to experiment and test their own ideas on cultivation. 
Community gardens provided the land and infrastructure resources on the path to their future dream job.

To Stephanie, a Brentwood gardener, community gardening was a way to explore agriculture or horticulture as her future profession. Stephanie's dream was to run her own agricultural business.

"I had a feeling that I want to be a farmer, but I did not have any experience in long term gardening. I did garden as a child, with my mom. I look at this plot as practice, I can try different ideas, see what grows better, this is a place I can do that. I can practice..." (Stephanie, Brentwood Gardener, 2009).

\section{(4) Summary of Learning Empowerment Themes}

The most dominant feeling of empowerment through learning was experienced by improving gardening techniques in a garden natural setting. Most gardeners recognized that the practical aspect of experimenting with different land cultivation approaches ("hands on" experience) in community gardens was an important way to learn as opposed to studying about urban agriculture in a classroom. Several gardeners also believed that experiencing and observing the natural cycle in life was stimulating and taught humans to acknowledge and embrace changes. A few gardeners viewed their experience in the community garden as a way to learn and practice new skills that might lead them to a new professional path. 


\section{B. Community Garden Empowerment Narratives}

\section{Shared Narrative of Empowerment}

Figure VI.1 contains a summary of the empowerment goals experienced by the community gardeners in all three gardens.

Figure VI.1. Empowerment in Community Gardens (Percentage of Gardeners Experiencing Each Goal)

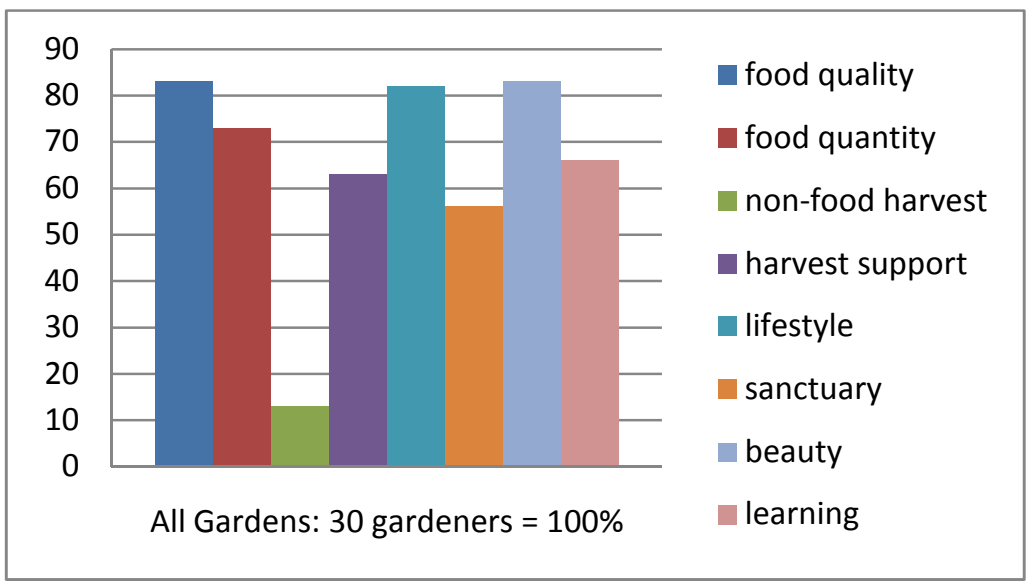

The study suggests that while food production is the primary reason to join the community gardening program, the appreciation for community gardens extended beyond just food growing for the majority of gardeners. Growing "healthy food," experiencing "garden beauty," and practicing the "community garden lifestyle" were the three most important empowerment goals. The "food quality" goal was harvest-related, which was traditionally associated with the agricultural view of the role of community gardens. The "lifestyle" and "beauty" goals were nonharvest related goals. Experiencing beauty and growing healthy food were the two equally most important empowerment goals by the majority of the gardeners. 
Twenty-five gardeners (83\% of all gardeners) felt that growing their own healthy and organic food is the most important aspect of community gardening. Surprisingly, experiencing beauty in the community garden was also viewed as empowering by twenty-five gardeners ( $83 \%$ of all gardeners). Practicing the community garden lifestyle was seen as empowering by twenty-four gardeners $(82 \%)$. Both empowerment through food quality and lifestyle were believed to be more important than empowerment through food quantity (producing enough food for sustenance). Twenty-two gardeners (73\% of all gardeners) felt empowered by producing a sufficient amount of produce for their own consumption.

The study found that while most of the empowerment themes related to harvest were similar in all three gardens, the empowerment non-harvest goals were typically a combination of several themes that varied across the gardens and among members of the same garden. Nevertheless, a prevailing empowerment theme emerged in each of the non-harvest goals.

Converting one's plot into an object of art in the green oasis was the most common theme in the "beauty" related empowerment feelings in all community gardens. This concept of beauty, which involved an act of physical transformation, was suggestive of mystery and fostered by an experience of being actively involved in making landscapes. 
The importance of the gardens practicing the "new domesticity" was the most commonly expressed feeling of empowerment in the context of "lifestyle" in the three gardens. The new domesticity embodies elements of new "green philosophy" in life: focusing on eating healthy food and avoiding excessive consumption.

The most dominant feeling of empowerment through learning was experienced by improving gardening techniques in a garden natural setting ("green laboratory").

"Feeling well" in the community garden was the most commonly expressed empowerment feeling in describing the spiritual aspects of community gardening. General well being in the garden suggested the restorative qualities of the gardens.

Figure VI.2 summarizes the dominant non-harvest empowerment goal themes in the gardens. The analysis of the prevalent themes across the empowerment goals suggests that most commonly, community gardeners experience empowerment by perceiving community gardens as sacred places where people feel well because they can grow healthy food, practice "green domesticity," and learn gardening from nature in a beautiful setting. This shared narrative of empowerment through Portland community gardening captures the prevailing themes common in all three gardens. 
Figure VI.2. Non-Harvest Empowerment Goals and Themes dominant empowerment theme

\begin{tabular}{|l|l|}
\hline Empowerment Goals/Themes & $\begin{array}{l}\text { All } \\
\text { Gardens }\end{array}$ \\
\hline Beauty & \\
\hline Plot conversion into art & \\
\hline Sharing the garden & \\
\hline Harvest usefulness & \\
\hline Lifestyle & \\
\hline Green domesticity & \\
\hline Green oasis/urban village & \\
\hline Recreation/fitness & \\
\hline Luxury/organic food & \\
\hline Learning & \\
\hline Gardening techniques in natural setting & \\
\hline Garden cycle and human life & \\
\hline Professional skills/ business & \\
\hline Sanctuary & \\
\hline Well being & \\
\hline Connection to spirit of nature & \\
\hline Memory and connection to past life & \\
\hline
\end{tabular}

\section{Fulton Empowerment Narrative: "The Beautiful Lifestyle"}

\subsection{Harvest versus Non-Harvest Goals}

The study suggested that empowerment achieved through fulfilling non-harvest goals was higher than empowerment related to harvest goals among Fulton gardeners (Figure VI.3). Experiencing beauty through community gardening was the empowering experience for nine $(75 \%)$ of the twelve Fulton gardeners, which exceeded the number of gardeners who believed that growing their own high quality food was empowering. Eight (66\%) gardeners felt that producing their own food was empowering. Eight gardeners $(66 \%)$ believed that incorporating trips to community garden enhanced their lifestyle. Non-food harvest, including ornamental plants, was an important aspect of gardening to four Fulton gardeners. 
Appreciation for the availability of garden land and infrastructure was the basis for empowerment feelings for seven (58\%) Fulton gardeners.

Figure VI.3. Empowerment in Fulton Community Garden

(Percentage of Gardeners Experiencing Each Goal)

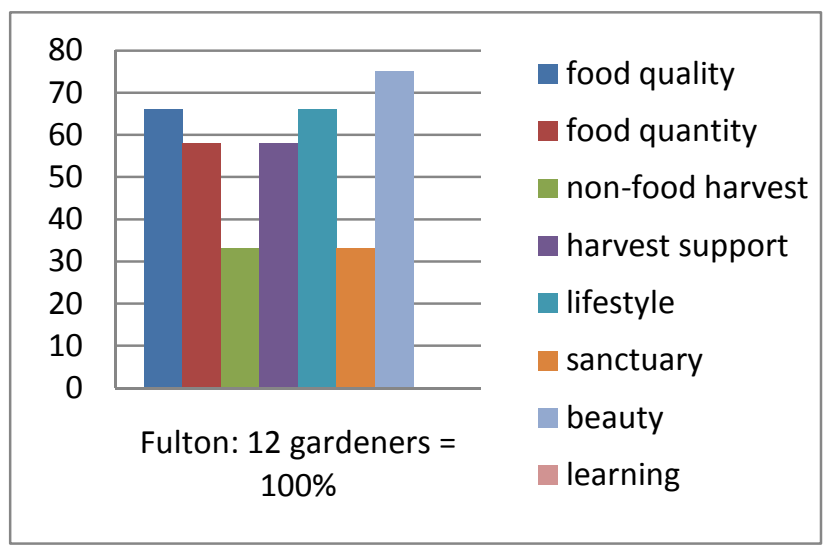

\subsection{Fulton Beauty}

The universal beauty of converting plots into objects of art was not complete without the act of sharing the garden with others. Sharing the garden with friends, family, fellow gardeners, and strangers was the ultimate and fundamental step in the community garden cycle and a condition of experiencing beauty. Thus, the presence of social realm was important in experiencing beauty-related empowerment to most of the Fulton gardeners. Garden plots, converted into objects of art, were personal and individual imprints and could be a source of admiration and enjoyment for others. 


\subsection{Fulton Lifestyle}

Fulton gardeners coupled the experience of "green domesticity" most commonly with fitness and recreation. The recreational lifestyle equated the use of the community garden plot with "your own back yard "in a subdivision. The feeling of empowerment came from the ability to enjoy outdoor recreation with social interaction and food production. Developing social connections in the garden was important in experiencing lifestyle related empowerment.

\subsection{Fulton Learning}

Fulton gardeners did not view the community garden as an important source of new information. Several of them believed that interaction with other gardeners was important in learning and improving their gardening skills.

\subsection{Fulton Sanctuary}

Fulton garden was considered as a special place to reconnect with the past and cherish personal memories for only a handful of gardeners.

\section{Brentwood Empowerment Narrative: "The Garden is Everything"}

\subsection{Harvest versus Non-Harvest Goals}

Food quality and quantity were the basis for empowerment feeling for all

Brentwood gardeners. Non- food harvest was not a factor in experiencing empowerment by Brentwood gardeners. Nine (90\%) gardeners felt empowered by experiencing beauty and learning in the garden. The garden was an important 
aspect of lifestyle to eight (80\%) gardeners. Eight gardeners $(80 \%)$ felt that the garden was also a sacred place to them.

Figure VI.4 provides a summary of empowerment goals experienced by Brentwood gardeners.

Figure VI.4. Empowerment in Brentwood Community Garden (Percentage of Gardeners Experiencing Each Goal)

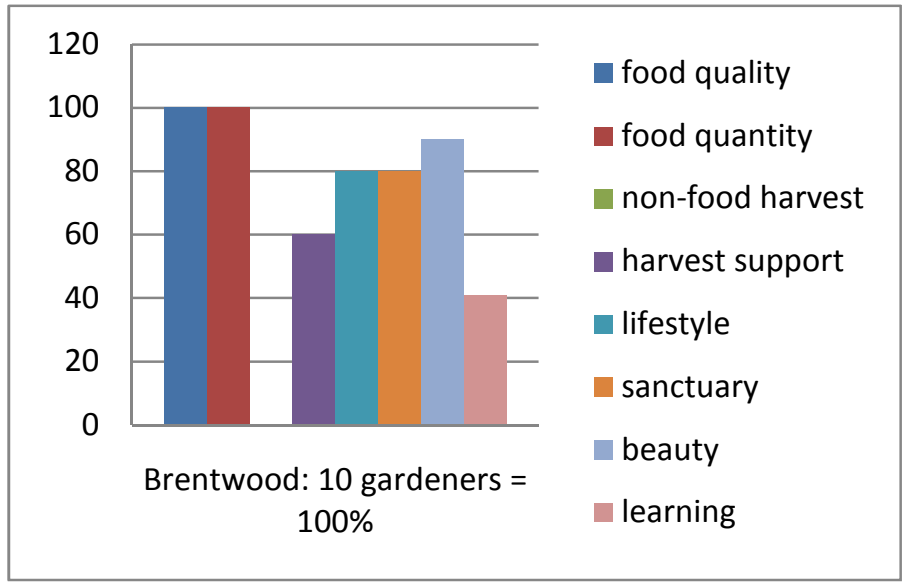

\subsection{Brentwood Beauty}

Converting garden plots into productive use was considered beautiful but the usefulness of garden vegetables and fruit was a condition of sensing beauty in the garden. In that context, only useful and wholesome plants could be beautiful. Shape, texture, color and smell of fresh garden plants and harvest defined the ultimate feeling of experiencing beauty. In that context, transforming garden plots into productive use was an act of beauty. 


\subsection{Brentwood Lifestyle}

Brentwood lifestyle combined "green domesticity" with the "luxurious lifestyle." The "luxurious lifestyle" associated access to a plot in the community garden with luxury of eating fresh vegetables. It was an image of luxury achieved by controlling one's source and quality of food. Growing one's own food is an indicative of "richness" and "health."

\subsection{Brentwood Learning}

Brentwood gardeners felt empowered by learning "from the garden" in a number of ways. First, the garden provided a space to learn from the reflection on their own practice and exchange experience with other gardeners. Second, observing nature was a source of inspiration in life and realization that everything was connected in nature. Third, Brentwood gardeners enjoyed observing the rainwater demonstration cistern installed by the city on the garden grounds. A few gardeners were hoping that learning urban gardening in the context of community garden may help them to acquire new professional skills and opportunities to establish their own urban agriculture business.

\subsection{Brentwood Sanctuary}

The community garden provided a special "sacred place" to eight of the ten Brentwood gardeners. The community garden space was considered the place to feel the Sprit of Nature, reconnect with memories, and was the only place that provided stability. The plot in the community garden offered a sense of 
rootedness for the gardeners who had changed apartments. In that context, the awareness of having "own place" to relax, to work, to harvest and experience beauty, was associated with safety, comfort and "well being."

4. Johns Empowerment Narrative: "The Community of Beauty and Food"

\subsection{Harvest versus Non- Harvest Goals}

All Johns gardeners who participated in the study believed the community garden was part of their lifestyle. Food quality was important to seven (83\%) gardeners. Five (63\%) gardeners felt that they were able to produce enough food for consumption to satisfy their needs and share with others. Seven (88\%) of the eight gardeners believed that experiencing beauty in the garden was important to them. Learning was important to six $(75 \%)$ gardeners and six $(75 \%)$ gardeners were appreciative of the community garden infrastructure available to them. Five $(63 \%)$ gardeners felt that the garden was the special "sacred" place to them.

Figure VI.5 provides a summary of empowerment goals experienced by Johns gardeners. 
Figure VI.5. Empowerment in Johns Community Garden

(Percentage of Gardeners Experiencing Each Goal)

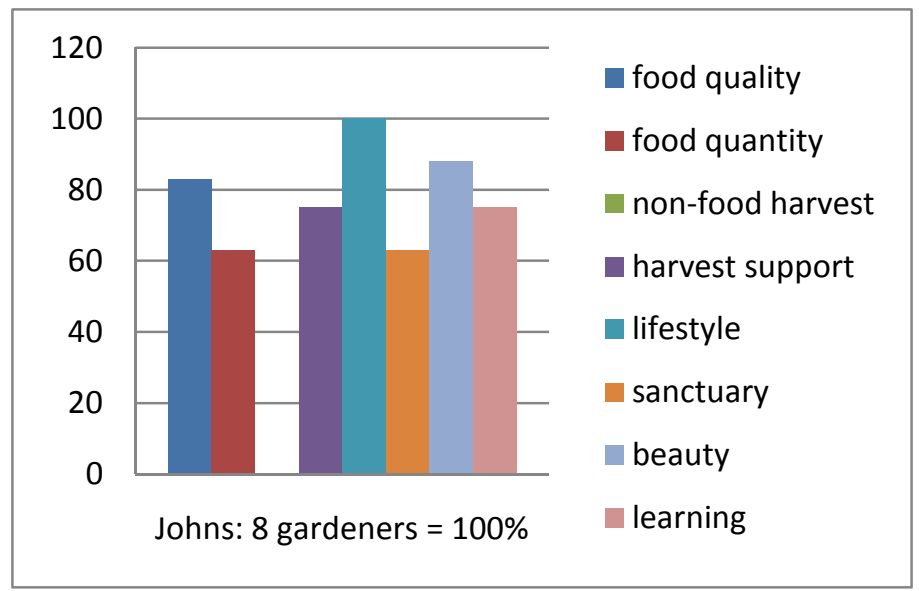

\subsection{Johns Beauty}

The sense of beauty experienced by Johns gardeners was entirely related to their satisfaction in converting individual plots into the objects of art in the garden "green oasis." As discussed earlier, converting garden plots into productive use was the universal feeling of beauty experienced by all community gardeners. What differentiated Johns gardeners was the way they defined the concept of "green oasis" as a context for experiencing beauty.

\subsection{Johns lifestyle}

Johns lifestyle coupled the "green domesticity" concept with the three, nationally recognized staples of Portland lifestyle: eating, drinking, and getting around. The community garden was incorporated into the small town-village within walking distance from Lombard Street, lined with local pubs, vegan eateries, and other conveniences of urban life. 
Most of the Johns gardeners indicated that while the overall ambience of the surrounding area was an important factor in finding a place to live, the presence and the availability of the garden was the "tipping" point in making the final determination for the choice of area to live in Portland.

\subsection{Johns Learning}

Improving gardening techniques was the most important aspect of learning in experiencing empowerment via learning in the community garden. Learning by interacting with other people was important in experiencing empowerment.

\subsection{Johns Sanctuary}

The community garden provided a "special place" for five Johns gardeners. Johns gardeners were mostly focused on "feeling well" in the garden. The restorative qualities of the Johns garden were influenced by the sense of beauty of the surrounding areas, discussed earlier.

\section{Garden Narratives: Summary of Findings}

Figure VI.6 contains a summary of empowerment goals across the gardens. 
Figure VI.6. Empowerment across Gardens

( Percentage of Gardeners Experiencing Each Goal)

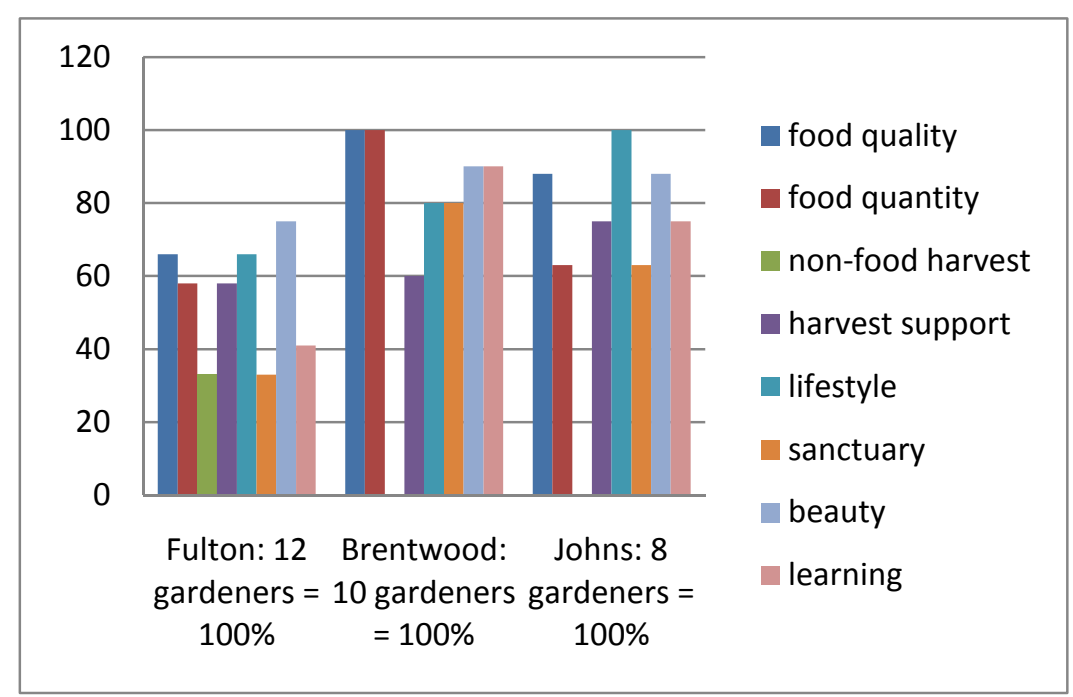

The study suggested that the garden specific empowerment narratives reflected three major factors: (1) relationship between harvest and non-harvest goals in each garden; (2) empowerment themes in non-harvest goals; and (3) relationship between space connections and non-harvest empowerment goals.

\subsection{Relationship between Harvest and Non-Harvest Goals}

Empowerment achieved through fulfilling non-harvest goals was higher than empowerment related to harvest goals among Fulton and Johns gardeners. At Fulton, gardeners who felt empowered by experiencing beauty outnumbered gardeners who believed that growing organic food was empowering. At Johns, empowerment related to lifestyle exceeded food quality empowerment. In contrast, all Brentwood gardeners believed that both food quality and food 
quantity were empowering. It may be inferred that while Brentwood gardeners were more likely to consider community gardening as important to satisfy the primary need for food and sustenance, Fulton and Johns gardeners were more focused on enhancing the quality of their life by growing organic food and recreating in the context of public space.

\subsection{Diversity in Empowerment Themes in Non-Harvest Goals}

Figure VI.7 summarizes the main differences across the gardens with regard to dominant non-harvest empowerment themes and goals in each garden.

Figure III.7. Non-Harvest Goals and Themes across Gardens

shared narrative in all gardens garden specific narrative

\begin{tabular}{|l|l|l|l|}
\hline & Fulton & Brentwood & Johns \\
\hline Empowerment Goals/Themes & & & \\
\hline Beauty & & & \\
\hline Plot conversion into art & & & \\
\hline Sharing the garden & & & \\
\hline Harvest usefulness & & & \\
\hline Lifestyle & & & \\
\hline Green domesticity & & & \\
\hline Green oasis/urban village & & & \\
\hline Recreation/fitness & & & \\
\hline Luxury/organic food & & & \\
\hline Learning & & & \\
\hline Gardening techniques in natural setting & & & \\
\hline Garden cycle and human life & & & \\
\hline Professional skills/ business & & & \\
\hline Sanctuary & & & \\
\hline Well being & & & \\
\hline Connection to spirit of nature & & & \\
\hline Memory and connection to past life & & & \\
\hline
\end{tabular}


(1) Beauty. The Fulton gardeners exclusively expressed the beauty of "sharing the garden," while the concept of beauty of garden harvest and usefulness was mostly appreciated by Brentwood gardeners. Brentwood gardeners tended to be focused on equating the beauty of garden harvest to functionality and usefulness. Johns gardeners were more focused on the beautiful conversion of individual plots into a green oasis.

(2) Lifestyle. The "Fulton garden lifestyle" was predominantly a blend of "new domesticity" and "recreation/fitness;" the "Brentwood lifestyle" emphasized "new domesticity" and "luxurious organic food;" and the Johns gardeners felt empowered by experiencing the "green oasis" and "new domesticity" lifestyles.

(3) Sanctuary. Fulton gardeners generally believed that the garden provided a special place to connect their present life with their memories of the past. Brentwood gardeners were more aware of the spiritual connection with the garden energy then Fulton or Johns gardeners. Johns gardeners were mostly focused on general well being in the garden.

(4) Learning. Fulton gardeners were primarily focused on learning or improving gardening techniques. Both Brentwood and Johns gardeners tended to be more reflective and felt that observing nature and learning from the natural cycle is empowering. 


\subsection{Influence of Space Connections on Empowerment}

As previously discussed in Chapter V, most gardeners believed that "physical" connections were more important that "social" connections in the community garden. "Physical" connections were defined as a complex and layered web of all people-plant-animal-land connections. The "social," people-to-people connections, were believed to be less relevant in experiencing the community garden space. Figure VI.8 summarizes the above discussion on the influence of space connections on empowerment across the three gardens.

Figure VI.8. Space Connections and Empowerment across Gardens $\square$ influence of people-to-people connections on empowerment $\square$ influence of physical connections on empowerment

\begin{tabular}{|l|l|l|l|l|l|l|}
\hline Empowerment Goals/Themes & \multicolumn{2}{|l|}{} & \multicolumn{2}{l|}{} \\
\hline & Fulton & \multicolumn{2}{l|}{ Brentwood } & \multicolumn{2}{l|}{ Johns } \\
\hline Beauty & & & & & & \\
\hline Plot conversion into art & & & & & & \\
\hline Sharing the garden & & & & & & \\
\hline Harvest usefulness & & & & & & \\
\hline Lifestyle & & & & & & \\
\hline Green domesticity & & & & & & \\
\hline Green oasis/urban village & & & & & & \\
\hline Recreation/fitness & & & & & & \\
\hline Luxury/organic food & & & & & & \\
\hline Learning & & & & & & \\
\hline Gardening techniques in natural \\
setting & & & & & & \\
\hline Garden cycle and human life & & & & & & \\
\hline Professional skills/ business & & & & & & \\
\hline Sanctuary & & & & & & \\
\hline Well being & & & & & & \\
\hline Connection to spirit of nature & & & & & & \\
\hline Memory and connection to past life & & & & & & \\
\hline
\end{tabular}


(1) Importance of Physical Connections in Experiencing Empowerment

The study suggests that the key differences in experiencing empowerment across the gardens were related to the influence of the surrounding areas on the diversity of empowerment themes in each garden, mostly in experiencing beauty, lifestyle, and sanctuary.

1) Beauty. Both Johns and Fulton gardeners appropriated the surrounding areas into their definition of "green oasis." Johns gardeners believed that the views of the areas surrounding the garden - the bridge, the ridge of the Forest Park, the river, the sky, and the village-like feel of nearby gravel streets - were an integral part of experiencing beauty in the community garden. Fulton gardeners equated the beauty of "green oasis" with the feeling of openness of the surrounding areas, the appearance of the gravel road, the view of Mt. Hood, the sky, and the general illusion of "rural life."

In contrast, Brentwood gardeners coupled the concept of beautiful plot transformation with the beauty of garden harvest. Interestingly, the Brentwood concept of empowerment through experiencing beauty did not incorporate the surrounding areas.

2) Lifestyle. The differences in surrounding areas and physical setting influenced the empowerment experience through lifestyle. In the Johns lifestyle, the presence of the community garden provided a transition between the best of 
urban experiences and rural experiences: green country living amid lively urban entertainment. At Fulton, gardeners tended to use the community garden plot for recreation in a park-like setting. The garden area was not fenced and could be used by both registered gardeners and strangers. Brentwood gardeners associated the "luxurious lifestyle" with the luxury of eating fresh fruit and vegetables. This was an image of luxury achieved by controlling one's source and quality of food. The physical aspect of the garden space and the importance of one's plot defined the physical context of experiencing "lifestyle" at Brentwood. The physical characteristics of the surrounding areas were not incorporated into experiencing lifestyle empowerment at Brentwood.

3) Sanctuary. The restorative ("sanctuary") qualities of the Johns and Fulton gardens were influenced by the sense of beauty of the surrounding areas. At Brentwood, the community garden space and one's own plot were considered the place to feel the Spirit of Nature. For several gardeners, the plot in the community garden offered a sense of stability and "rootedness." In that context, the awareness of having one's "own place" to relax, to work, to harvest and experience beauty, was associated with safety, comfort and "well being" in the mobile life.

(2) Importance of Social Connections in Experiencing Empowerment The study found that people-to-people ("social") connections played an important role in fulfilling mostly learning, lifestyle, and beauty empowerment goals. 
Learning in the community garden was closely associated with the presence of other people or their imprints in the garden. Gardeners believed that improving garden cultivation techniques could come because of their reflection on their own practice in the garden or by watching and/or interacting with their fellow gardeners. Social interactions associated with the exchange of garden wisdom were considered the most pleasurable activities by most gardeners.

While the presence of the social realm was universally important in improving gardening techniques in all three gardens, several Fulton gardeners also associated their beauty-related empowerment with the presence of other people. "Sharing the garden" was part of the beauty experience at Fulton and an integral part of gardening. The presence of other people was important in experiencing "recreational" lifestyle empowerment, mostly at Fulton.

\subsection{Relevance of Socioeconomic Characteristics of Gardeners in Experiencing Empowerment}

One of the study objectives was to examine the influence of physical settings on forming sense of place and empowerment experience across the gardens. The physical characteristics of the gardens and the length of membership in a garden, described in detail in Chapter III, were the key criterion in selecting the three gardens and gardeners. 
The limited socioeconomic data that were collected during the in-depth interviews tentatively suggest that some socioeconomic conditions may have influenced the experience of empowerment of individual gardeners.

\section{(1) Housing Conditions}

Table VI. 2. Housing Types by Gardeners and Gardens

\begin{tabular}{|l|l|l|}
\hline \multicolumn{1}{|c|}{ Garden } & Single Family & $\begin{array}{l}\text { Multifamily } \\
\text { (condos and } \\
\text { apartments })\end{array}$ \\
\hline $\begin{array}{l}\text { Fulton } \\
(12 \text { gardeners }=100 \%)\end{array}$ & $\begin{array}{l}9 \text { gardeners } \\
75 \%\end{array}$ & $\begin{array}{l}3 \text { gardeners } \\
25 \%\end{array}$ \\
\hline $\begin{array}{l}\text { Brentwood } \\
(10 \text { gardeners }=100 \%)\end{array}$ & 4 gardeners & 6 gardeners \\
\hline $\begin{array}{l}\text { Johns } \\
(8 \text { gardeners }=100 \%)\end{array}$ & 2 gardeners & $60 \%$ \\
\hline $\begin{array}{l}\text { All Gardens } \\
(30 \text { gardens }=100 \%)\end{array}$ & $25 \%$ & $75 \%$ \\
\hline & $50 \%$ & 15 gardeners \\
\hline
\end{tabular}

Both Johns and Brentwood participants showed a higher ratio of multifamily apartment dwellers compared to Fulton participants: $60 \%$ of Brentwood gardeners and $75 \%$ of Johns gardeners lived in multifamily units (Table VI.2). In contrast, only $25 \%$ of Fulton gardeners who participated in the study lived in multifamily units.

As previously discussed in this chapter, to Brentwood gardeners, the plot in the community garden offered a sense of rootedness and stability for the gardeners who had changed apartments numerous times. In that context, the awareness of having one's "own place" to relax, to work, to harvest and experience beauty, 
was associated with safety, comfort and "well being." In comparison, a majority of the Fulton gardeners resided in single-family houses and a plot in the community garden provided complementary space for vegetable production in a park-like setting.

At Brentwood and Johns, percentages of gardeners experiencing each goal (with the exception of non-food harvest) were higher compared to Fulton (Table VI.6). This may indicate more appreciation and need for public community garden spaces among Johns and Brentwood gardeners, which is more typical for people living in multifamily residential areas.

To the majority of gardeners who resided in single-family houses (mostly at Fulton), a plot in a community garden provided an additional or complementary space to grow vegetables. To the gardeners who lived in multifamily residential areas (mostly at Brentwood), a plot in a community garden was much more than a place to grow food; it was considered an investment and an oasis of stability and safety in their mobile life.

Most of the Johns gardeners were attracted to the ambiance of the Johns neighborhood area and access to the community garden was a desirable feature that complemented the lifestyle associated with a friendly small town image in a sustainable community that favors bicycling, mass transit, and compact housing. 
In that context, living in an apartment or condominium was a reflection of this choice.

(2) Socioeconomic Characteristics of Community Garden Vicinities

As previously discussed in Chapter III, the City of Portland does not require that participants in community gardens live in close proximity to the garden. During my interviews, I asked all the gardeners about the distance between the community garden and their residence. Although most of the gardeners would have preferred to have their own sunny gardens next to their area of residence, the physical distance to the garden was not a significant factor in practicing community gardening. Most of the gardeners who participated in my study drove to the garden. Typically, gardeners explored several community gardens to choose the most suitable location to them. Several Johns gardeners chose their garden based on the physical amenities of the Johns area (view of bridge, surrounding neighborhood land use pattern, and the type of soil). Several Fulton gardeners who lived in downtown chose their plots based on convenient car access to the garden. Several Brentwood gardeners lived in the Sellwood area and chose to drive to the Brentwood garden because of its sunny location and convenient parking on local streets surrounding the garden.

The table below (Table VI.3) provides a glimpse of the socioeconomic pattern in the vicinities of the three community gardens. The census data indicate that the Fulton garden area has the lowest percentage of individuals below poverty level, 
highest percentage of people with bachelor's degrees and the lowest percentage of people speaking a language other than English at home. In contrast, the Johns area has the highest percentage of individuals below poverty level compared to both Fulton and Brentwood.

Table VI.3. Socioeconomic Data/Garden Vicinity

Source: American Community Survey 2006-2009

\begin{tabular}{|l|l|l|l|}
\hline & Fulton & Brentwood & Johns Census \\
Socioeconomic Data & $\begin{array}{l}\text { (Census Tract } \\
64.02)\end{array}$ & $\begin{array}{l}\text { (Census Tract } \\
\text { \% of census }\end{array}$ & $\begin{array}{l}\text { \% of census } \\
\text { (Census Tract } 42)\end{array}$ \\
tract & of census tract) \\
\hline $\begin{array}{l}\text { Bachelor's degree and } \\
\text { higher }\end{array}$ & 68.5 & 38.4 & 36.3 \\
\hline $\begin{array}{l}\text { Speak language other } \\
\text { than English/home }\end{array}$ & 5.8 & 7.8 & 7.4 \\
\hline $\begin{array}{l}\text { Individuals below } \\
\text { poverty level }\end{array}$ & 3.3 & 7.9 & 12.7 \\
\hline
\end{tabular}

As previously discussed in this chapter, the empowerment experience in the Fulton garden reflects the preferences of more affluent people whose focus is on the recreational aspect of community gardening, which may mean that most of the gardeners who participated in my study lived near the garden. Although census data indicates that the Johns area had the highest percentage of people below poverty level, to most of the Johns gardeners food quantity was not the most empowering goal. My study shows that to all Brentwood gardeners the 
community garden plot was an important place to grow food for individual consumption, but according to the census data, the Brentwood vicinity had a lower percentage of people below poverty level than Johns did.

In sum, with the limited socioeconomic data collected as part of my study and the mobility of the community gardeners and their reliance on cars, it is not possible in this study to analyze in a meaningful way the relationship between social characteristics of the gardeners and their empowerment goals.

\section{Individual and Group Action in Fulfilling Empowerment}

\section{Relevance of Individual Action}

\subsection{Individual Atomistic Empowerment}

The focus of individual atomistic empowerment is to provide the direct consumption of the service. The predominant power experience comes from the feeling of being strengthened by support from a service provider. All the gardeners who participated in the program were appreciative of the opportunity to have access to a plot in the community garden and felt empowered by the opportunity to cultivate their own plot in the context of public land. Rocha's conceptualization of atomistic empowerment focuses on providing emergency services and receiving these services without which individuals may not survive (homeless services, emergency food). 
In the context of the community gardening program, all community gardeners experience empowerment by cultivating their own plots to fulfill a range of empowerment goals, discussed earlier in this chapter. Every person I interviewed emphasized how fortunate and grateful they were to be able to use public land for their own gardening. A tool shed, a path connecting one's own individual plot with the tool shed, and a water source were the primary communal infrastructure improvements that supported land cultivation in the garden and source of empowerment. Although all the gardeners did not associate their experience with emergency services, their direct use of city land illustrates the direct consumption of the community garden resources, which reflects an atomistic empowerment experience.

\subsection{Individual Embedded Empowerment: Maximizing Pleasure in Community} Gardens

Embedded individual empowerment conceptualizes individuals as embedded within the larger context affecting their circumstances. This type of empowerment is associated with the ability to understand one's external context and to maneuver through it with the goal of increasing personal efficacy and satisfaction. The power experience comes from understanding the setting and the pursuit of autonomy through self-directed action. The physical setting in which a group operates defines the space that members of that group can control. The process of empowerment is achieved through individual action in the context of the group and program. This approach emphasizes self-respect, self-reliance, and self- 
determination. The elements of the setting and the organizational context are understood in order to control and accomplish individual goals.

Most of the gardeners who participated in the study signed up for a plot in the community garden to fulfill the primary goal of food production for individual consumption. As previously discussed in Chapter IV, private and community realm activities that dominated the community gardens were typically associated with maximizing pleasure-related activities and activities directly related to food production. Community gardeners tended to "maneuver" through the community garden settings to "increase personal efficacy and satisfaction" in accomplishing their own goals by optimizing both the physical and social connections.

(1) Optimizing Physical Connections to Increase Individual Empowerment in Community Gardens

Access to the best possible sunniest plot, not too close to the fence, was the most important factor in optimizing the satisfaction achieved by producing healthy food. The distance between the residence and the community garden was more important to Johns and Fulton gardeners. Brentwood gardeners were more "rooted" in their community garden plots than their apartments. Once they moved to a better part of the garden, Brentwood gardeners considered their plots a substantial investment and the primary source of food, stability, and comfort.

(2) Optimizing Social Connections to Increase Individual Empowerment in Community Gardens 
Learning in the community garden was closely associated with the presence of other people or their imprints in the garden. Optimizing social interactions associated with the exchange of garden wisdom were considered as most pleasurable activities by most gardeners. To some gardeners "learning from people" could also mean "getting to meet and know other people" and developing social connections outside the garden.

Meeting new people in the garden was a life changing experience to several gardeners who participated in the study. In that context, "optimizing" garden related social connections led to the formation of friendships and, on a few occasions, romantic involvements.

Several gardeners associated their beauty-related empowerment with people.

"Sharing the garden" with friends, family, fellow gardeners, and strangers was the ultimate and fundamental step in the community garden cycle and a condition of experiencing beauty.

\subsection{Individual Mediated Empowerment: Balancing Pleasure and Annoyance in Community Gardens}

In mediated empowerment, an expert or professional mediates the process of empowerment. This model revolves around the relationship between the expert and the client/consumer, through which the empowerment is realized. Rocha's typology emphasizes primarily the unequal power relationships between the community or individual and the professional/expert representing an agency and 
the unintended imposition of middle-class professional values on the poor and minority programs.

In the context of the community gardening program, the expert-client power relationship between gardeners and city staff, the usefulness of the agency was seen by the gardeners in the context of either (1) enhancing pleasurable activities or (2) eliminating annoyance in fulfilling their empowerment goals.

(1) The Role of the Agency in Enhancing Pleasurable Experiences in Community Gardens

Community gardeners appreciated the city's expertise in providing an organizational structure to distribute the surplus of food produced in community gardens.

The availability of the city-run Produce for People program that linked the Portland community gardens with local emergency food agencies was an important aspect of food production in community gardeners because it provided a secondary level of assurance that the oversupply of fresh food would not be wasted. This program played an important role in experiencing the feeling of empowerment related to garden harvest by not wasting valuable food and being able to provide it to the people who benefited from it. 
Most of the gardeners believed that the pleasure of controlling the growth of one's own food was not complete without the satisfaction that all possible opportunities were explored to avoid the waste of this high quality food. Thus, the Produce for People program was an important element in the distribution of the oversupply of produce and an important factor in experiencing harvest related empowerment in Portland community gardens.

(2) The Role of the Agency in Mitigating Annoyance Experiences As discussed earlier in this chapter, the concept of "lifestyle" varied among the gardeners in the same garden and across the gardens and meant different things to different people and was the main reason for conflicts among the gardeners. The City of Portland Handbook contains rules and guidelines that guide general behavior of gardeners (Portland Community Gardens: A Handbook, 2008). Most of the gardeners felt dissatisfied by the level of enforcement, which rested on the garden managers who were volunteers, not city staff members. This was a tricky relationship.

In the case of Portland community gardens, individual gardeners were required to pay a fee to use a garden plot but did not see themselves as members of a selfgoverning group that benefits from an expert agency, as assumed by the mediated model. Rather they saw the agency as the provider of a service to enhance their own individual goals. Learning in the garden primarily took three forms (gardening techniques; learning from nature; and learning to enhance 
professional skills). Learning decision making and conflict resolution skills were not perceived as part of the empowering process by the gardeners who participated in the study. They associated conflicts in the garden with the city's lack of enforcement of rules that prevented them from maximizing their satisfaction from the primary empowerment goals.

It should be emphasized that my study did not provide any evidence that gardeners felt empowered by learning conflict resolution skills or recognized their lack of conflict resolution skills as their deficiency. Rocha notes, "in order for help to be given, it must be received. In order to accept help, the receiver is implicitly acknowledging weakness and subordination to the dominant help" (Rocha, 1977, p.37).

The study finds that empowerment through learning in community gardens is mostly associated with learning from one's own practice, observing nature, and receiving instructions from other people in the garden. While most of the gardeners appreciated the city resources, they typically chose to comply with only those agency rules that made their plots more "habitable" to them (i.e., the objective of their learning was to maximize the pleasurable accomplishment of their goals.) Most importantly, their learning of conflict resolution and selfgovernance skills related to the enforcement of homogenizing rules, while extremely important to the agency, was not at all important to them. 


\section{Relevance of Group Action}

The study suggested that gardeners were likely to consider working together with other gardeners when there was a need to deal with "garden threats." Personal safety, harvest security or safety, and lack of support for the community garden program were considered "threats" by most of the gardeners who participated in the study.

\subsection{Political Empowerment: "Protecting Our Garden"}

According to Rocha (1997), political empowerment involves expanded access to group resources -education, housing, employment, health care, or political representation. The focus is not on the process of change within the individual or group, but on the outcome, equating empowerment with visible results. The infusion of dollars, programs, and other forms of economic development into a geographically defined community is often seen as the empowering result.

Political empowerment is frequently realized as a form of community development by local, state, and nonprofit organizations and is typically narrowly focused on providing material and economic benefits, usually housing and jobs. Thus, it does not build community capacity with which to challenge power relations. Political empowerment provides group products but lacks collective capacity to sustain momentum in seeking redistributive effects.

Research on attachment to natural places (Ryan, 2003) indicates that place connections may be most apparent in the face of negative change. The responses 
to hypothetical negative changes related to natural areas fall into two categories around the themes of emotional responses and environmental activism. The emotional response is associated with personal loss and feeling sad. The environmental activism manifested itself in taking environmental action to protect a special place.

During my in-depth interviews, I asked what each gardener what would he or she do if the garden were to be redeveloped. The responses were divided into four groups:

1) Some gardeners indicated that they had already testified before the City Council against budget cuts that would impact their garden and that they would do so again, if needed;

2) Several gardeners indicated that, they had not participated in the process before, but would do so, if there were adverse changes that would impact their garden;

3) Some gardeners said they would be sad and depressed and would look for another place (either another garden in the city program or lease space from other property owners; look for some nonprofit organizations; ask their friends to use their property; or buy a different house and move somewhere else );

4) Some gardeners said that they would be sad and depressed and would not know what to do or that they would let it go. 
Table VI.4 provides a summary of responses across the gardens.

Table VI.4. Protecting Our Garden: Summary of Responses by Garden

\begin{tabular}{|l|l|l|l|l|}
\hline \multicolumn{1}{|c|}{$\begin{array}{l}\text { What would you do if your } \\
\text { garden were to redevelop? }\end{array}$} & $\begin{array}{l}\text { Fulton } \\
12 \\
\text { gardeners } \\
(100 \%)\end{array}$ & $\begin{array}{l}\text { Brentwood } \\
10 \text { gardeners } \\
(100 \%)\end{array}$ & $\begin{array}{l}\text { Johns } \\
8 \text { gardeners } \\
(100 \%)\end{array}$ & $\begin{array}{l}\text { All } \\
30 \\
\text { gardeners } \\
(100 \%)\end{array}$ \\
\hline $\begin{array}{l}\text { Would protest; we have done it } \\
\text { before and will do again, if } \\
\text { needed }\end{array}$ & $6(50 \%)$ & $1(10 \%)$ & 0 & $7(23 \%)$ \\
\hline $\begin{array}{l}\text { Never done it here, but would } \\
\text { protest if needed }\end{array}$ & $6(50 \%)$ & $1(10 \%)$ & $5(63 \%)$ & $12(40 \%)$ \\
\hline $\begin{array}{l}\text { Would be sad and would look for } \\
\text { another opportunity }\end{array}$ & & $4(40 \%)$ & $2(25 \%)$ & $6(20 \%)$ \\
\hline $\begin{array}{l}\text { Would be sad; do not know what } \\
\text { to do; would let it go }\end{array}$ & & $4(40 \%)$ & $1(12 \%)$ & $5(17 \%)$ \\
\hline
\end{tabular}

The study suggested that at Fulton, a threat to the garden could result in the most intense and coordinated political action to support the city program, while at Brentwood several people would consider it as a personal loss and would look for different gardening opportunities. Eight (80\%) Brentwood gardeners believed that they would not participate in any organized action to support the city program and access to the garden. Forty (40\%) Brentwood gardeners would rather look for different options. They would explore nonprofit organizations, lease properties from private property owners, or perhaps, look for another plot in another garden operated by the city. Five (17\%) Johns gardeners felt strongly that they would organize or join an organized action to support the gardening program. 


\subsection{Sociopolitical Empowerment: Fighting for "The Right to Community Gardens"}

Rocha notes that the sociopolitical empowerment model is the most complex because it operates on an individual basis as well as a community basis (Rocha, 1997). Members of the community are transformed from bystanders into participants in the process, as the community itself is transformed into a partner in the political process. This empowerment model recognizes the people who comprise the community as the first priority. The physical development of the area is considered the second priority.

Sociopolitical empowerment focuses on the process of change in the context of the collaborative process to alter social, political, or economic relations. It emphasizes the importance of growth through knowledge acquisition and collaborative social action. Thus, this model of empowerment uses grassroots and political action as a benchmark. Rocha identifies two core elements in sociopolitical empowerment: (1) critical reflection by the members of the community rethinking their relationship to structures of power and (2) collective action upon those structures. Without the development of critical awareness, action is empty. Without action, critical awareness is useless. The process of change becomes an accepted long-term process in which defeats as well as successes are acknowledged as part of an extended struggle. 
More than half of the gardeners (63\%) either had already participated in an organized political action to protect their garden or believed that they would organize a protest or participate in such an action (Table VI.4). Six gardeners (20\%) stated they would rather look for different opportunities and consider exploring community groups, other agencies, or private landowners to get access to urban agricultural land.

\section{Community Garden Empowerment: Summary of Findings}

\section{Empowerment Goals and Narratives}

Based on the analysis of in-depth interviews, my study suggests that gardeners who participate in the City of Portland Community Garden Program most commonly experience empowerment by perceiving community gardens as sacred places where people feel well because they can grow healthy food, practice "green domesticity," and learn gardening from nature in a beautiful setting.

The importance of the gardens practicing the "new domesticity" was the most commonly expressed feeling of empowerment in the context of "lifestyle" in the three gardens. The new domesticity embodied elements of new "green philosophy" in life: eating healthy food and producing sustainably instead of consuming rampantly.

The most dominant feeling of empowerment through learning was experienced by improving gardening techniques. While some gardeners saw community 
garden spaces as places to experience spiritual unity with Nature, for the most part, their experience suggested the restorative qualities of community gardens and their influence on the general well being of the gardeners.

\section{Empowerment and Space Connections}

\subsection{Physical Connections}

The key differences in experiencing empowerment across the gardens were related to the influence of the surrounding areas on the diversity of non-harvest empowerment themes in each garden, mostly in experiencing beauty, lifestyle, and sanctuary. The influence of surrounding areas was not relevant in experiencing harvest empowerment.

\subsection{Social Connections}

The "social" aspect of gardening, although recognized as important by many gardeners was not considered as the primary connection in the community garden. The study finds that people-to-people ("social") connections play an important role in fulfilling mostly learning empowerment goals. Learning in the community garden was closely associated with the presence of other people or their imprints in the garden. 


\section{Rocha's Ladder of Empowerment in the Community Garden Context}

Rocha notes that the empowerment ladder she constructed is based on a review from the empowerment literature and "it can be best understood as a way to think about empowerment rather as a how -to manual with specific (emphasis added) instructions for each type" (Rocha, 1997, p.32). It provides a conceptual framework for understanding empowerment and "for the reflective planner, the ladder will serve as a framework by which personal, agency, or community values may be located with respect to possible courses of action (Rocha, 1997, p.41). The ladder of empowerment is meant to enable planners to gain an understanding about the types of empowerment in a specific context. The ladder is based on the assumption that there is a spectrum of empowerment that is embedded within everyday practice. The "reflective planner" should be able to unearth different types of empowerment

The objective of my research was to apply the conceptual framework developed by Rocha to the "ground level" of community gardens in Portland. Thus, my findings illustrate an effort of a "reflective planner" trying to "unpack" the spectrum of empowerment experiences. Through the fulfillment of diversified empowerment goals (harvest, non-harvest), gardeners tend to experience a nuanced spectrum of empowerment feelings. 


\subsection{Individual Empowerment in Community Gardens}

The study finds that community gardeners experience individual empowerment at three levels: (1) atomistic; (2) embedded; and (3) mediated.

Atomistic empowerment. Within the context of the Portland Community Garden Program, gardeners tend to be individualistic. The direct use of city land illustrates the direct consumption of the community garden resources, which reflects an atomistic empowerment experience.

Embedded empowerment. In this variation of individual empowerment, emphasis is placed on the individual's immediate context. The difference between atomistic experience and embedded experience is that embedded empowerment conceptualizes individuals as embedded within the larger context affecting their circumstances. In this type of empowerment, individuals have the ability to understand their external context to maneuver through it with the goal of increasing personal satisfaction. Within the context of the Portland Community Gardens, the gardeners tend to "maneuver" through the community garden settings to "increase personal efficacy and satisfaction" in accomplishing their own goals by optimizing mostly their physical and social connections. Mediated empowerment. In mediated empowerment, an expert or professional mediates the process of empowerment. This model revolves around the relationship between the expert and the client/consumer, through which the empowerment is realized. In the context of the community gardening program, the expert-client power relationship between gardeners and city staff, the 
usefulness of the agency was seen by the gardeners in the context of either (1) enhancing pleasurable activities or (2) eliminating annoyance in fulfilling their empowerment goals. In the case of Portland community gardens, individual gardeners were required to pay a fee to use a garden plot but did not see themselves as members of a self-governing group that benefits from an expert agency. Rather they saw the agency as the provider of a service to enhance their own individual goals.

\section{2, Group Empowerment}

The data collected through in-depth interviews did not provide sufficient and compelling evidence to suggest that the gardeners value group action to experience empowerment.

In my in-depth interviews, I used responses to hypothetical negative changes related to the garden. In the context of my hypothetical question, there was no evidence that most of the community gardeners actually experienced group empowerment to advance their empowerment goals.

In sum, my hypothesis was that most of the gardeners would experience individual embedded and/or mediated empowerment in the context of community gardens in Portland. My research provided evidence that all the gardeners experienced atomistic, embedded, and mediated empowerment.

The evidence collected through my research provided a nuanced concept of "atomistic empowerment" in Rocha's ladder in the context of the community 
garden. Rocha's conceptualization of atomistic empowerment focuses on providing direct emergency services. In the context of the community gardening program, all community gardeners experience empowerment by direct access to community garden resources. A very individualistic gardener (as in the case of the Portland Community Garden Program) may fall into this category.

\section{Consumerism and Empowerment in Community Garden}

In the case of Portland community gardens, where individual gardeners needed to pay a fee to use a garden plot, they did not see themselves as members of a self-governing group. Rather they saw the agency as the provider of a service to enhance their individual goals.

My study shows that in the context of the Portland community gardening program, community gardeners behave as consumers of the products and services provided by the city to maximize their pleasurable experiences. Thus, the community gardeners tend to see themselves as a group of customers of the community gardening program.

The study finds that the prevailing experience of empowerment related to community gardening resonates with the consumer society values, where the shared narrative of community garden empowerment (i.e. practicing "green domesticity" and growing organic food in a beautiful setting) is perceived as a 
commodity. In that context, my study suggests that community gardens managed by the City of Portland may be seen as the manifestation of consumerism. 


\section{EMPOWERMENT AND IMAGE IN COMMUNITY GARDENS}

There has been no research linking visual images of empowerment and sense of place of community gardens. The study is intended to initiate discussion on empowerment images associated with community gardens in the context of sense of place. The photo storytelling method was applied in this research to gain further insights into sense of place.

During the in-depth interviews, the gardeners were asked to describe their feelings and experiences related to each picture or group of pictures. At the end of the first part of the interview, each gardener was asked to select up to four pictures that she or he considered the "most important" in the story. Eighteen gardeners $(60 \%)$ were able to select their "three most important" pictures. Eleven gardeners (37\%) selected "the four most important pictures," and one gardener felt that "two most important pictures" were sufficient to summarize the feelings and experiences related to the community garden. Thus, the collection of "the most important pictures" selected by the thirty gardeners consists of one hundred pictures.

The most important pictures selected by the gardeners typically carried more than one meaning. The one hundred most important pictures taken by the community gardeners were the basis for the formation of one hundred fifty symbolic representations of empowerment feelings. Several pictures were associated with 
one or two empowerment goals/themes, but, on average, each picture represented three empowerment themes.

The collection of "one hundred most important pictures" was used for the analysis of image types associated with community garden space transformation and symbolic representations of empowerment feelings.

The first part of Chapter VII contains a discussion of image types. The second part contains a discussion of symbolic representation of empowerment.

A. Types of Images in Community Garden

Figure VII.1 represents the distribution of pictures by image type of the one hundred most important pictures taken by all the gardeners who participated in the study.

$$
\mathrm{N}=100
$$

Figure VII.1. Percentage of Garden Images by Type

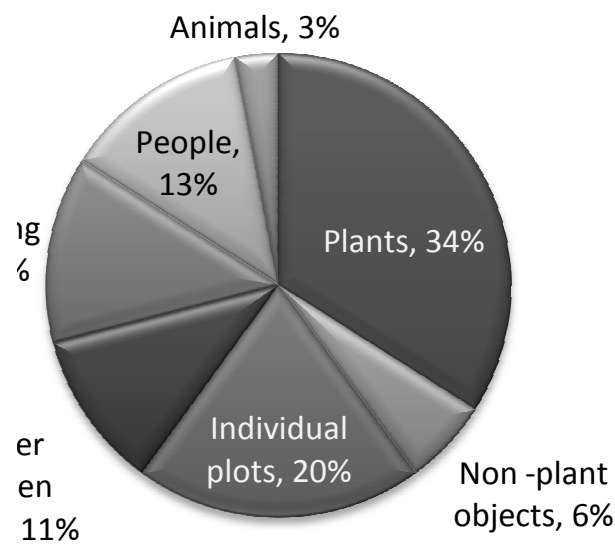


Table VII.1 provides more detailed information on the type of images related to community gardening space transformation.

Figure Table VII.1. Summary of Space Transformation Images

\begin{tabular}{|c|c|c|c|c|c|}
\hline $\begin{array}{l}\text { Image } \\
\text { Type }\end{array}$ & $\begin{array}{c}\text { Fulton } \\
12 \\
\text { gardeners }\end{array}$ & $\begin{array}{c}\text { Brentwood } \\
10 \\
\text { gardeners }\end{array}$ & $\begin{array}{c}\text { Johns } \\
8 \\
8 \\
\text { gardeners }\end{array}$ & $\begin{array}{c}\text { Number } \\
\text { of } \\
\text { Images }\end{array}$ & $\begin{array}{c}\% \\
\text { of } \\
\text { Total } \\
\text { images }\end{array}$ \\
\hline \multicolumn{6}{|l|}{ A. Object } \\
\hline 1. $\quad$ Plant & 7 & 16 & 11 & 34 & $34 \%$ \\
\hline 2. Non Plant & 2 & 1 & 3 & 6 & $6 \%$ \\
\hline $\begin{array}{l}\text { Total Images of } \\
\text { Objects }\end{array}$ & 9 & 17 & 14 & 40 & $40 \%$ \\
\hline \multicolumn{6}{|l|}{ B. Garden Space } \\
\hline 1. Individual Plot & 10 & 4 & 6 & 20 & $20 \%$ \\
\hline 2. Other Areas & 4 & 5 & 2 & 11 & $11 \%$ \\
\hline $\begin{array}{l}\text { Total Images of } \\
\text { Garden Space }\end{array}$ & 14 & 9 & 8 & 31 & $31 \%$ \\
\hline \multicolumn{6}{|l|}{$\begin{array}{l}\text { C. Surrounding } \\
\text { Areas }\end{array}$} \\
\hline 1. Vicinity & 5 & 1 & 3 & 9 & $9 \%$ \\
\hline 2. Landmark & 0 & 1 & 3 & 4 & $4 \%$ \\
\hline $\begin{array}{l}\text { Total Images of } \\
\text { Surrounding Areas }\end{array}$ & 5 & 2 & 6 & 13 & $13 \%$ \\
\hline \multicolumn{6}{|l|}{ D. People } \\
\hline $\begin{array}{l}\text { 1. Single Person } \\
\text { or Couple }\end{array}$ & 6 & 6 & 0 & 12 & $12 \%$ \\
\hline 2. Group & 0 & 1 & 0 & 1 & $1 \%$ \\
\hline Total Images of People & 6 & 7 & $\mathbf{0}$ & 13 & $13 \%$ \\
\hline \multicolumn{6}{|l|}{ E. Animals } \\
\hline 1. Wild & 0 & 2 & 0 & 2 & $2 \%$ \\
\hline 2. Pets & 0 & 0 & 1 & 1 & $1 \%$ \\
\hline $\begin{array}{l}\text { Total Images of } \\
\text { Animals }\end{array}$ & $\mathbf{0}$ & 2 & 1 & 3 & $3 \%$ \\
\hline Total Images & 34 & 37 & 29 & 100 & $100 \%$ \\
\hline
\end{tabular}

\section{People Images}

Thirteen (13\%) out of the 100 most important pictures were images of people

.Twelve (12\%) of them were pictures of one person, or sometimes, a couple.

Only one picture represented a group of friends working together in the garden. 
The single-person pictures showed either the gardener who participated in the project or a family member of the participant.

As discussed in Chapter IV, most gardeners believed social, "people-to-people" interactions and connections are less important that "physical" connections in community gardens. In that context, it was not surprising that images of people made up a relatively small segment of the one hundred most important pictures (Figure VII.1 and Table VII.1). First, it was difficult to spot more than two or three people working at the same time in the garden. Second, those who happened to be working in the garden may have not evoked pleasurable connections and memorable gardening moments. Third, while human imprints in the garden could be a source of enjoyment and pleasure, the actual presence of people in the space and direct social contact were not a condition of experiencing a spiritual bond with the fellow gardeners.

Six (18\%) of thirty-four Fulton pictures and seven (19\%) of thirty-seven Brentwood pictures represented people. Johns gardeners did not select pictures of people as their most important pictures. This distribution of images of people across the three gardens reflected the general patterns in social realms in the three gardens, discussed in Chapter IV.

Fulton gardeners tended to regard their interaction with both strangers and fellow gardeners as the most enjoyable part of community gardening. While Brentwood 
gardeners enjoyed organized social activities, they tended to be less appreciative of ad hoc interaction with the fellow gardeners or strangers in the garden. In contrast, Johns gardeners did not view a community garden as a vibrant social scene. The garden space provided an additional dimension and interaction for the people who had already met each other through other neighborhood activities.

\section{Plot and Plant Transformation}

Images of garden objects and garden spaces dominated the collection of the one hundred most important pictures (Figure VII.1 and Table VII.1). The physical transformation of one's own plot was the most enjoyable and beautiful activity in the community gardens. This included land cultivation activities to produce fruit and vegetables and ways of marking one's own plot by creative use of plants or placing garden structures or other objects signifying the uniqueness of the plot.

This type of "plot-to-plant" space appropriation reflected the main gardening purpose, which was food production. The thirty-four images (34\%) of plants symbolized the ultimate garden transformation - the garden harvest and the miracle of growth. The images of six non-plant objects were typically placed on the individual plot to signify the uniqueness of the space and commemorate the special connection to the place. 


\section{Influence of Surrounding Areas on Image Types}

Thirteen (13\%) of the one hundred most important pictures contained images of either the areas surrounding the garden or views from the garden (Figure VII.1).

Figure VII.2 captures the influence of surrounding areas on the formation of images across the three gardens.

Figure VII.2. Distribution of Image Types across Gardens

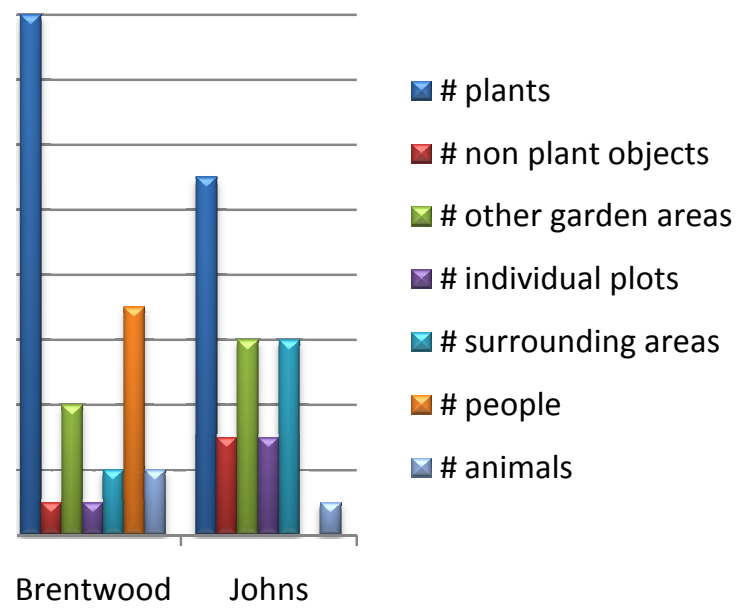

The study suggested that the images of the surrounding areas were influenced by the physical characteristics of the areas surrounding the garden and the integration of the garden with surrounding areas.

Most of the Brentwood gardeners drove to the garden. Once they arrived at the garden, they tended to spend the time efficiently and focus on their plot, behind the locked gate and the fence. Driving to the garden was not a leisure trip and its 
purpose was only to reach the garden. The garden itself was bordered by a barren tract of land to the east with a cell tower to the south of the garden boundary. It was not surprising that to the most of the Brentwood gardeners this type of scenery was not a basis to form space images reflecting their connections to the space (Appendices A13-A.22).

In contrast to the Brentwood garden, the gravel perimeter road linking Fulton Garden with the nearby Fulton Community Center (Appendices A.5, A.9. and A.10), and the combination of unimproved and gravel streets in the vicinity of Johns Community Garden created a romanticized version of simple, bucolic, rural life, a road to a "green oasis", a quiet place on earth . Most of the Johns gardeners walked to the garden through the neighborhood surrounding the garden. An ambiance of mixed uses along nearby Lombard street, the view of the river, the bridge with the background of Forest Park, and the gravel road leading to the garden created pleasant scenery, stimulated meditation, and provided visual images for space connection (Appendices A.26, A.29, and A.30).

Fulton gardeners tended to focus on the amenities and features surrounding the garden that provided an impression of the rural and bucolic area in the city to combat the roaring noise of the nearby freeway traffic. The images of the gravel road and the native plant trail amid lush greenery, just steps away from the freeway, suggested the importance of the surrounding areas in creating own 
experience and illusion in developing connections to the space (Appendices A.2, A.5, A.9, and A.10) .

4. Types of Images in Community Garden: Summary of Findings

The study suggested that the type of images contained in the one hundred most important pictures reflected the practice of everyday life and the space connection pattern discussed in Chapter IV, (i.e., the "everyday practice" in community gardening).

First, the most important community garden connections and activities revolved around the conversions of individual plots, regardless of the physical characteristics of the surrounding areas. The image of one's own plot with growing plants dominated the collection of the most important pictures. Second, the physical characteristics of the surrounding areas enhanced the image formation related to community gardening. Both Johns and Fulton gardeners were inclined to incorporate scenery of the surrounding areas into their spatial images, in contrast to Brentwood gardeners who did not incorporate the surrounding area images into their spatial experience.

\section{B. Symbolic Representations of Community Garden Empowerment}

The one hundred most important pictures taken by the community gardeners were the basis for the formation of one-hundred fifty representations of empowerment 
feelings experienced by the gardeners. Figure VII.3 captures the distribution pattern of symbolic representations of empowerment goals in all gardens.

Figure VII.3. Distribution of Symbolic Representations of Empowerment Goals

$$
\mathrm{N}=150
$$

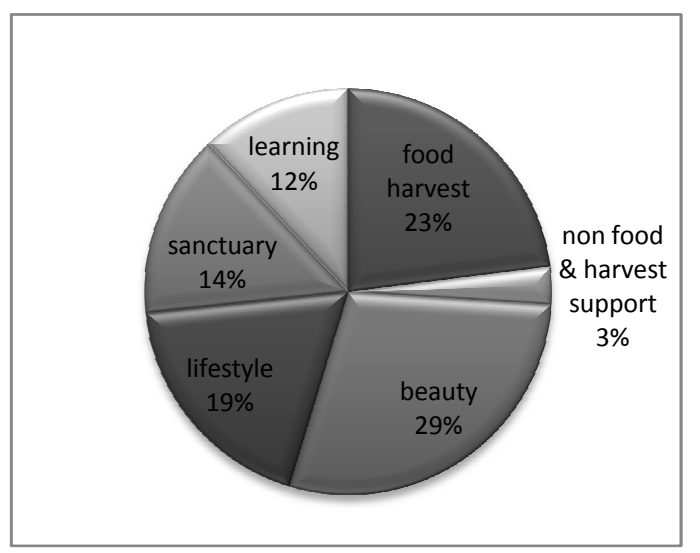

The representations of empowerment achieved by experiencing beauty in community gardens were the most dominant group of representations (29\% of all representations). Food harvest (23\% of all representations) was the second most dominant group of representations. Lifestyle representations made up $19 \%$ of representations. The representations of sanctuary empowerment made up $14 \%$ of the total representations and the representations of empowerment achieved by learning in the community garden made up twelve percent of the representations. 
Table VII.2. Summary of Symbolic Representations of Empowerment Goals

\begin{tabular}{|c|c|c|c|c|c|c|c|c|}
\hline \multirow{3}{*}{ 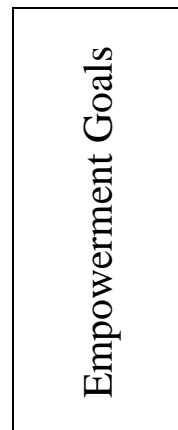 } & \multicolumn{8}{|c|}{ Representations } \\
\hline & \multicolumn{2}{|c|}{ Fulton } & \multicolumn{2}{|c|}{ Brentwood } & \multicolumn{2}{|l|}{ Johns } & \multirow{2}{*}{ 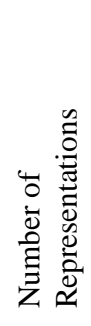 } & \multirow{2}{*}{ 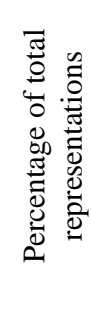 } \\
\hline & 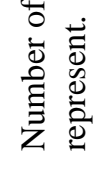 & 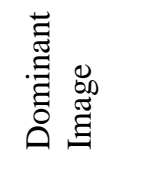 & 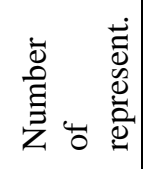 & 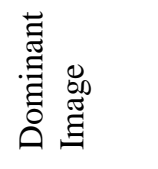 & 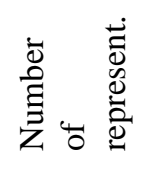 & 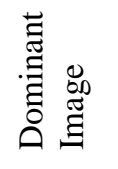 & & \\
\hline \multicolumn{9}{|l|}{ Harvest } \\
\hline Food & 11 & $\begin{array}{l}7 \\
\text { individual } \\
\text { plots } \\
3 \text { plants } \\
1 \text { person } \\
\end{array}$ & 12 & $\begin{array}{l}3 \text { individual } \\
\text { plots } \\
8 \text { plants } \\
\text { 1 other parts } \\
\text { of garden }\end{array}$ & 11 & $\begin{array}{l}11 \\
\text { plants }\end{array}$ & 34 & $23 \%$ \\
\hline $\begin{array}{l}\text { Non } \\
\text { food }\end{array}$ & 3 & \begin{tabular}{|l|}
1 \\
individual \\
plot \\
1 person \\
1 plant \\
\end{tabular} & 0 & & 0 & & 3 & $3 \%$ \\
\hline Support & 0 & & 0 & & 2 & $\begin{array}{l}2 \\
\text { objects }\end{array}$ & 2 & \\
\hline $\begin{array}{l}\text { Total } \\
\text { Harvest }\end{array}$ & 14 & & 12 & & 13 & & 39 & $26 \%$ \\
\hline \multicolumn{9}{|l|}{$\begin{array}{l}\text { Non- } \\
\text { Harvest }\end{array}$} \\
\hline Beauty & 18 & \begin{tabular}{|l}
$5-$ \\
indivdual \\
plots \\
4 plants \\
3 \\
surroundi \\
ng areas \\
1 other \\
parts of \\
garden \\
5 - people \\
\end{tabular} & 17 & $\begin{array}{l}5 \text { individual } \\
\text { plots } \\
11 \text { plants } \\
1 \text { other parts } \\
\text { of garden }\end{array}$ & 8 & $\begin{array}{l}1 \\
\text { individu } \\
\text { al plot } \\
2 \text { plants } \\
4 \\
\text { surround } \\
\text { ing areas } \\
1 \text { object }\end{array}$ & 43 & $29 \%$ \\
\hline Lifestyle & 5 & $\begin{array}{l}2 \\
\text { individual } \\
\text { plots } \\
2 \text { other } \\
\text { parts of } \\
\text { garden } \\
1 \text { people }\end{array}$ & 14 & $\begin{array}{l}3 \text { individual } \\
\text { plot } 4 \\
\text { plants } \\
1 \text { object } \\
6 \text { people }\end{array}$ & 9 & $\begin{array}{l}1 \\
\text { individu } \\
\text { al plot } \\
4 \\
\text { surround } \\
\text { ing areas } \\
3 \text { plants } \\
1 \text { animal }\end{array}$ & 28 & $19 \%$ \\
\hline Sanctuary & 5 & \begin{tabular}{|l|}
4 \\
surroundi \\
ng areas \\
1 other \\
parts of \\
garden
\end{tabular} & 11 & $\begin{array}{l}4 \text { individual } \\
\text { plots } 3 \\
\text { plants } \\
1 \text { object } \\
1 \text { people } \\
2 \text { animals }\end{array}$ & 6 & $\begin{array}{l}2 \\
\text { surround } \\
\text { ing areas } \\
3 \text { plots } \\
1 \text { plant }\end{array}$ & 22 & $14 \%$ \\
\hline Learning & 8 & $\begin{array}{l}2 \\
\text { individual } \\
\text { plots } 3 \\
\text { other parts } \\
\text { of garden } \\
2 \\
\text { surroundi } \\
\end{array}$ & 5 & $\begin{array}{l}1 \\
\text { individual } \\
\text { plot; } \\
1 \text { other } \\
\text { parts of } \\
\text { garden } \\
1 \text { people } \\
\end{array}$ & 5 & $\begin{array}{l}3 \\
\text { individu } \\
\text { al plots } \\
1 \text { plants } \\
1 \text { object }\end{array}$ & 18 & $12 \%$ \\
\hline
\end{tabular}




\begin{tabular}{|c|c|c|c|c|c|c|c|c|}
\hline \multirow{3}{*}{ 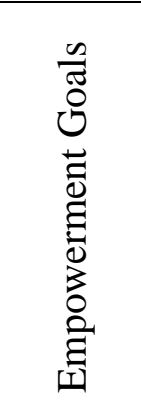 } & \multicolumn{8}{|c|}{ Representations } \\
\hline & \multicolumn{2}{|c|}{ Fulton } & \multicolumn{2}{|c|}{ Brentwood } & \multicolumn{2}{|l|}{ Johns } & \multirow{2}{*}{ 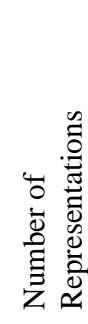 } & \multirow{2}{*}{ 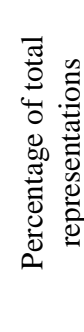 } \\
\hline & 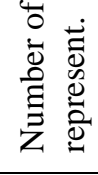 & 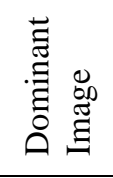 & 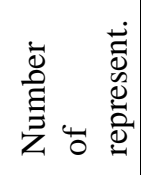 & $\begin{array}{l}\stackrel{\Xi}{\Xi} \\
\stackrel{\Xi}{\Xi} \\
\stackrel{\Xi}{\Xi} \\
\stackrel{\Xi}{\Xi}\end{array}$ & 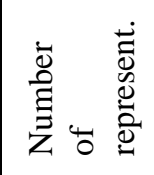 & 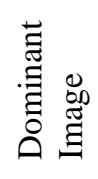 & & \\
\hline & & $\begin{array}{l}\text { ng areas } \\
1 \text { people }\end{array}$ & & 2 plant & & & & \\
\hline $\begin{array}{l}\text { Total Non } \\
\text { Harvest }\end{array}$ & 36 & & 47 & & 28 & & 111 & $74 \%$ \\
\hline $\begin{array}{l}\text { Total by } \\
\text { Garden }\end{array}$ & 50 & & 59 & & 41 & & 150 & $100 \%$ \\
\hline
\end{tabular}

\section{Food Harvest Empowerment Representations}

The "harvest" related empowerment goals were dominated by "food quality" and "food quantity" associated with the ability to control and grow healthy food for human consumption. Satisfaction from growing safe and healthy food was the primary feeling of empowerment related to the harvest goals. The food harvest representations were mostly symbolized by individual plants grown by the gardeners or individual plots cultivated by the gardeners. The ability to cultivate land with "your own hands" was the ultimate expression of control for a number of gardeners. This importance was expressed in the pictures showing the hands of gardeners touching and holding the harvest themes.

Figure VII.4 is an example of the most typical representations of empowerment feelings achieved by growing and controlling food production. A Johns gardener took a picture of a carrot he was holding in his own hand. 


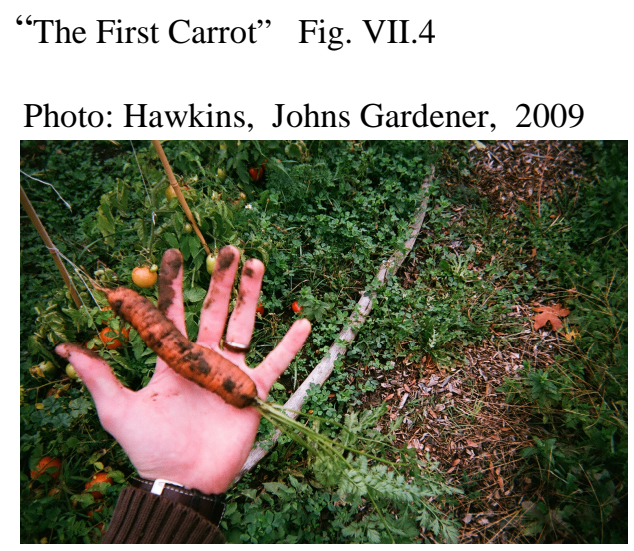

\section{Non- Food Harvest Representations}

Non-food harvest imagery included growing plants with the goals extending beyond food production for human consumption. Three gardeners chose pictures to represent the importance of their empowerment feeling achieved by growing and harvesting plants that were not directly related to human consumption.. Figure VII.5 is an example of a non -food harvest empowerment representation. A Fulton gardener arranged a bouquet of sunflowers to symbolize the non-food harvest in community gardens and the importance of sharing space with both people and animals. Sunflowers symbolized both the ultimate food harvest for humans and animals and enjoyment of sharing beauty and harvest with people and animals. 
"A Bouquet of Sunflowers: Sharing Harvest" Fig. VII.5. Photo Andrea, Fulton Gardener, Summer/Fall 2009

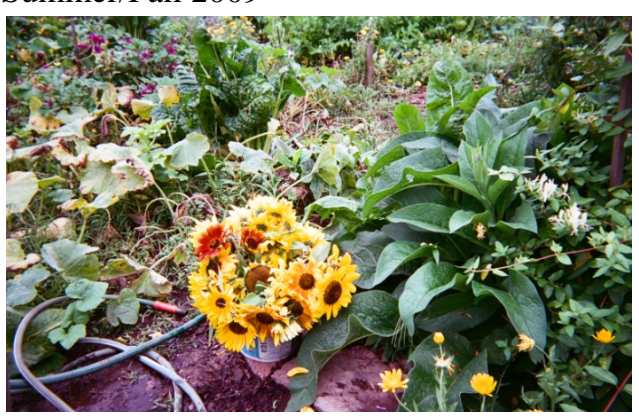

\section{Harvest Support Empowerment Representations}

Only two gardeners chose pictures that symbolized the empowerment related to the presence of infrastructure in community gardens. A picture taken by a Johns gardener (Figure VII.6) symbolized the empowerment experience by being able to access water in community garden to cultivate individual plots. A picture of the water station in the garden symbolized the availability of water to cultivate plants. The water station was located in a common space where everybody needs to go to get water. "It is water, the watering station above my garden, without water nothing is possible. If we did not have water, it would be a much different task growing. It is something I do not take for granted; we do not have to pay for it other than our fees for the year, a very important picture for me..." (Robby, Johns Gardener, 2009). 


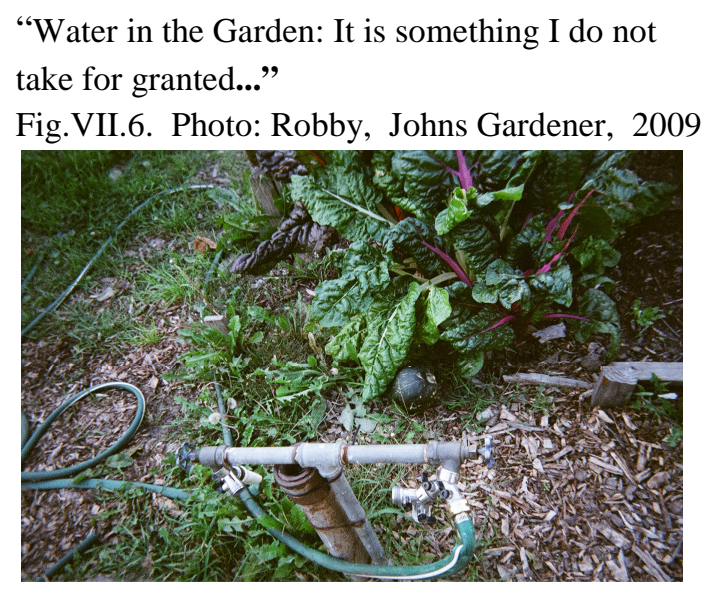

\section{Beauty Empowerment Representations}

Community gardeners experienced beauty related empowerment in three ways:

(1) converting individual plots into the objects of art in the garden "green oasis;"'( 2) sharing the "garden" (experience, knowledge, and harvest) with other people; and ( 3) associating aesthetic values of garden produce with sustenance of garden harvest (i.e., plants must be edible to be beautiful). The beautyinfluenced empowerment could be any combination of the three experiences, which varied across the gardens and among the members of the same garden. The representations of empowerment achieved by experiencing beauty in community gardens were the most frequently represented feeling. Forty-three representations out of one hundred fifty empowerment images (29\% of all representations) were related to experiencing beauty in community gardens. 
The gardeners used a relatively wide range of images as symbolic representations of beauty empowerment: plants, individual plots, images of surrounding areas, pictures of people in the gardens, pictures of garden areas other than individual plots, and one object. The range of images used to represent beauty empowerment reflects the diversity of the concepts of beauty, discussed in Chapter VI.

The three pictures, presented below, illustrate the three concepts of beauty themes that emerged during the in-depth interviews.

\subsection{Converting Individual Plots into the Objects of Art in the Garden "Green Oasis"}

Figure VII.7 is an example of "converting individual plots into the objects of art in the garden "green oasis." David's plots were ever changing objects of art in progress; David was looking for a perfect expression of beauty. The natural cycle in the garden, the change in vegetation and landscape, provided the context for his art making in the garden "The spaces meshes together: it is urban and rural; it is an oasis in the city; it is natural art; it an oasis of natural beauty, defined by sky, trees, and mountains." Gardening was about composing art "All the variety of flowers; it is like painting with plants..." (David, Fulton Gardener, 2009) 
"Art and Garden Beauty: Compositions of Natural Shapes, Colors, and Structures" Fig. VII.7 Photo: David, Fulton Gardener, 2009

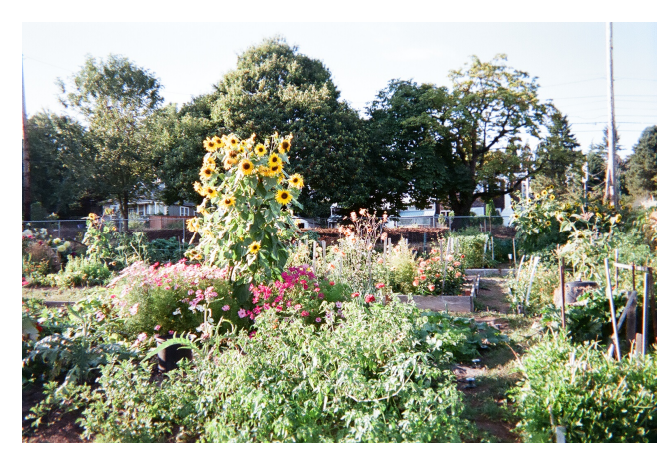

\subsection{Sharing Garden Beauty}

Figure VII.8 is an example "sharing garden beauty" and represented the belief that the act of "sharing the garden" was a condition of experiencing beauty in the community garden and the production cycle is not complete without the act of sharing. "Sharing the garden" was not limited to sharing harvest products but also included sharing gardening knowledge and art in the garden. Sharing the harvest from the garden with both his family, fellow gardeners and strangers was an important part of the cycle in the garden for Merrill. The ultimate beauty of the garden was about sharing with family, friends, and strangers. Sharing the beauty of garden harvest was about the smile on his granddaughter's face. This picture symbolized the complete garden cycle, from the beautiful and tidy row of vegetables to the smile on people's faces who received produce from Merrill's 
garden. Thus, the complete gardening cycle was about cultivating land and sharing the harvest with other people. Sharing made gardening beautiful.

\section{"Sharing the Beauty and the Bounty of the Garden"}

Fig. VII.8. Photo: Merrill, Fulton Gardener, 2009

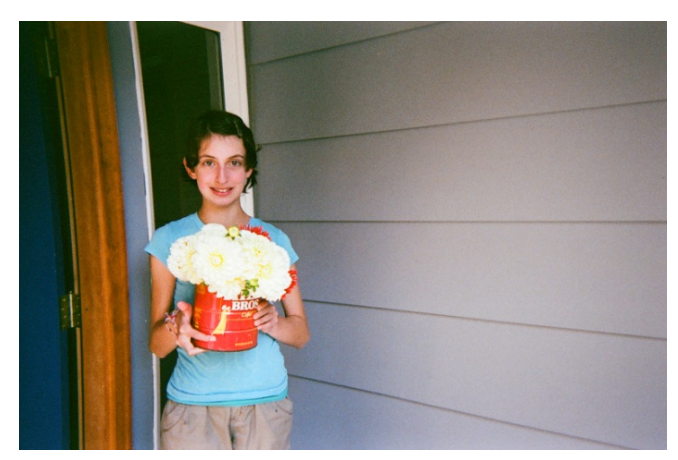

\subsection{Useful and Beautiful Plants}

Figure VII.9 is an example of useful and beautiful plants and associating aesthetic values of garden produce with sustenance (plants must be edible to be beautiful). The beauty of the garden was to be able to grow your own food. Here the leaves of Japanese mustard symbolized Stephanie's passion for growing beautiful and useful plants. The contrast between different shades of burgundy and green defines the beauty of a single leaf. "My favorite time is when I can harvest several things at the same time, late June, first harvest, lettuce, peas, kale, beets, it is exciting. First harvest coming ...The whole harvest season makes me really happy; harvesting in general is my favorite..." (Stephanie, Brentwood Gardener, 2009). Stephanie's primary gardening passion revolved around food 
production but she enjoyed the beauty of the garden, the shapes, textures, and colors of plants.

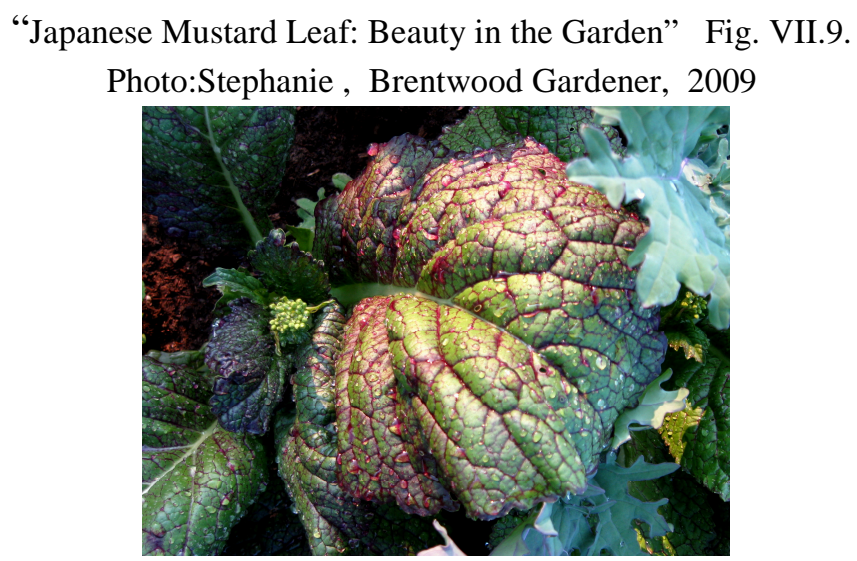

\section{Lifestyle Empowerment Representations}

Four descriptions of "lifestyle" emerged during the interview process: (1) community gardens as an element of the "new domesticity; (2) community gardens as a green oasis in urban area; (3) community gardens as part of fitness and recreation; and (4) community gardens as a status symbol of luxury and healthy life. The lifestyle -influenced empowerment could be any combination of the four experiences, which varied across the gardens and among the members of the same garden.

The four pictures below represent the four-lifestyle empowerment themes that emerged during the interview phase of the study. 


\subsection{Practicing Green Domesticity in Community Gardens}

Figure VII. 10 is an example of the "green domesticity" representations. The three white buckets full of summer vegetable depicted a typical harvest of red beets, yellow squashes, green beans, leaks, and green kales." A picture of a typical small harvest from my garden; it is lots of food, really, twice per week. Some of that could be frozen, canned; I eat out of my garden the whole year... I can get kale in February, from my winter crop..." (Mike, Johns Gardener, 2009). "I like to harvest and I like to eat it right on the spot..."

"My rotation is almost per square inch, I like new vegetables, and there are so many new varieties..." Mike's garden is known for its crop diversity and the extraordinary number of plants he cultivates in the garden. "Raspberries, black cups, boysenberries, blueberries, lots of intense planning to squeeze it in, the diversity, the bounty of the garden. It takes a high level of rotation and careful and intense planning... winter squash blooming, green beans, red peppers, green peppers, leaks, for the winter, layers, to keep it going the whole year...parsnip, tomatoes, leeks..." 
"The prolific garden: summer harvest" Fig. VII.10.

Photo: Mike ,Johns Gardener, 2009

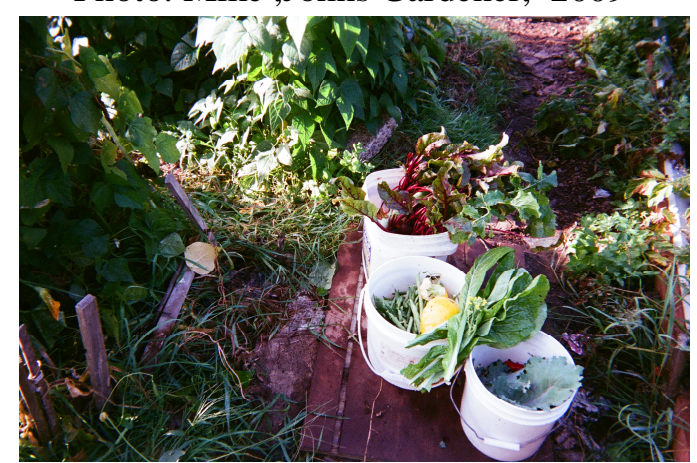

\subsection{Living in Urban Green Oasis}

Figure VII.11 represented the empowerment feeling derived from being able to work in the "green oasis" of the community garden located in the romanticized happy neighborhood. The surrounding houses symbolized the city life: the garden area was a reminiscent of bucolic rural life in the city. In this picture, Mark has tried to capture the slope of the garden, which makes it unique and challenging to design and develop. The surrounding houses appeared to be cheerful and pleasant; they evoked an image of happy people living in a happy place overlooking the garden.

"I like this picture because, it is representative of the houses and the area I always liked. They sit above the road; they look down at the garden. I like the character of the garden that is on the slope... the overall garden. The majority of the gardens are relatively flat; this one is hilly, with the houses above, it is a story you 
can made up of the people who live there, what they see from their windows; it triggers your imagination of happy and cheerful life..." (Mark, Johns Gardener, 2009).

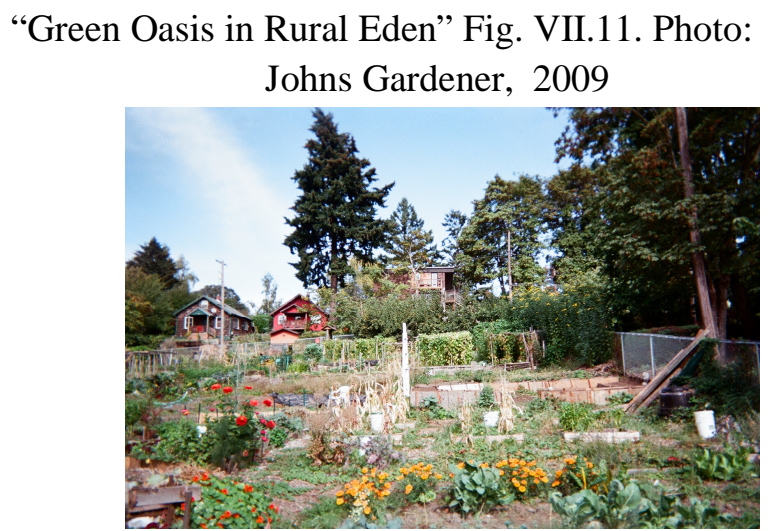

\subsection{Recreation and Fitness in Community Gardens}

"My most important thing is the feeling that the garden is the family place. It is not about the specific place. It is about the feeling; it cements the family feeling..." (Florence, Fulton Gardener, 2009). The place of beauty in the garden is about transforming a small portion of the community garden area into the extension of her backyard. Florence and her husband moved to Portland six years ago to be closer to their daughter and grandchildren. They live in a condominium in downtown Portland.

The transformation of the community garden plot was about having a place for her family where her husband was comfortable and she can spend time with her grandchildren. The flowers symbolized the safe and relaxing place, the 
extension of the home yard. "It is vibrant, warm and energetic, the energy, the way you use the place, people come by and ask why did you do that? " (Florence, Fulton Gardener, 2009).

"The Place of Beauty: Family Space in the Community Garden"

Fig. VII.12. Photo: Florence, Fulton Gardener, 2009

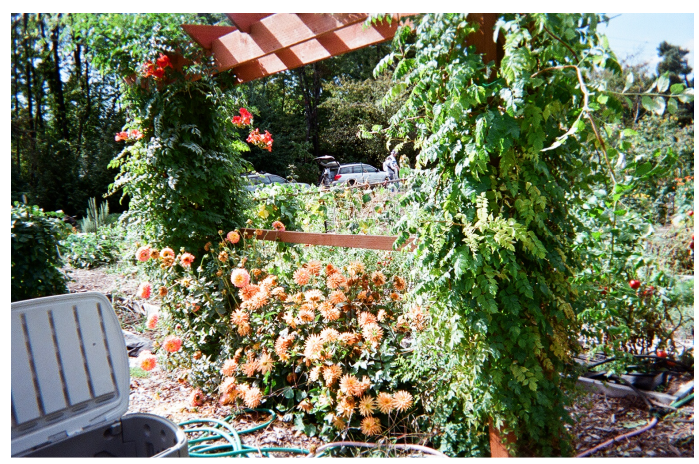

\subsection{Luxurious Lifestyle}

Figure VII.13 contains a picture of a lush raspberry bush with gold ripe berries.

Gracie took a cutting of a discarded raspberry plant from a compost pile and planted it on her plot several years ago. She could not afford to buy plants from a nursery. "A lot of my thinking is about my personal economy. I could not afford to go to a nursery to buy raspberry plants and here they were in the compost..." (Gracie, Brentwood Gardener, 2009).

The freshly picked raspberries were a symbol of luxurious food. "This type of raspberries, the golden ones you cannot transport, they would fall apart, and they became my treat. They produce fruit twice per year; it is like a celebration, I just shove them in my mouth and go to work, or if I get thirsty, I 
can also have them. It is a special treat otherwise I would not have it..." (Gracie, Brentwood Gardener, 2009).

"Raspberries: Luxurious Food and Celebration of Healthy Lifestyle"

Fig. VII.13. Photo: Gracie, Brentwood Gardener, 2009

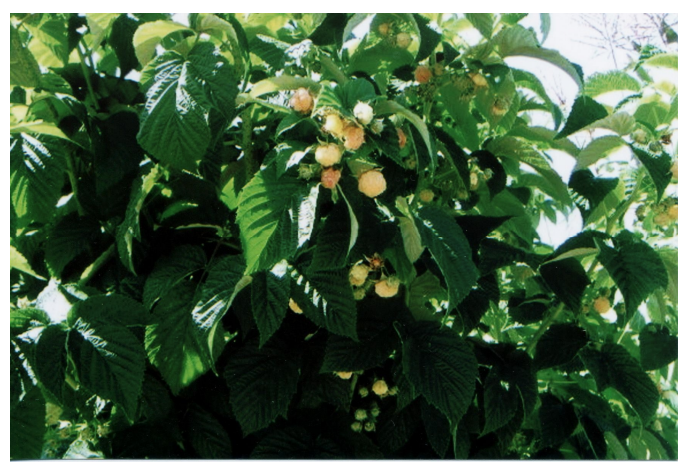

6. Sanctuary Empowerment Representations

Community gardeners considered the gardens as "sacred places" for three reasons: (1) it is a place to feel spirit and flow of energy in nature; (2) it is a place to reconnect with their past; and (3) it is a place to experience general well being.. The pictures below represent the three sanctuary empowerment themes that emerged during the interview phase of the study.

\subsection{Connecting with Spirit of Nature}

A brilliant red system of tiny leaf veins, a hole in the leaf with the shining dot of blue sky symbolized a universal pattern of life in nature (Figure VII.14). It represented the illusive balance between perfection and imperfection and the 
energy flow and glow in nature. The red veins symbolized the flow of energy, the blue hole was a symbol of imperfection and vitality in life; it channeled a steam of light for other plants. An "imperfect" leaf with a hole stimulated the plants beneath that were dependent of the stream of light for their growth. Thus, the imperfection in the leaf was the source of growth for other plants and the energy flow. The Spirit of Nature, the unveiled presence of energy was symbolized by the illusiveness of concepts of perfection and beauty in nature.

"Being close to the soil, where the air meets the earth, the border, the boundary... The ground, it does not matter where...everywhere in the garden. I come to the garden to reconnect with earth...to feel the unveiled presence, the energy, the spirit of place... You cannot quite capture the illusive element of natural world, you can feel but you cannot see the details you cannot really harness feeling the presence not feel the shape, it is indefinable form it is the spirit of things, life's creative force, it is veiled..." (Lisa, Brentwood Gardener, 2009).

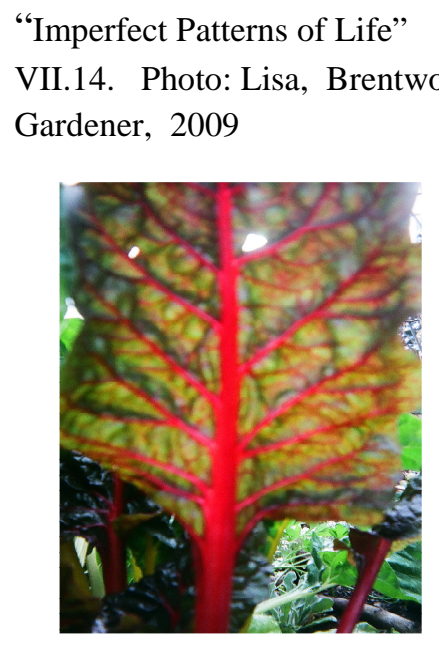




\subsection{Connecting with the Past}

Florence referred to the line from Robert Frost's poem to illustrate her nostalgic feelings about changes in her life (Figure VII.15). "It is fall: the color, the shadows, and the nut trees. I am from New England where it gets red, the shadows, the sky, it is fall in the garden, it is time to harvest, it is country, a touch warm, sun is out, it sun warm, trees are turning red, a nip of frost; just like in Robert Frost' poem..." It reminds Florence about her childhood in New England, coming back home from a boarding school in New York. The country road took her home, to her parents' house. "It is fall in the garden, it is time to harvest, and it is country, a touch warm..." (Florence, Fulton Gardener, 2009).

The picture of the road connecting the Fulton Community Center parking area with the gravel road to the community garden suggested a tranquil and bucolic country setting despite the constant, roaring sound of the nearby freeway. "It is safe on the road, the country is quiet. Looking at the picture one tries to forget the roaring noise of the freeway, we are on the freeway here..."

The country road reflected the connection between the Florence's past and the present life. Getting closer to the garden meant getting closer to her new home. The plot in the community garden became Florence's new concept of her home in Oregon. The road symbolized this transition from her New England roots to her new place in Portland. 
"The Road to the Garden and Childhood Memories: O hushed October morning mild, Thy leaves have ripened to the fall"

Fig. VII.15. Photo: Florence, Fulton Gardener, 2009

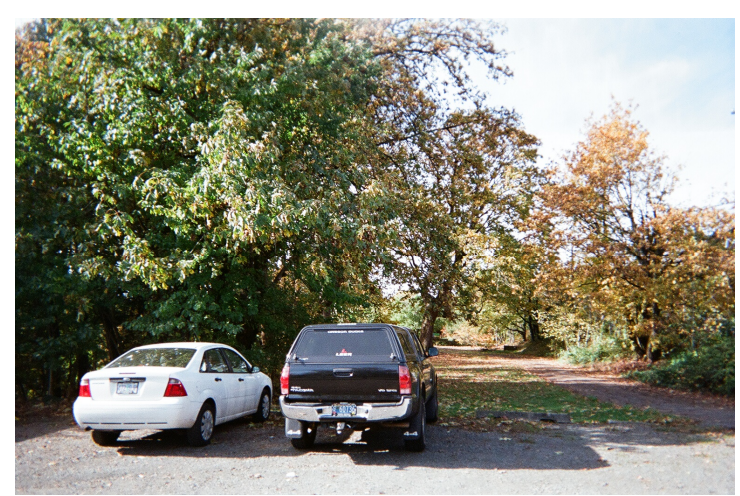

\subsection{Restorative Garden}

The people Gracie met at the garden were her inspiration and source of enjoyment (Figure VII.16). "We laugh together, we work together, and we care about each other. Stephanie is like a daughter she never had. Donna taught me everything I know about gardening...For the first time in my life, here, in the garden I felt loved and respected...first time ever in my life..." (Gracie, Brentwood Gardener, 2009).

Gracie met many people who inspired her and helped her start the garden. The garden became a reminder that she could change her life and accomplish anything she wants to do. Gracie's plot in the community garden marked the happy place where she grew herself and met people who became her friends. 
"I got to see different types of people, I had been treated abusively before and I could experience people in a whole new way.... I did not realize the power of the community garden. It is a community; it is the feeling of being loved by other people..." (Gracie, Brentwood Gardner, 2009).

\footnotetext{
"Working Together in the Community Garden: Growing Friendships" Fig. VII.16. Photo: Gracie,
} Brentwood Gardener, 2009

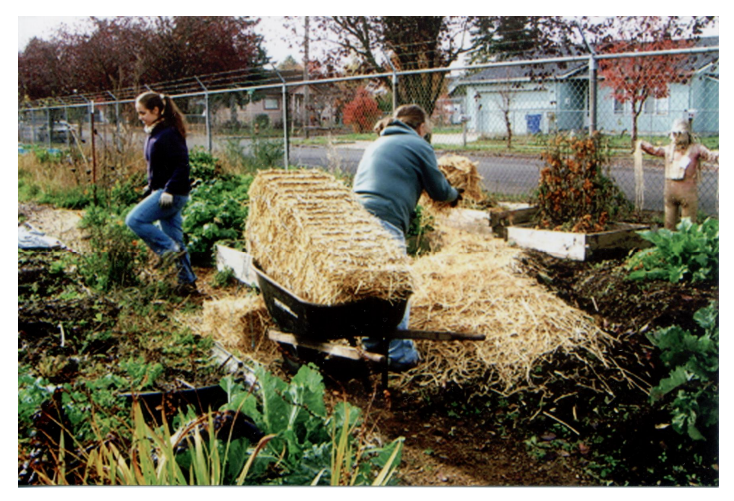

\section{Learning Empowerment Representations}

The analysis of the interview data suggested that community gardeners experienced empowerment related to learning at three levels:( 1) increasing knowledge of garden cultivation techniques; (2) relating human experience to the natural garden cycle; and (3) acquiring or improving professional skills. Improving garden cultivation techniques could be the result of either reflection on one's own practice or interacting with other gardeners. Occasionally, gardeners also observed garden demonstration projects installed by the city on the garden grounds in order to increase their knowledge. 
The gardeners used twenty-two (12\%) representations to symbolize empowerment feelings related to learning achieved in the community gardens. Most of the images reflected the garden areas or individual plots that symbolized the accomplishments of learning either from observing nature or improving gardening techniques. The two pictures below represent empowerment related to increasing knowledge of gardening techniques and relating human experience to the natural cycle of renewal.

\subsection{Increasing Knowledge of Gardening Techniques}

Figure VII.17 is "the end of the season picture." It symbolizes survival in the garden and in life. After several difficult months, Dan was able to spend more time in the garden and experience his first garden harvest. The picture represented achievement, endurance, and survival. The picture was taken at the end of September when Dan felt that, after all, his garden survived and he was even able to harvest tomatoes.'This is my first year ever, I did not have any expectation to have a crop, vegetables to eat, and it was to learn ... I was doing too much this summer, I had to find a balance to do better..." Dan's story was about his first year experience in the community garden. "It was hard work. In my mind, I had this utopia of a bountiful garden...tomatoes and zucchinis..." It was also the first time in his life Dan embarked on a serious and independent gardening effort on his own piece of land. Dan's story and pictures centered on his plot and the efforts 
it took to maintain the garden. This was a success story of a first year gardener who overcame his initial garden panic and was able to experience a sense of satisfaction and accomplishment at the end of his first gardening season. It was about panic, perseverance and the joy of accomplishment. "I was doing too much this summer; I had to find a balance to do better..."

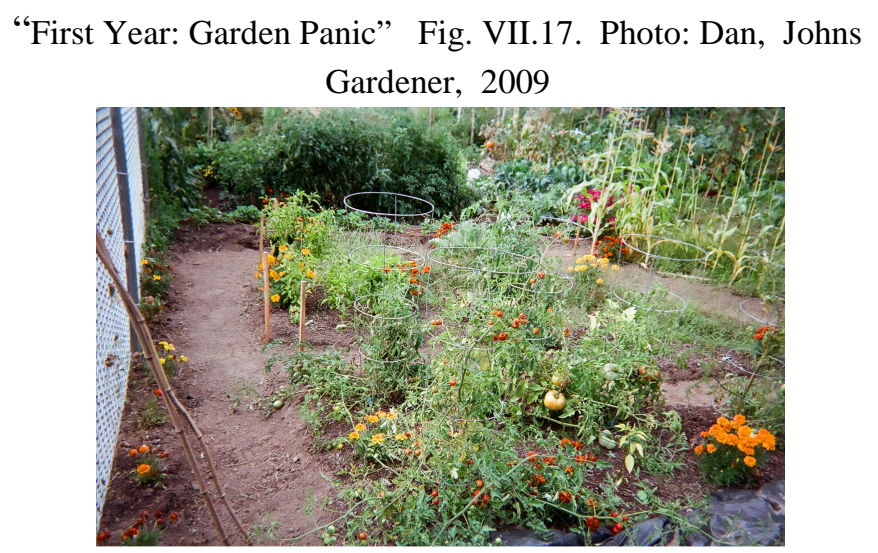

7.2.Relating Human Experience to the Natural Cycle of Garden

The picture (Figure VII.18) captured an emerging mustard plant, a garden delight, an unexpected pleasure of welcoming a plant that was not planted by Bill. "This plant is a volunteer, one of my favorite things, the plant comes out and it grows..." (Bill, Brentwood Gardener, 2009). Bill's primary interest in gardening is to convert land into productive use - to control it to grow crops.

To Bill, this picture represented the pleasure of spontaneity in life. Bill did not plant the "volunteer" mustard plant. The emerging young plant reminded Bill 
about the limited extent of control a person can impose on nature and life. Bill's objective of converting land through controlling the area of cultivation was contrasted with his pleasure of spotting a volunteer plant that he did not plant.

"Accepting the Unexpected: Control and Pleasure in Garden and Life" Fig. VII.18. Phot: Bill, Brentwood Gardener, 2009

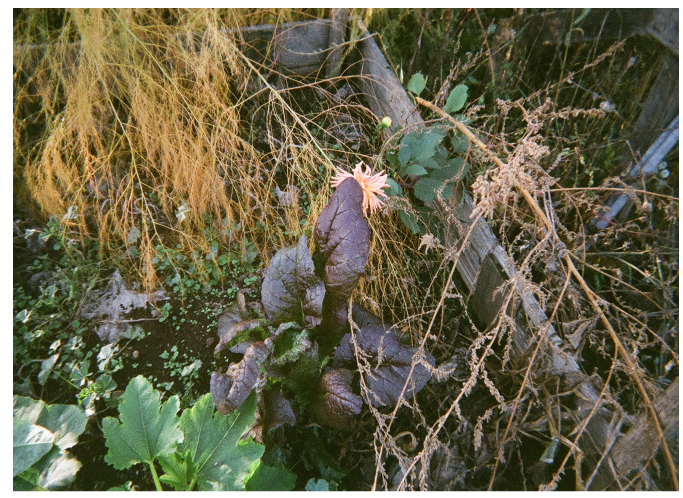

8. Symbolic Representation of Empowerment in Community Garden: Summary of Findings

Figure VII.19 and Figure VII.20 summarize the relationship between the image types and symbolic representations of empowerment goals. 
Figure VII. 19. Symbolic Representations of Empowerment Goals

by Number of Image Types

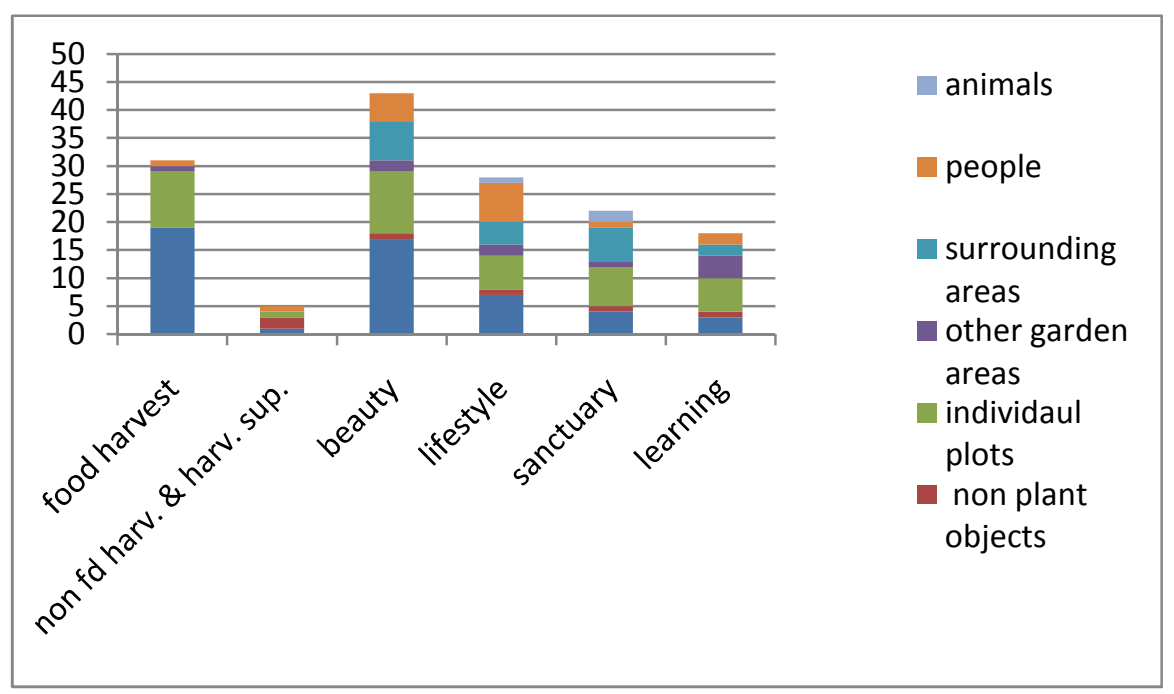

Figure VII. 20. Distribution of Image Types by Empowerment Goals

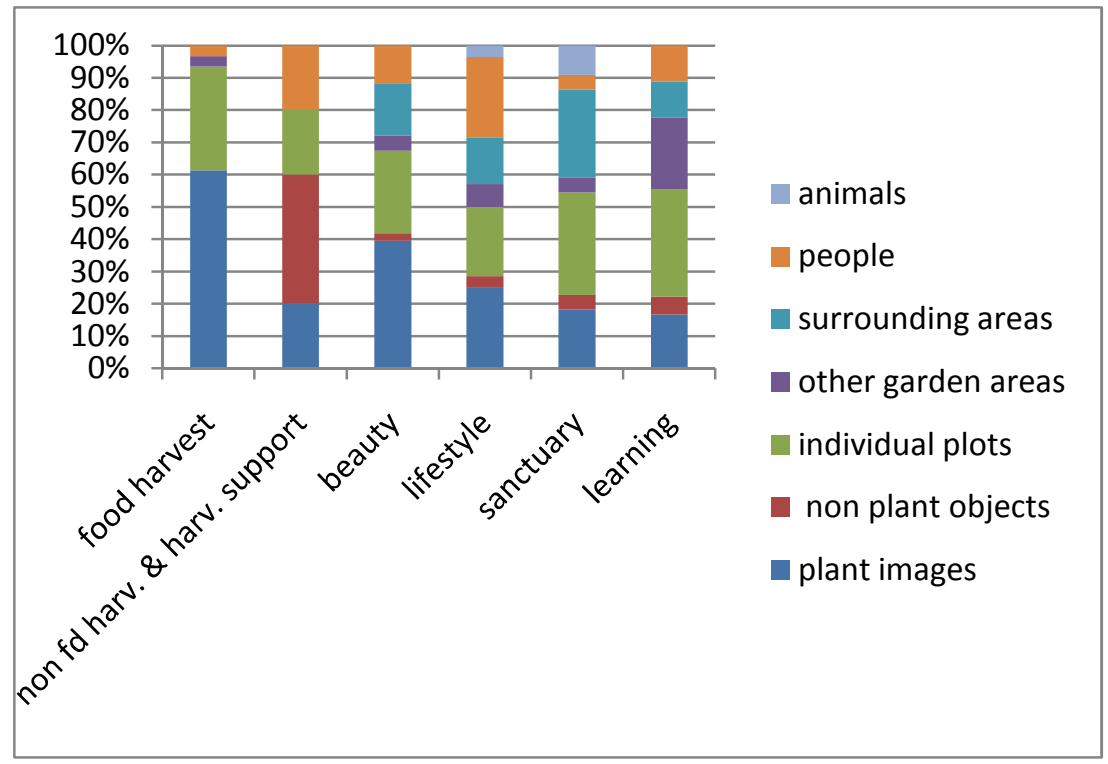

The analysis of representations feeling of empowerment suggested that harvest empowerment images were typically associated with individual plots and plants that symbolized the empowerment achieved by controlling the source of food. The 
harvest goals, primarily associated with the ability to control and grow healthy food for human consumption, were mostly associated with images of plants and objects and individual plots cultivated by gardeners.

The non-harvest representations were more diversified and contained more images of surrounding areas, other parts of the garden, and images of people.

The beauty empowerment representations were the most prominent imagery. Although images of individual plots were typically associated with converting one's plot into an object of art and beauty (which was the most commonly shared beauty narrative), the areas surrounding the garden provided important images to symbolize the context for shaping one's own beautiful plot.

The lifestyle empowerment representations, in addition to the images of surrounding areas and other parts of the garden were likely to contain pictures of people. The presence of people symbolized the social aspect of the garden as a place to meet people, to take friends and family, and, in general, to recreate with other people.

The sanctuary images were dominated by representations of the surrounding areas. The gravel road to the garden was the most frequently used symbol of sanctuary. It represented the everyday journey and meditation and the transition in time and space. The walk to the garden, the everyday journey, inspired people to reflect 
about life. The beautiful scenery of the bridge evoked appreciation for natural beauty.

The images of learning empowerment tended to reflect individual plots or other parts of the area, including other gardeners' plots and communal areas of the garden, mostly demonstration projects installed by the city. The images of learning contained individual plots or the plots of other gardeners. As discussed in Chapter VI, the dominant empowerment feeling through learning was experienced by improving gardening techniques by reflecting on one's own practice, interacting with other people, or observing other people's plots and actions in the garden. The learning empowerment representations reflected these feelings.

\section{Empowerment Representations Across Gardens}

As discussed in Chapter VI, the data obtained during the interviews suggested that certain empowerment goals were more commonly experienced by all gardeners regardless of the difference in the physical settings of the community gardens. These common empowerment transcripts were reflected in the shared representations of empowerment feelings, previously described in this chapter. Although this shared empowerment, narrative was held in common by most of the interviewed gardeners, each garden had its own unique narrative that differentiated it from the other two gardens. This section of Chapter VII explores 
how and whether the differences in garden specific empowerment narratives influenced formation of empowerment images.

1. Fulton: "The Beautiful Lifestyle” Imagery

Figure VII.21 and Figure VII.22 provide a summary of the relationships between image types and symbolic representations of empowerment feelings at Fulton. Appendices A.1-A.12 contain a complete set of Fulton imagery.

Figure VII.21. Fulton Representation of Empowerment Goals by Number of Image Type

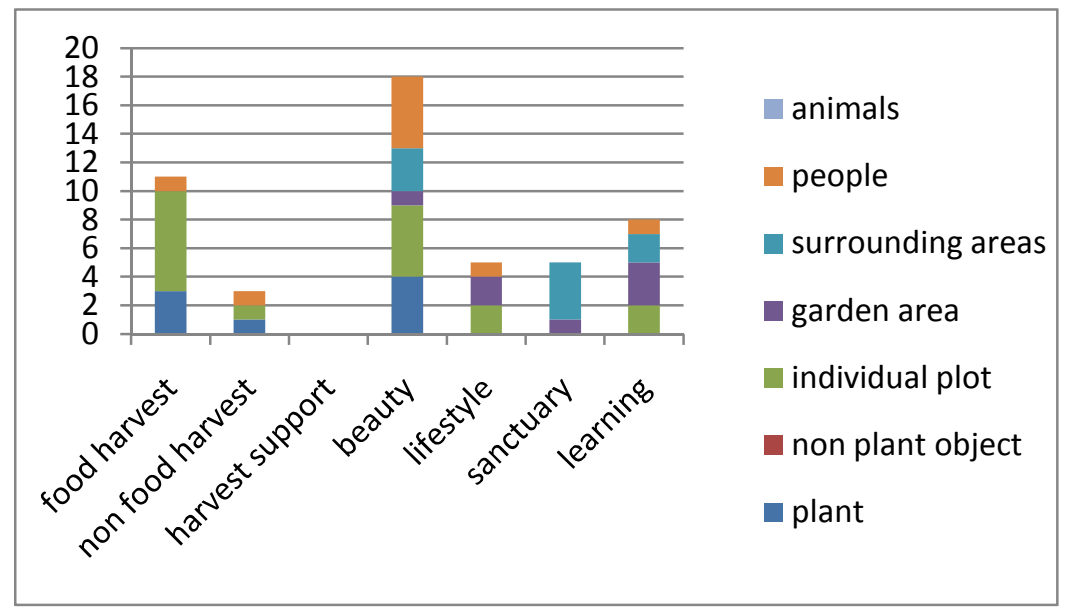


Figure VII.22. Fulton Distribution of Image Types

by Empowerment Goals

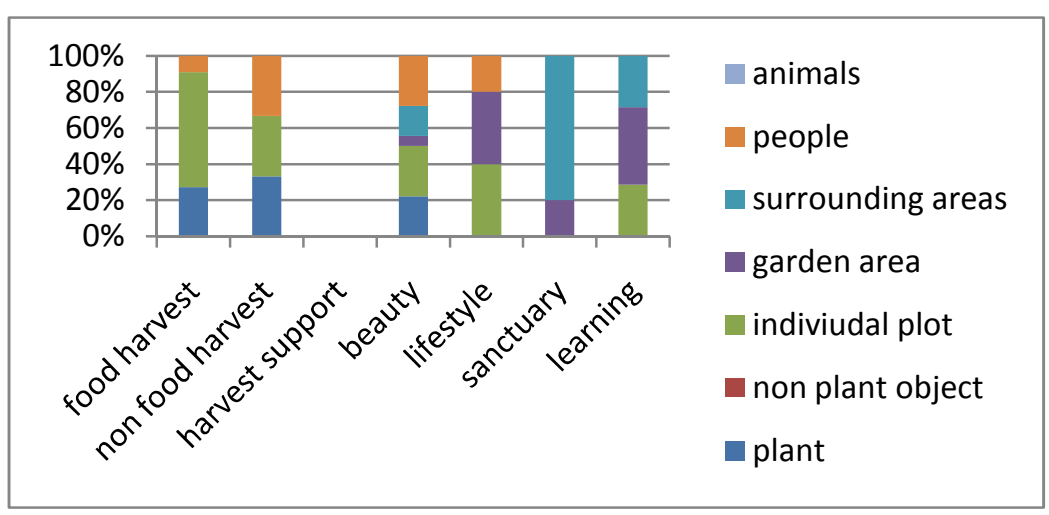

The representations of empowerment were dominated by beauty, symbolized by a relatively wide range of images (individual plots, people, surrounding areas, individual plants, and garden areas). The sanctuary empowerment representations were associated with either the surrounding area images or the entire garden area, without any focus on one's own plot. Individual plots, garden area, and people images were used to symbolize lifestyle empowerment. Learning representations were associated mainly with one's own plot, other parts of the garden, and the areas surrounding the garden.

The imagery of empowerment was dominated by the pictures of the overall views of the garden area, with less focus on individual plots. The images of plants and people were the second dominant group of representations. Both individual plots and surrounding areas were less dominant than images of people. 
2. Brentwood: "The Garden is Everything " Imagery

Figure VII.23 and Figure VII.24 provide a summary of the relationships between image types and symbolic representations of empowerment feelings at

Brentwood. Appendices A.13-A.22 contain a complete set of Brentwood imagery.

Figure VII.23. Brentwood Representation of Empowerment Goals

by Number of Image Types

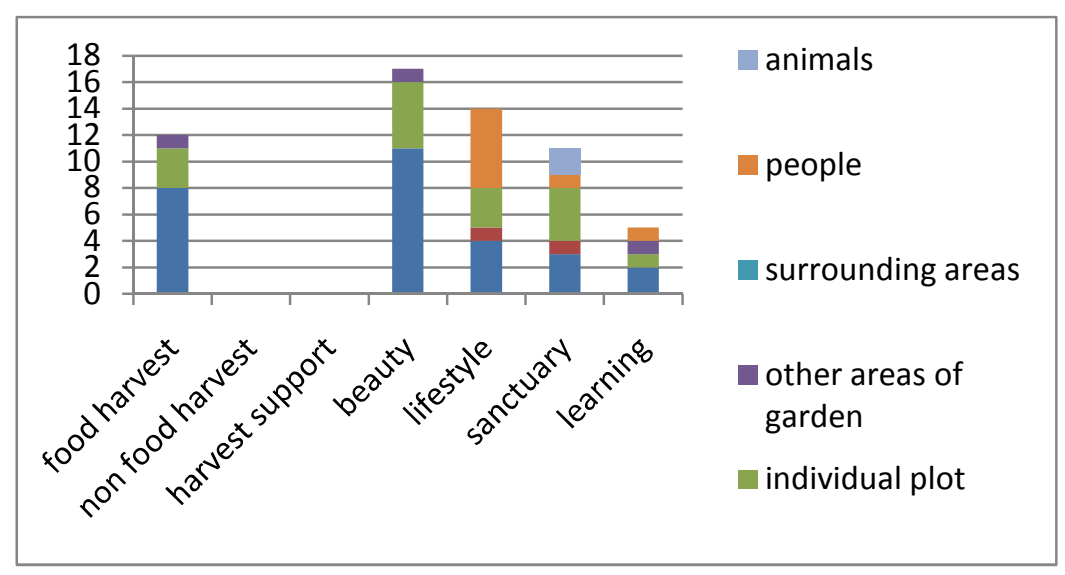

Figure VII.24. Brentwood Distribution of Image Types by Empowerment Goals

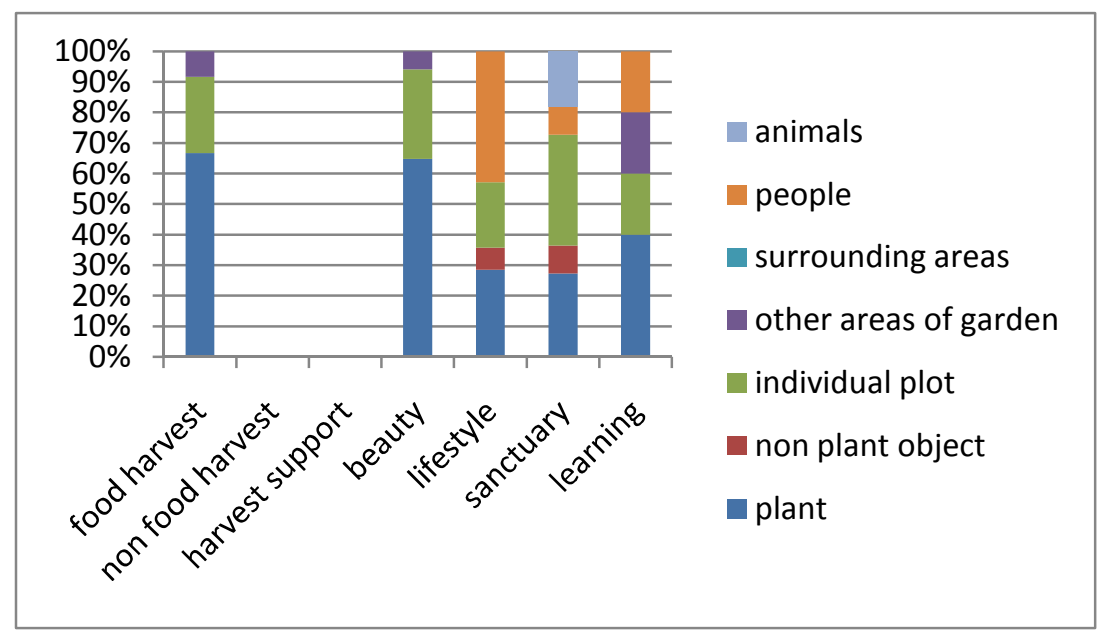


The beauty representations dominated the imagery of the garden empowerment representations. The lifestyle representations were the second, most important group, and exceeded the number of representations related to food harvest (Figure VII.23 and Figure VII.24).

Learning empowerment representations made up the most diversified segment of representations. They contained images of people, individual plots, and other parts of the garden. Sanctuary empowerment was mostly symbolized by own plots. The imagery of the landscape of empowerment, with the exception of the lifestyle related empowerment, was dominated by the closeness to own individual plots and plants. Two animal images symbolized sanctuary related empowerment and the unity of all living animals in one space. People images were important in symbolizing mostly lifestyle related empowerment.

3. Johns: "The Community of Beauty and Food" Imagery

Figure VII.25 and Figure VII.26 provide a summary of the relationships between image types and symbolic representations of empowerment feelings at Johns. Appendices A.23-A.30 contain a complete set of Brentwood imagery.

In contrast to both Fulton and Brentwood, Johns gardeners did not use images of individual plots and garden areas to symbolize the lifestyle related empowerment. Lifestyle related empowerment was symbolized mostly by 
surrounding areas and plants. The image of their own, individual plots dominated the learning representations. The imagery of Johns garden empowerment representations revolved around plants, own plots, and surrounding areas. The image of the overall garden space was used only once and the images of people were not relevant in forming empowerment representations by Johns gardeners who participated in the study.

Figure VII. 25. Johns Representation of Empowerment Goals by Number of Image Types

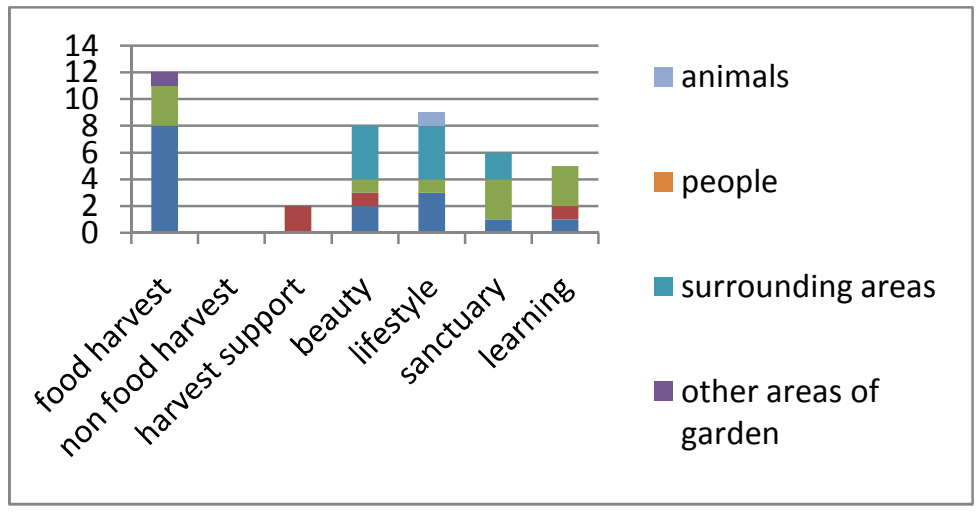

Figure VII. 26. Johns Distribution of Image Types by Empowerment Goals

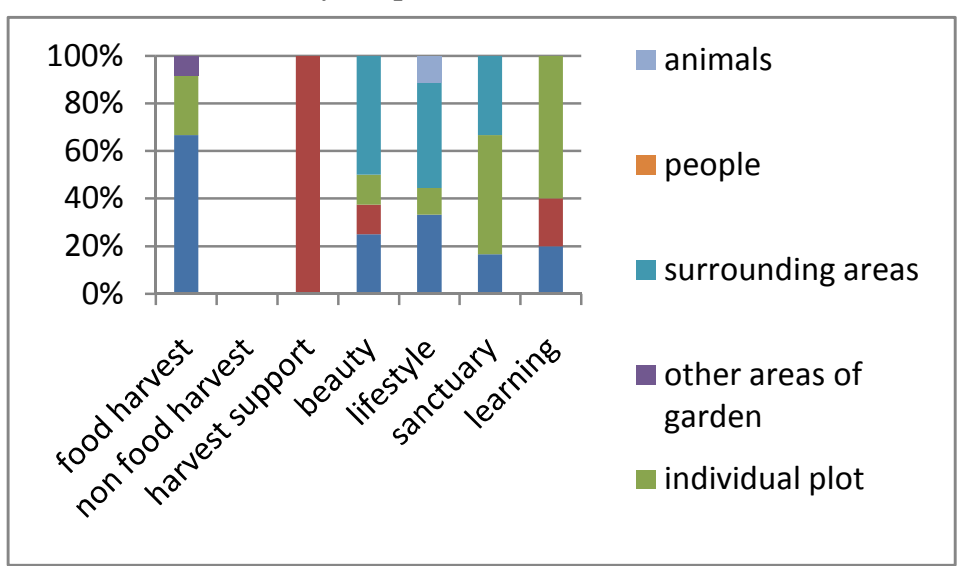


4. Empowerment Representations Across Gardens: Summary of Findings

Figure VII.27. Dominant Image Types across Gardens

dominant image type

\begin{tabular}{|l|l|l|l|l|l|}
\hline \multirow{2}{*}{ Garden } & \multicolumn{5}{|c|}{ DOMINANT IMAGES } \\
\cline { 2 - 6 } & Plant & $\begin{array}{l}\text { Individual } \\
\text { Plot }\end{array}$ & $\begin{array}{l}\text { Garden } \\
\text { Area }\end{array}$ & $\begin{array}{l}\text { Sur. } \\
\text { Areas }\end{array}$ & People \\
\hline Fulton & & & & & \\
\hline Brentwood & & & & & \\
\hline Johns & & & & & \\
\hline
\end{tabular}

The study proposes that the main differences in empowerment imagery across the gardens were related to the use of individual plots, surrounding areas, and people in creating the empowerment representations in the gardens. Figure VII.27 summarizes the imagery of landscapes of empowerment across the gardens. It takes into account these three most dominant images in each garden.

The imagery the Fulton landscapes of empowerment representations revolved around the entire garden area, with no major focus on individual plots or surrounding areas. Individual plot images and the images of the entire garden area dominated the Brentwood representations of empowerment. Johns landscapes of empowerment reflected mostly the surrounding areas and the entire garden area, with less focus on individual plots. Images of people were relevant in forming the basis for Fulton and Brentwood landscapes of empowerment imagery, but were not relevant in Johns imagery of empowerment. 
D. Empowerment and Image in Community Gardens: Summary of Findings

1. Influence of Space Transformation on Empowerment Imagery

The types of images contained in the one hundred most important pictures reflected the space transformation and space connection pattern discussed in Chapter IV (i.e., "the practice of everyday life" in community gardening in the context of the Natural Realm). First, the community garden imagery deemphasized the human-centric view of nature. Second, the non-people images, (i.e., the images of objects, garden space and surrounding areas) reflected two important aspects of the community garden space appropriations: (1) plot and plant transformation; and (2) the influence of surrounding areas on forming spatial images of community gardens.

\subsection{Plot and Plant Transformation}

Most important, community garden connections and activities revolved around conversions of individual plots. The plant-to-plot space appropriation reflected the main purpose of gardening, which was food production. Pictures of plants and garden plots dominated the community gardens imagery and confirmed the importance of this most important type of space transformation in community gardening. The ability to cultivate land with one's own hands was the ultimate expression of control over the source of food. This importance was represented in the images showing the hands of gardeners touching and holding the harvest 
and marking boundaries of their own plots. Images of people made up a relatively small segment of the community garden imagery - only thirteen of the one hundred most important pictures contained images of people. The relatively low number of people images was consistent with the general perception that people-to-people connections were believed to be less important in the Natural Realm.

\subsection{Influence of Surrounding Areas}

Although only $13 \%$ of the most important pictures contained images of surrounding areas, these played an important role in influencing symbolic representations of non-harvest empowerment goals and confirmed the importance of physical characteristics of the surrounding areas on sense of place in the community garden travel story, discussed in Chapter IV.

The gravel road to the garden was the most frequently used symbol of sanctuary. It represented the everyday journey and meditation. The walk to the garden on the gravel path inspired people to reflect and meditate. The beautiful scenery of the bridge evoked a feeling of awe and appreciation for natural beauty among Johns gardeners. The sky over the garden and the view of Mount Hood were important to Fulton gardeners in their spiritual every day journey to the garden. Fulton gardeners focused on the amenities and features surrounding the garden that provided an impression of the rural and bucolic area in the city to combat the roaring noise of the nearby freeway traffic. Despite being just steps away from 
the freeway, the images of the gravel road and the native plant trail amid lush greenery suggested the importance of the surrounding areas in experiencing and developing connections to the space.

The areas surrounding the garden also provided an important context for shaping beautiful plots. The views of surrounding areas functioned as the canvas and the context for one's own creations of beauty. The road to the garden, the view of the surrounding areas, was the most typical example of the context for the beautiful individual plots in the community garden. The gravel road symbolized the rural, simple, and bucolic life - a wholesome life closer to earth at Fulton and Johns.

The lifestyle empowerment representations were also likely to incorporate images of the surrounding areas. The village-like feel, the sky, the river, and the gravel streets were integral parts of the lifestyle empowerment imagery. This symbolized the illusion of small town ambiance; the simple but enriching pleasures of everyday life at Johns.

Most Brentwood gardeners did not incorporate the images of the surrounding areas into their symbolic representations of empowerment. The ambience of the cell tower looming over the southern boundary of the garden and the barren land to the east did not form the basis for sublime space images and symbolic representations for Brentwood gardeners. 
The analysis of the pictures provided evidence that the most important images reflect three key aspects of space transformation in the Natural Realm. First, a relatively low number of images of people reflected the prevailing belief that people-to-people connections tend to be less relevant in the sense of place in community garden. Second, the images of individual plots and plants were the most dominant group of images and underscored the importance of the individual plot in community gardening. Third, the difference in the images of the surrounding areas reflected the differences in space connections across the gardens that influenced their sense of place.

\section{Visual Images and Diversity of Empowerment}

The study suggests that certain images representing empowerment goals were more commonly shared by all gardeners regardless of the differences in the physical settings of the community gardens. Symbolic representation of harvest goals tend to be similar in all gardens and reflect the plant- to-plot transformation. The symbolic representations of non -harvest goals tend to be more diversified and, typically, incorporate images of surrounding areas and people.

Figure VII.28 summarizes differences across the gardens in regard to the presence of people and surrounding area images in forming symbolic representations of empowerment. 
Table VII.28. People and Surrounding Area Images in Empowerment Representations presence of image

\begin{tabular}{|l|l|l|}
\hline Garden & $\begin{array}{l}\text { People } \\
\text { Images }\end{array}$ & $\begin{array}{l}\text { Surrounding } \\
\text { Area Images }\end{array}$ \\
\hline Fulton & & \\
\hline Brentwood & & \\
\hline Johns & & \\
\hline
\end{tabular}

The analysis contained in this chapter suggests the use of images of people and surrounding areas in representing empowerment differentiates the empowerment imagery in the gardens. The analysis of the one hundred pictures suggests that visual images reflect the contextual diversity in space transformation phases and their influence on the image of empowerment through community gardening.

The differences in symbolic imagery of empowerment goals across the three gardens is associated mostly with the influence of surrounding area images and people images that were used by the gardeners to symbolize the non-harvest empowerment goals.

3. Importance of Photo Storytelling Method in Analyzing Sense of Place and Empowerment

The photo storytelling method provided rich data to several key aspects of the research by providing additional evidence and insights on the relationship between sense of place and empowerment in community gardens. 


\subsection{Sense of Place and Natural Realm}

It provided additional evidence on the importance of the Natural Realm connections in the practice of everyday life in community garden. The garden sense of place imagery reflected the prevailing view of community gardeners that people-to-people connections were considered less important and activities related to one's own plot dominate the sense of place connections in community gardening.

\subsection{Sense of Place and Contextual Empowerment}

It provided additional evidence that physical characteristics of the surrounding areas and the type of social realm shape the garden specific differences in sense of place and influence empowerment. The differences in symbolic imagery of empowerment goals across the three gardens was associated mostly with the influence of surrounding area images. People images that were used by the gardeners to symbolize the non-harvest empowerment goals.

\subsection{Landscapes of Beauty in Community Garden}

The photo storytelling method revealed that in community gardening, the expression and representation of beauty was the most important element in the community garden shared narrative with regard to the number of representations, the diversity of beauty related empowerment feelings, and the range of their representations. The representations of empowerment achieved by experiencing 
beauty in community gardens were the most frequently represented feelings. The gardeners used a relatively wide range of images as symbolic representations of beauty empowerment: plants, objects, individual plots, surrounding areas, people in the gardens, and garden areas other than individual plots. 


\section{CONCLUSION: EXPLORING SENSE OF PLACE OF PORTLAND COMMUNITY GARDENS}

The main purpose of this study is to link the concept of sense of place with community development by examining the role of community gardens as public spaces at the beginning of the third millennium.

The study focuses on three aspects of sense of place that are important to community development: (1) the influence of time dimension on forming physical and social connections to community gardens - whether physical connections to spaces play an important role in constructing sense of place in the short term, but are less important in the long term; (2) the influence of social and physical connections on experiencing empowerment in community garden settings - whether and how space connections influence the feeling of empowerment and whether individual empowerment is achieved through individual or group action; and (3) the representation of empowerment images held in common by community gardeners - whether and how garden empowerment is represented in visual images held by community gardeners.

The narrative storytelling methodology that was used in my research enabled gardeners to express in their own terms their connections to space and their experiences of empowerment achieved through community gardening. The temporal and thematic aspects of the narratives captured the impact of time dimension on forming social and physical connections to the garden with the 
contextual aspect of empowerment. The photo images provided an additional understanding of the empowering impact of community gardens in the context of storytelling.

\section{A. The Concept of Natural Realm}

The study introduces a new concept of the Natural Realm that forms the context to experience both time dimension and empowerment in community gardening. The Natural Realm deemphasizes the human-centric view of nature and recognizes that humans are part of animal-plant-land connections (Chapter IV). The awareness of accumulated positive energy in the Natural Realm provides a tacit understanding of the spiritual ties binding the people, plants and animals sharing one garden space.

In the Natural Realm, gardeners do not engage with the community garden spaces in terms of "social" and "physical" connections but define their connections through the people-plant-animal-land web. The "social" aspect of gardening, although acknowledged as important by many gardeners, is not considered as their primary connection.

\section{B. Time Dimension and Space Connection in Community Gardens}

My hypothesis was that the physical dimensions of gardens would play an important role in constructing sense of place in the short term, but would be less important in the long term. 
This study finds that physical characteristics are considered to be more important in constructing sense of place, regardless the length of membership in the community garden. In community gardens, the cyclical concept of time and the non-people space connections reflect the influence of the Natural Realm connections and seasonal renewal in nature.

The study proposes that the time dimension, measured in chronological years, is not relevant in influencing the connections to community gardens. The community garden narratives are built around the Natural Realm, where the story's plot is cyclical, not chronological.

In the community garden narrative, the cyclical concept of time constitutes the primary time dimension. Gardeners relate their memories and expectation to this circular time dimension. The concept of "present time" is associated with the natural cycle and renewal. Spatial memories and expectations are materialized through cyclical land cultivation. The "past" embodies efforts to commemorate ones past life experiences. Individual plots are reservoirs of past memories. The "future" is about expectations and goals related to gardening. The primary goals of most gardeners relate to food production, food security, and food quality. Once the primary gardening goals are satisfied, gardeners appreciate other benefits of community gardening, not directly related to food harvest. 


\section{Experiencing Empowerment in Community Gardens in Portland}

My hypothesis was that, given the entire spectrum of "empowerments" suggested by Rocha's ladder, community gardeners in Portland experience multiple forms of empowerment; mostly at the embedded individual and/or mediated empowerment levels.

\section{Community Garden Empowerment Shared Narrative}

My study finds that the gardeners who participate in the City of Portland Community Garden Program experience multiple empowerment goals by perceiving community gardens as sacred places where people feel well because they can grow healthy food, practice "green domesticity," and learn gardening from nature in a beautiful setting.

\section{Empowerment and Physical Space Connections}

The study suggests that the key differences in experiencing empowerment across the gardens are related to the influence of the surrounding areas on the diversity of empowerment themes in each garden, mostly in experiencing beauty, lifestyle, and sanctuary. 


\section{Individual Empowerment in Community Gardening}

The study finds that community gardeners experience individual empowerment at three levels: (1) atomistic; (2) embedded; and (3) mediated.

Atomistic empowerment. Within the context of the Portland Community Garden Program, gardeners tend to be individualistic. The direct use of city land by community gardeners is a form of consumption of the community garden resources, which reflects an atomistic empowerment experience.

Embedded empowerment. Within the context of the Portland Community Gardens, the gardeners tend to "maneuver" through the community garden settings and rules to "increase personal efficacy and satisfaction" in accomplishing their own goals by optimizing their physical and social connections.

Mediated empowerment. In the case of Portland Community Gardens Program, individual gardeners are required to pay a fee to use a garden plot and do not see themselves as members of a self-governing group that benefits from an expert agency. Rather they see the agency as the provider of a service to enhance their own individual goals. In that context, the gardeners tend to use the agency "expertise" to enhance pleasurable activities or eliminate annoyance in fulfilling their empowerment goals. 


\section{Community Gardening as a Reflection of Consumerism}

Zukin (2004) argues that consumers often define themselves in the context of the places they get products and their consumerism defines the "sense of community" and "sense of place." Harvey (1989) hopes that the crisis of identity where locality becomes a commodity will lead to radical and political change and a new social system. My study suggests that although the community garden space connections draw attention to the importance of local food consumption and control of local resources, there is no indication that community gardening in Portland is a manifestation of a new social system. Community gardens managed by the City of Portland may be seen as the manifestation of consumerism rather than a step towards a change in the sociopolitical system. My study shows that in the context of the Portland Community Garden Program, community gardeners behave as consumers of the products and services provided by the city to maximize their pleasurable activities. Thus, their "community garden sense of place" resonates with Zukin's concept of commodified sense of place, where consumers define themselves in the context of the place of consumption. i.e., a "community garden" is a "community of urban garden plot consumers." 


\section{Image of Community Garden Empowerment}

The photo storytelling methodology that was used in my study enriched the understanding of the influence of space connection on spatial images and gave further insights into sense of place of community gardens.

First, the community garden imagery deemphasizes the human-centric view of nature. Second, the non-people images are representative of two key aspects of the community garden space appropriations: (1) importance of an individual plot; and (2) influence of surrounding areas on forming spatial images of community gardens.

The expression and representation of beauty is the most important element in the community garden shared narrative with regard to the number of representations, the diversity of beauty related empowerment feelings, and the range of their representations.

E. Imagining Future of Community Gardening in Portland

This study suggests that people feel empowered through the practice of everyday life in the community gardens. More specifically, they find relaxation and solitude, satisfy their need for locally grown food, and learn from nature in an urban setting. This diversity of views and needs led to conflicts that are 
symptomatic of the broader concern of how to merge agriculture, community greening and recreation into community gardening.

Research on urban gardens typically views them as stalwarts of urban agriculture, but the concept of urban agriculture is much broader and includes not only the cultivation of food crops in a non-rural setting, but the processing, marketing, and distributing of food. It may also include producing and selling non-food products (Kaufman and Bailkey, 2000). Community greening is typically associated with recreational and ecological values of parks and green public spaces in urban systems (Pincetl and Gearin, 2005). Traditionally, ecological values of parks, wildlands, and other natural areas were the focus of biodiversity conservation efforts in urban settings, but research that is more recent claims that the successful conservation of the world's biodiversity must include urban and urbanizable areas in addition to natural areas. Scientists and environmentalists begin to recognize that they need to work closely with planners and policy makers to identify ways that urban development can better be incorporated in the maintenance of ecological values (Marzluff and Rodewald, 2008).

Community gardens present a pathway to start celebrating urban biological diversity and foster connections between people and their natural heritage. Gardens can be designed with the goal of attracting aesthetically pleasing wildlife and pollinators, like birds and butterflies, but other important garden visitors, like bees, can be drawn to specially planned and modified gardens. 
This study reveals that the appreciation of the Natural Realm as life's guiding force was one of the most empowering aspects of community gardening for the gardeners who participated in my research. Although the study involved only thirty partipants, their range of empowerment goals highlighted a broader need to evaluate community gardens as public spaces in the context of the Natural Realm and biodiversity in Portland.

Imagining the future for community gardens must reflect the biodiversity and the multiple views on the role of urban gardens in the city. Recently, Portland has experienced a growing number of grassroots groups that reflect a range of divesity in approaches to merging agriculture with biodiveristy in an urban setting. At the beginning of the third millenium, Portland is poised to play the primary role in that movement.

Research on strategic governance (Healey, 2006) may provide guidance to investigate the role of the city in imagining the future of community gardens in Portland.

The concept of governance refers to a shift from state sponsorship of economic and social programs to partnership agreements that usually involve both government and non-government agencies. The research on strategic public governance explores the design of an interactive governance process in carrying out the principles of creative public dialogue. 
Healey argues that strategic governance efforts should focus on creating infrastructure to build more engagement among citizens and businesses with the shared context of locality. Strategic planning is viewed not in the traditional understanding of making physical form, but in articulating and mobilizing its imaginative form to frame the mental landscapes and material actions of the many actors who reshape the relations and meanings to be found within urban areas. In contemporary urban governance, the efforts to understand multiple readings of the city have the potential to reduce the risk of dominance by a narrow conception of a powerful interest group.

The strategic governance approach rests on the possibility for generating meanings for the "city." A collective process of "imagining the city" has the potential to build governance capacity around the multiple qualities of "places" and the diverse ways places are experienced in an era when urban life is often experienced as fragmented.

The twentieth century recognizes that there are all kinds of movement patterns and time -space rhythms, some shaped in a daily, weekly, and yearly cycle (Healey, 2006). The space of what is taken to be the city is a complex layering of time-space rhythms of multiple time-space relations. Interweaving with these relational webs are the processes by which identities are constructed, in all their ranges and diversities. Healey's research, embedded in the communicative planning theory, claims that through strategic governance efforts, the process of 
imagining the city by the participation of diversified groups has the potential to understand locality and to build collective approaches to resolve conflicts.

\section{F. Future Research}

\section{Towards Landscapes of Empowerment}

Communicative action theory recognizes that the purpose of planning is to handle multiple meanings and representations of city spaces. My study draws from the phenomenological research tradition that recognizes individual consciousness for the ways in which individuals construct their lives and their knowledge of the everyday world. Through narrative storytelling, the gardeners were able to express in their own terms their connections to space and the experience of empowerment achieved by community gardening. The temporal and thematic aspect of narratives permitted me to capture the impact of circular time dimension of forming social and physical connections to the gardens. By demonstrating multiple ways that people perceive space connections and how these connections influenced their experience of empowerment, the study provides evidence of the need for applying imaginative strategic governance in envisioning the future of community gardens in Portland.

The study focuses on the importance of everyday life of ordinary people in creating their landscapes of empowerment through community gardening. Through space transformation, people develop connections and represent the image of space that empowers them. The image of empowerment reflects the 
appropriation of space in the practice of everyday life of ordinary people - their landscapes of community garden empowerment.

The primary purpose of the study is to link the concept of sense of place with community development and empowerment by exploring the role of community gardens as public spaces at the beginning of the twenty first century. Figure VIII.1 contains the proposed methodological framework to explore public spaces in the context of sense of place and empowerment.

Figure VIII.1. Towards Landscapes of Empowerment

\begin{tabular}{|c|c|c|c|c|}
\hline $\begin{array}{l}\text { Urban } \\
\text { Space }\end{array}$ & $\begin{array}{c}\text { Dominant } \\
\text { Spatial } \\
\text { and Temporal } \\
\text { Relations }\end{array}$ & $\begin{array}{l}\text { Empowerment } \\
\text { Spectrum }\end{array}$ & $\begin{array}{c}\text { Dominant } \\
\text { Image and } \\
\text { Representation }\end{array}$ & $\begin{array}{c}\text { Sense of Place } \\
\text { Narrative and } \\
\text { Empowering } \\
\text { Resources }\end{array}$ \\
\hline $\begin{array}{l}\text { Community } \\
\text { Garden }\end{array}$ & $\begin{array}{l}\text { Natural Realm } \\
\text { rhythm } \\
\text { Cyclical time } \\
\text { concept/renewal } \\
\text { in nature } \\
\text { Physical } \\
\text { connection }\end{array}$ & $\begin{array}{l}\text { Food and non - } \\
\text { food harvest } \\
\text { spectrum } \\
\text { Primary } \\
\text { connection: food } \\
\text { production } \\
\text { Optional/seconda } \\
\text { ry activity: } \\
\text { non- food } \\
\text { production }\end{array}$ & $\begin{array}{l}\text { Dominant } \\
\text { representations: life } \\
\text { in beauty } \\
\text { Dominant image: } \\
\text { plant and plots } \\
\text { reflect dominant } \\
\text { plant to plot space } \\
\text { transformation }\end{array}$ & $\begin{array}{l}\text { Practicing } \\
\text { green } \\
\text { domesticity } \\
\text { and learning } \\
\text { from nature in } \\
\text { a place of } \\
\text { beauty } \\
\text { Most } \\
\text { empowering } \\
\text { resources in } \\
\text { the sense of } \\
\text { place narrative } \\
\text { : plot, } \\
\text { surrounding } \\
\text { areas, and } \\
\text { people }\end{array}$ \\
\hline
\end{tabular}

\section{Gardener Types}

The diversity of empowerment experiences in the community garden may be used to define "gardener types." Figure VIII. 2 contains a proposed typology to be tested in later research. 
Figure VIII.2. Gardener Types

\begin{tabular}{|l|l|l|l|l|l|}
\hline \multirow{2}{*}{ Empowerment } & \multicolumn{5}{c|}{ Gardener Types } \\
\cline { 2 - 6 } & $\begin{array}{l}\text { Urban } \\
\text { Farmer }\end{array}$ & $\begin{array}{l}\text { Garden } \\
\text { Artist }\end{array}$ & Epicurean & $\begin{array}{l}\text { Recreational } \\
\text { Gardener }\end{array}$ & $\begin{array}{l}\text { Spiritual } \\
\text { Gardener }\end{array}$ \\
\hline Food Quality & & & & & \\
\hline & & & & & \\
\hline Food Quantity & & & & & \\
\hline & & & & & \\
\hline Beauty & & & & & \\
\hline $\begin{array}{l}\text { Plot conversion } \\
\text { into art }\end{array}$ & & & & & \\
\hline Sharing the garden & & & & & \\
\hline Harvest usefulness & & & & & \\
\hline Lifestyle & & & & & \\
\hline Green domesticity & & & & & \\
\hline $\begin{array}{l}\text { Green oasis/urban } \\
\text { village }\end{array}$ & & & & & \\
\hline Recreation/fitness & & & & & \\
\hline $\begin{array}{l}\text { Luxury/organic } \\
\text { food }\end{array}$ & & & & & \\
\hline Learning & & & & & \\
\hline $\begin{array}{l}\text { Gardening } \\
\text { techniques in } \\
\text { natural setting }\end{array}$ & & & & & \\
\hline $\begin{array}{l}\text { Garden cycle and } \\
\text { human life }\end{array}$ & & & & & \\
\hline $\begin{array}{l}\text { Professional skills/ } \\
\text { business }\end{array}$ & & & & & \\
\hline Sanctuary & & & & & \\
\hline Well being & & & & & \\
\hline Spirit of nature & & & & & \\
\hline Memories & & & & & \\
\hline
\end{tabular}

Urban Farmer. The primary focus of an Urban Farmer is on food growing and food quantity. The Urban Farmer is bothered by both weeds and the excessive amount of flowers grown by other gardeners. All plants must be useful, i.e., for human consumption. 
Garden Artist. The Garden Artist is not interested in converting garden plots to "productive" use. A garden plot is an expression of her/his sense of aesthetics. The Garden Artist is bothered by neglected (non-weeded) plots because they negatively impact her/his sense of aesthetics.

Epicurean. The Epicurean sees a community garden plot as a way to practice "green domesticity" amid the lively urban neighborhood. The Epicurean enjoys fresh organic food and may be an active member of a vegan network

Recreational Gardener. The Recreational Gardener appreciates the value of fresh and organically grown vegetables but recognizes and respects other types of gardeners and their preferences. The Recreational Gardener sees gardening as part of her/his lifestyle that combines social interactions with outdoor activities in an urban setting.

Spiritual Gardner. The Spiritual Gardener develops a strong attachment to her/his garden plot. The garden plot is a private sanctuary to contemplate life and the power of the natural cycle. The Spiritual Gardener materializes her/his memories and desires through land cultivation.

\section{Class and Ethnic Dimensions in Community Gardening}

One of the objectives of my study was to explore the impact of physical attributes of the gardens on empowerment experienced by the gardeners but it did not research the relationship between empowerment and class and ethnic dimensions. There is the need for further research to investigate the relationship 
between empowerment goals and the socioeconomic characteristics of urban gardeners. Figure VIII. 3 reflects a conceptual model to investigate the influence of socioeconomic dimensions on empowerment experience.

\section{G. Study Limitations}

1. The small number of study sites (three) and participants (thirty) will limit the analysis and ability to generalize about the results.

2. The study focused on the City of Portland Community Garden Program, where garden plots are provided as a commodity. The sense of place experience may be different where community gardens were established by neighborhood grassroots action.

3. The gardeners who participated in my study were racially homogenous (white). A racially diversified sample, including immigrants from other countries could have provided different responses and conclusions.

4. The gardens were selected to get variations in their locations, because my central interest is in the impact of physical attributes on sense of place. The limited socioeconomic data I collected through the in-depth interviews did not allow me to fully explore the impact of class and ethnic dimensions on sense of place. 


\section{INTERVIEWS}

1. List of In-depth Interviews

Andrea. (2009). Fulton Gardener. (B. Shields, Interviewer)

Barbara. (2009). Fulton Gardener. (B. Shields, Interviewer)

Bill. (2009). Brentwood Gardener. (B. Shields, Interviewer)

Dan. (2009). Johns Gardener. (B. Shields, Interviewer)

David. (2009). Fulton Gardener. (B. Shields, Interviewer)

Dawn. (2009. Fulton Gardener. (B. Shields, Interviewer)

Florence. (2009). Fulton Gardener. (B. Shields, Interviewer)

Gerry. (2009). Fulton Gardener. (B. Shields, Interviewer)

Gracie. (2009). Brentwood Gardener. (B. Shields, Interviewer)

Hawkins. (2009). Johns Gardener. (B. Shields, Interviewer)

Heike. (2009). Brentwood Gardener. (B. Shields, Interviewer)

Jan. (2009). Brentwood Gardener. (B. Shields, Interviewer)

Jim. (2009). Fulton Gardener. (B. Shields, Interviewer)

John. (2009). Brentwood Gardener. (B. Shields, Interviewer)

Ken. (2009). Fulton Gardener. (B. Shields, Interviewer)

Lisa. (2009). Brentwood Gardener. (B. Shields, Interviewer)

Marguerite. (2009). Johns Gardener. (B. Shields, Interviewer)

Mark. (2009). Brentwood Gardener. (B. Shields, Interviewer)

Mark. (2009). Johns Gardner. (B. Shields, Interviewer)

Marsha. (2009). Fulton Gardener. (B. Shields, Interviewer)

Mary-Anne. (2009). Johns Gardener. (B. Shields, Interviewer) 
Melinda. (2009). Brentwood Gardener. (B. Shields, Interviewer)

Merrill. (2009). Fulton Gardener. (B. Shields, Interviewer)

Mike. (2009). Johns Gardener. (B. Shields, Interviewer)

Perky. (2009). Fulton Gardener. (B. Shields, Interviewer)

Robby. (2009). Johns Gardener. (B. Shields, Interviewer)

Stephanie. (2009). Brentwood Gardener. (B. Shields, Interviewer)

Sydney. (2009). Fulton Gardener. (B. Shields, Interviewer)

Tom. (2009). Brentwood Gardener. (B. Shields, Interviewer)

Wendy. (2009). Johns Gardener. (B. Shields, Interviewer)

2. List of Interviews with Portland Community Garden Staff

Franek, D. (2009).City of Portland Community Garden Office Employee. (B. Shields, Interviewer)

Iott, J. (2009a, 2009b, 2009c, 2009d). City of Portland Garden Office Employee (B. Shields, Interviewer

Phol-Kosbau, L (2009a, 2009b, 2009c). City of Portland Garden Office

Employee (B. Shields, Interviewer)

3. List of Interviews with Community Garden Managers

Cepurna, B. (2009a, 2009b, 2009c, 2009d). Brentwood Community Garden CoManager. (B. Shields, Interviewer)

Corbert, D (2009a, 2009b, 2009c). Brentwood Community Garden Co-Manger (B. Shields, Interviewer)

Decker, G. (2009a, 2009b). Fulton Community Garden Manager (B. Shields, Interviewer) 
Holmes, R. (2009a, 2009b, 2009c, 2009d), Johns Community Garden Manager (B. Shields, Interviewer) 


\section{REFERENCES}

Altman, I. (1975). Environment and Social Behavior: Privacy, personal space, territory and crowding. Monterey, CA: Brooks/Cole.

Altman, I., \& Low, S. (1992). Human Behavior and Environment: Advances in Theory and Reserach, Volume 12, Place Attachment. New York: Plenum.

Altman, I., \& Wohlwill, J. (1983). Behavior and the Natural Environment. New York: Plenum Press.

Amstrong, D. (2000). A survey of community gardens in upstate New York: Implications for health promotion and community development. Health and Place, 319-329.

Ashmun, B. B. (2008, November 6 ). The Happy Gardener. Portland Tribune, p. 10.

Banerjee, T. (2001). The future of public space. Beyond invented streets and reinvented places. Journal of the American Planning Association, 67(1) , 9-24.

Berger, A. (1995). Cultural Critisism: a primer of concepts. Thousand Oaks: Sage.

Bonaiuto, M. A. (1999). Multidimensional perception of residential environment quality and neighborhood attachment in the urban environment. Journal of Environmental Psychology, 19, 331.

Bonaiuto, M. C. (2002). Local identity processes and environmental attitudes in land use changes: The case of natural protected areas. Journal of Economic Psychology, 23, 631-653.

Boulding, K. (1956). The Image. Ann Arbor: University of Michigan Press.

Brettman, A. (2009, August 23). Community unites at garden party. The Oregonian .

Brown, B. B., \& Brown, G. (2003). Place attachment in a revitalizing neighborhood: Individual and block levels of analysis. Journal of Environmental Psychology 23 , 259-71. 
Brown, B. B., \& Perkins, D. (1992). Disruptions in place attachment. In I. Altman, \& S. Low, Place Attachment (pp. 279-304). New York: Plenum Press.

Carmona, M., Heath, T., Oc, T., \& Tiesdell, S. (2003). Public Places - Urban Spaces. Oxford: Architectural Press.

Carr, S., Francis, M., Rivlin, L., \& Stone, A. (1992). Public Space. Cambridge: Cambridge University Press.

Certeau, M. d. (1984). The practice of everyday life . Berkeley: University of California Press.

City of Portland Community Gardens Office. (2008). Community Garden Survey 2008. Portland: City of Portland .

Coe, M. (1978). Growing with Community Gardening. Taftsville, Vermont: The Countryman Press.

Cohen, M., \& Potter, J. (2000). Gardens for the third millennium: The Garden of Eden to urban paradise. The Environmentalist, 20, 273 - 276.

Coley, R., Sullivan, W., \& Kuo, F. (1997). Where Does Community Grow?: The Social Aspect Created by Nature in Urban Public Housing. Environment and Behavior , 468-492.

Crang, M. (1998). Cultural Geopgraphy. New York: Routledge.

Ferris, J., \& Norman, C. (2001). People, land and sustainability: community gardens and the social dimension of sustainable development. Social Policy \& Administration 35 (5), 559-568.

Francis, M. (1988). Changing values for public spaces. Landscape Architecture, $78,54-59$.

Francis, M., Cashdan, L., \& Paxon, L. (1984). Community open spaces. Washington, DC: Island Press.

Glover, T. D. (2004). Social Capital in the Lived Experiences of Community Gardens. Leisure Science, 26 , 143-162.

Glover, T., Shinew, K., \& Parry, D. (2005). Association, Sociability, and Civic Culture: The Democratic Effect of Community Gardening. Leisure Sciences Vol. 27/1, 75-92. 
Harvey, D. (1990). The condition of postmodernity. Oxford: Blackwell.

Healey, P. (2006). Relational Complexity and the Imaginative Power of Strategic Spatial Planning. European Planning Studies 14 (4) , 526-546.

Hidalgo, M. C., \& Hernandez, B. (2001). Place attachment: conceptual and empirical questions. Journal of Environmental Psychology, 21 , 273-281.

Jackson, J. B. (1994). A Sense of Place, A Sense of Time. New Haven, CT: Yale University Press.

Jamison, M. (1985). The joys of gardening: Collectivist and bureaucratic cultures in conflict. The Sociological Quarterly, 26(4) , 473-490.

Kaplan, R. (1973). Some psychological benefits of gardening. Environment and Behavior, 5 , 145-161.

Kaplan, R., \& Kaplan, S. (1989). The experience of nature. New York: University of Cambridge.

Kasarda, J., \& Janowitz, M. (1974). Community attachment in mass society. American Sociological Review 39(3), 328-39.

Kaufman, J., \& Bailkey, M. (2000). Farming Inside Cities: Entrepreneurial Urban Agriculture in the United States. Lincoln Institute of Land Policy.

Keith Tidball, M. K. (2006). Community Greening Scholars Talk Shop: Fighlighs, Findings, and Future Directions for the Field. Community Greening Review.

Landman, R. H. (1993). Creating community in the city: Cooperatives and community gardens in Washington, D.C. . Westport, CT: Bergin \& Garvey. Lawson, L. J. (2005). City Bountiful. Berkely and Los Angeles: University of California Press.

Lofland John, D. S. (2006). Analyzing social settings : a guide to qualitative observation and analysis. Belmont, CA: Wadsworth/Thomson.

Lofland, L. (1998). The Public Realm. New York: Aldine De Gruyter. Lynch, K. (1960). The Image of the City. Cambridge, MA: MIT Press. 
Manzo, L. C. (2003). Beyond home and haven: Toward a revisioning of emotional relationships with places. Journal of Environmental Psychology 23(1), 47-61.

Manzo, L. C. (2005). For better or worse: Exploring multiple dimensions of place meaning. Journal of Environmental Psychology 25(1) , 67-86.

Manzo, L., \& Perkins, D. (2006). Finding Common Ground: The Importance of Place Attachment to Community Participation and Planning. Journal of Planning Literature, Vol. 20, No.4, 335-350.

Marzluff, J., \& Rodewald, A. (2008). Conserving Biodiverisity in Urbanizing Areas: Neotraditional Views from a Bird's Perspective. Cities and the Environment Vol.1 , 1-27.

McIntyre, A. (2003). Through the eyes of women: Photovoice and participatory research as tools for reimagining place. Gender, Place and Culture, 10(1) , 47-66.

Meinig, D. (1979). The Interpretation of Ordinary Landscapes. New York: Oxford University Press.

Naimark, S., \& ed. (1982). A Handbook of Community Gardening. New York: Charles Scribner's Sons.

Norberg-Schulz, C. (1980). Genius loci: Towards a phenomenology of architecture. New York: Rizzoli International Publications, Inc.

Nowell, B., Berkowitz, S., Deacon, Z., \& Foster-Fishman, P. (2006). Revealing the Cues Within Community Places: Stories of Identity, History, and Posibility. American Journal of Community Psychology , 29-46.

Pincetl, S., \& Gearin, E. (2005). The Reinvention of Public Green Space. Urban Geopgraphy, Vol. 26, $365-384$.

(2008). Portland Community Gardens: A Handbook. Portland: City of Portland Parks and Recreation.

Pudup, M. ( 2008). It takes a garden: Cultivating citizen-subjects in organized garden projects . Geoforum 39, 1228-1240.

Radley, A., \& Taylor, D. (2003). Images of recovery: A photoelicitation study on the hospital ward. Qualitative Health Research, 13 , 77-99. 
Rappaport, J. (2000). Community narratives: Tales of terror and joy. American Journal of Community Psychology, 28(1), 1-24.

Rappaport, J. (1995). Empowerment Meets Narrative: Listening to Stories and Creating Settings. American Journal of Community Psychology 23 , 795-807.

Rappaport, J. (1993). Narrative studies, personal stories, and identity transformation in the mutual help context. The Journal of Applied Behavioral Science, 29 , 239- 254.

Rappaport, J. (1984). Studies in empowerment: Introduction to the issue.

Prevention in Human Services 3 , 1-7.

Rappaport, J. (1987). Terms of empowerment/examplars of prevention: Toward a theory for community psychology. American Journal of Community Psychology, $15,121-148$.

Recreation, P. a. (2008). Portland Community Gardens: A handbook. Portland, OR: City of Portland.

Relph, E. (1976). Place and Placelessness. London: Pion.

Robby. (2009, November 27). Johns Gardener. (B. Shields, Interviewer)

Rocha, E. (1997). A ladder of empowerment. Journal of Planning Education and Research $17,31-44$.

Rudkin, J. K. (2007). Photography as a Tool for Understanding Youth Connections to Their Neighborhood. Children, Youth and Environments 17(4), 107-123.

Ryan, R. (2005). Exploring the effects of environmental experience on attachment to urban natural areas. Environment and Behavior, 37 (1) , 3-42.

Savage, J. (2000). Participative observation: Standing in the shoes of others? Qualitative Health Research 10(3), 324-39.

Schensul, S. L., Schensul, J. J., \& LeCompte, M. D. (1999). Essential ethnographic methods : observations, interviews, and questionnaires. Walnut Creek, Calif.: AltaMira Press.

Schmelzkof, K. (1996). Urban Community Gardens as contested space. Geographical Review, 85(3), 364-381. 
Schrieber, P. (1998). Community gardening: Design, technique, and tools. In S. Simson, \& M. Straus, Horticulture as therapy: Principles and practice (pp. 377397). New York: The Food Products Press/Haworth Press.

Schwartz, D. (1989). Visual ethnography: Using photography in qualitative research. Qualitative Sociology, 12(2), 119-154.

Seamon, D. (1984). Emotional experience of the environment. American Behavioral Scientist 27(6) , 757-70.

Seamon, D. (1982). The phenomenological contribution to environmental psychology. 119-40.

Setha M. Low, I. A. (1992). Place Attachment: A Conceptual Inquiry. In S. M. Irwin Altman, Place Attachment (pp. 1-12). New York: Plenum.

Spradley, J. P. (1979). The ethnographic interview . New York: Holt, Rinehart and Winston.

Tuan, Y.-F. (1977). Space and Place: The Perpsective of Experience. Minneapolis: University of Minnesota Press.

Twigger-Ross, C. L., \& Uzzell, D. (1996). Place and identity processes. Journal of Environmental Psychology, 16 , 205-220.

Twiss, J., Dickinson, J., Duma, S., Kleinman, T., Paulsen, H., \& Rilveria, L. (2003). Community Gardens: Lessons Learned From California Healthy Cities and Communities . American Journal of Public Health Vol. 93 Issue 9 , 14351438.

Vitek, W., \& Wes, J. (1996). Rooted in the land: Essays on community and place. New Haven, CT: Yale University Press.

Wang, C. C., Morrel-Samuels, S., Pete Hutchison, L. B., \& Pestronk, R. M. (2004). Flint Photovoice: Community Building among Youth, Adults and Policy Makers. American Journal of Public Health 94(6) , 911-913.

Wang, C. (1999). Photovoice: A participatory action research strategy applied to women's health. Journal of Women's Health, 8(2) , 185-192.

Wang, C., \& Burris, A. (1997)). Photovoice: Concept, methodology, and use of participatory needs assessment. Health Education and Behavior, 24 , 369-387. 
Wang, C., Burris, M. A., \& Xiang, Y. P. (1996). Chinese women as visual anthropologists: A participatory approach to reaching policy makers . Social Science \& Medicine, 42(10), 1391-1400.

Wendy. (2009, November 23). Johns Gardener. (B. Shields, Interviewer)

Zimmerman, M. (2000). Empowerment Theory: Psychological, Organizational, and Community Levels of Analysis. In J. Rappaport, \& E. Seidman, Handbook of Community Development (pp. 43-63). New York: Kluwer Academic / Plenum .

Zukin, S. (2004). Point of Purchase: How shopping changed American culture. New York: Routledge. 


\section{APPENDIX A. 1 \\ EMPOWERMENT IMAGES \\ Sydney}

1. Oasis under Pear Tree: Leisure and Sharing

"Oasis under Pear Tree: Leisure and Sharing"

Fig.A.1a. Photo: Sydney, Fulton Gardener, 2009

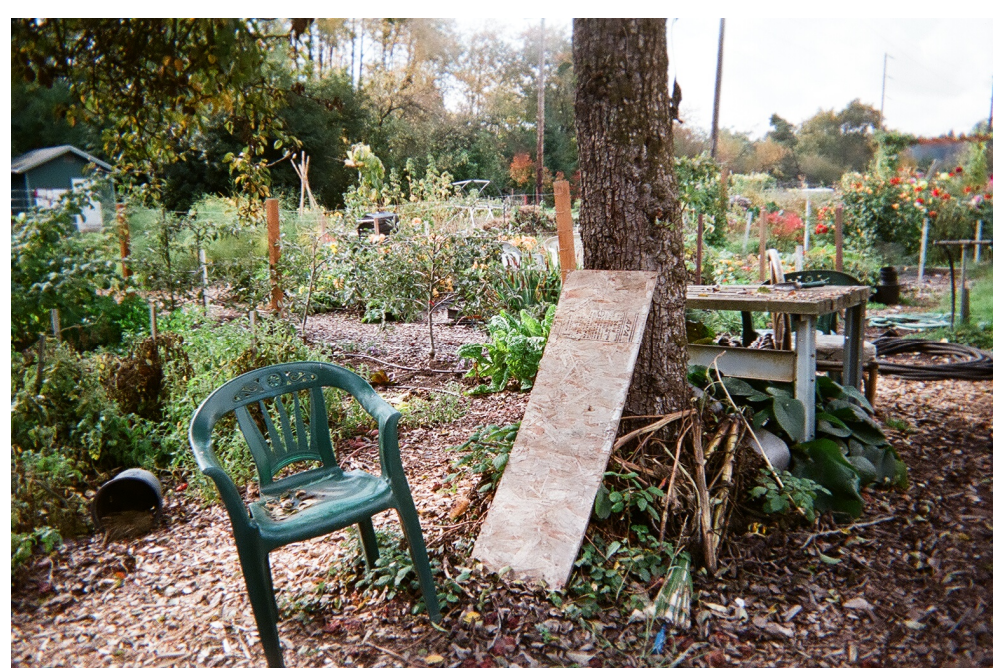

"The little oasis area, the gardens around me, under the tree" A plastic chair and a potting table under an old pear tree mark the most important place in the garden. Here, Sydney can come and sit if she needs to take a break. "This is our garden oasis where five of us share vegetables..."

The table is also used for sharing tools and vegetables. Frequently, Sidney comes here and sits at the table. It is located just several feet from her plot. It was her first season in the garden and she watched the garden from here; it became her vantage point for observation and contemplation. Occasionally, she would have her sandwich here.

The "pear tree oasis" is an important observation point to watch the action in the garden. This informal resting place, which is mostly used by the immediate five gardeners, is the area where Sydney feels comfortable: it is under the tree that provides the shade. It is a space for sharing and a safe place. The safe place is marked by other people's presence. It is an old plastic chair, a potting table, and a bench. 
2. Sunflowers: Developing Connections between People and Nature

"Sunflowers: Developing Connections between People and Nature"

Fig. A.b. Photo: Sydney, Fulton Gardener, 2009

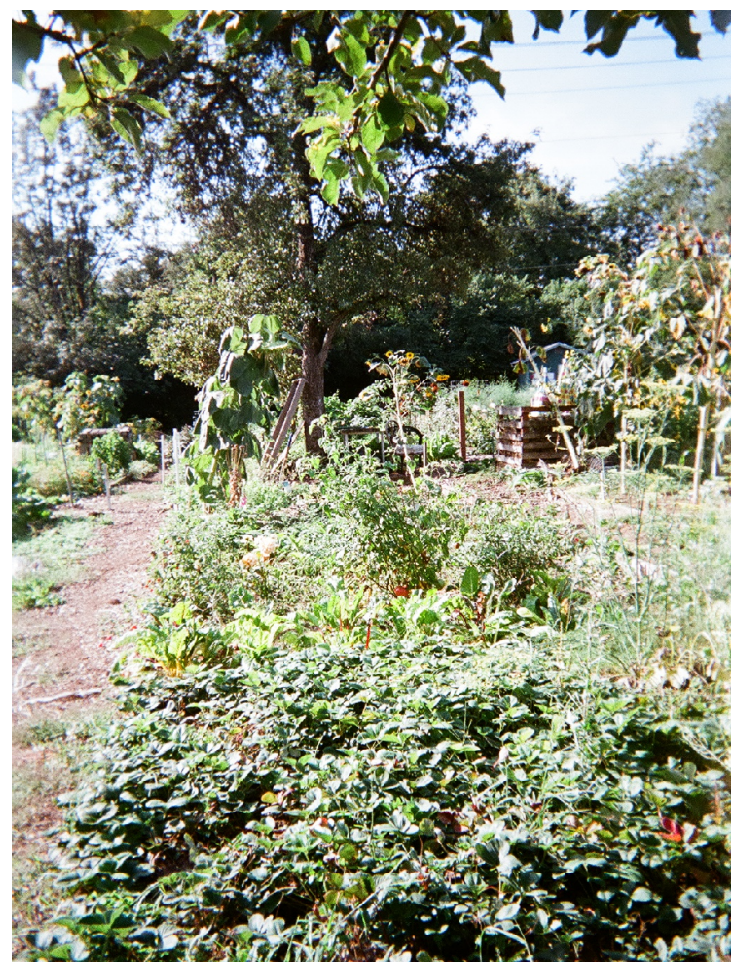

"Sunflowers are so reminiscent of van Gogh. If you are quiet birds come in flocks..." This picture is a general view of Sydney's plot with sunflowers in the background. The sunflowers symbolize connections at different levels.

First, they connect people with birds. "I will leave them on the plot for the birds..."

Second, they provide a vertical dimension to Sydney's garden. Sydney is not able to construct garden structures on her plot ("I refuse to accept gracefully my limitations as I get older...") and sunflowers provide a different visual and structural element despite her inability to construct things.

Third, they symbolize sharing and help in the garden.

Gerry, the garden manager, propped up one of the falling sunflowers with a board when Sydney was gone for a week and was unable to tend her garden. Thus, Gerry became Sydney's "sunflower angel" in the garden, somebody who cares about other people. The sunflowers remind Sydney about Gerry's kindness, the spirit of sharing, and safety. 
"Rooted in Community Garden: Permanent Installation"

Fig. A.1.c . Photo: Sydney, Fulton Gardener, 2009

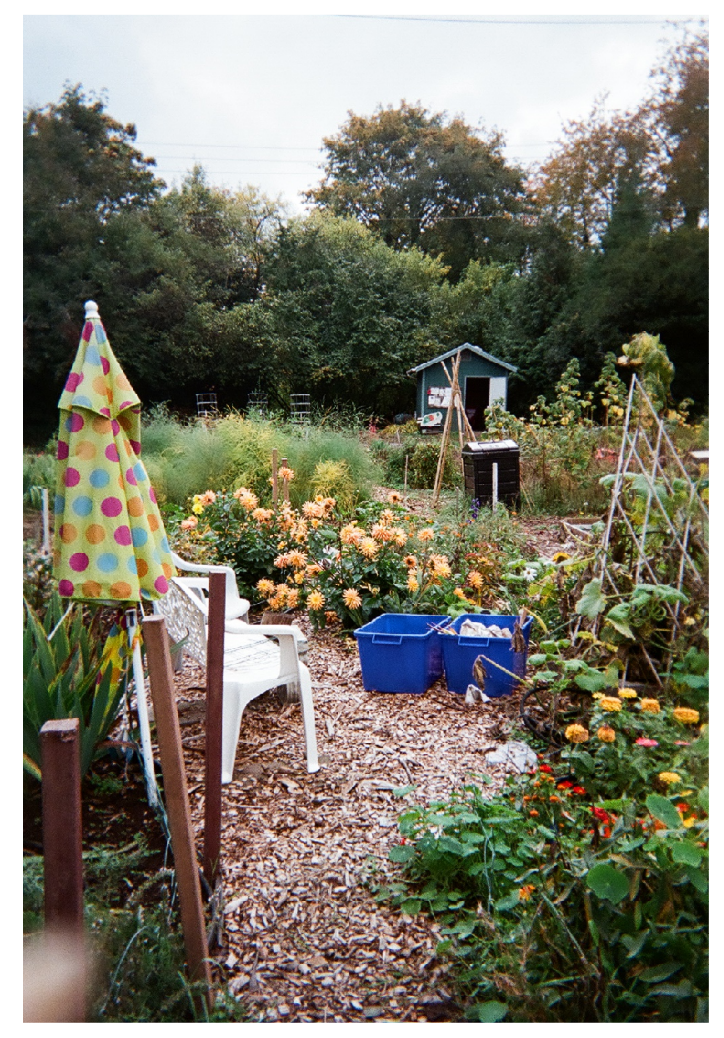

This picture is of a permanent installation. It has chairs, umbrellas, and an arbor. It symbolizes people who are rooted in the community garden.

"It is permanent. It is about putting roots down, having a cup of tea, sitting down, and the feeling of belonging. I imagine that this space provides them with their connection to earth and other places they have somewhere else... If you are renting, you do not plant

the same things. Some people plant bushes, if they feel they are more rooted".

The structures of the garden are a visual representation of people feeling safe in the garden. It could be a set of umbrellas, plastic chairs, an arbor, or simply some small trees or berry bushes. 


\section{Next Plot Zinnias: Utility and Beauty}

"Next Plot Zinnias: Utility and Beauty"

Fig. A.1.d. Photo: Sydney, Fulton Gardener, 2009

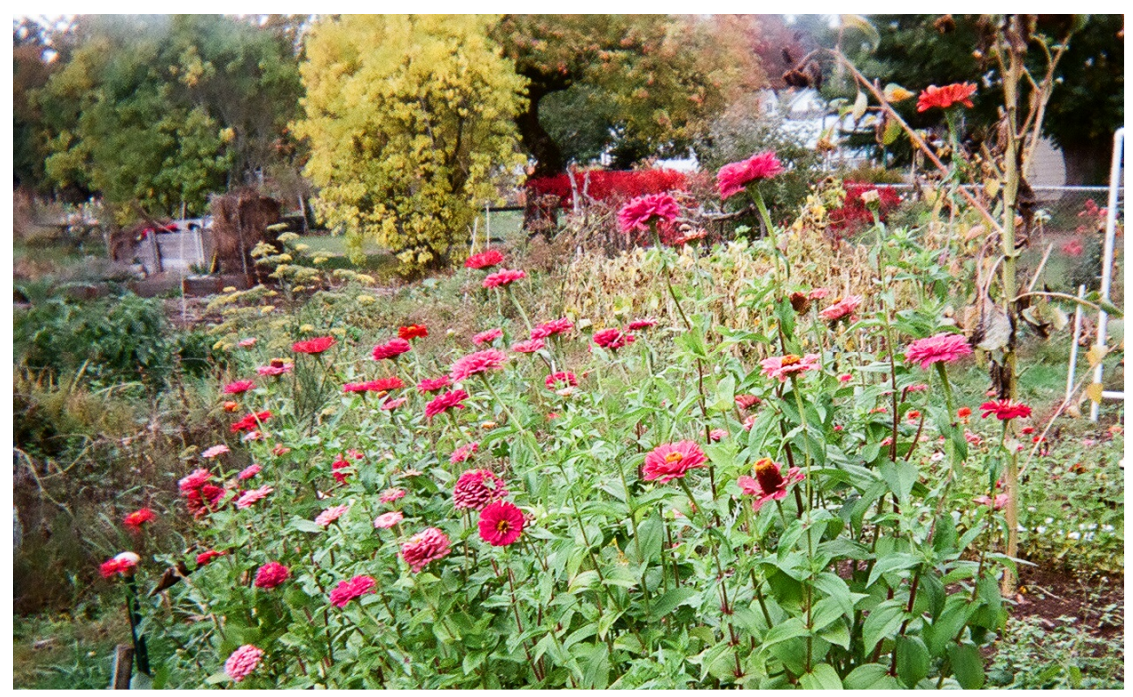

"My neighbor is very utilitarian but still has room for flowers so that everyone can enjoy their beauty." Beautiful zinnias are an example of Sydney's explorations and observations of other gardeners' preferences and reflections of their personalities imprinted on their garden plots. In this picture, David planted zinnias on his otherwise very utilitarian plot, which is used mostly for growing vegetables.

Zinnias are planted on the edge of the wooden frame marking David's plot and provide a splash of color and enjoyment. They also attract bees and hummingbirds, which are needed to pollinate plants. They epitomize the need for beauty and sharing in the garden.

Sydney and David work "separately but together" to maintain the walking path between their plots. They typically do not see each other, but make sure that the common space between their plots is well maintained. It is a reminder that people share the same general space and the impacts from their own plots influence the other plots in the garden. Thus, the garden quilt is a woven space of relationships between the people and nature, between the beautiful and utilitarian use of space and how they complement each other. 


\section{APPENDIX A. 2 \\ EMPOWERMENT IMAGES \\ Andrea}

1. A bouquet of Sunflowers: Sharing Harvest

"A Bouquet of Sunflowers: Sharing Harvest"

Fig. A.2.a .Photo:Andrea, Fulton Gardener, 2009

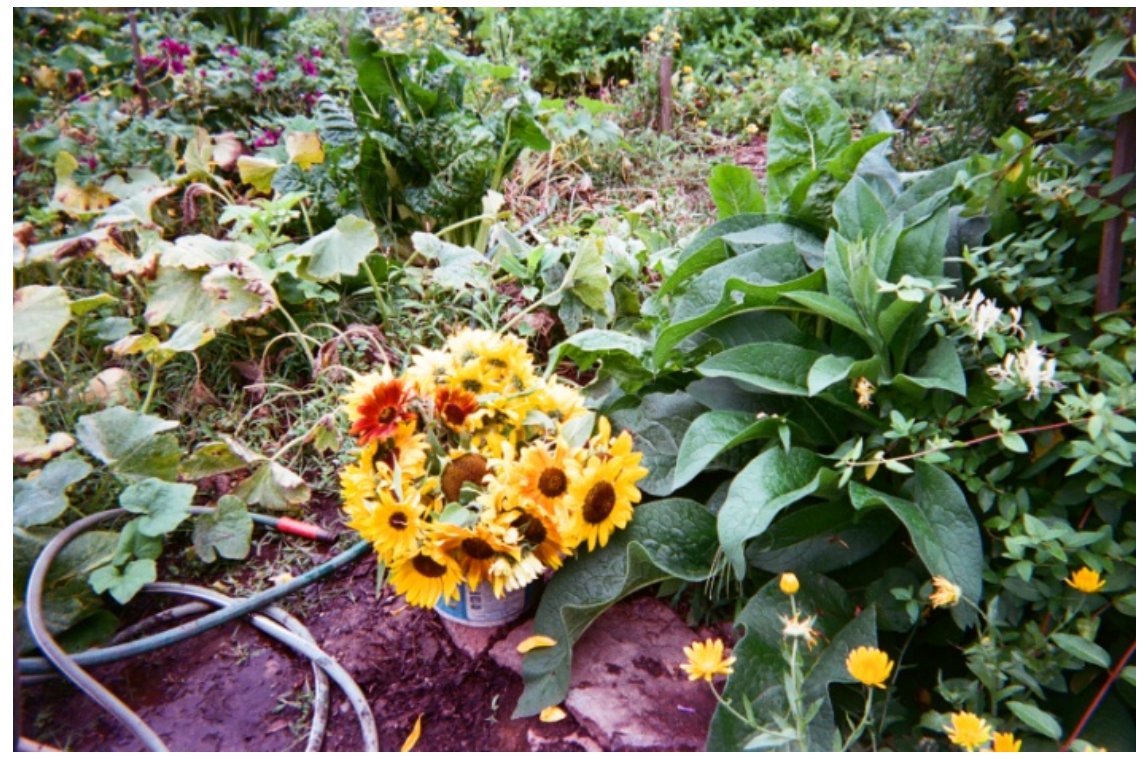

Andrea placed a bouquet of freshly cut sunflowers on her plot. It was a reminder that the she grew the sunflowers for her daughter's $18^{\text {th }}$ birthday. Andrea does not have enough sun in her home yard and was never able to grow sunflowers around her house. She also brought bunches of sunflowers and shared them with her students and teachers at the school where she works.

The concept of sharing the harvest from her plot in community garden with other people is important to her. Sunflowers symbolize both sharing produce and beauty in the garden. 
2. People and Their Stories

"People and Their Stories"

Fig. A.2.b . Photo:Andrea, Fulton Gardener, 2009

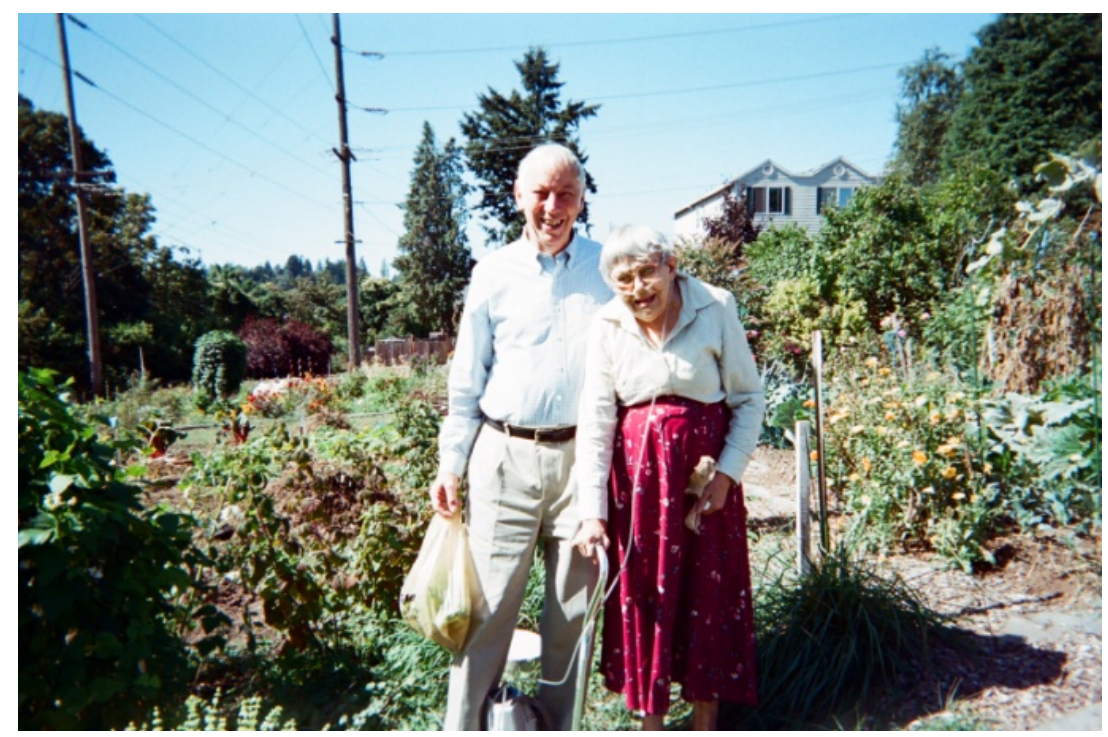

The presence of people is important in Andrea's garden story. Andrea likes people and their stories. Every Sunday afternoon she meets Perky and her husband, who have their plot just next to her plot. "I like people and their stories, and also how I can learn from them, not only about gardening," said Andrea.

People and their stories inspire her. She likes to watch people working on their plots together, arranging space, and talking to each other. Gerry, a few plots down from her, was a real inspiration to improve her gardening skills. Andrea's hope is that she can eventually grow more produce on her plot. Marsha, who asked her to work on the "rose garden" plot, also inspired her. 


\section{Naturescape: Green Connections and Global Healing}

"Naturescape: Green Connections and Global Healing"

Fig. A.2.c . Photo:Andrea, Fulton Gardener, 2009

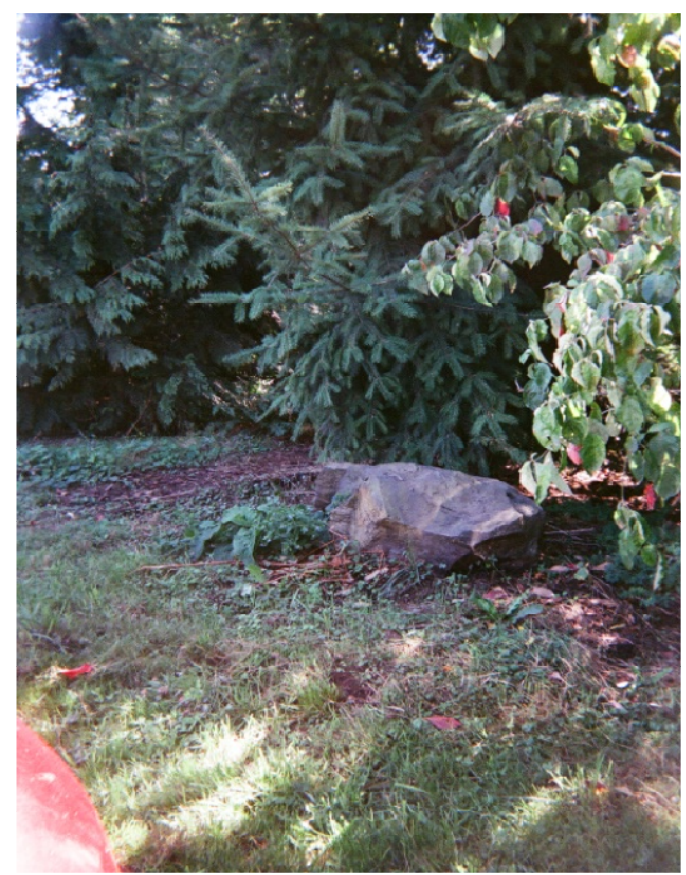

The rock in the native plant and the landscaped border separating the garden from the freeway is important to Andrea for several reasons. The landscaped border at the southerly part of the garden area provides a visual buffer from the nearby freeway and creates an illusion of a bucolic garden enclave amid the busy city and civilized life. First, it represents connections to nature. It is a reminder that a community garden is just a small part of the natural environment that is, and should be, connected to the rest of the natural system. Second, the native plants remind Andrea that growing crops is only a small part of the system. People do not have enough appreciation to see their environment in a balanced way. Community gardens are reminders that human activities are part of the natural environment and the community as a whole. The Portland gardens should be more connected, through a system of greenways. There should be more connection s to the community and more greenspaces to help people to connect with nature and themselves. There should be more natural green connections through the city to connect people and places. Community gardens are just one small part of the system. The city should encourage people to do more natural landscaping in the urban areas. 


\section{Food Production}

"Food Production"

Fig. A.2.d . Photo:Andrea, Fulton Gardener, 2009

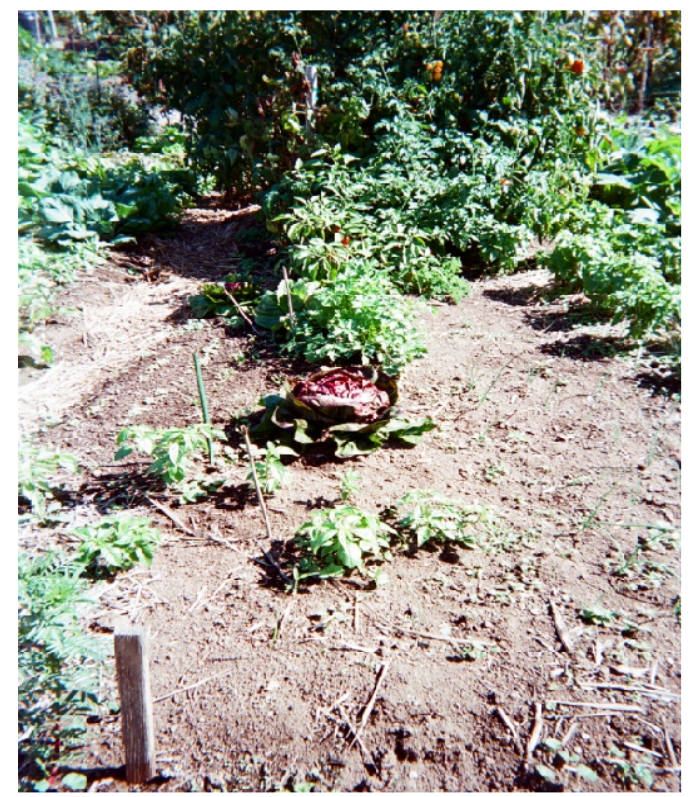

Producing her own vegetables is one of Andrea's future goals. She does not have enough access to sun on her home yard and is hoping that she can use the community garden plot to grow more produce. People are disconnected from the natural ways of growing food. This picture is a reminder that soil and land are important for the gardening cycle and growing food.

The ability to touch warm soil, to work in the garden, and to sit on the warm soil are some of the most enjoyable activities. The healing of the soil and the direct contact with nature are important Andrea uses parts of garden produce to feed her chickens that she keeps on her home yard. Growing her own chickens is important and is a reminder that animals are important in the natural cycle. 


\section{APPENDIX A. 3 \\ EMPOWERMENT IMAGES \\ Jim}

1. It Is about Making People Happy

"It Is about Making People Happy"

Fig. A.3.a. Photo: Jim, Fulton Gardener, 2009

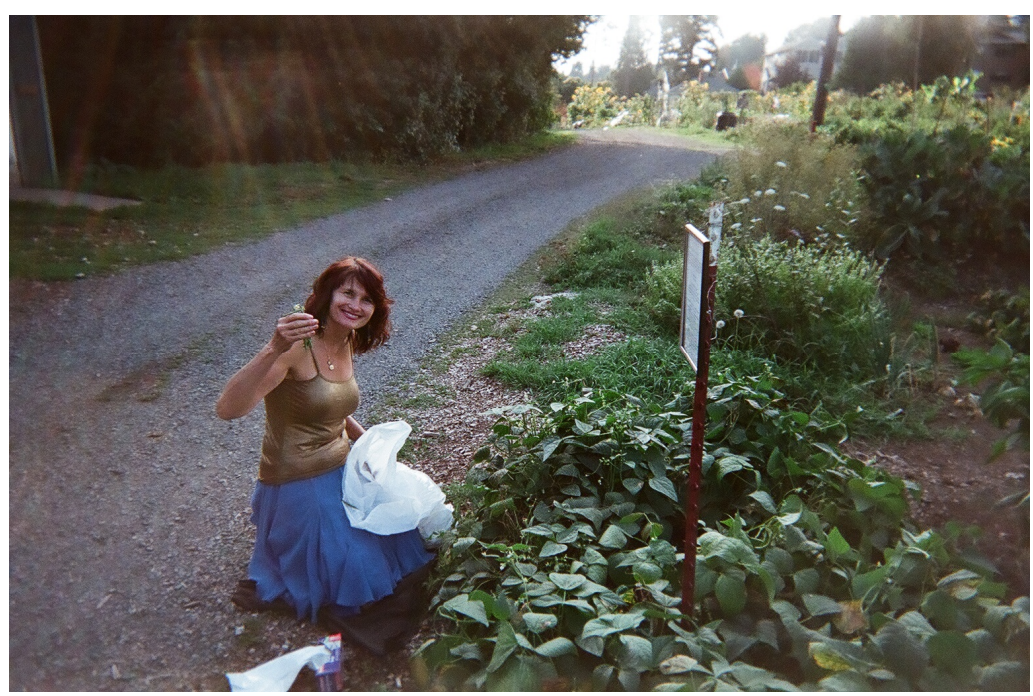

"This is my sweetheart. We have been married for over 25 years. She does not come to the garden but enjoys the harvest".

This picture is of Jim's wife who is happy to harvest the plot. Jim and his wife share produce and flowers from their plot with many people. His wife takes flowers to the hospital, where she works. It makes people happy; the beauty of the garden and sharing the beauty is important to Jim. "This time in my life I would like to give back."

The power of the garden is about nurturing the spirit and the body to make people happy. 
2. Poetry in the Garden: Nurturing the Spirit

"Poetry in the Garden: Nurturing the Spirit"

Fig. A.3.b. Photo: Jim, Fulton Garden, 2009

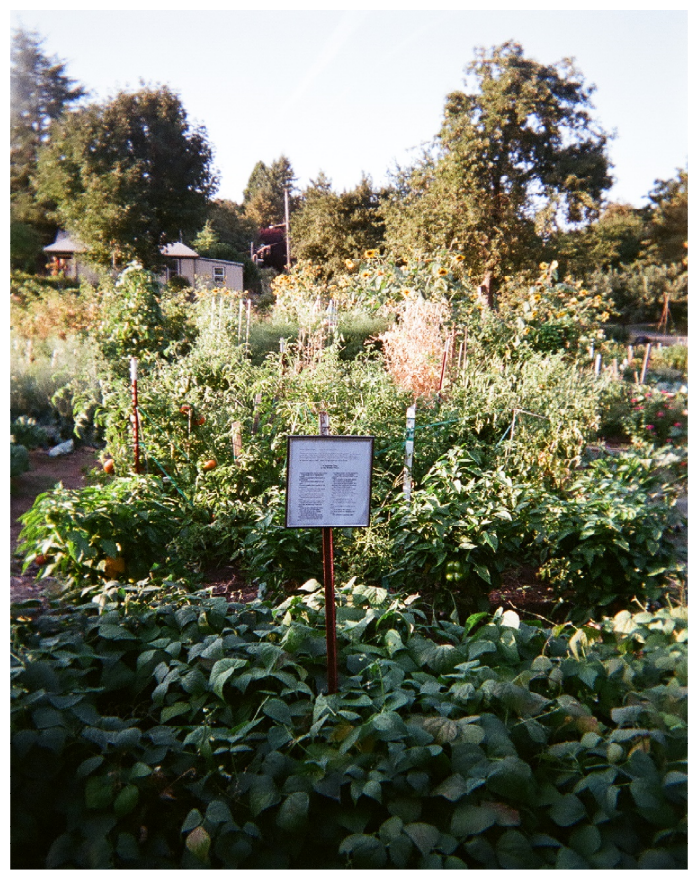

"My plot is close the road. I put a few poems" This is the first time in his life that Jim posted a poem in any public space. "I have never posted any poetry before. Now I can share poetry. It seems right to me."

Poetry symbolizes the spiritual aspect of the nurturing power of the garden. Sharing poetry is about sharing the spiritual meaning of life with other people. The community garden space was "the right time and right place" to start "giving back". "Poetry goes with gardening and ties it together for me. It is nurturing the spirit and the body". 
3. It Is About Tomatoes, Peppers, Soil, and Sun: Nurturing the Body

"It Is About Tomatoes, Peppers, Soil, and Sun: Nurturing the Body" Fig. A.3.c. Photo: Jim, Fulton Gardener, 2009

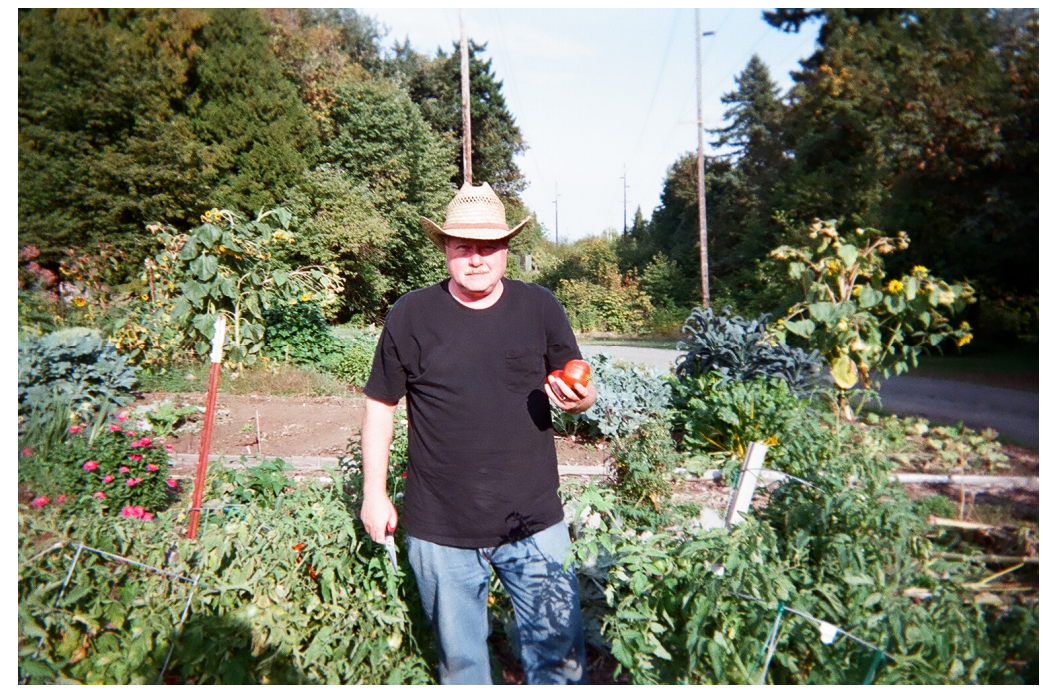

"I love tomatoes, peppers, and soil. It is my passion and expertise." Having a plot in the community garden gave Jim an opportunity to share both his produce from the garden and his knowledge of gardening. It was "the right time to give back and share" with other people. Jim's home garden does not have enough sun to grow peppers and tomatoes.

Jim is grateful to have a plot in the community garden where he can cultivate his vegetables and share his passion with other people. "I do it every year. I start hundreds and hundreds of start plants and give them away in the spring. It is a gift to the universe, sharing I am happy to do because it makes people happy. I grow different varieties and people come by my house and pick them up." 
APPENDIX A. 4.

EMPOWERMENT IMAGES

Ken

1. Utilizing Public Space for Food Production

"Utilizing Public Space for Food Production"

Fig. A.4.a. Photo: Ken, Fulton Gardener, 2009

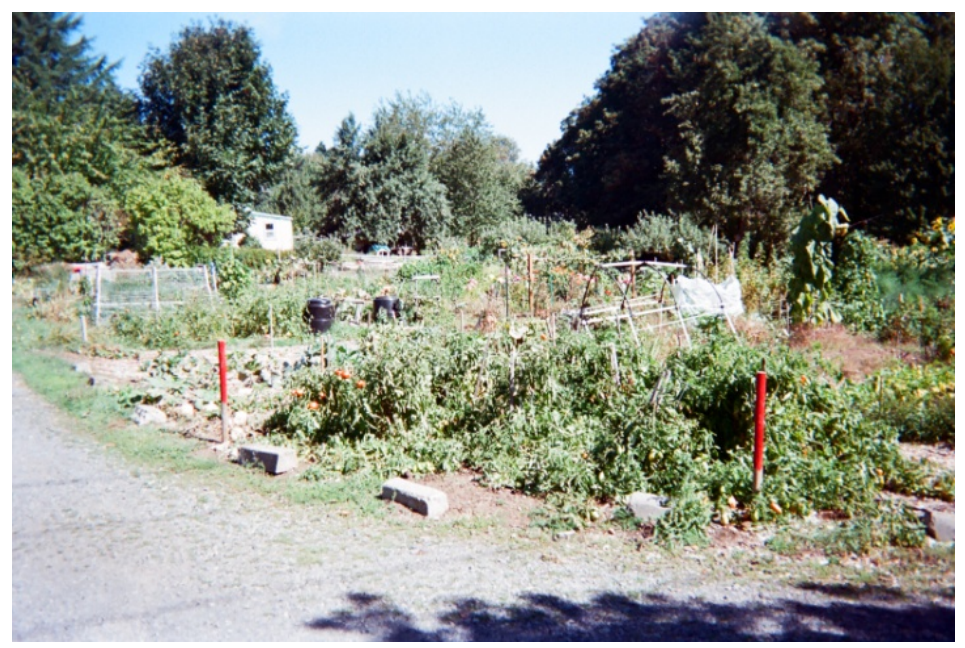

The two humble red stakes mark an important corner in Fulton Garden. This is Ken's plot. The red stakes clearly mark the boundaries of Ken's plot. His plot is located at the intersection of two internal roads cutting through the garden. This is one of the most convenient spots for many visitors to stop by and talk to Ken, when he works in his garden. The red stakes make it easier to see the plants and alert drivers that this is a garden area and they should be careful and try not to damage the growing produce. Ripening red tomatoes are just at the corner.

Because of the location of this plot, Ken became an informal ambassador of the community gardening program. He answers questions related to the garden and talks about gardening rules. In this part of the garden, there could have been a conflict between utilizing space for food production and recreation. Some people who visit the Fulton Recreational Center are not fully aware of the restrictions related to the community garden space. Thanks to Ken's patience, knowledge, kindness, and conversational abilities, this corner is the first point for interaction between non-gardeners and registered gardeners. Here, they learn about community gardening and rules for public spaces. 
2. Abundance in the Garden

"Abundance in the Garden "

Fig. A.4.b. Photo:Ken, Fulton Gardener, 2009

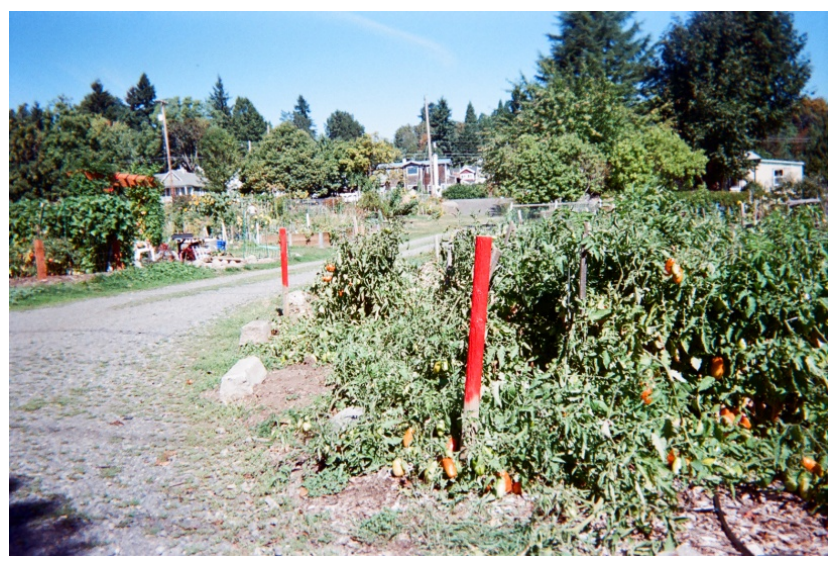

"My main reason is to produce and share with others". People should be responsible for making use of the garden space. The picture of garden bounty is a symbol of people's responsibility to take care of land and convert it to productive use. People who signed up for a community

garden plot should strive to make a productive use of their plot. Red, ripe tomatoes symbolize the food production and abundance in the garden.

3. Food Production

"Food Production in Community Garden"

Fig. A.4.c. Photo: Ken, Fulton Gardener, 2009

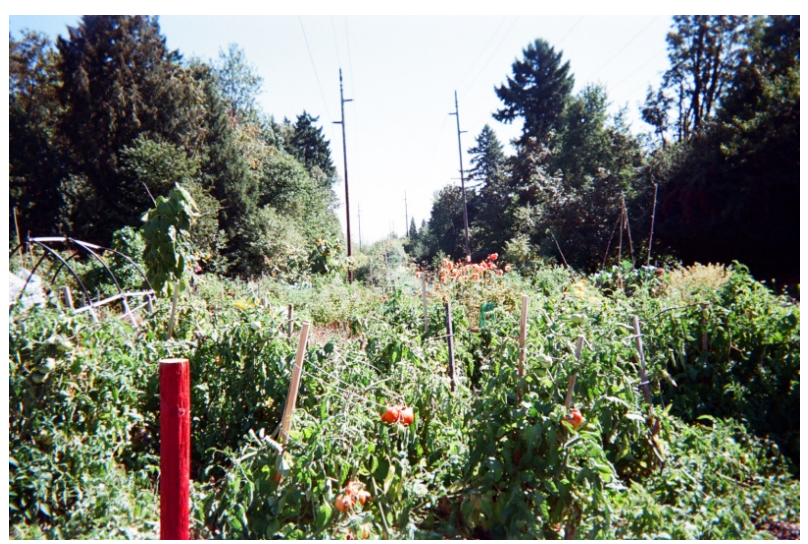

The garden is the place for food production.

Land in the garden should not go to waste. Some people tend not to use their space efficiently. People should be responsible to convert garden space into productive use for good production.

It was a very good year for tomatoes, zucchinis, and squashes. 


\section{APPENDIX A. 5. \\ EMPOWERMENT IMAGES \\ Dawn}

1. Picnic Table in the Common Area: "It Is Home Away of Home"

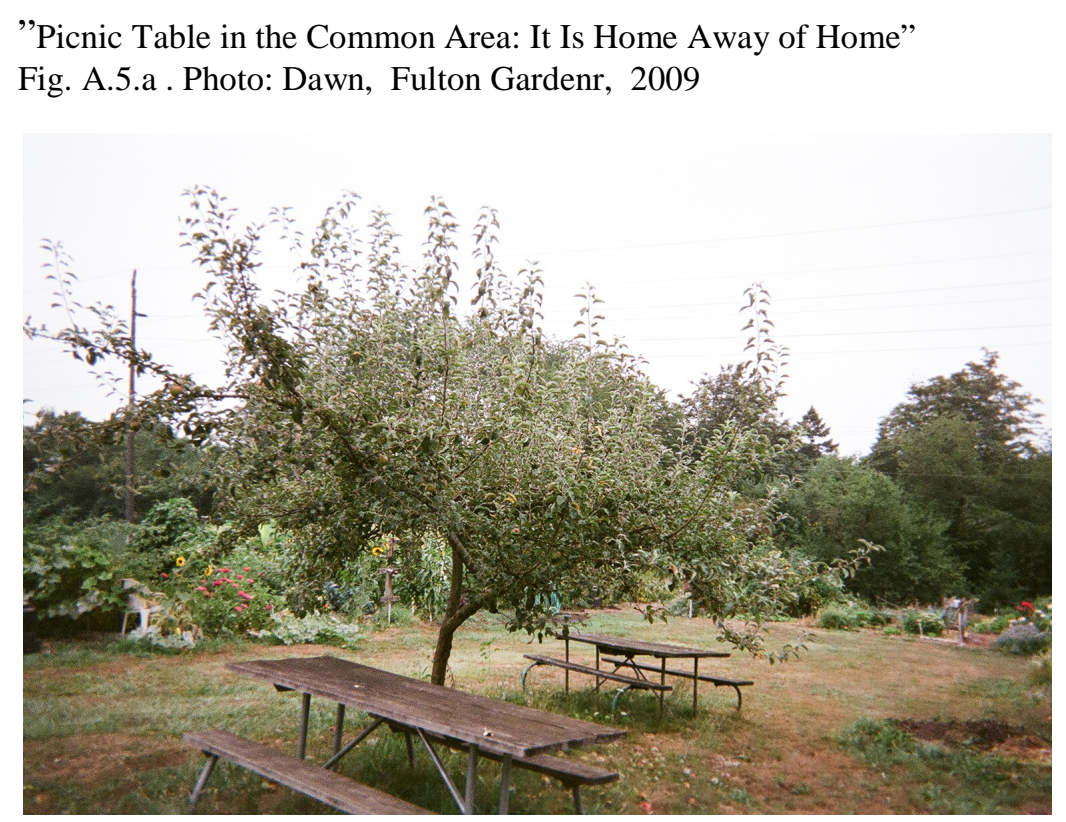

Dawn's plot is just across from the picnic table and apple trees in the common area at Fulton.

The picnic table symbolizes the comfort of public space in life transitions. Dawn's plot borders the communal area and she frequently uses the picnic area. She used to bring her dog here. The apple tree provided the shade. "My dog was pretty happy there. I put a bowl of water, after work or on weekends.'

Coming to the garden is more than cultivating land and growing plants. It is also about relaxation, meditation, and healing. The garden cycle is a reminder of the transformation in life: from birth to the end of the journey. The view from the picnic table defines the garden place for Dawn. It includes the surrounding houses, the rose garden area, the road to the garden, the vistas of downtown, and the magnificent view of Mount Hood. The juxtaposition of urban and rural images is a reminder that community gardens are part of the city fabric. "The community garden is part of the city, is part of city life, and of nature in the city." 
2. Education and Beauty: Ecoroof in the Fulton Rose Garden

" Education and Beauty: Ecoroof in the Fulton Rose Garden" Fig. A.5.b. Photo: Dawn, Fulton Gardener, 2009

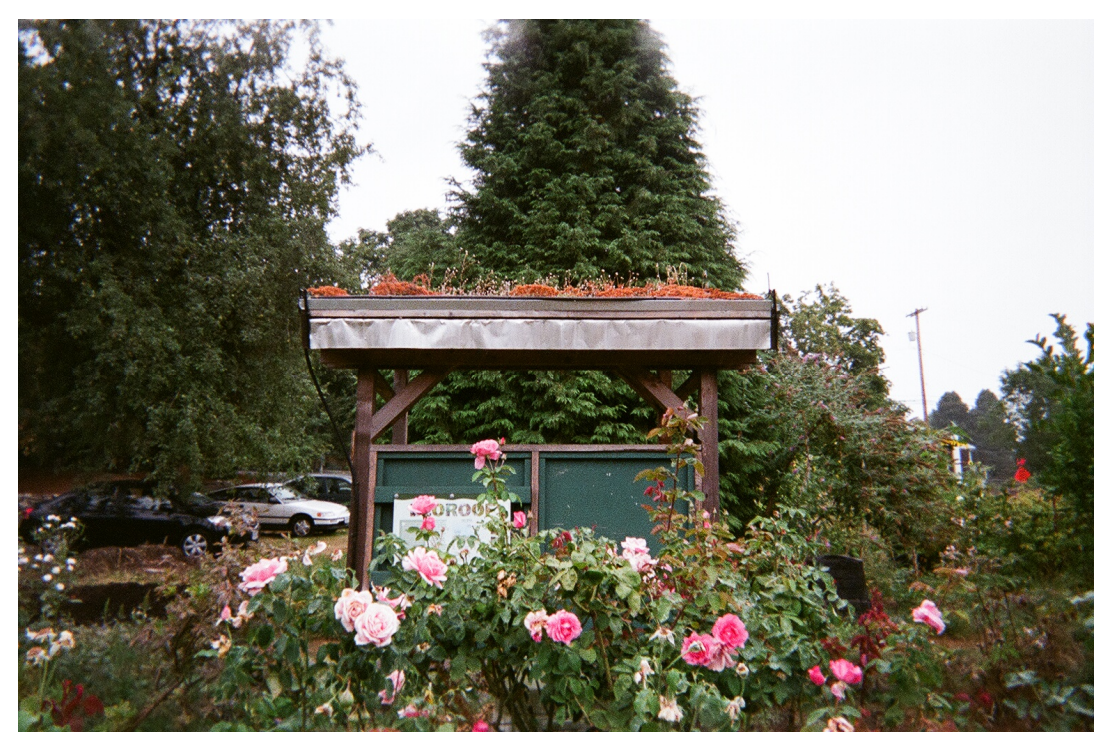

Community gardens are about education and beauty. The eco roof demonstration project highlights the value of community gardens as public spaces. "Ecoroof, the beauty of the flowers, the notion that the education and environmental practices are important to the garden, the water, and other resources". Anybody can come here, learn about designing an ecoroof, and enjoy the beautiful rose garden next to it. "It is an educational opportunity. Everybody has the right to the peace and quiet. People should be able to use the space. It is a public space. It is a safe place for everybody". The community garden also symbolizes the place of harmony and unity between people, plants, and animals. "Bees are important, without the bees we would not have a garden... It is sharing space with animals and people" 


\section{The Road to the Garden}

"The Road to the Garden"

Fig. A.5.c. Photo: Dawn, Fulton Garden, Summer/Fall 2009

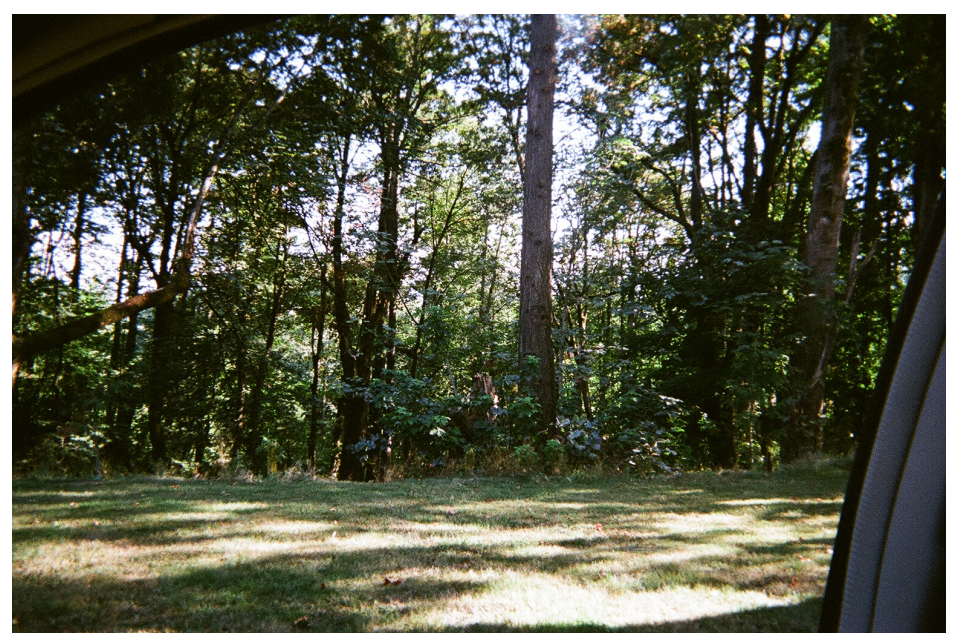

Being in the garden is also about getting to the garden. "My first view of the garden, getting closer to the garden, changing the territory, the experience of getting closer, changes in what I am thinking about: it is a transition zone to get to the garden". The road through the shadow, near the canyon signifies everyday travel to the garden, the memories of the surrounding areas, the contrast between the sun and the shade, and the change in life.

"The experience is just not being there, it is also how I go there. This is a vista of downtown. We are not that far from downtown. We are close to the city. The transition that you see on the way to the garden is a reminder that there is a big city. On my way to the garden, I see the rest of the big city." It is about transition in place and time. It is about the expectation of watching the change and being part of the change through the life cycle. "Appreciation of the garden's random texture, color, and life. The compost bin and the flowers, the natural beauty; not designed by humans; the 'at random' beauty." 
APPENDIX A. 6.

EMPOWERMENT IMAGES

Perky

1. Beauty in the Garden

"Sunflowers: Beauty in the Garden"

Fig. A.6.a. Photo: Perky, Fulton Gardener, 2009

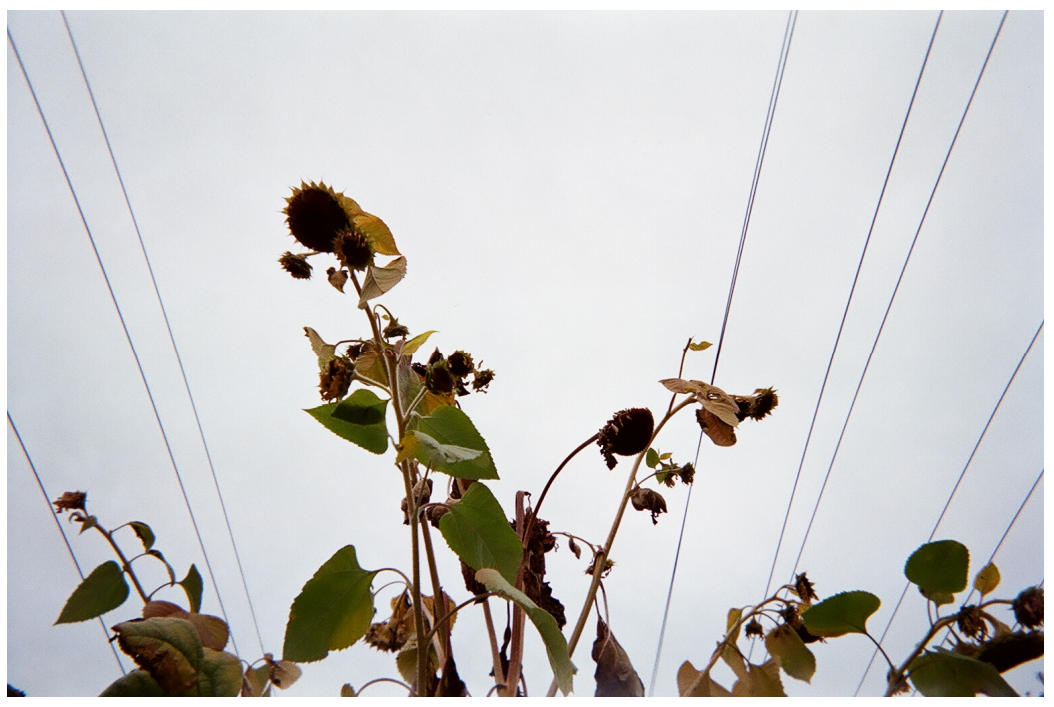

"The sunflowers, they are pretty."

Gardening is about beauty. Sunflowers are a symbol of beauty in the garden and enjoyment of being there. "There is no one important spot in the garden for me; just enjoying the area, being here." It is also the symbol of being alive and being able to do things that are enjoyable and the quintessential part of life." Perky enjoys being able to go the garden to enjoy its beauty. "Sitting there. Watching things growing. Being there in the sun. Being warm. The beauty of nature." 
2. Working in the Garden

"Working in the Garden"

Fig. A.6.b. Photo: Perky, Fulton Gardener, 2009

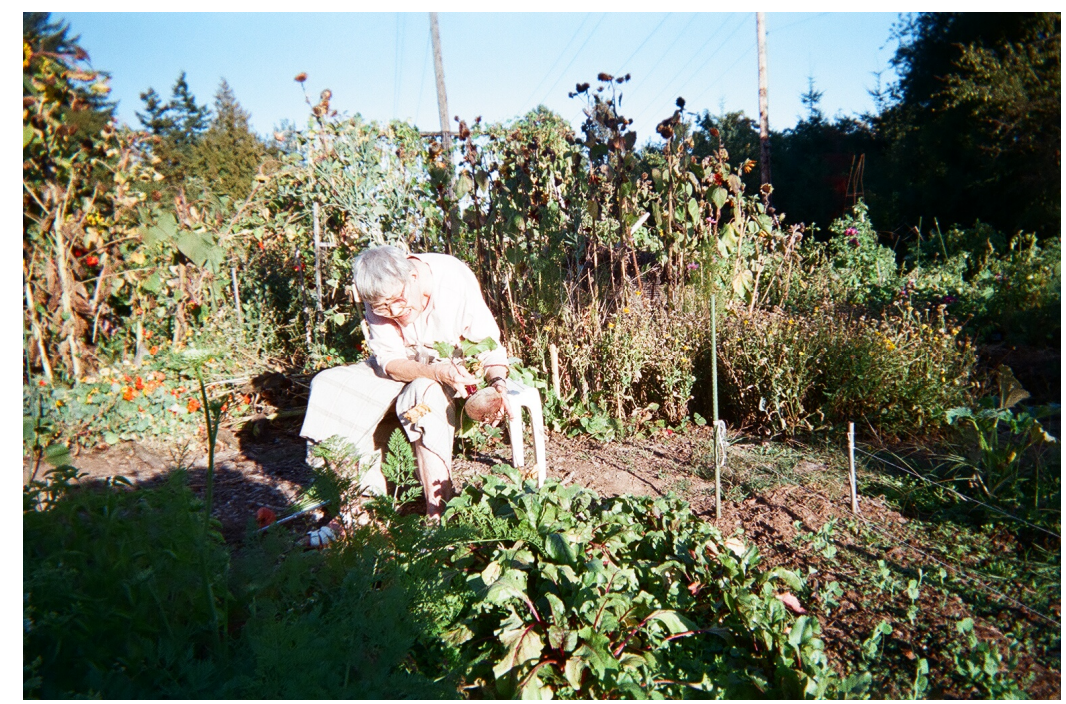

"This one is showing produce, a beet". Perky enjoys the moments she can touch freshly harvested vegetables in the garden. This picture illustrates that she can touch the dirt. She can harvest. She can simply come to the garden and be there. Being able to work in the garden is important."I should not be doing it because of exposing myself to dirt. Why do I do that? The enjoyment and watching the nature; I ignore the fact that I should not be doing it." 
3. Harvest in the Garden

"Harvest in the Garden"

Fig. A.6.c. Photo: Perky, Fulton Gardener, 2009

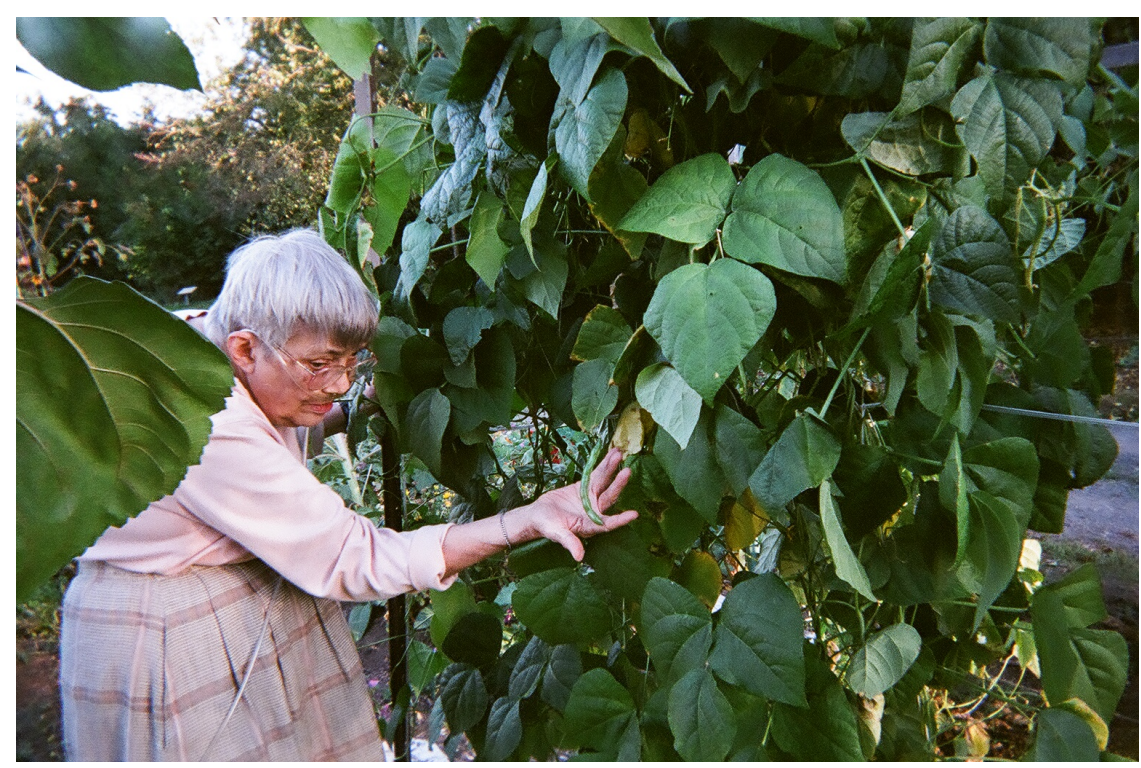

Here, Perky is picking green beans. Perky enjoys coming to the garden and being able to pick vegetables that she and her husband planted in the spring.

"I like this picture because I am working in the garden; picking the green bean..." 
APPENDIX A. 7.

EMPOWERMENT IMAGES

Barbara

1. Proud of My Achievements

"I Am Proud of My Achievements: I Get my Produce from the Garden"

Fig. A.7.a. Photo:Barbara, Fulton Gardener, 2009

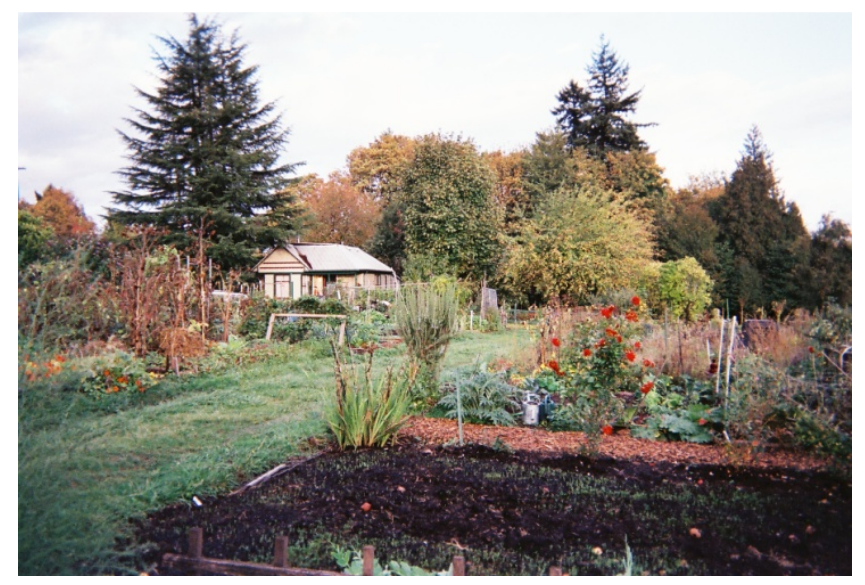

"I am proud of my achievements. I get my produce from my garden". Barbara is proud that she was able to grow her own plants in the garden. The community garden plot is her first experience cultivating vegetables. Both her plot and the asparagus symbolize her sense of individual accomplishment. The fact that she can actually plant seeds and watch the plants grow and observe their visible manifestation on the plot was very important to her.

Barbara considers having access to enough land to be able to produce vegetables as her main accomplishment. "My parents always had a garden, but having my own soil is different. It is my project and it is working in my garden. It is my accomplishment." 
2. The Community of Fulton Gardeners

"The Community of Fulton Gardeners"

Fig. A.7.b. Photo:Barbara, Fulton Gardener, 2009

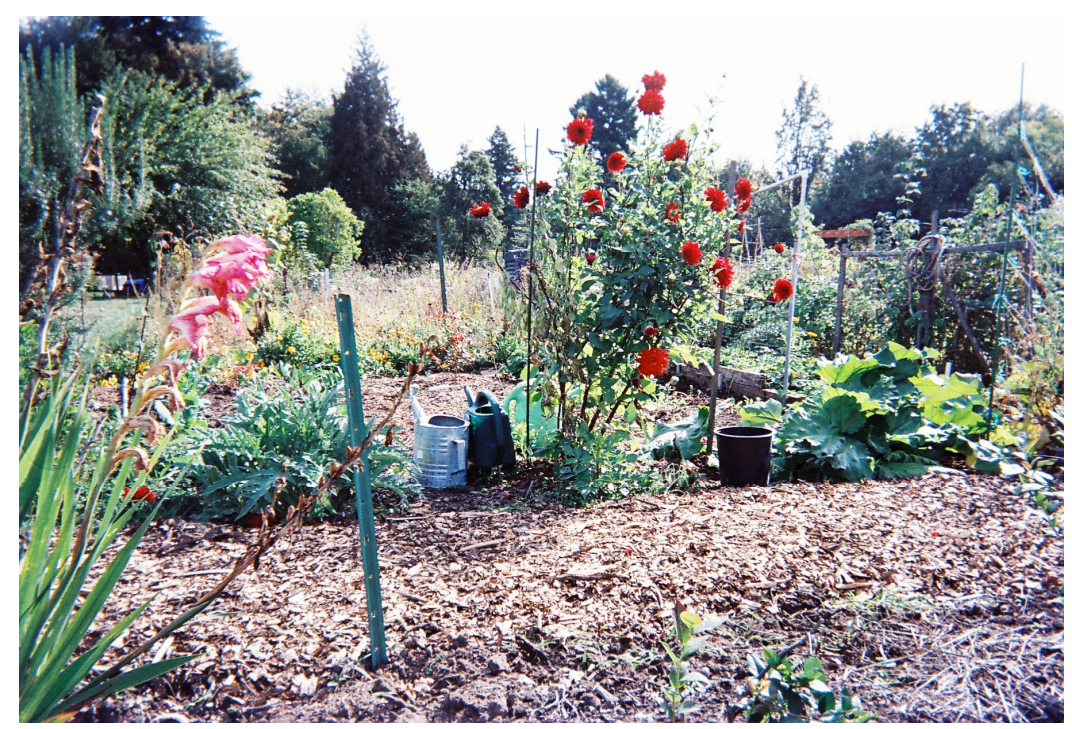

"I get my sense of community in the garden. I get produce, but also I get my community interaction, I do not have to be social all the time. I am not the most outgoing person, but I like having people talking to me".

Barbara defines her sense of enjoyment, relaxation, and safety by the presence of other gardeners' helping hands. In the second picture, she placed two watering cans and a pot on the plot. The next-door plot neighbor, Marsha, frequently leaves the watering cans for Barbara to make it easier to water. In addition, Marsha shares plants with her. David, a few plots down, comes frequently to talk about the changes in the garden. Gerry, the garden manager stops by almost every morning. 
APPENDIX A. 8.

EMPOWERMENT IMAGES

Gerry

1. It Starts with Your Own Land

"It Starts with Your Own Land"

Fig. A.8.a. Photo: Gerry, Fulton Gardener, 2009

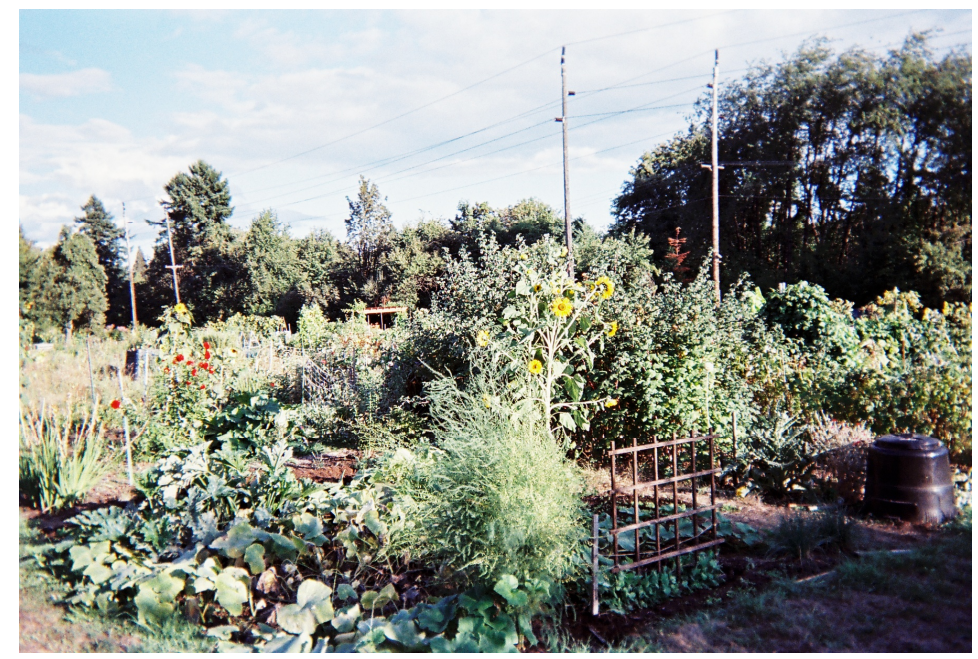

"To have land and awareness of continuity of land is very nurturing". The community garden allowed Gerry to be seriously involved in food production. Being able to grow his own food is the primary reason he cultivates the plants. His fellow gardeners provide a sense of enjoyment and relaxation in the garden; they turn physical chores into pleasurable moments. Having a plot in the garden is a symbol of his ability to grow food and grow connections with other people, inside and outside the garden.

"It is hard to grow things". Gerry's plot represents his hard work in the garden and his subsequent sense of accomplishment in having his own, garden-grown food. "The continuity of the soil, the stability of it, it is there".

Gerry's own plot is the most important part in the garden because first, he can grow his own food; and second, he can enjoy the company of other gardeners. While being able to grow his own food is the primary reason Gerry cultivates, his fellow gardeners provide enjoyment and relaxation in the garden. Gerry is growing food and growing social connections with other people both inside and outside the garden. 
2. Growing Connections in the Community Garden

"Growing Connections in the Community Garden"

Fig. A.8.b. Photo: Gerry, Fulton Gardener, 2009

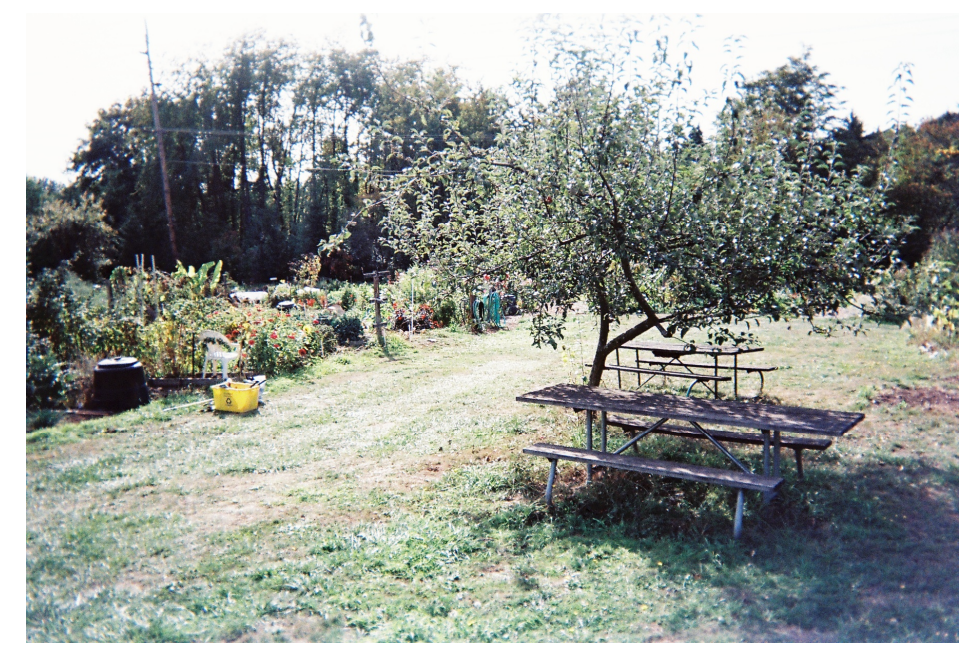

"I became more aware of this picnic area this summer". From his vantage point at his own plot, Gerry had frequently watched people using the picnic table for social occasions. "People would come here, have a sandwich, a drink, and enjoy the evening. It is nice here when the sun goes down." The garden is a "reservoir of social connections". It is enjoyable and relaxing to meet people. The garden provides a different context and reason for people to socialize. "It is the social part that is important here."

The communal space in the garden represents a complex social life people develop in community gardens. People exchange information about gardening, learn from each other, and simply enjoy each other's company. "Picnic tables are not for a big celebration, just to sit down and watch the sun goes down...People come to relax here." The social part is tied with the gardening cycle and is as important as the physical aspect of gardening. Establishing social connections is an integral part of gardening. 
3. Learning in Community Garden: "Where Does Food Come From?

"Learning in Community Garden: "Where Does Food Come From?" Fig. A.8.c . Photo: Gerry, Fulton Gardener, 2009

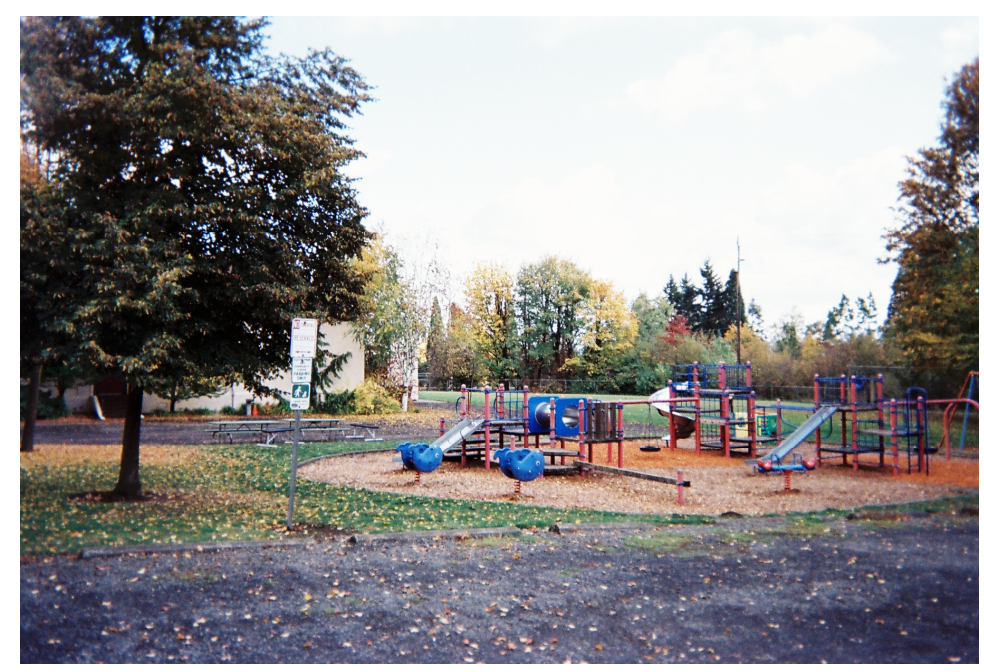

"During the summer, when I work at my plot, I see a group of kids is taking a tour through the garden, with a teacher, the teacher is talking about the garden..." Fulton Garden is part of a larger community recreational area. The Fulton Community Center provides a place for children to play and also, some educational opportunities. Gerry watched groups of well-behaved young children coming to the garden with their teacher and learning about gardening and growing plants in the garden.

This picture symbolizes the value of community gardens in learning about food production "Where does the food come from? "Community gardens provide important places for children to learn about agricultural activities. "The garden provides continuity for social and education activities. They walk around.

Teaching the children from the food comes from connecting the garden with the school. If you down there you would see..." 
APPENDIX A. 9.

EMPOWERMENT IMAGES

Florence

1. The Road to the Garden and Childhood Memories: "O hushed October morning mild,

Thy leaves have ripened to the fall..."

\begin{abstract}
"The Road to the Garden and Childhood Memories: O hushed October morning mild, Thy leaves have ripened to the fall"
\end{abstract}

Fig. A. 9.a. Photo: Florence, Fulton Gardener, 2009

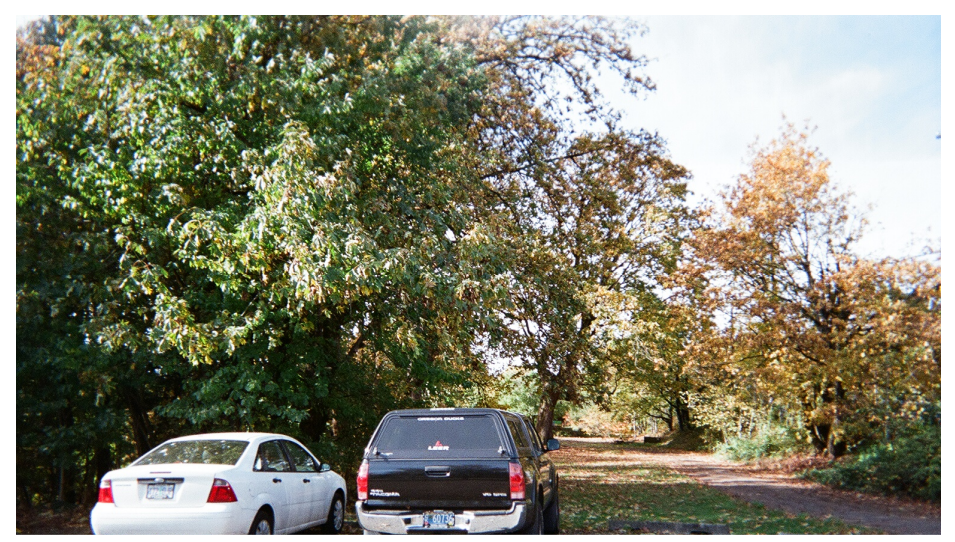

Florence referred to the line from Robert Frost's poem to illustrate her nostalgic feelings about changes in her life. "It is fall: the color, the shadows, and the nut trees. I am from New England and when it gets red, it is fall in the garden. It is time to harvest. It is country, and a touch warm. The sun is out, it sun warm. Trees are turning red and there is a nip of frost, just like in Robert Frost' poem." It reminds Florence about her childhood in New England, coming back home from a boarding school in New York. The country road took her home, to her parents' house. "It is fall in the garden, it is time to harvest, it is country, a touch warm..."

This is a picture of the road connecting the Fulton Community Center parking area with the gravel road to the community garden. It suggests a tranquil and bucolic country setting despite the constant, roaring sound of the nearby freeway. "It is safe on the road, country is quiet. Looking at the picture one tries to forget the roaring noise of the freeway. We are on the freeway here."The country road symbolizes the connection between the past and the present. The road to the garden is about the expectation of getting closer to the garden, the place she is transforming for her family. Getting closer to the garden is getting closer home; it is a new definition of her home in Oregon. The garden space is becoming Florence's new concept of home. The road symbolizes the transition from her New England roots to a new place in Portland. 
2. The Place of Beauty: Family Space at the Community Garden

"The Place of Beauty: Family Space at the Community Garden"

Fig. A. 9.b. Photo: Florence, Fulton Gardener, 2009

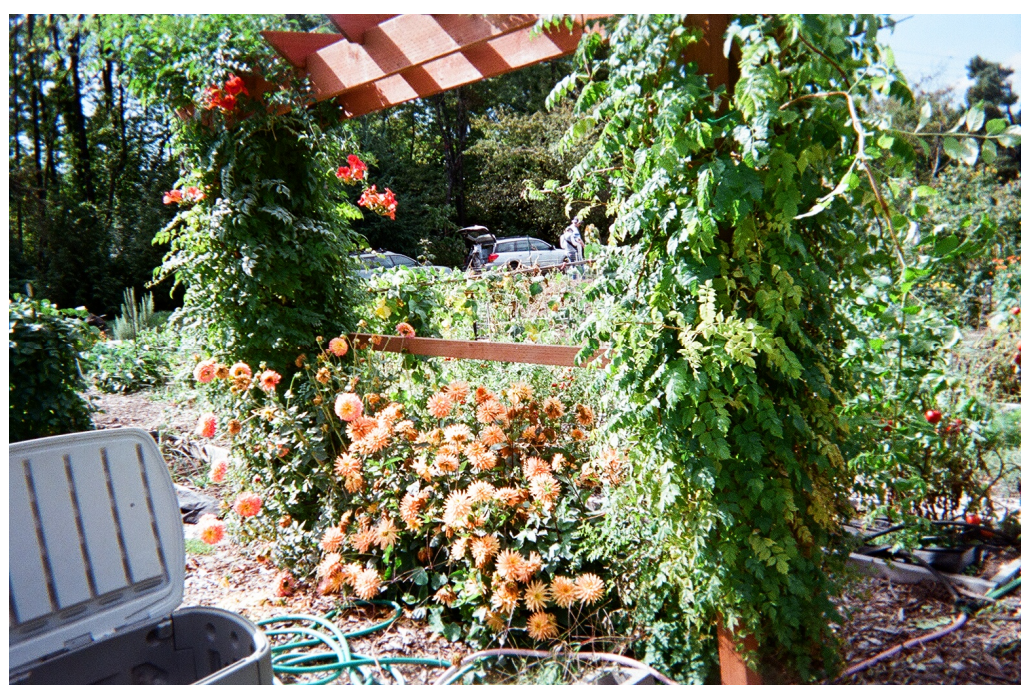

"My most important thing is the feeling that the garden is the family place. It is not about the specific place. It is about the feeling, and it cements the family feeling."

The place of beauty in the garden is about transforming a small portion of the community garden area into an extension of her backyard. Florence and her husband live in a condominium in downtown Portland and relocated from the east coast six years ago to be near her daughter and granddaughter.

The transformation of the community garden plot is about having a place for her family where her husband is comfortable and she can spend time with her grandchildren. The flowers symbolize the safe and relaxing place, an extension her backyard. "It is vibrant, warm and energetic. The energy is in the way you use the place. People come by and ask why did you do that? " 


\section{Family and Community Connections}

"Growing Family in the Community Garden"

Fig. A. 9.c Photo: Florence, Fulton Gardener, 2009

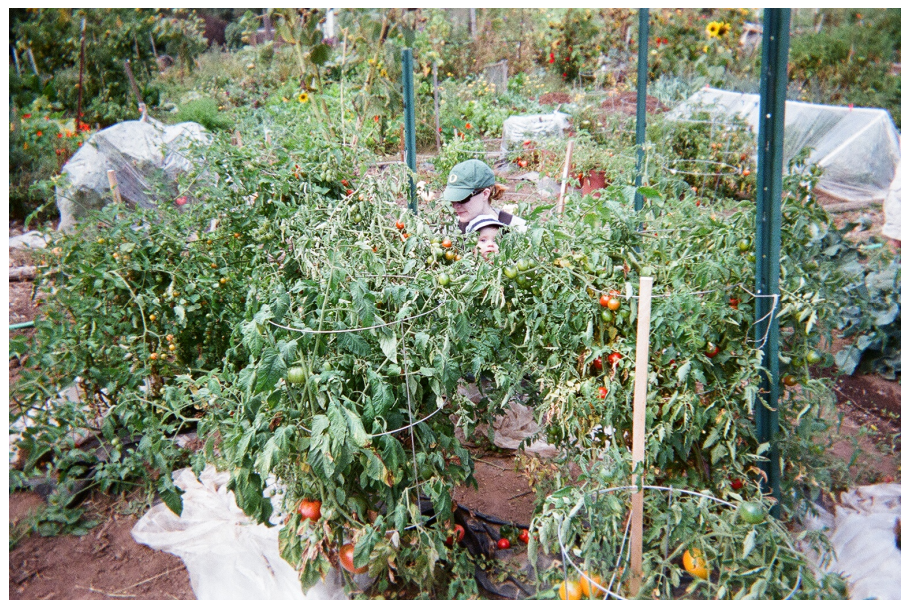

"The family connections through the land are part of me. It is realization that your childhood is important in shaping memories that shape your life." The garden space is important for grandchildren to shape their memories about safe and happy places and to learn about nature and community. "It is multigenerational. I have the garden for my grandchildren. I like to watch them and help them learn things: how to grow vegetables and how to respect other people's produce. I like them to play."

The garden place is important to make a connection with the family. "Family connections. I am a grandmother and I like the children to have a good time. I would like them to remember me as a vibrant person." The grandchildren come to the garden and learn not only about growing vegetables, but also about interacting with other people "They need to ask for permission to get other people's produce. It is public space, it is not private". Gardening is important to connect families through creating memories of other people. It is about feelings. "The garden is a place for children and adults to grow and learn together." 


\section{Garden Bounty: Harvest in the Garden}

"Garden Bounty: Harvest in the Garden"

Fig. A. 9.d. Photo: Florence, Fulton Gardener, 2009

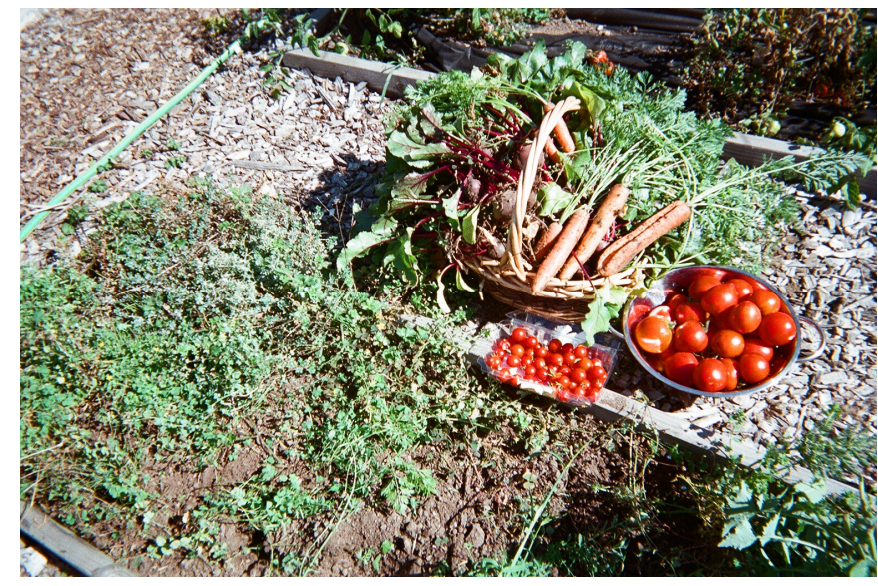

"Garden Bounty: Harvest in the Garden"

Fig. A. 9.e. Photo: Florence, Fulton Gardener, 2009

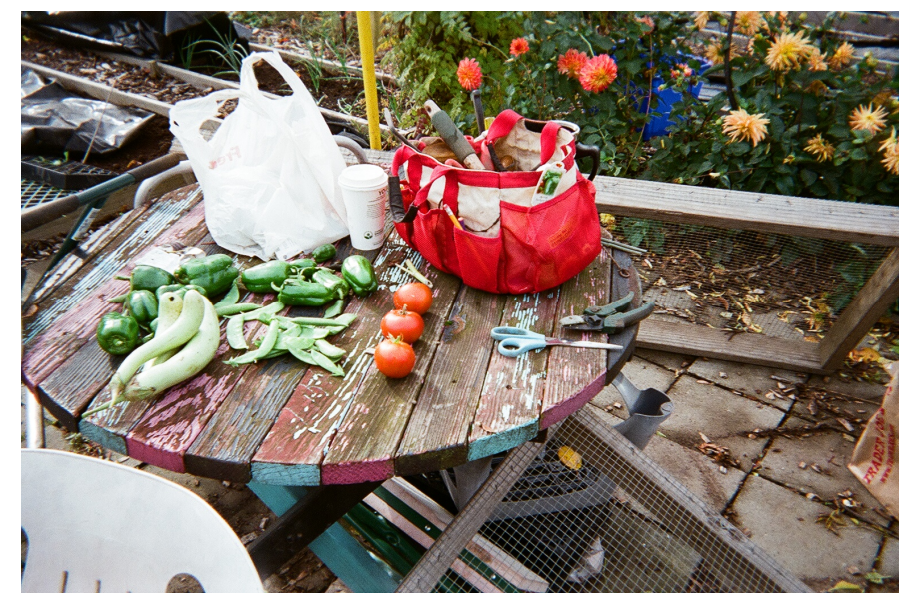

"The bounty of the garden, that which you work for. We work hard. We eat well. It is tastier and you appreciate it more if you work for it. It is a reward for the hard work." Growing organic food is important for heath purposes. It is about cultivating and transforming land. Florence has two plots at the garden. One of the plots is converted into a vegetable garden. The enjoyment of growing root vegetables in Oregon, in contrast to the New England climate, is a way Florence is transitioning to her new life in Oregon. "The harvest is the most enjoyable activity. It is the reward for what you do." These pictures are another reminder about learning and transformation in life. "The season is very different in Boston. By November, you have frozen ground. We never grew any root vegetables in Boston. Being able to grow carrots and beets..." 
EXHIBIT A. 10.

EMPOWERMENT IMAGES

Marsha

1. Beauty and Diversity in Life and Garden

"Beauty and Diversity in Life and Garden"

Fig. A. 10.a. Photo:Marsha, Fulton Gardener, 2009

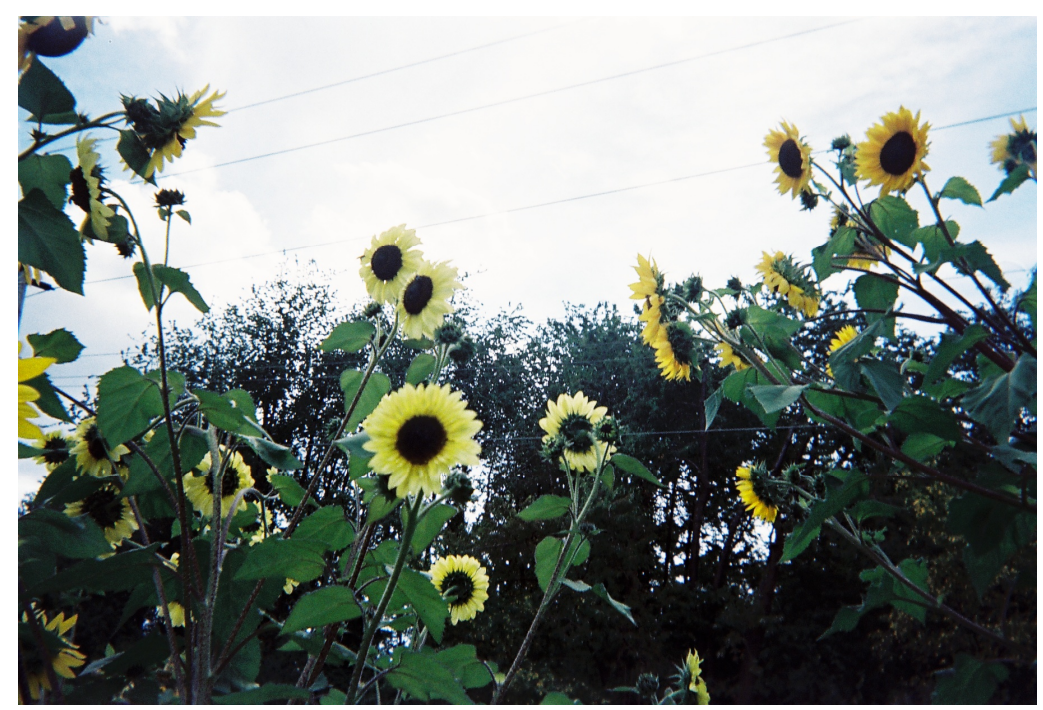

Marsha grows sunflowers in her garden. She always has sunflowers: people like them and birds love them. The picture of sunflowers represents the diversity and beauty in the garden." I am always fascinated by how plants look. A variety and shapes, a number of patterns in nature."Sunflowers are cheerful and forgiving; they will survive and return. They are very faithful.

Sunflowers are a symbol of diversity, beauty, endurance, and survival in the garden and in life. They share their stories like people. Just like in Marsha's favorite poem by Mary Oliver "Come with me into the field of sunflowers". 
2. The Everyday Meditation, Expectation, and Promise: Starting the Journey to the Sacred Place

"The Everyday Meditation, Expectation, and Promise: Starting the Journey to the Sacred Place" $\quad$ Fig. A. 10.b. Photo:Marsha, Fulton Gardener, 2009

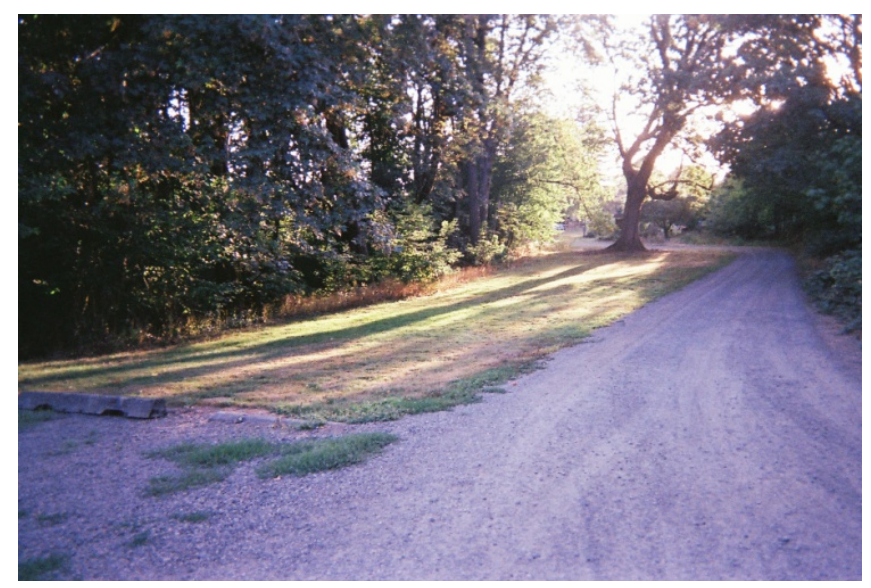

"This is where it begins, a transition between urban and rural. This is why the gardens are so amazing". The unpaved and graveled road is the most important part of Marsha's garden experience. "Anything that has a road is part of the gardening experience for me". First, the road symbolizes a wonder of the urban garden, a gravel and unpaved road in the middle of the bustling city. It is located between two busy roads: I-5 and Barbur Boulevard and yet it gives a sense of being connected to nature in the city. Second, it symbolizes an everyday journey to discover and experience life in a different way.

The garden is constantly changing and there is an element of surprise, the beauty of life and expectation of anticipation. The gravel road is about meditation. "The sun is going down, the naturescape of the woods, the gardens, the interstate, Barbur, and here we are, in between the streets ... I see people walk here and their demeanor changes; I see them walk on the path around the garden; I seem them pray, I see a rosary in their hands." 


\section{The Garden is Near:” I Can See the Splash of Light “}

"The Garden is Near: I can see the splash of light"

Fig. A. 10.c. Photo:Marsha, Fulton Gardener, 2009

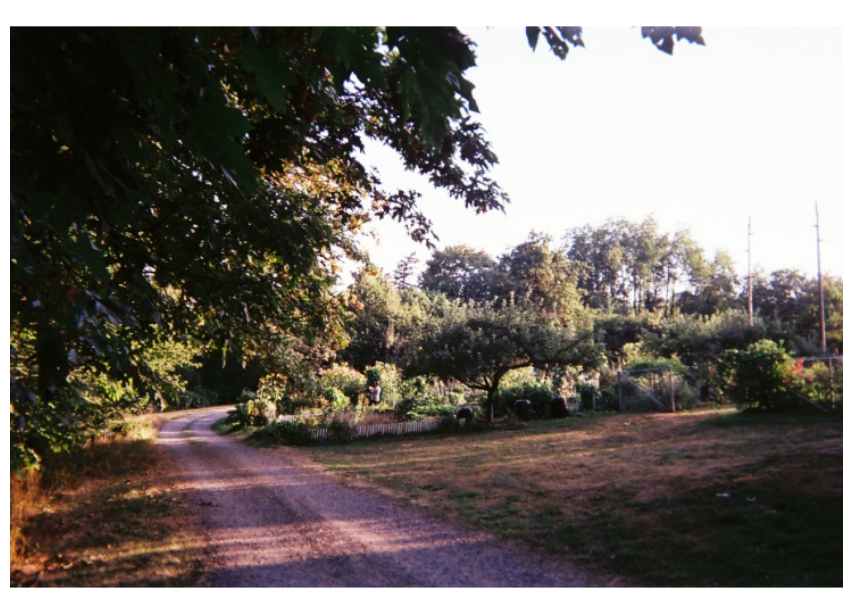

The five-minute walk is just about to end as we come closer to the sacred space in the garden. I lose track of time. It is like a yoga breathing experience. I walk over the sky, come to the garden, and there is the element of surprise. The garden is different than the day before".

Every day is different. Light and sun, as the plants grow and look different. Their beauty is in their shape, color, and diversity. "You can imagine how the people rest after they work here; people come and spend their time and not just garden." 
APPENDIX A. 11.

EMPOWERMENT IMAGES

Merrill

1. A Well Tended Garden: The First Step to Beauty

"A Well Tended Garden: The First Step to

Beauty"

Fig. A. 11.a. Photo: Merrill, Fulton

Gardener, 2009

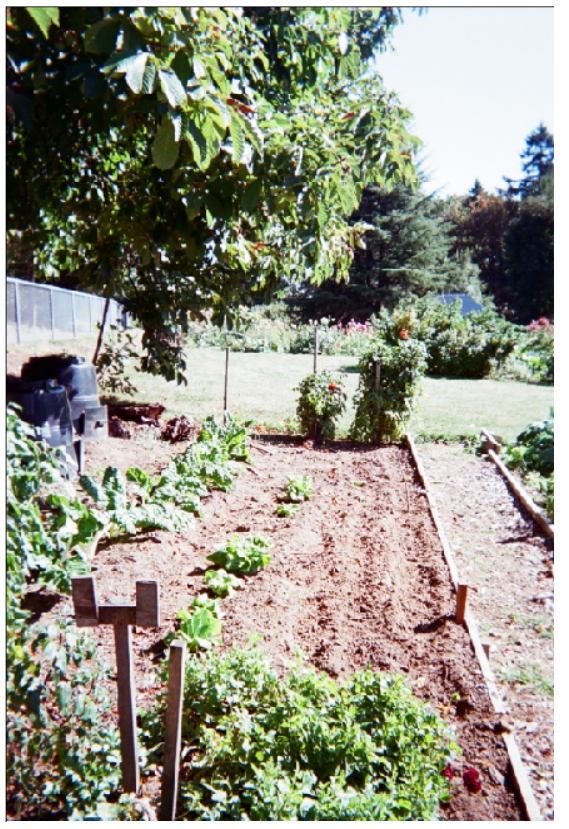

A well-tended garden is a joy.

Tending the garden in an organized way is one of Merrill's most enjoyable activities. The picture represents one of his two

plots, the vegetable plot. Rows of orderly organized plants, a composting bin, and a watering hose holder are the centerpiece of his plot. A well-weeded path is clearly visible next to the plot. A well-tended plot is a promise of future joy of harvesting and beauty in the garden. Merrill constructed a special water hose holder to make his gardening activities more orderly and efficient. It signifies the beginning of expectations for the future joy of gardening: harvesting and sharing the beauty of the garden.

It is pleasurable to look at a well-tended plot. Well-arranged vegetables, leeks, squash, and zucchini are planted in tidy rows that symbolize beauty and harvest in everyday living.

Merrill is a bit resentful of people who seem not to be able to tend their garden properly and waste land by not maintaining their plots for food and beauty production. 
2. Beauty in the Garden

Merrill's second plot is devoted entirely to flowers. Here, in one of his three most important pictures, a splash of colorful dahlias marks the corner of Merrill's plot. Dahlias are one of the most" giving flowers", they bloom endlessly from midsummer to mid fall. Gardening is about beauty. Tending garden is converting soil into beautiful flowers and vegetables. Merrill decided to maintain his second plot in the garden to grow fresh flowers for his wife and his family. The cheerful splash of colors symbolizes both the beauty and sustenance of the garden. 
3. Sharing the Beauty and the Bounty of the Garden

"Sharing the Beauty and the Bounty of the Garden"

Fig. A. 11.c. Photo: Merrill, Fulton Gardenrt, 2009

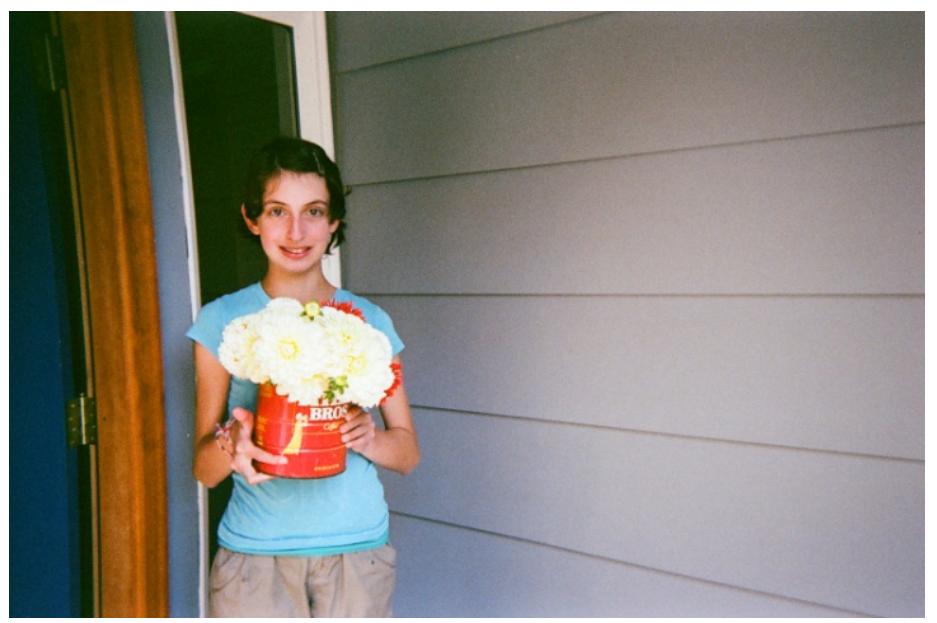

Merrill's granddaughter holds beautiful flower in her arms. Gardens are needed to share beauty with family and strangers.

Sharing the harvest from the garden with both his family and strangers is an important part of the cycle. Merrill not only brings flowers home for his wife and granddaughter, but also gives away flowers and produce to his fellow gardeners and people who just walk through the garden. The ultimate beauty of the garden is about sharing with family, friends, and strangers. Sharing the beauty of garden harvest is about the smile on his granddaughter's face. This picture symbolizes the complete garden cycle, from the beautiful and tidy row of vegetables in Picture 1, through the splash of color in the garden, to the smile on people's faces who received produce from Merrill's garden. Thus, a complete gardening cycle is about cultivating land and sharing the harvest with other people. 


\section{APPENDIX A. 12. \\ EMPOWERMENT IMAGES \\ David}

1. Art and Garden Beauty: Compositions of Natural Shapes, Colors, and Structures

"Art and Garden Beauty: Compositions of Natural Shapes, Colors, and Structures"

Fig. A. 12.a. Photo: David, Fulton Gardener, 2009

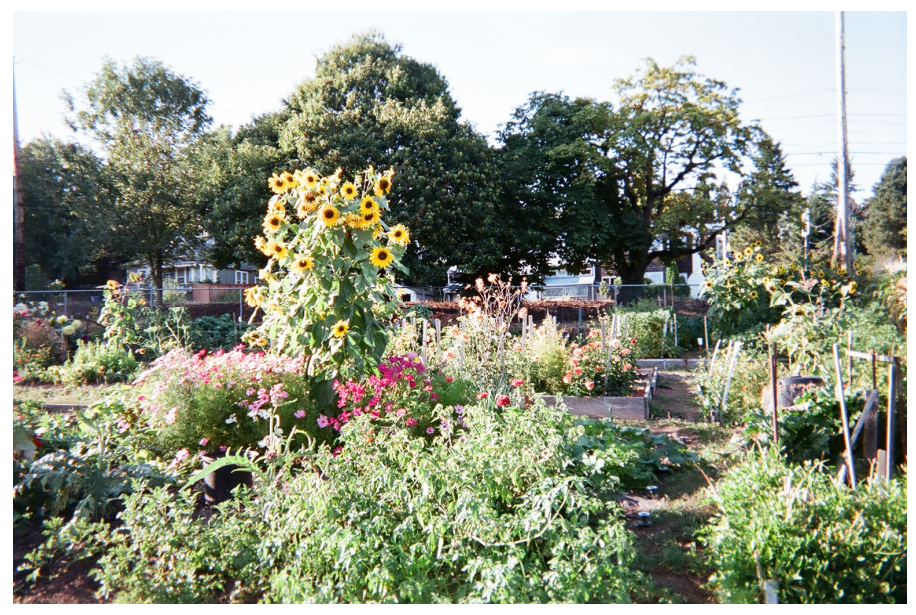

"The big view of all the magnificent flowers and their composition give a good sense of space." The beauty of the garden, the texture, the colors, the sunflowers, and the roses create a background for his own art, his plots. "

"It is like painting with plants...I like to get a big picture of the garden, I like a view of the overall area. Many of my pictures are 'big pictures' of the whole area, basically a forest park. Trees around the garden give so much character ... I love the sky; sky shows are tremendous, the clouds, the evening, the open space around me, the country side, the open country feeling..." 
2. Gardening as the Act of Creating Art

"Gardening as the Act of Creating Art"

Fig. A. 12.b. Photo: David, Fulton Gardenrt, 2009

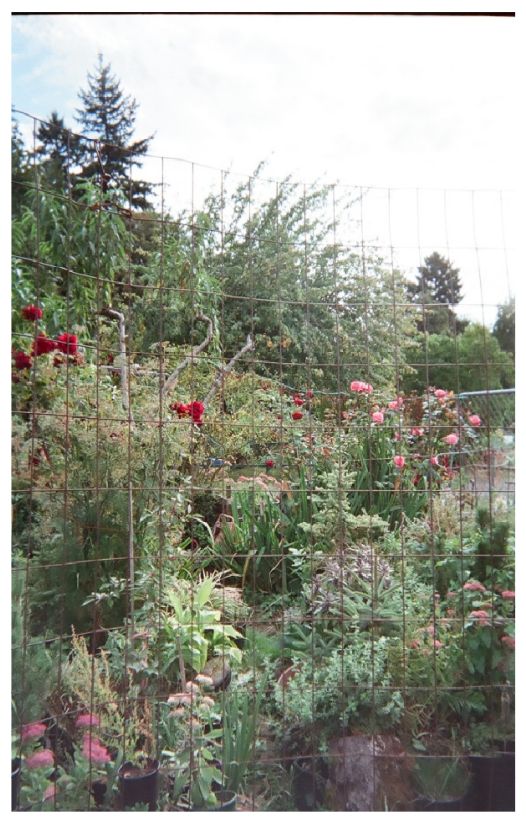

In second picture, David captured the details of his artistic expression from the outside of his plots. The chain link fence marks the separation between David's unique art and the rest of the garden. "Gardening is like working on a piece of art; you use materials at hand: flowers, stones, pots, trees, other things... It is about composing it into an object of art..."

David has two plots in the garden and his primary interest is to transform his plots into objects of art and beauty. His plots represent his artistic expression of beauty and unique objects of art. "I try to capture as many different colors, a variety. It is never boring, so many different shapes. It is always changing, different pictures every day. The more natural, the more I like it...I like to see what happens when they grow..."

David's two plots are his most important places in the garden. "Making changes in the garden and personal space is important to me..." David can watch the garden from his own, fenced plots. He feels safe behind his own fence. 
3. Unused Land: Eyesore and Nuisance in the Garden

Unused Land: Eyesore and Nuisance in the Garden

Fig. A. 12.c. Photo: David, Fulton Gardenrt, 2009

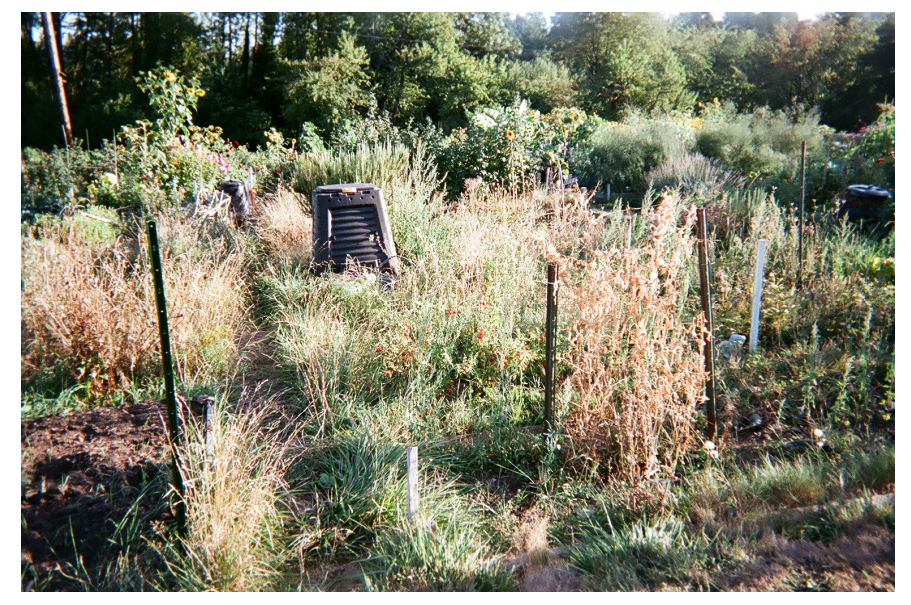

"It is an eyesore. It is ugly. It is a nuisance. It is a problem..."

"The garden is too unique to be underutilized; every single plot needs to be used, to the maximum." Unused land is a nuisance in the garden. First, the land is not transformed into productive use. Second, weeds from the unused plots spread into the rest of the garden. Third, it is not pretty. If people are not responsible, the land is wasted. "They should have resigned. We have a waiting list. We signed a contract with certain responsibilities. These are invasive plants and they will be everywhere soon.

The wasted land symbolizes the need to convert the land into an object of beauty. "From the artistic point of view, it ruins the context of the garden as a place of natural beauty. It is a shame that this land is not cultivated..." 
APPENDIX A. 13.

\section{EMPOWERMENT IMAGES}

Lisa

\section{1. "Imperfect" Patterns of Life}

"Imperfect" Patterns of Life" Fig. A. 13.a. Photo: Lisa, Brentwood Gardener, 2009

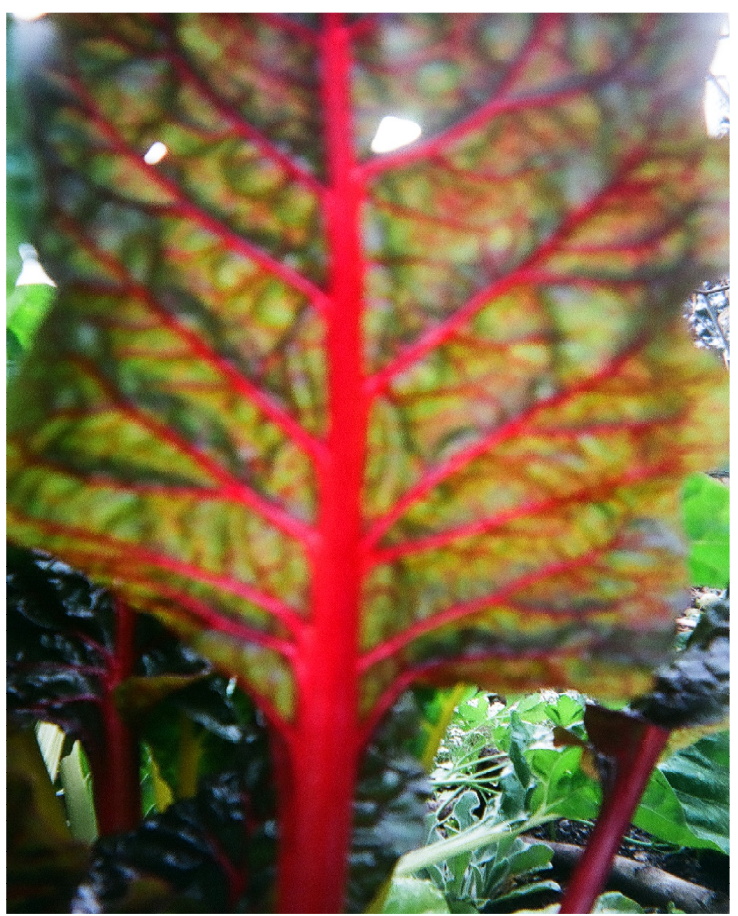

"Sun shines through the hole in the leaf made by an insect. There is a crack in everything. That's how the light comes in..." A brilliant red system of tiny leaf veins, a hole in the leaf with the shining dot of blue sky symbolizes a universal pattern of life in nature. It represents the illusive balance between perfection and imperfection and the energy flow and glow in nature. The red veins symbolize the flow of energy.

The blue hole is a symbol of imperfection and vitality in life; it channels a steam of light for other plants. An "imperfect" leaf with a hole stimulates the growth of the plants beneath that are dependent of the stream of light for their growth. Thus, the imperfection in the leaf is the source of growth for other plants and the energy flow. It also symbolizes the illusiveness of the human perception of what is perfect and beautiful in nature.

"Being close to the soil, where the air meets the earth, the border, the boundary... The ground, it does not matter where...everywhere in the garden. I come to the garden to reconnect with earth...to feel the unveiled presence, the energy, the spirit of place... You cannot quite capture the illusive element of the natural world. You can feel but you cannot see the details. You cannot really harness feeling of the presence. It is indefinable form. It is the spirit of things, life's creative force..." 
2. Transition and Natural Order in Nature

"Transition and Natural Order in Nature"

Fig. A. 13.b. Photo: Lisa, Brentwood Gardenrt, 2009

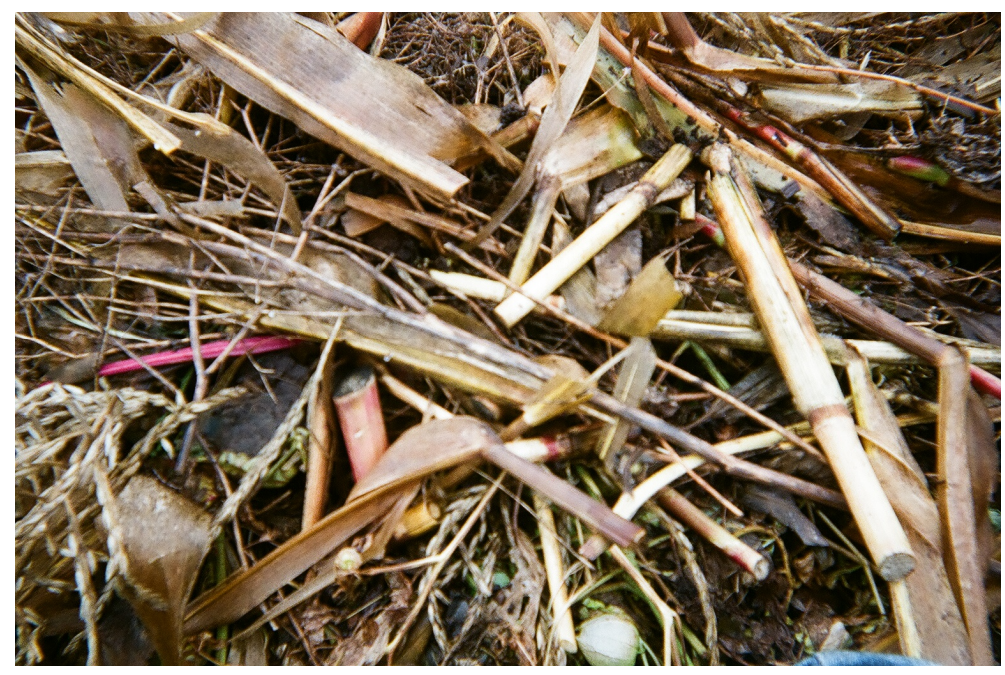

"Compost debris, there is always this natural order that looks like chaos... "

A picture of a heap of plants, ready for composting. Brown, reddish and gray hues connect. Corn and sunflower stalks blend with withering herbs. "A picture of earth and compost, just dark, rich soil that is there, a transition picture...It is corn, green beans, cabbage, tomatoes, in the center. All corn, from the summer. The sunflower stalks, roots of things, compost..."

The picture is a reminder that observing nature is the first condition to understanding it and being respectful of other spirits in the garden. There is a little frog hiding in the pile. It is hard to see in this picture. Lisa discovered it when she was watching the birds "Birds were pulling and grabbing the pieces of the compost stalks of corn. When I pulled it out, there was a green frog on the piece of the stalk. The frog, he kept moving on... I called him Prince Charming..." 


\section{Cycle of Life, Presence and Unity}

"Cycle of Life, Presence and Unity" Fig. A. 13.c.

Photo: Lisa, Brentwood Gardenrt, 2009

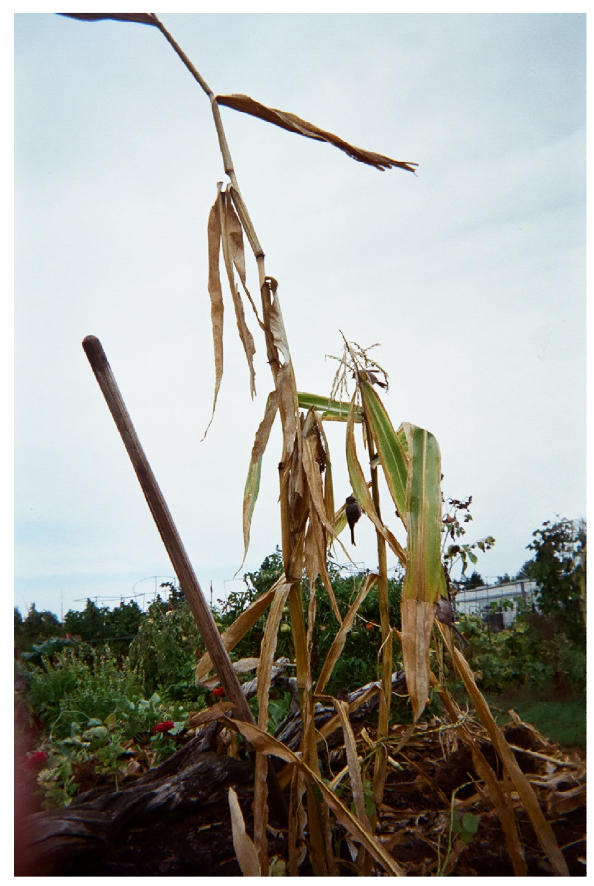

"The bird I captured from the ground level looking up; the symbols of work in nature. The garden is working too; we are getting ready for winter. I was not alone in my preparation for winter; this is my shovel. The bird is working. We are all working in the garden, it is nature " $\mathrm{A}$ bird, little sparrow, sitting still, aware that it has been watched by me..." A picture was taken from the ground level and reflects a human perspective in observing nature. "Pictures of wildlife are really

important to me, Fava bean germinating is important, a giant spider, delicateness of the spider, the birds, the frogs..."

The picture also symbolizes the unity of animals and humans working together in the garden: the sparrow was getting ready for the winter just as Lisa was working in the garden. The shovel symbolizes the human work in the garden, next to the bird sitting on the withering stalk of corn, as fall and winter is coming, marking transition time in the garden. "You have to be grounded to grow. It takes time. It is not going to happen overnight. It is in the passing of the season. People tend to be disconnected and disturbed by mechanical things. To be grounded is to grow, go the base level, and accept yourself. The mechanical things deprive people from a moment of connection. Humans are part of nature, the connection is important... the solitude is a way to achieve it..." People need spaces to meditate their connection to nature to grow and thrive in life. 
EXHIBIT A. 14.

EMPOWERMENT IMAGES

Stephanie

\section{Stephanie's Garden}

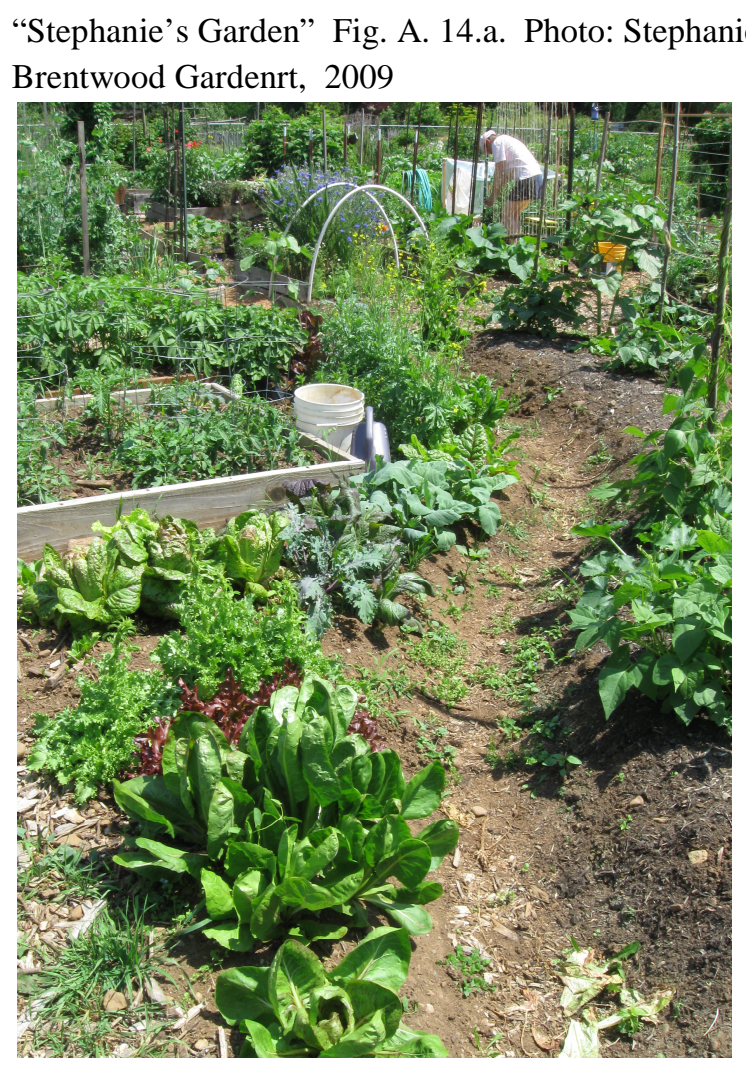

Stephanie's plot is her most important part in the garden. It is her pride, enjoyment, and relaxation.

"A view from my plot, the whole garden... I love to look at what is around me. You can imagine that you are on the farm, no houses on one side, it looks open..."

The feeling of having her own place is important to Stephanie. The garden provides a sense of openness and country in the city. "Open space, no houses, vistas from the garden, no houses, I do not focus on the cell tower, the cell tower, I do not think about it..." 
2. Japanese Mustard Leaf: Beauty in the Garden

"Japanese Mustard Leaf: Beauty in the Garden" Fig.A. 14.b. Photo:Stephanie, Brentwood Gardener, 2009

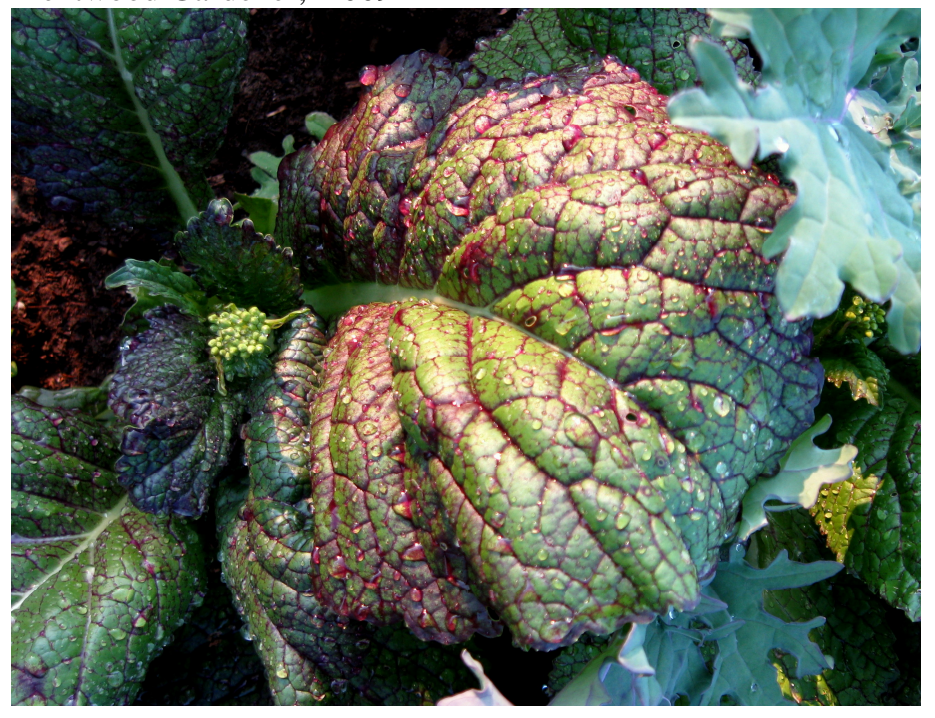

The beauty of the garden is to be able to grow your own food. Here the leaf of Japanese mustard symbolizes Stephanie's passion for growing beautiful and useful plants. The contrast between different shades of burgundy red and green defines the beauty of a single leaf. "The whole harvest season makes me really happy; harvesting in general is my favorite..." 


\section{A Drop of Water on a Collard Green Leaf: Simple Beauty}

"A drop of water on a collard green leaf: simple beauty"

Fig. A. 14.c. Photo:Stephanie, Brentwood Gardener, 2009

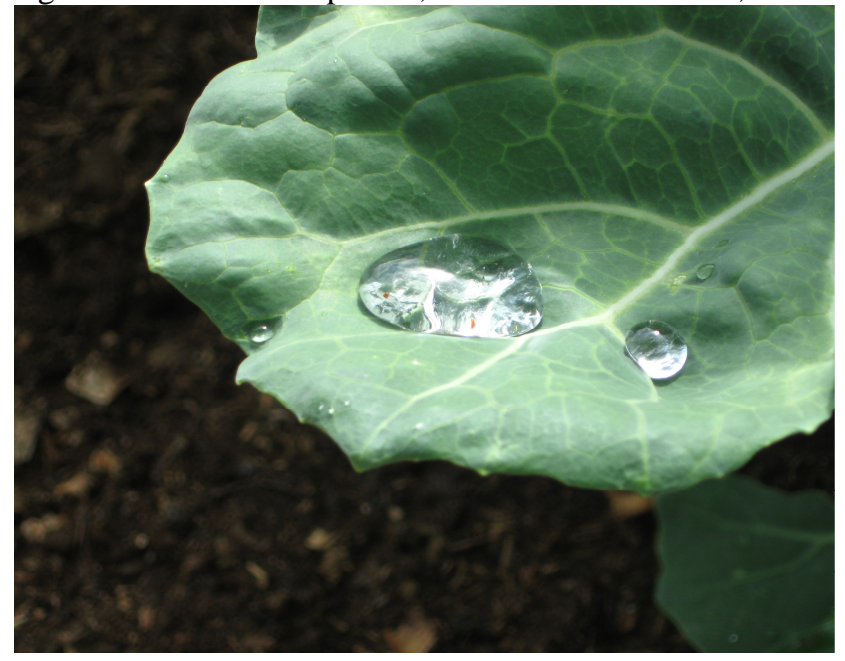

The simple beauty of a few drops of water lingering on a single leaf..." A reflection of life in the drop of water; it is beautiful to me..." This picture symbolizes the juxtaposition of simplicity and usefulness as attributes of beauty in garden vegetables.

The contrast of dark soil in the background and the shades of green, symbolize the simplicity of the beautiful and edible plants.

"My sense of beauty is the wholesome vegetables, the beauty of things growing..."

\section{The Beauty of Growing Your Own Food}

"The beauty of growing your own food" Fig. A. 14.d. Photo:Stephanie, Brentwood Gardener, 2009

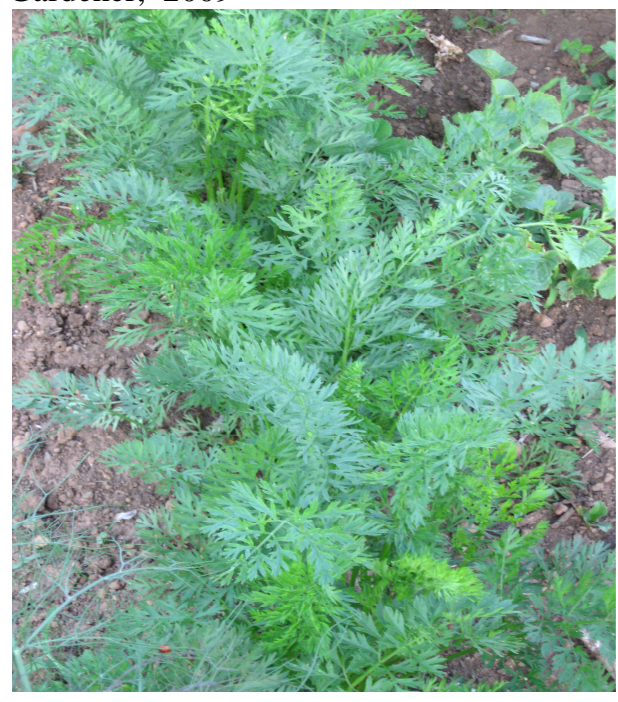

A picture of exuberant carrots with blue and green tops is an example of Stephanie's fascination with the beauty and bounty of the garden. "It makes me so happy to look at my carrots..." Simplicity, beauty and happiness blend in this picture of early carrots.

They also symbolize the promise of harvest, which is Stephanie's favorite activity in the garden. Harvesting her own vegetables and processing them is Stephanie's joy and relaxation. The ability to grow her own food and experiment with different gardening techniques is one of her major accomplishments in the garden. "I can grow my own food, and the beauty around it, the beauty associated with growing my own food..." 
APPENDIX II. A. 15.

EMPOWERMENT IMAGES

John

1. The Beginning: Reed College Community Garden

"The Beginning: Reed College Community Garden"

Fig. A. 15.a. Photo:John, Brentwood Gardener, 2009

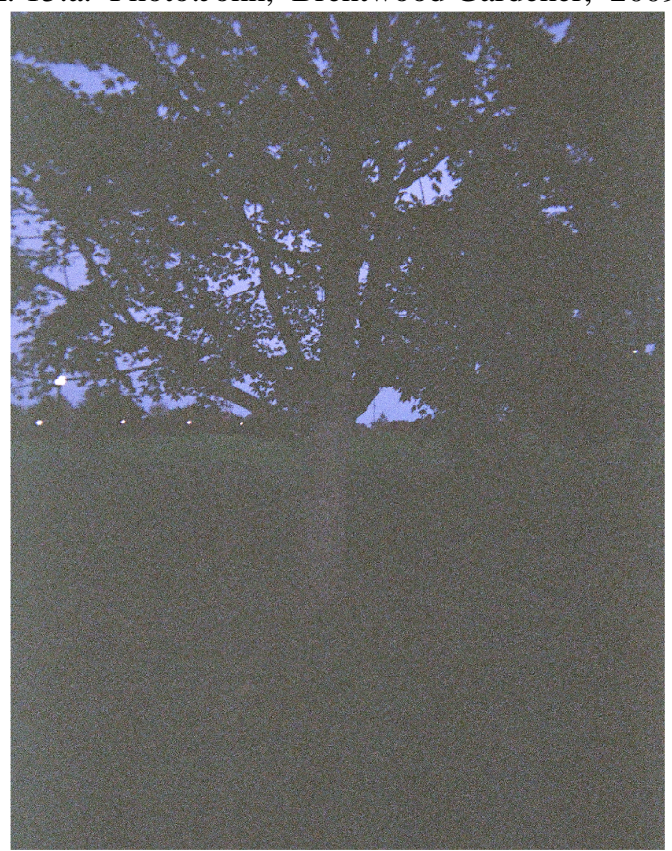

The starry night picture of the former site of the community garden at Reed College. It symbolizes the beginning of change in John's life. The garden was redeveloped into a dormitory. The flickering lights in the dormitory windows

mark the location of the garden on the site.

This is an important starting point in John's garden story.” This is the tree. This is where it all began, in the Reed College community garden. They replaced the garden with some dorms, very pretty buildings, but threw us out and the connection to gardening is lost. It is a beginning of the story of how we came over to Brentwood."

The Reed College garden is the place where John first became aware of gardening. It is a memory of the beginning of John's interest in gardening and his partner's help to transform his life. John's story is about the work in the garden as a life transformation and expression of love. John's partner encouraged him to start gardening at Reed. It was the beginning of change in his life. The tree on the Reed Garden site marks the beginning of change in John's life through gardening. 
2. A Path to the Garden: A Path to Life Transformation and Love

"A Path to the Garden: Path to Life Transformation and Love"

Fig. A. 15.b. Photo:John, Brentwood Gardener, 2009

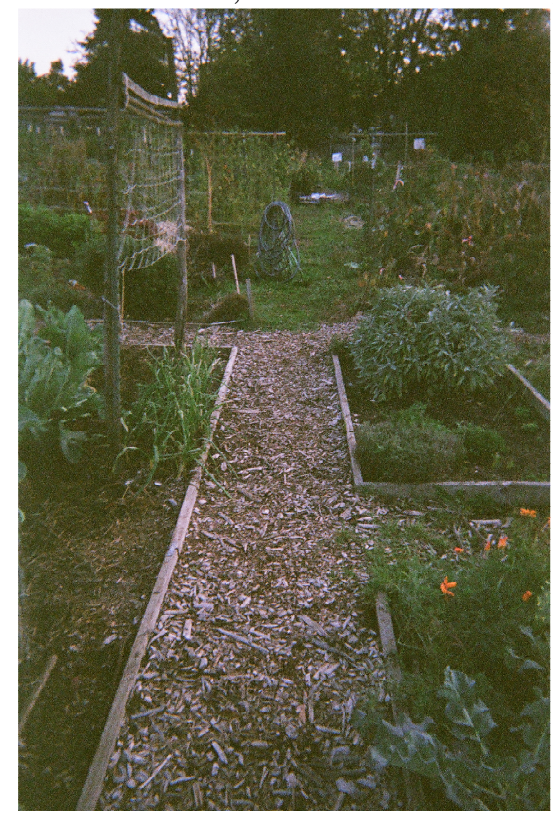

"A nice clean path, no weeds, a lot of joy, doing tedious things to have an internal life to free your mind, to be in the moment".

A picture of a wellmaintained path is a symbol of a change in life and love for another person. The path is well maintained, no weeds, with fresh

wood chips; it is tidy and pleasant to watch.

"The paths, the structures are virtually wee- free. The path structures are a little imprint of me. When I am gone and dead, the structures will be there, the small improved corner of the universe, where I tried to do a little of good thing. Even if I am gone...it is my work, here, in the garden. .."

The path borders the plot John shares with his partner. It is a symbol of a welltended garden and everyday journey and work in life. It was good for me to know that my partner was very proud of me for having accomplished something. This is why I have pathways virtually weed-free..." It is also a symbol of change in John's life: learning gardening from scratch, watching nature, meeting new people, observing other people, and developing new social connections. 


\section{The Garden Plot: Expression of Happy and Harmonious Love}

"The garden plot: expression of happy and harmonious love"

Fig. A. 15.c. Photo:John, Brentwood Gardener, 2009

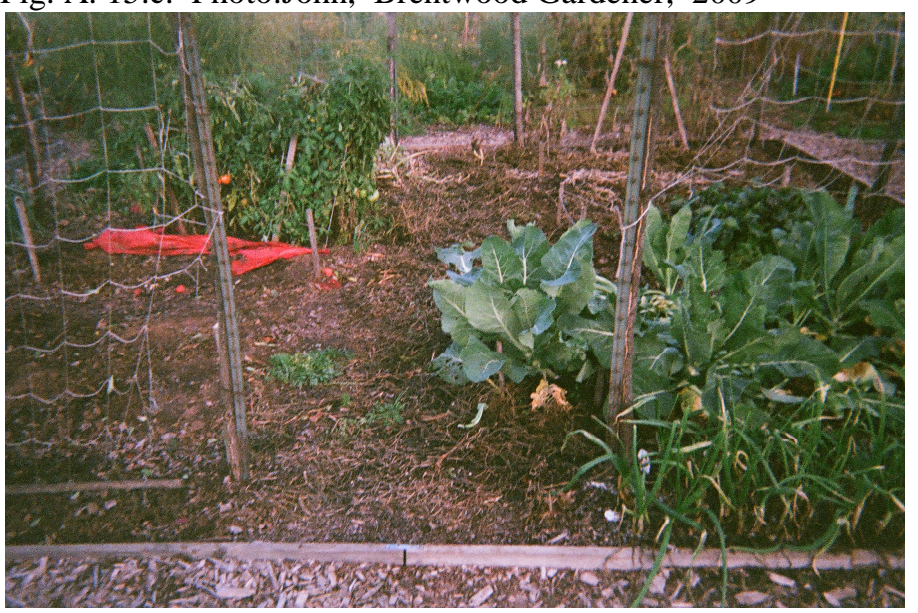

John's main objective is to make his partner happy. A well-tended plot is a gift of love for his partner. "Not everyone is willing to find a balance; you need to work with another person. The harmony how to work with another person is important..."

John prepares soil, removes weeds, and waters the plot to make sure that the plot is ready for spring planting, summer growing, and fall harvesting. "It is way to support my partner; he may not know how much time I spend in the garden to prepare the soil; it gives him some happiness..."

The work in the garden is an expression of love. John is happy if his partner enjoys the garden. The happiness of his partner is the ultimate goal of John's work in the garden. "Having done my partner's garden so it is in good shape for him...Having him feel good is the most important thing to me..." The picture is also a symbol of harmony and happiness in life. "It takes more than one person to maintain the garden; I always laugh when people ask me how I deal with the weeds. Setting the scene for planting, the amount of work, the base work in the garden: I form the bases for gardening, then my partner blossoms... The groundwork, I am accomplishing so much. It frees him up to do small things... To make a perfect garden..." 
4. Creativity and Imagination the Garden

"Creativity and Imagination in the garden" Fig. A. 15.d. Photo:John, Brentwood Gardener, 2009

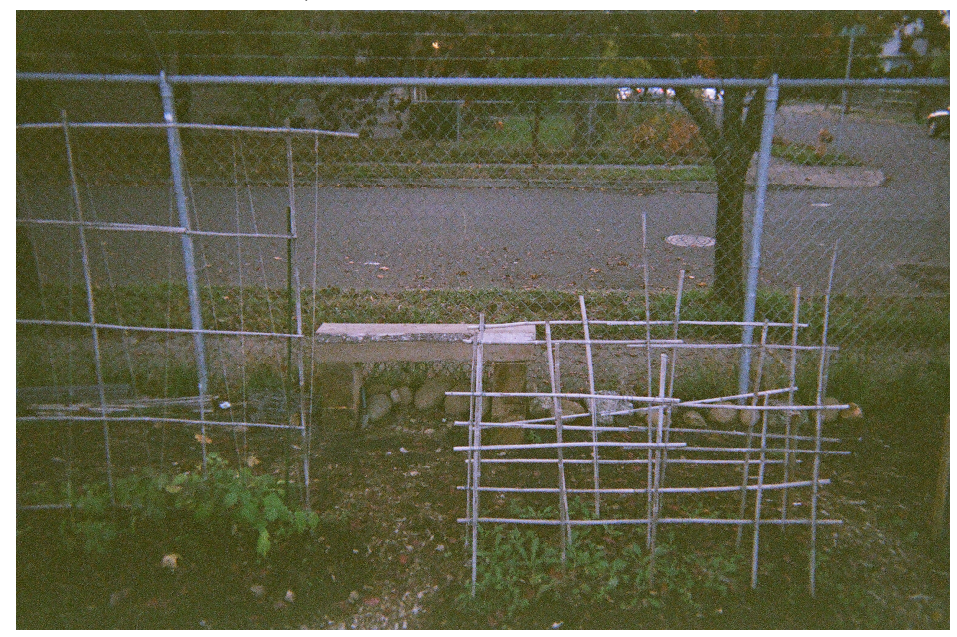

The picture symbolizes vibrant creativity and imagination of other people in the garden. A simple wooden bench, next to the fence, enhances the spirit of blending nature and art in the garden. The bench is also functional: one could imagine a person sitting on the beautifully designed and built bench, after several hours of hard work.

The bench symbolizes the presence of other people in the garden and their imagination in converting plots into objects of art. It also represents a harmony and comfort in natural areas. "Lovely, beautiful bench, just gorgeous, just lovely, it is so simple and lovely, a little piece of wood. It is wonderful how people individualize their gardens, the touch like that..."

"It is so cool, simple, creating something good, entering the world, making the world better..." Individual art symbolizes change for the better and a belief in goodness in people. "I do not see this hideous fence anymore behind the bench and the dirty street full of garbage. The fence is not that important. The image of the beautiful simple bench shows that people make the world a better place. Their own creation of art and beauty is becoming more important ..." 
APPENDIX II. A. 16.

\section{EMPOWERMENT IMAGES}

Melinda

1. Peace on Earth: Sharing Beauty and Bounty with All Creatures in the Garden

"Peace on Earth: Sharing Beauty and Bounty with All Creatures in the Garden"

Gardenrt, 2009

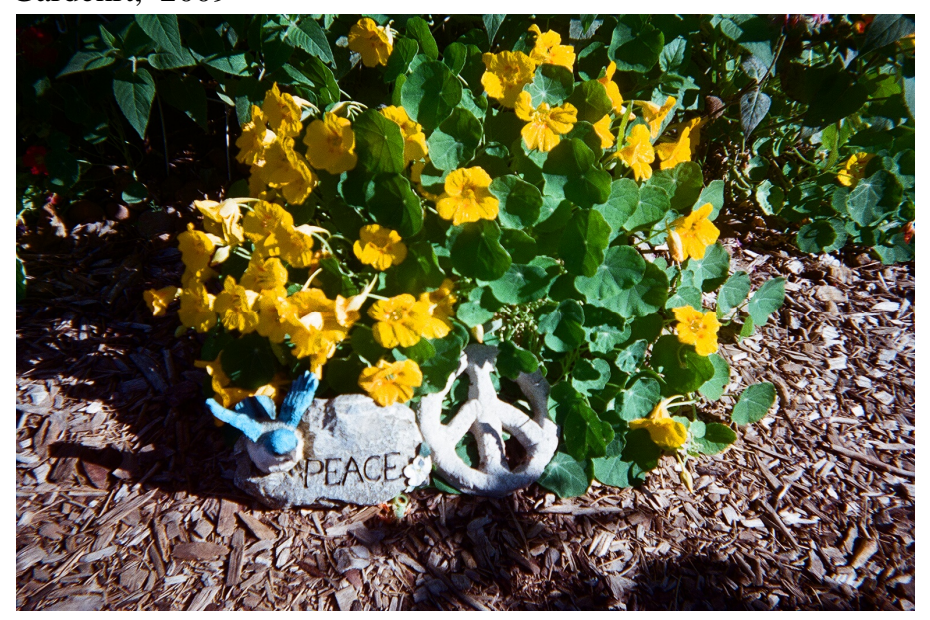

A small

sculpture of a

blue bird

perching on a

PEACE sign is

placed on

Melinda's plot.

It symbolizes

her private

space, a

sanctuary

where she

comes to

reflect and meditate. "I

respect other

lives to live:

grasshoppers,

aphids, humming birds, frogs, spiders, and lady bugs... “

Through her private sanctuary in the community garden, Melinda shares her respect for all creatures. Here, a PEACE sign, with a perched bird, symbolizes her philosophy in living in harmony and beauty with nature. Nasturtiums represent sharing the beauty and bounty with people and animals. Humming birds and bees love them for nectar, her friend rabbit likes to eat them. They are pretty and can be used for salads. Their seeds can be made into capers.

"I like flowers in the garden, I love flowers where you can eat them. It is a dual purpose. It is pretty and it is edible. Potato and squash flowers blooms are pretty. They are also edible... I plant bee balms for bees and humming birds...I see frogs in my compost bin..."

Gardening is also about "giving it back to nature", i.e. Melinda grows the plants that are enjoyed by the birds and the bees. She placed a birdbath on her plot to provide water for birds. The garden is a way of being respectful of nature and awareness that people should share their space with other living creatures. 
2. Harvest: We Do Not Have to Speak the Same Language to Share Things

"Harvest: We Do Not Have to Speak the Same Language to Share Things..." Fig. A. 16.b. Photo: Melinda, Brentwood Gardener, 2009

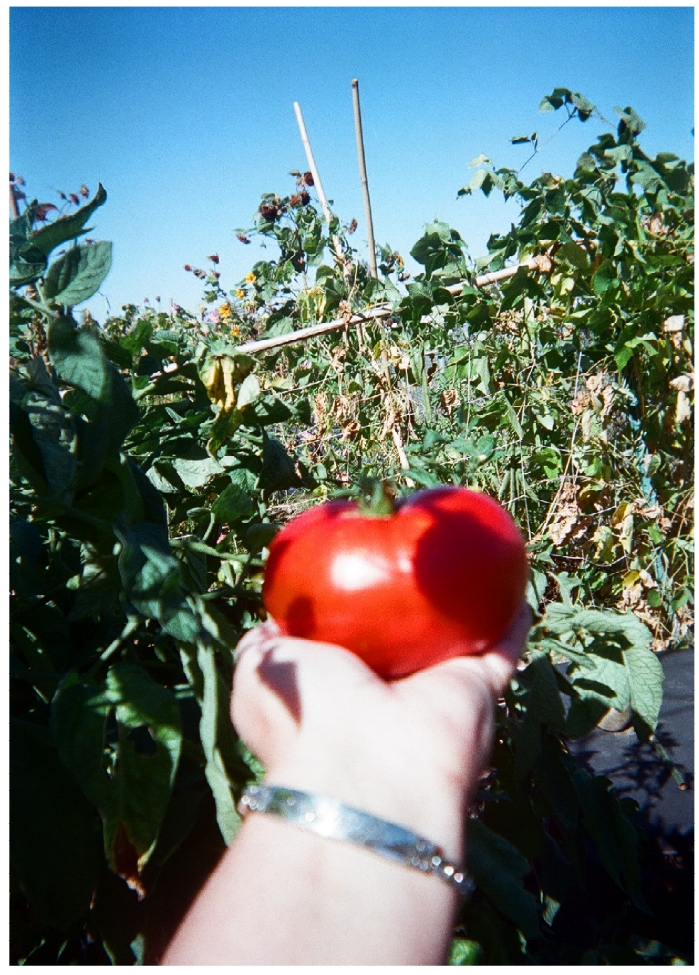

Melinda took a picture of a ripe tomato she grew in the garden. Growing her own food is a matter of pride and accomplishment for Melinda.

" I do not grow just anything, I grow unique things... I research what to grow. I grow purple carrots. I like to do more unique things. I read about plants. I like to learn about them, I have my criteria on what to choose for growing. I enjoy reading about it. It is a matter of pride..."

A picture of a huge red tomato is a symbol of Melinda's accomplishment in researching and growing spectacular vegetables that are turned into dishes that shine at various potlucks. Growing vegetables is her entertainment, her fun, and her sense of accomplishment. It provides a context for social interactions.

"My friends have fancy careers, they talk about it. I have my gardens, my purple tomatoes, my green tomatoes. It gives me something to talk about at potlucks. It is my life..." 


\section{Beauty and Bounty in the Garden}

"Beauty and Bounty in the Garden..."

Fig. A. 16.c. Photo: Melinda, Brentwood Garden,er Summer/Fall 2009

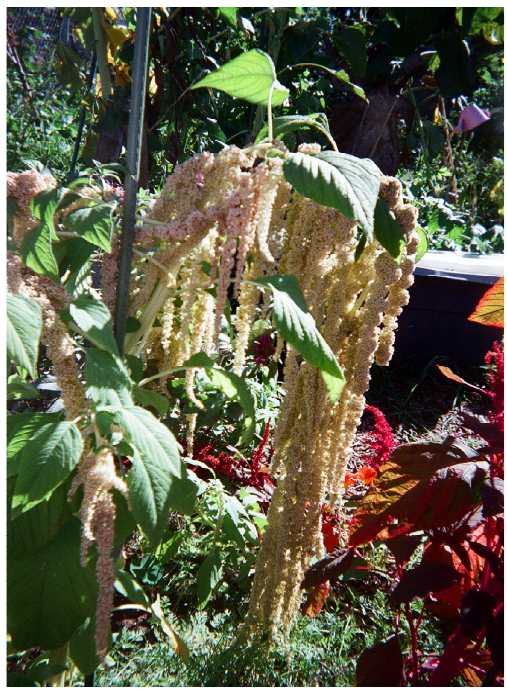

Beauty and Bounty in the Garden..."

Fig. A. 16.d. Photo: Melinda, Brentwood Gardener, 2009

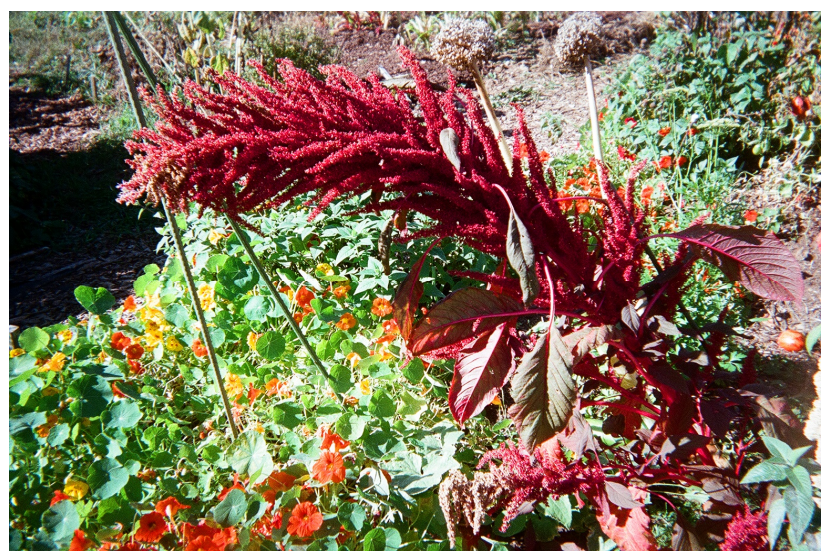

Two pictures of two different amaranth plants symbolize both bounty and beauty in the garden. They are pretty and birds love their seeds. They also provide a sense of beauty in nature through a combination of colors, shapes, shades, and textures. The pictures reflect the pleasure of watching natural patterns in plants and their ability to connect people and animals through their "purpose": they are pretty and edible. Both birds and people can eat them.

Beauty and bounty in the garden is about living in harmony with nature and respecting it.

If Melinda had more space, she would grow more beautiful things. She does not have any green area in the apartment complex where she lives. "I have no way to sit outside my apartment; I do not even have a balcony. I need a place to be myself. I would like places like that to be in apartments. I want to be outside and read my book... I like to be unique..." 


\section{APPENDIX A. 17. EMPOWERMENT IMAGES}

Tom

1. Adventure in the Community Garden: Food Production

"Advanture in the Community Garden: Food Production"

Fig. A. 17.a. Photo: Tom, Brentwood Gardenrt, 2009

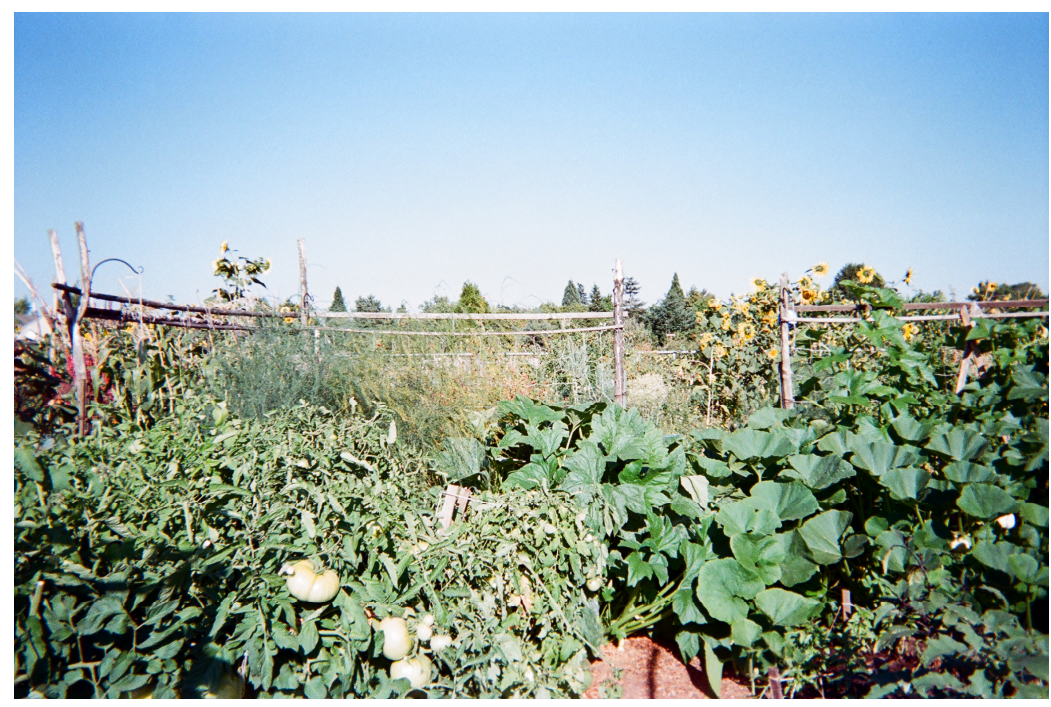

"I grow pretty much what I like, I do not like lettuce. For preserving, I will try a different variety of things until I settle on the variety I like. Every year I grow something different. It is an adventure in gardening..."

"I do enjoy plants going from seed and seeing the fruit and the number of tomatoes. The marvel of seeing it, from the tiny seed to huge plants. The change the miracle of life, from the seed to the vegetable..."

"For people who enjoy fresh vegetables I enjoy giving it to them; if people appreciate it..." 
"Fellow Gardeners"

Fig. A. 17.b. Photo: Tom, Brentwood Gardener, 2009

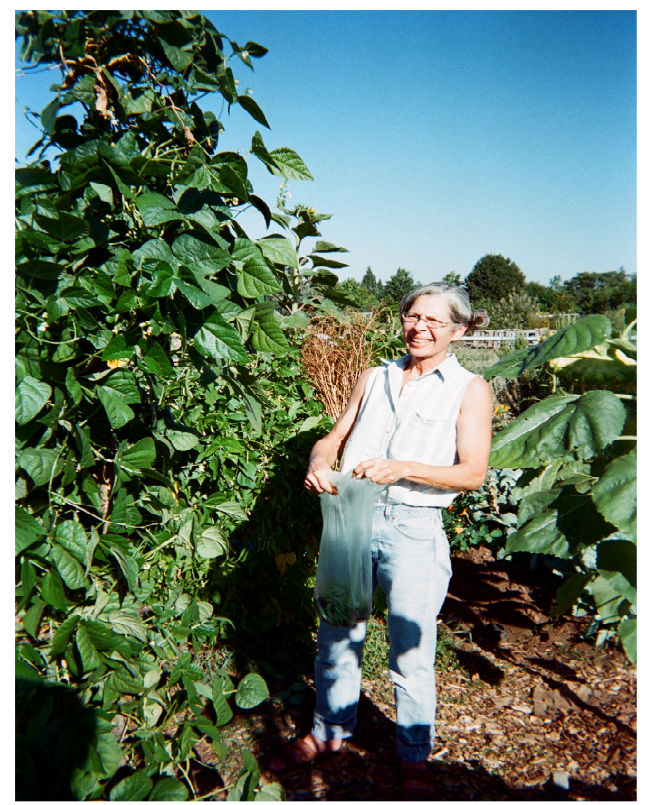

gardeners in their plots..."
This picture of a friendly fellow gardener symbolizes other people in the garden. It is a reminder that people are an important component of community gardening at different levels. Tom's experience embodies both pleasant and unpleasant experiences in the garden. Tom likes to interact with other gardeners and the social aspect of community gardening is important to him. "It has been a social outlet for me, which I did not have before. It is always interesting to see the personalities of other

"The picture does not represent a special person Tom met in the garden: it symbolizes the joy of meeting other people in the garden. "I wanted to take more pictures of people, but they were not always there, representative of the people, most of the time I like. All have something to teach..."

But Tom's social experience also includes interactions with the people who are not pleasant. "A few people are very selfish, and destructive and I do not like those". A few times somebody took ripening tomatoes from his plot. And his winter squashes were taken this fall.

The challenging part of community gardening is the occasional lack of respect for other people plots and their hard work to produce food. "Somebody came and started stealing my tomatoes, I did not see anybody. It could be anyone. There is one that I suspect. It is the part of community gardening I do not really like..."

"The idea is for the community to enjoy it, not to steal it and to respect it. To be able to come in and to know the gardener..." 
3. Fellow Gardeners' Plots

"Fellow Gardeners' Plots"

Fig. A. 17.c. Photo: Tom, Brentwood Gardenr, 2009

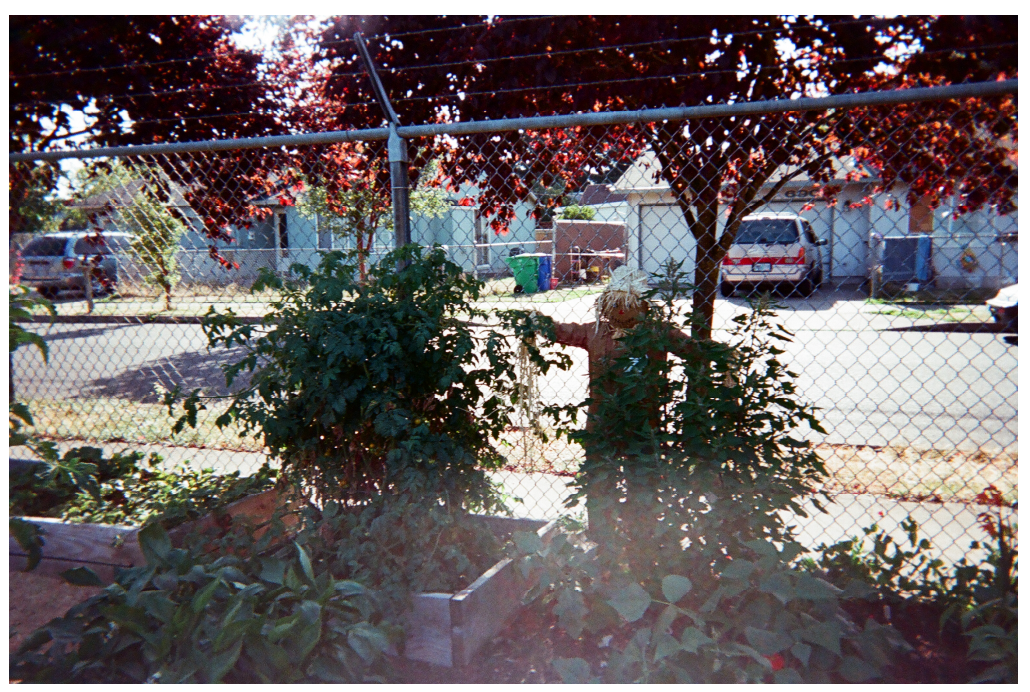

Tom enjoys cultivating his own plots and the opportunity to meet other people in the garden.

The presence of other gardeners is marked by the way they put their own individual imprints on their plots. Here, a scarecrow, symbolizes the personal imprints of other gardeners in Brentwood; the way they arrange their plots and their artistic expressions through tending the garden.

"Sunflower and corn, I enjoy the summer time to see how the garden grows and how much variety is here. People's personal touches, the little scarecrow. I enjoy seeing it and walking around the garden. ..." 


\section{APPENDIX A. 18. \\ EMPOWERMENT IMAGES \\ Heike}

1. Abundance of Healthy Food

"Abundance of Healthy Food"

Fig. A. 18.a. Photo: Heike, Brentwood Gardener, 2009

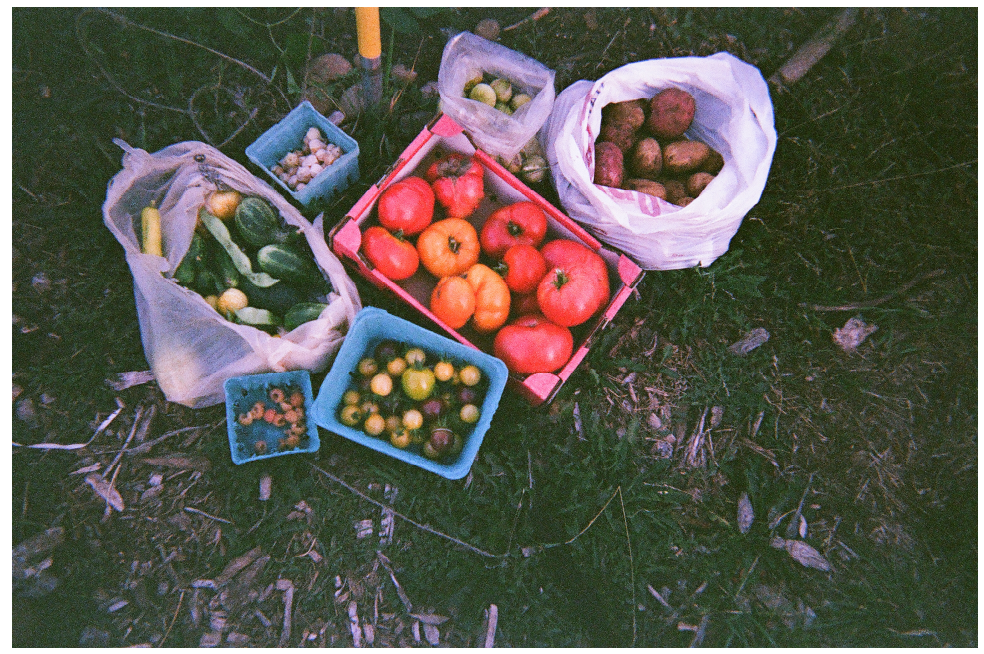

Growing food is the primary reason Heike signed up for a plot in a community garden.

"Different vegetables we grew, it is nice and colorful... Food processing, making our own food, connecting the place to live with the place to grow vegetables..." The picture of Heike's vegetables is a reminder that fresh and healthy food is vital in life. "When I have guests, I like to share food we produced in the garden... The produce we are growing is my own food. Otherwise, I would not be able to eat that well..." 


\section{People and Communal Spaces in the Garden}

"People and Communal Spaces in the Garden"

Fig. A. 18.b. Photo: Heike, Brentwood Gardener, 2009

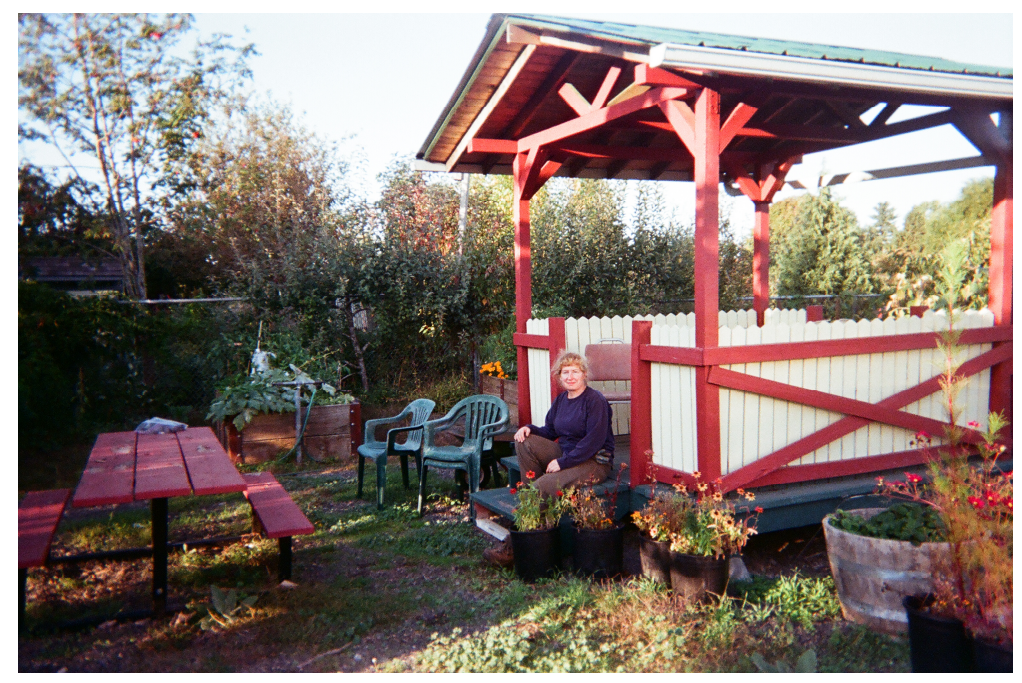

Here, Heike sits on the steps of the gazebo, next to the picnic table. Both the gazebo and the picnic table symbolize the enjoyment of meeting fellow gardeners and socializing with them. The garden is a place to meet and enjoy other people's company. Heike and her partner also like to sit at the picnic table to have their lunch together, after the work in the garden. It provides a good opportunity to have casual conversations with other people who come to the garden.

The picnic table is next to the shed. Occasionally, people who go to the shed to grab a tool, stop by the table, if somebody is sitting there, for a social moment. The picnic table and gazebo symbolize both garden parties and ad hoc social moments. It is a center of the social life at Brentwood. The table is used for sharing produce; people frequently leave produce to share with other gardeners.

"The community space, it is important. It is a reminder about the many interesting people we meet... you can learn a lot from them... the community space symbolizes it..." 


\section{Sharing Responsibilities}

"Sharing responsibilities"

Fig. A. 18.c. Photo: Heike, Brentwood Gardener, 2009

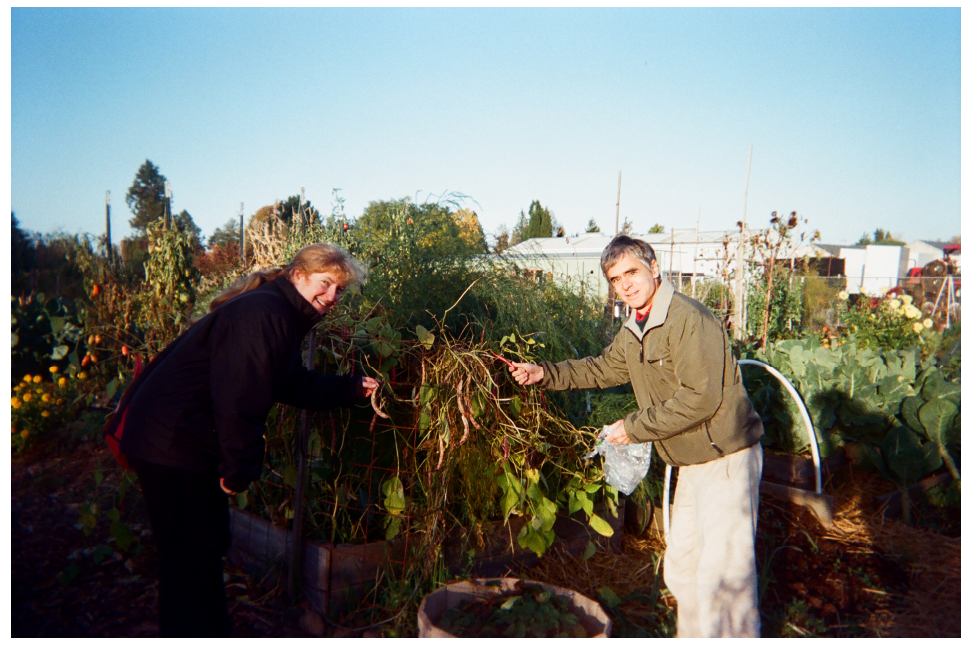

"Picking beans together... we grow the garden and share the responsibility, it is a really good bonding experience for two of us..."

This picture is of Heike and John, her partner. It picture symbolizes their relationship in life and in the garden. Working together in the garden provides another context to get to know each other, to share responsibilities in the garden and in life. John frequently comes to the garden with Heike to help her with the chores. Gardening together plays an important role in the relationship. "I am the gardener and he is a learner, I have to be careful not to micro manage... it is important to have a balance. I do the planning, and then we decide on our priorities in the garden. We decide what we want to do, in what order. Next, we communicate about it and we just do it. So we first talk about it, we decide to do it, and we do it together..." 
4. The Garden: A place to Take Family

"The Garden: A Place to Take Family"

Fig. A. 18.d. Photo: Heike, Brentwood Gardener, 2009

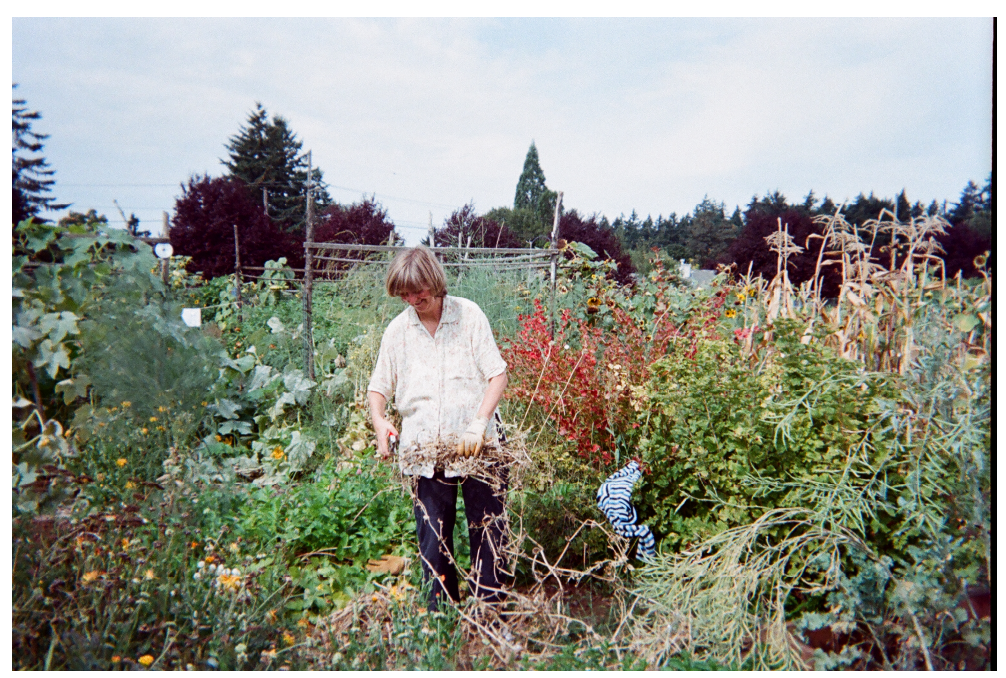

A picture of Heike's mom, visiting the garden.

Heike brought her mom to the garden to show her the place and meet fellow gardeners. Heike's parents emphasized the importance of healthy and fresh food. Heike grew up in Germany where she helped her parents in tending their garden.

"I started gardening when I started walking around..." Heike continues this family tradition by working on her own plots in a community garden.

Whenever her parents come from Germany to visit her in Oregon, a trip to Brentwood is an important part of their visit. Heike shares her garden accomplishments with her family. Here, Heike's mom admires the garden. 


\section{APPENDIX A. 19. EMPOWERMENT IMAGES}

Mark D.

\section{A Triangular Garden Composition with a Water Cistern}

"A Triangular Garden Composition with a Water Cistern"

Fig. A. 19.a. Photo: Mark D., Brentwood Gardener, 2009

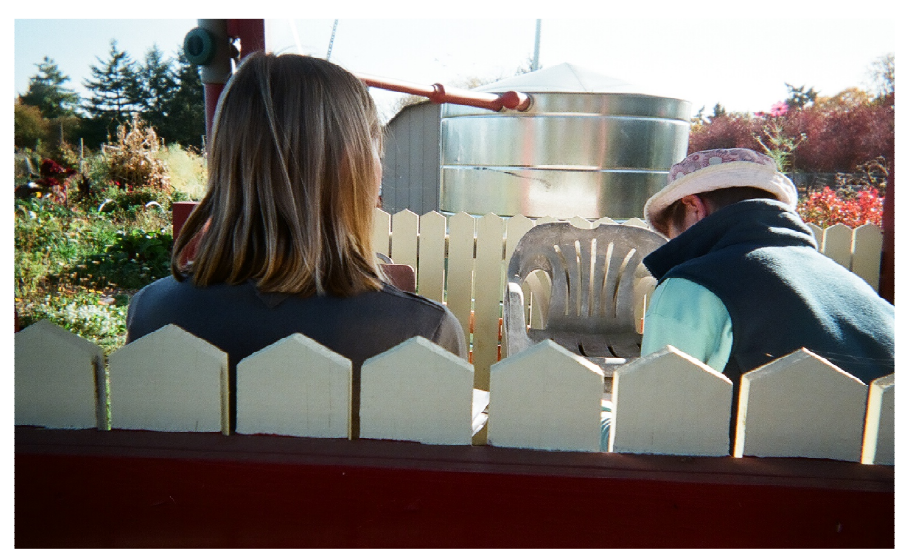

The picture is centered on a water cistern, its shape, shiny colors and flickering and efflorescent pink reflection of the sunshine. Two people are sitting in the arbor, conversing. Lush garden vegetation is in the far background of the picture. The sky above the garden is blue. A white picket fence defines the triangular base of the scene. It is calming: the cool metallic shade is balanced with the brilliant colors of the garden plants. It is a perfectly balanced composition, a garden scene. It blends images of people, plant, and garden infrastructure.

The cistern was funded by a grant from "Organic Gardening Magazine" and is part of a demonstration project in the garden. Rainwater from the gazebo roof is directed through a piping system to the cistern, which was supposed to water the small fruit orchard garden. Mark does not like the location of the cistern in the middle of the communal space. He does not like the look of it, the metallic walls, and the obtrusive piping. Nevertheless, he likes the composition of the picture, the color contrasts, the lines, and the balance and calmness of the scene.

"It is a very creative experience, visually very stimulating, interesting photograph, shape, lines, texture, color, variety, and a repetition. It is where your eyes go, for the contrast. Nothing it is nothing wrong with this photograph..." 


\section{Garden Hats: "Mug Shots"}
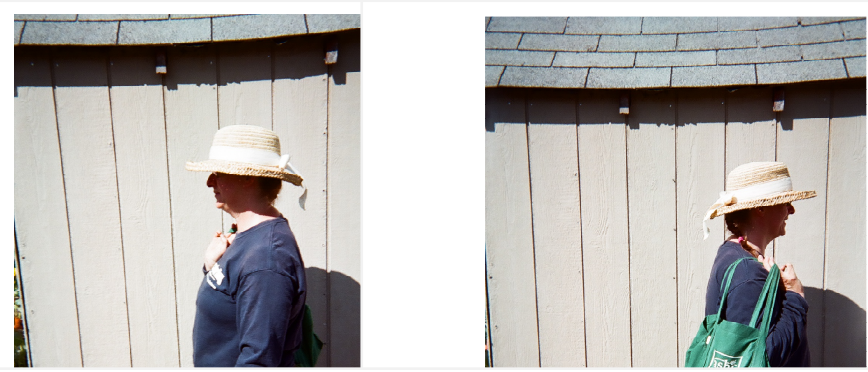

"Garden Hats: Mug Shots"

Fig. A. 19.b(1)(2). Photo: Mark D., Brentwood Gardener, 2009

Mark considers himself as an antisocial person. Nevertheless, he is fascinated by garden hats as a symbol of proper gardening attire. One of his friends posed for his "mug shot" pictures with a garden shed in the background. The friend is wearing appropriate garden hat: stylish and white with a wide brim protecting her head and shoulders. It is a playful composition of two "mug shots," where the hat is a form of identification of "who is a gardener?" A hat is a must for a real gardener.

This photograph raises the question of how to recognize a "real gardener". Are hats indicative of the real gardener?

"Garden hats... the bigger and floppier the brims, the more I like them. I do not like baseball caps. It is a shame that gardeners do not wear straw hats... they protect them from water and sun, a baseball cap would not do that... Hats should be made of sustainable materials: straw, branches, whatever...My ideal is a women in a Victorian cottage garden, wearing a frock and a floppy straw hat, my ideal gardener..." 
3. Garden Technology: The Joy of Gardening - Back to Earth

" Garden Technology: The Joy of Gardening - Back to Earth" Fig. .A. 19.c. Photo: Mark D. Brentwood Gardener, 2009

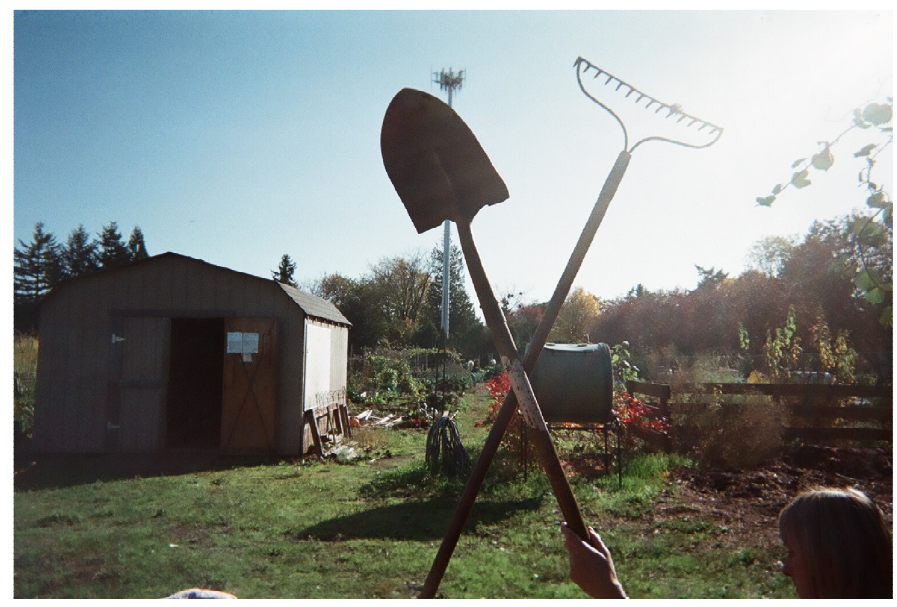

This picture is another composition of gardening symbols. This time Mark took a picture of a spade and rakes. A cell tower, slightly obscured by the spade, signifies the contrast between basic tools and "high tech" tools in contemporary America. This juxtaposition of the "simple" and the "complex" raises a

question of the quality of life: is more advanced technology better that simple gardening tools in achieving the objectives of the "good life?

"What constitutes a good life? The four tools I use are the spade, rake, scissors and wheelbarrow. I find it is basic and makes me think that I am tied to basic cultures... My tools are so basic and yet powerful..."

The cell tower symbolizes the "high tech" and consumer culture in America. People come to America in search of an advanced "better" lifestyle, which is frequently associated with more commercialized "high tech" life. Paradoxically, in America, more people are coming to realization that simpler life styles are better. Gardening is an example of this trend of simplifying life and getting closer to nature.

"Immigrants come because they are fascinated by American consumerism and people in America go back to growing chickens and simplify life to be more sustainable and happier..."

The picture is a reminder of the connection to earth through simple tools in the era of advanced digital technology. The spade and the rakes symbolize the earth connection. The shed, on the left, marks the gathering place in the garden where people store gardening tools. The cell tower looms over the garden, a reminder of the twenty first century technology. The picture also contrasts two types of connection: digital connections and place-based connections. It is a reminder that community gardens provide an important place for people to connect with earth and other people. It contrasts high tech tools with simple tools and ties it to the question of happiness: does consumerism and high tech bring more happiness? 


\section{APPENDIX A. 20. EMPOWERMENT IMAGES \\ Gracie}

\section{Raspberries: Luxurious Food and Celebration of Healthy Lifestyle}

"Raspberries: Luxurious Food and Celebration of Healthy Lifestyle"

Fig. .A. 20.a. Photo: Gracie, Brentwood Gardener, 2009

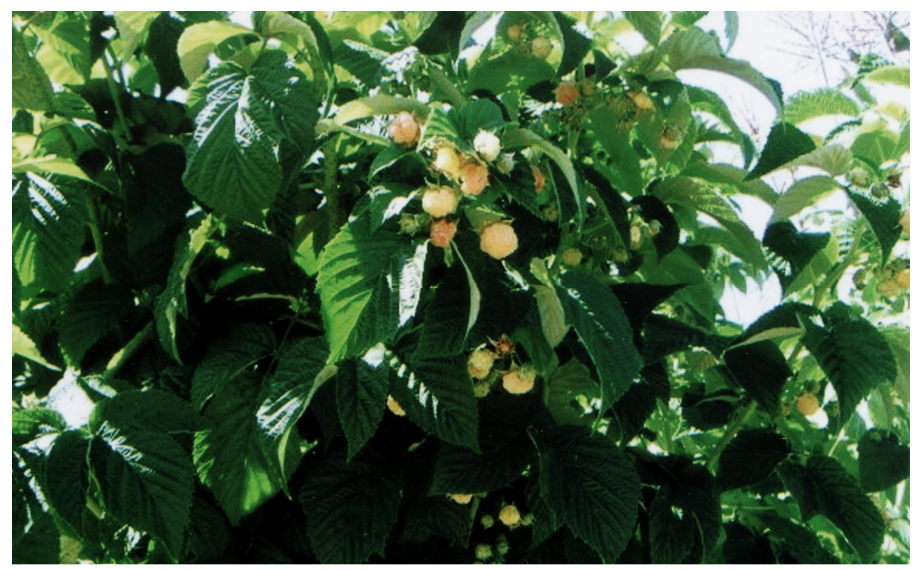

This picture is of a lush raspberry bush with gold ripe berries. "Having all the raspberries I want to eat is an incredible luxury to me; like buying a BMW or Mercedes. It became the most important thing in my diet. It is an incredible luxury. It shifted my perception of myself. I can get also luxurious things in my life and it was pretty significant..."

Gracie took a cutting of a discarded raspberry plant from a compost pile and planted it on her plot several years ago. She cannot afford to buy plants from a nursery. "A lot of my thinking is about my personal economy. I could not afford to go to a nursery to buy raspberry plants and here there were in the compost..."

The freshly picked raspberries are a symbol of luxurious food. Gracie was not able to afford fresh organic berries and vegetables at farmers markets and grocery stores. She used to get her food at discount stores that do not offer a wide range of high quality fresh produce. The small raspberry plant Gracie planted several years ago thrives in her garden. Gracie can have a fresh cup of raspberries every day during the growing season. Having a fresh cup of raspberries grown in her garden on the plant she cultivated, is Gracie's definition of the luxurious life; it is her treat. Gracie's feeling of safety comes from the assurance that she can grow enough of her own high quality food. She does not have to depend on the food available in discount stores.

"This type of raspberries, the golden ones you cannot transport, they would fall apart. They became my treat. They produce fruit twice per year; it is like a celebration. I just shove them in my mouth and go to work, or if I get thirsty, I can also have them. It is a special treat otherwise I would not have ..." 


\section{The Happy Gardener}

"The Happy Gardener"

Fig. A. 20.b. Photo: Gracie, Brentwood Gardener, 2009

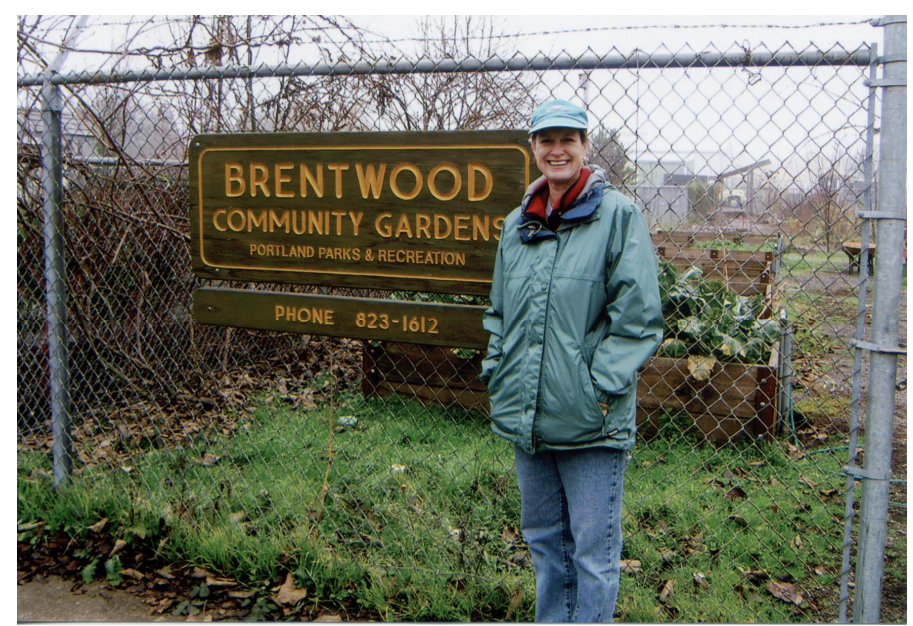

A picture of smiling Gracie in front of the Brentwood Community Garden. Gracie walks to the garden almost every day. She lives approximately two miles from the garden. Walking to the garden and working in her plot became her lifestyle. "The happy face. This is something you would not see before I had a garden: the smile on my face. When I have a bad day I look at this picture and it documents what the garden has done to me..."

The garden provided several opportunities to learn new skills." Learning is about stimulation, about using your brain, about mental health...about making your life better and longer..."

With the help of other gardeners, Gracie was able to build several structures in her plot to support plants. She learned about composting, cold frames for winter gardening and using rainwater for watering. Learning how to make garden structures was a big achievement. 
3. Working Together in the Community Garden: Growing Friendships

"Working Together in the Community Garden: Growing Friendsips"

Fig. A. 20.c. Photo: Gracie, Brentwood Gardener, 2009

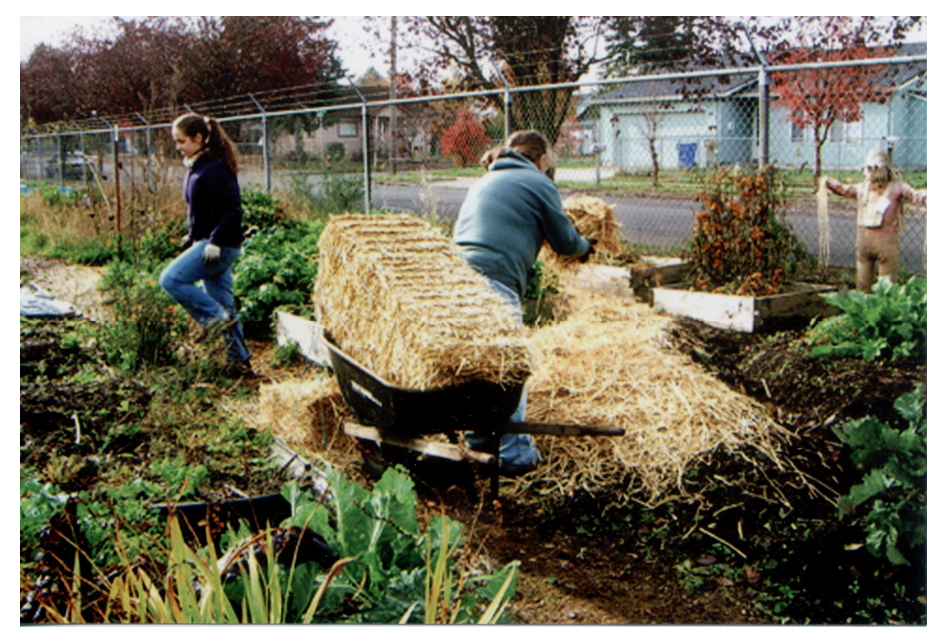

"For the first time in my life, here, in the garden I felt loved and respected...first time ever in my life" A picture of Gracie's friends working in the garden. The people Gracie met at the garden are her inspiration and source of enjoyment "We laugh together, we work together, we care about each other... Stephanie is like the daughter I never had. Donna taught me everything I know about gardening..."

"I got to see different types of people, I had been treated abusively before and I could experience people in a whole new way...."

I did not realize the power of the community garden. It is a community; it is the feeling of being loved by other people..." 


\section{Garden Success: Harvesting Winter Squash}

"Garden Success: Harvesting Winter Squash"

Fig. A. 20.d. Photo: Gracie, Brentwood Gardener, 2009

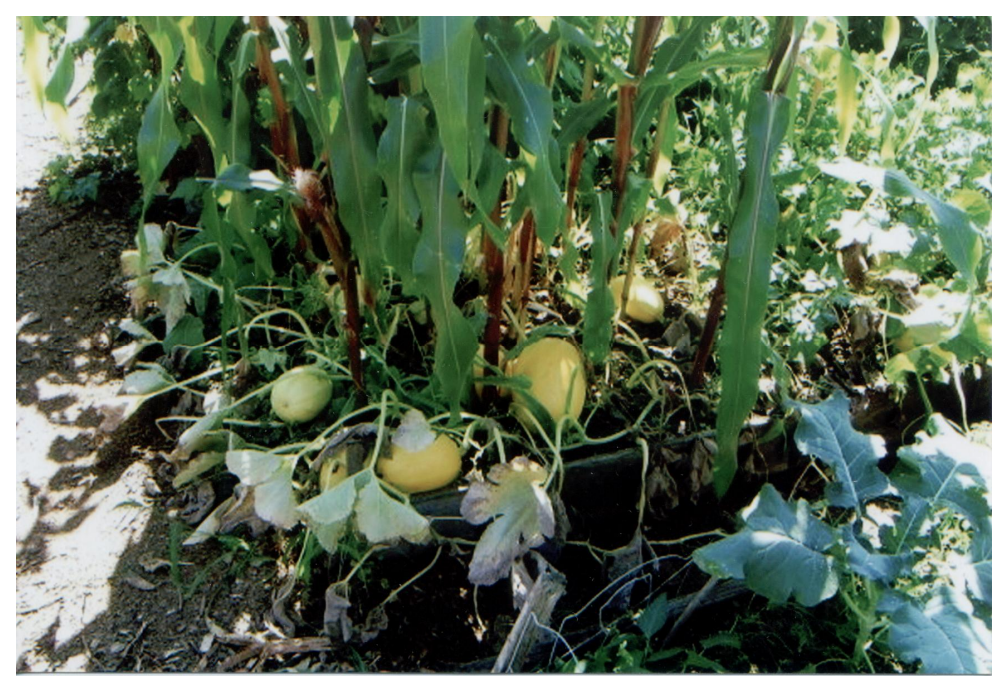

This picture is of winter squashes.

"Winter squash...This is my very first awareness of success in the garden... I did not used to plant vegetables for winter. When the season ended I was back to buying. This time I specifically planted things that would get me through the winter. I had never planted spaghettis squash before. I had big ones, the grand success of the year. It will keep me going through the winter. All the winter squashes you harvest are the most wonderful things..."

The winter squash mingles with the robust corn. The corn is a gift from one of Gracie's garden friends, Donna. Donna planted corn seeds when Gracie was gone. The corn plants were a total surprise and pleasure to Gracie when she came back. "Donna took care of my garden when I was gone. I asked her to harvest my greens when I was gone. She took them and in their place, she put corn seeds. Here I came and the corn was growing where my greens were..." 
APPENDIX A. 21.

\section{EMPOWERMENT IMAGES}

Jan

1. Our Produce for People Baskets: It Warms my Heart...

"Our Produce for People Baskets: It Warms my Heart” Fig. A. 21.a. Photo:, Brentwood Gardener, 2009

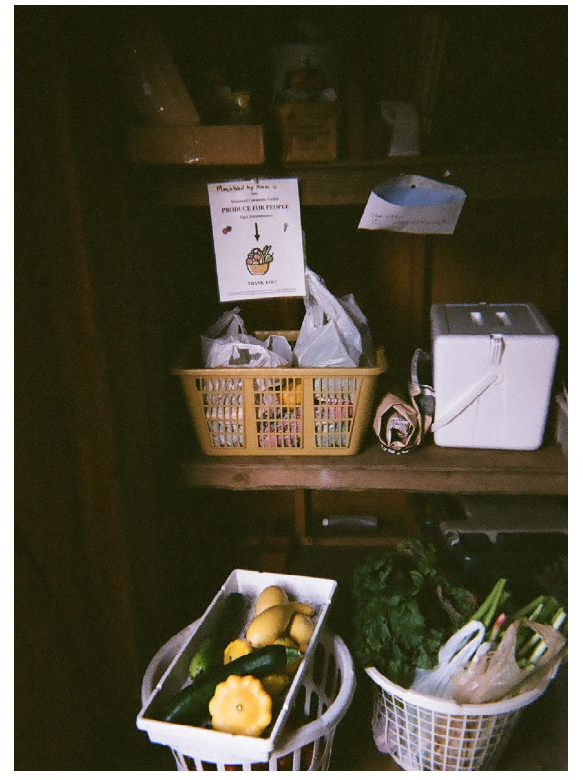

"It warms my heart...

Produce for People, in the shed. It warms my heart to know that we can provide fresh organic vegetables to people who really need it. It is sharing bounty. We are able to share the bounty with other people I do not know. It is being connected with people I do not know... Even if I do not have money to give, I can give food. It is fundamental, it you think about it there is nothing more powerful that giving food to people..."

The plastic baskets were

placed in inside the shed at Brentwood to collect fresh vegetables for people who do not have access to fresh food. All surplus food is collected here. The garden manager takes it to designated places to feed homeless and hungry people.

"You do not need to have a lot of space to grow vegetables... My community plot gives me more food that I need, I constantly give stuff away. I produce way more than I need. I can get by with one third or a quarter of the space I have just to feed me, but I love to give away. I have not always been making money, but I can always give my produce to the emergency food services...

"I like to give something locally. I would like to know that is not wasted. Very rewarding, it is going directly to the people who truly need it. The food you get from a food bank is not very nutritious. As a society, we are not aware that there is so much horrible food, empty calories, and white flour products. People can survive, but not thrive. There is nothing better that locally and organically grown produce, the counteraction to pasta and cheese. It is hard for a food bank to have fresh food available... 
2. Rooted in the Garden

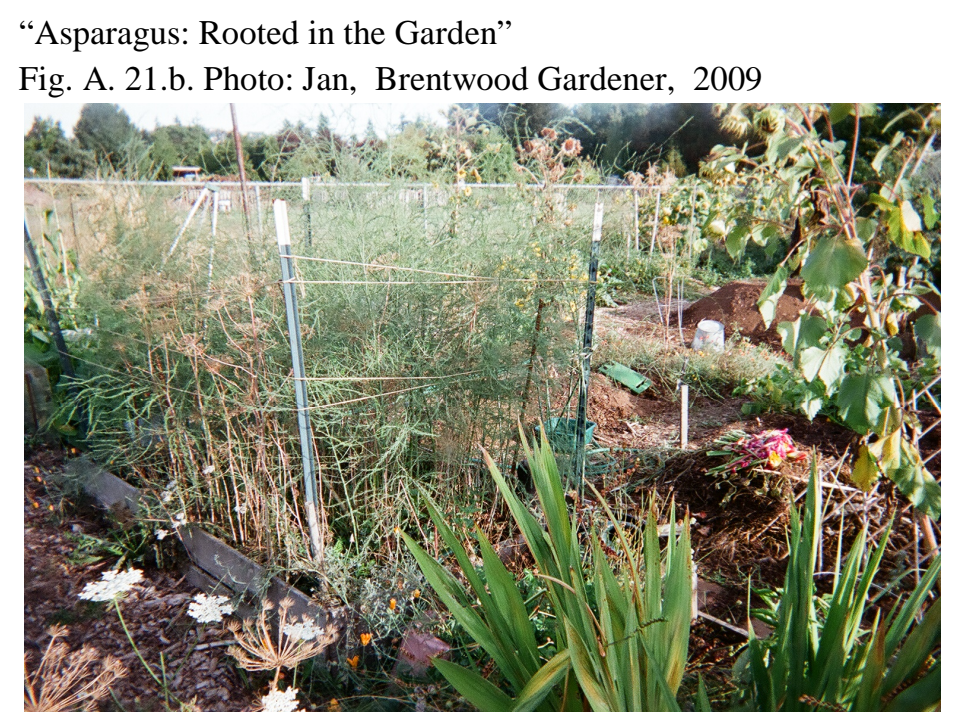

A picture of robust asparagus symbolizes stability in life and the emotional and economic investment in the garden. "It is a shot of my plot with my asparagus all grown, and it is yummy, I call it my "crack asparagus"... I rarely bring it home; I snack on it as it grows... It grows more and more each year. It gets bigger sustaining me at many different levels. I never bring it home, I eat it in the garden or on my way from the garden. It is too good, why cook. Very rarely, I have enough to bring home. It is gone before I get home. I love corn too, but corn comes and goes, asparagus accumulates..."

"The garden provided a sense of connection, I could always count on it. You can move in your living situation, but the garden provided the grounding for me, sense of security. Moving is so disruptive. To know that I have my own space is to know that I have control over my life..."

"I moved three times since I got the garden. What was nice is that I knew that the garden is there. It grounded me. It centered me. I was moving around and I knew I might be here and there, but I will not lose the investment in my garden. It is perennial, and it takes a major investment, it takes several years. I have established asparagus here, I will not give it up readily. It my history for the last six or seven years, I know, were I fertilize, my crop rotation. I am settled, I am grounded there..." 


\section{Amaranth: Garden Beauty}

"Amaranth: Garden Beauty"

Fig. A. 21.c. Photo: Jan, Brentwood Gardener, 2009

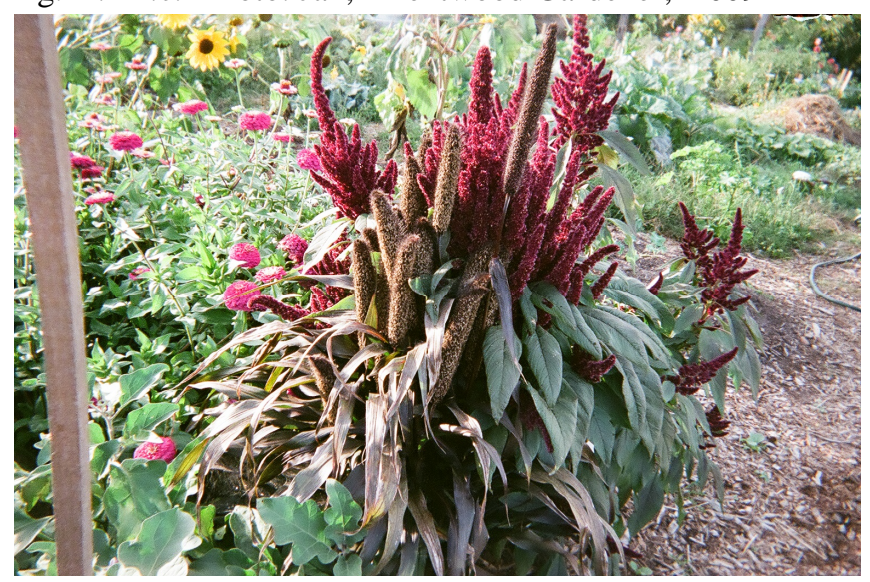

This is a picture of red-flaming flowers of amaranth in the garden. The picture symbolizes a pleasure of seeing vigorously blooming plants in the garden. "I just love these plants, amaranth. I like the fluffiness of it. It is cool and funky plant, aesthetics, funky texture..."

Jan is an artist. She is a professional musician and accomplished photographer. The garden offerings, with their natural beauty, shapes, flickering of light, and seasonal color change, inspire her to take pictures. "My pictures are an extension of my art. My art is the extension of my pictures..."

The perpetual act of creation and expression of beauty defines Jan's image of the garden. "This little patch of earth is little like bit of artwork. I choose what shape to make. I choose what to plant where. You need to rotate plants to new places. It behooves you to move crops. There are only so many options. I am also very keen on how it looks the balance of aesthetics, practicality and logistics..." 
APPENDIX A. 22.

\section{EMPOWERMENT IMAGES}

Bill

1. Creative Conversion of Land to Wealth and Beauty

"Creative Conversion of Land to Wealth and Beauty"

Fig. A. 22.a. Photo: Bill, Brentwood Gardener, 2009

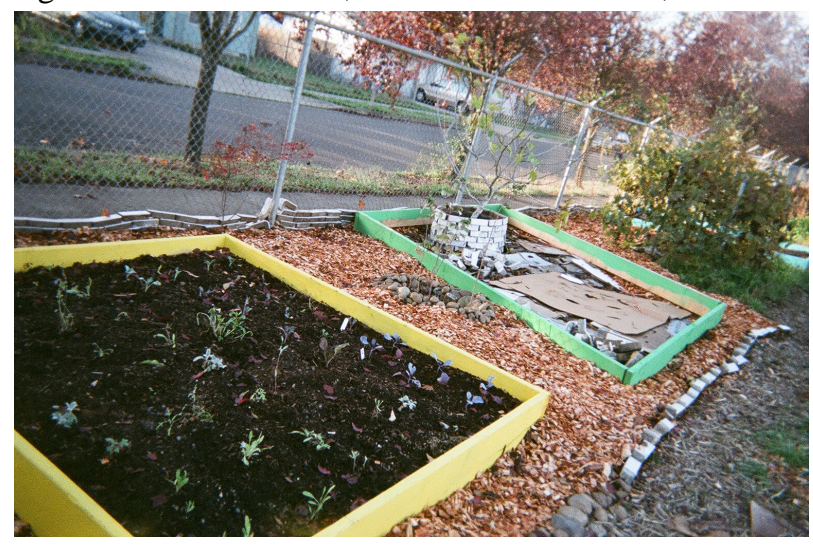

"This is a first year gardener. This area has been always a bad mess. They came and cleaned it really well. I felt good about it. They took control over the place..."

The picture is of converting a piece of unused land to a productive use and a happy place. Two colorful garden frames mark a new activity in the garden. This important to Bill on several levels. First, there is a general concept of converting a messy, unused area to productive use in a creative way: two cheerful garden frames reflect a sense of creativity in transforming land into food production. Second, Bill was delighted to see that parents brought their children to the garden and were working together. It reminded him about his childhood and his parents giving him a place to set up his own garden. Bill has not watched many children coming to the garden and working with their parents. This picture is a reminder that gardens are an important area to inspire children and teach them about plant cultivation.

"It takes a garden to raise children... They bring their kids, the kids were fully participating in the garden. Some families do not engage their children. I see these kids and it reminds me about me when I was five years old, and my parents gave me my first place to garden. Having a garden will be part of the rest of their lives..."

The conversion of a previously unused place into a productive use, that involves children, makes Bill happy. "The conversion of an ugly place into a nice way of growing plants. They used their imagination. It is part of garden prettiness. When somebody grows something, they create wealth. It is creating wealth." 
2. Accepting the Unexpected: Control and Pleasure in Garden and Life

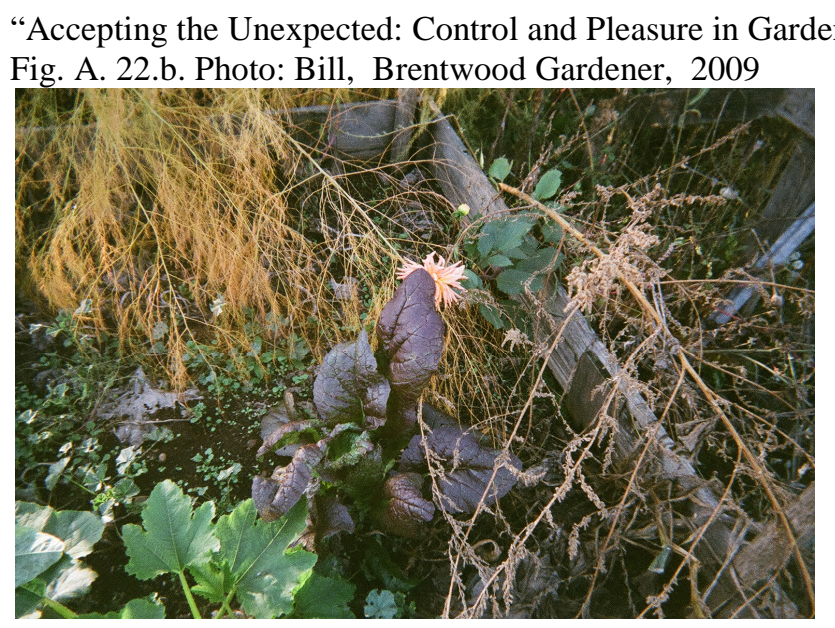

The picture captures an emerging mustard plant, a garden delight, an unexpected pleasure of welcoming a plant that was not planted by Bill.

"This plant is a volunteer, one of my favorite things, the plant comes out and it grows..."

Bill's primary interest in gardening is to convert land into productive use; to control it to grow crops.

This picture reminds him about the pleasure of spontaneity in life. A small emerging mustard plant was not planted by Bill. It is a "volunteer" plant: it self seeded from another plot.

It reminds Bill about the extent of control a person can impose on nature. Here, Bill's objective of converting land through controlling the area by cultivation is contrasted with his pleasure of spotting a volunteer plant he did not plant. The garden taught Bill to appreciate the pleasure to balance controlled and unplanned events in life and gardening. 
3. Natural Beauty and Surprise

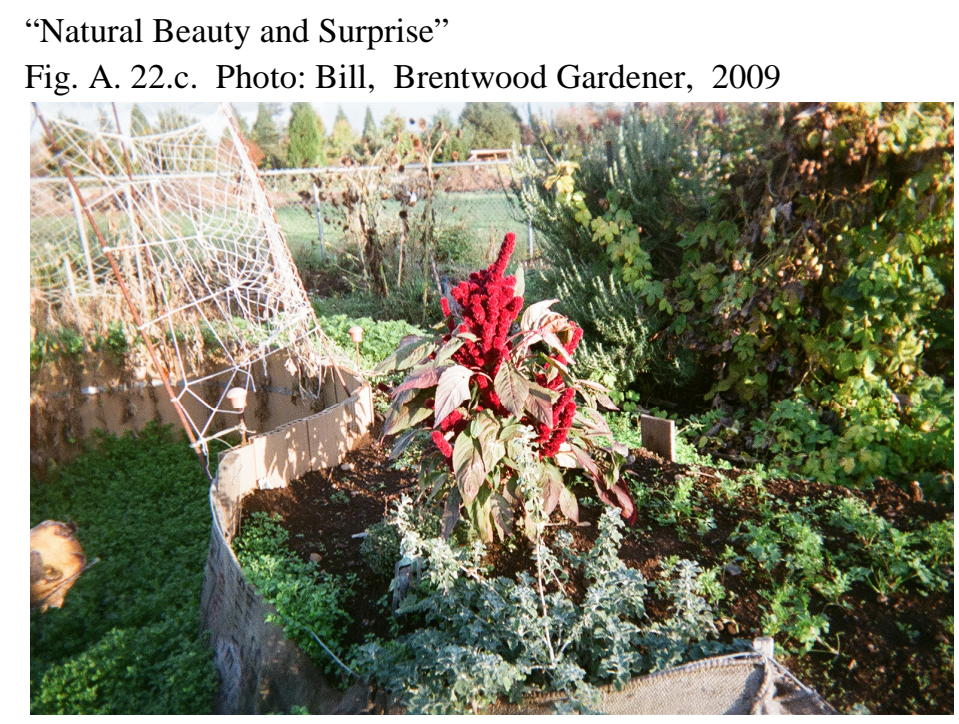

The picture is of a brilliant red amaranth plant emerging from Bill's plot. This is another example of unexpected pleasure of seeing a plant that self-seeded in Bill has highly controlled garden place.

Amaranth is not a food crop. Nevertheless, Bill decided to keep this plant in his garden to enjoy its color and shape. It provides a spark of beauty in the garden. It symbolizes the illusion of control and the enjoyment of unexpected pleasures in garden and in life. It symbolizes the acceptance of unpredicted events that enhance the garden and turn it into a place of beauty. Beauty in life is about accepting surprises.

Gardening is about the balance between the illusion of control and appreciation for the unexpected. 


\section{APPENDIX A. 23. EMPOWERMENT IMAGES \\ Dan}

\section{First Year: Garden Panic}

"First Year: Garden Panic"

Fig. A. 23.a. Photo:Dan, Johns Gardener, 2009

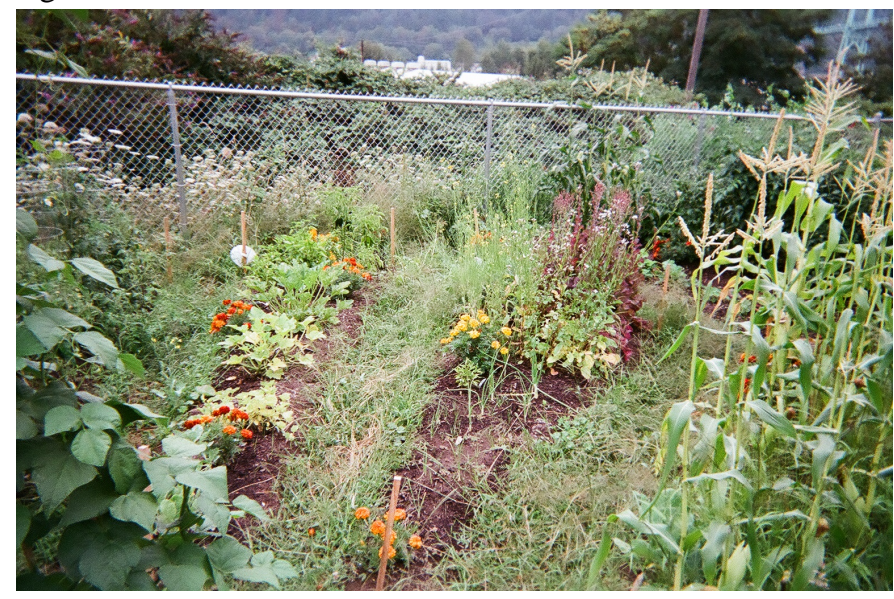

The picture shows Dan's plot overgrown with weeds "The weeds are growing better than the vegetable garden... Tomatoes and cucumbers are hardly visible..."

It was Dan's first gardening year and he was not aware of how much time and effort it took to turn a weedy piece of land into a thriving garden. First, his garden was overgrown with weeds and black berries. "When I got a plot it was just a weed garden... and blackberries. There was not any evidence that it has been a garden..."

Dan never gardened before and it was overwhelming to get started. He did not know what to do. He tried to remove the weeds and black berries, but, inadvertently, dug them in into the garden because he did not know who to handle weeds. This picture reminds Dan about his panic when he realized that the weeds were back in the garden in the middle of the growing season and that his schedule did not allow him to spend enough time to tend the garden. "I got it all planted and I stopped going to the garden, I got so busy... The weeds are growing better than the vegetable garden..."

Dan would prefer to have a garden in his backyard; it would be much easier to tend the garden. Even a short distance to the garden is a significant obstacle to tending the garden in an effective and efficient way. Successful gardening requires close attention to a crop cultivation routine and plant needs watering, fertilizing, and weeding. 
2. Getting Control over the Garden

"First Year: Garden Panic"

Fig. A. 23.b. Photo:Dan, Johns Gardener, 2009

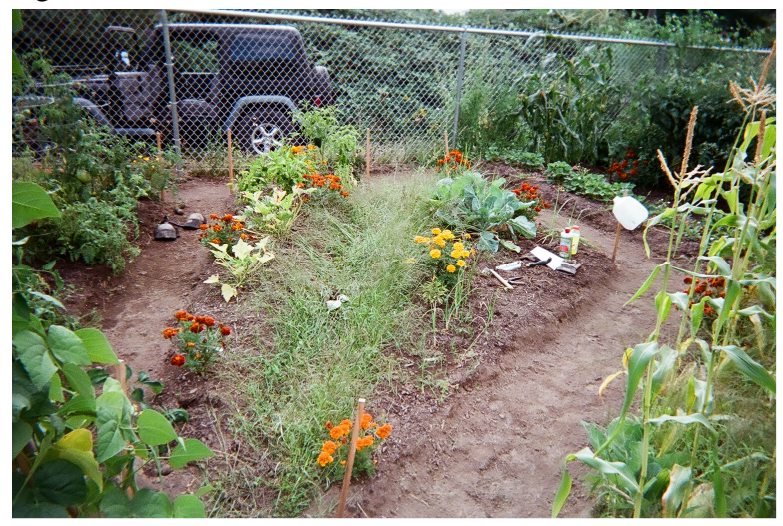

"I was doing too much this summer, I had to find a balance to do better ..." This picture shows signs of control in Dan's garden. Some parts of his plot were cleaned so they did not impact the tomatoes. Cucumbers seem to be surviving. The paths are clean from weeds, but it is clear that the beans and corn did not survive well in the hot summer days. It is at a halfway point on the path to recovery. After his summer term at PSU was over, Dan went back to the garden, with vengeance, to reclaim back his plot. "I basically dug weeds in. I did not mulch my paths, and the weeds came back. It was overwhelming, Next time I will do things better..."

\section{First Year : Garden Success Story}

"First Year: Garden Panic"

Fig. A. 23.c. Photo:Dan, Johns Gardener, 2009

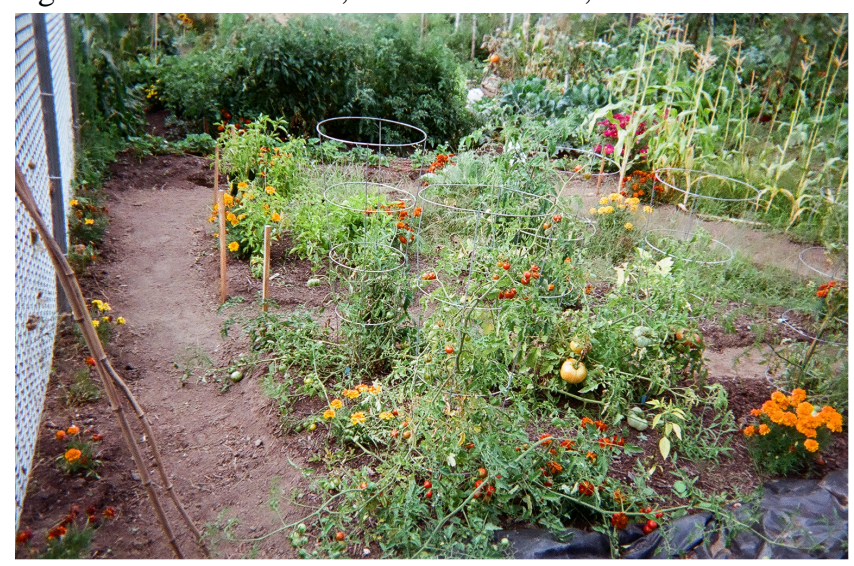

This is Dan's end of the season picture. It symbolizes survival in the garden and in life. After several difficult months, Dan was able to spend more time in the garden and experience his first garden harvest. The picture symbolizes his achievement, endurance, and survival. This picture was taken at the end of September when

Dan felt that, after all, his garden survived and he was even able to harvest tomatoes."This is my first year ever, I did not have any expectation to have a crop or vegetables to eat, and it was to learn ... I was doing too much this summer. I had to find a balance to do better..." 
APPENDIX A. 24.

EMPOWERMENT IMAGES

Hawkins

1. The First Carrot

"The First Carrot"

Fig. A. 24.a. Photo: Hawkins, Johns Gardener, 2009

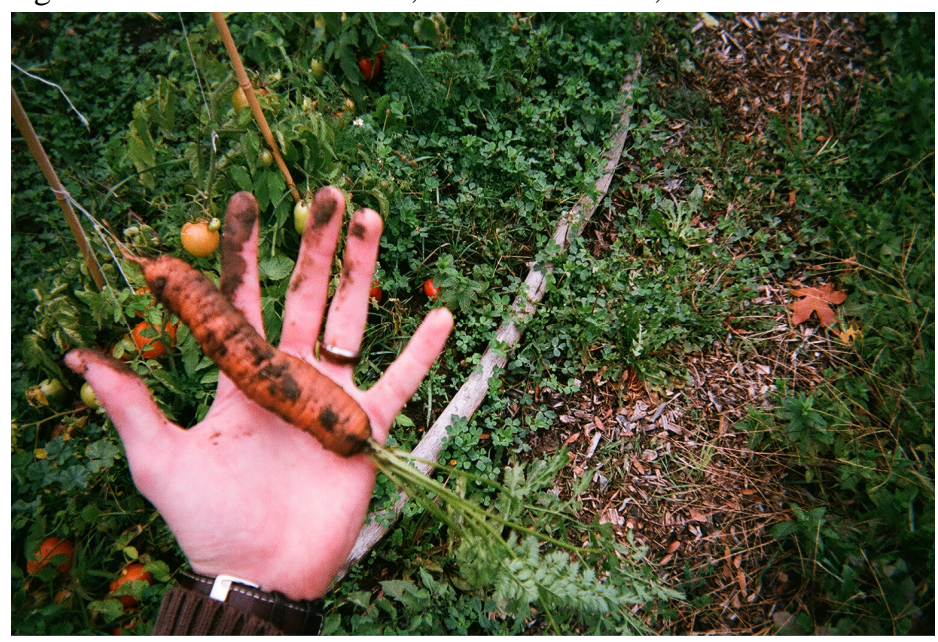

The picture

shows the first

carrot Hawkins

harvested in his

garden. "It is a

very attractive

carrot to me, I

was very proud

of it..." $\mathrm{He}$

placed the carrot

on his palm, just

a few inches

about the

ground. The specks of soil cover both the carrot and his fingers. "I get a chance to get dirt and get that smell on you; the smell of soil. Touching and smelling the soil. It grounds you...”

2. Beauty and Spirituality in Garden

"Beauty and Spirituality in Garden"

Fig. A. 24.b.Photo: Hawkins, Johns Gardener, 2009

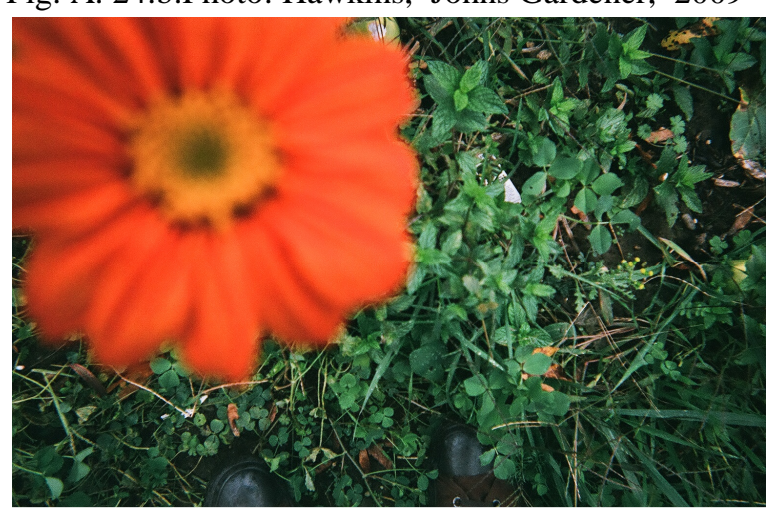

A red flower and its beauty captured Hawkins' attention in his picture. The warmness of the flower reminds him about the beauty in the garden. Hawkins associates the garden beauty with positive energy he experienced there... "All the positive energy that was put into it. It is very sacred space to many people, just to be around this space..." 


\section{The First Pepper}

\section{"The First Pepper"}

Fig. A. 24.c. Photo: Hawkins, Johns Gardener, 2009

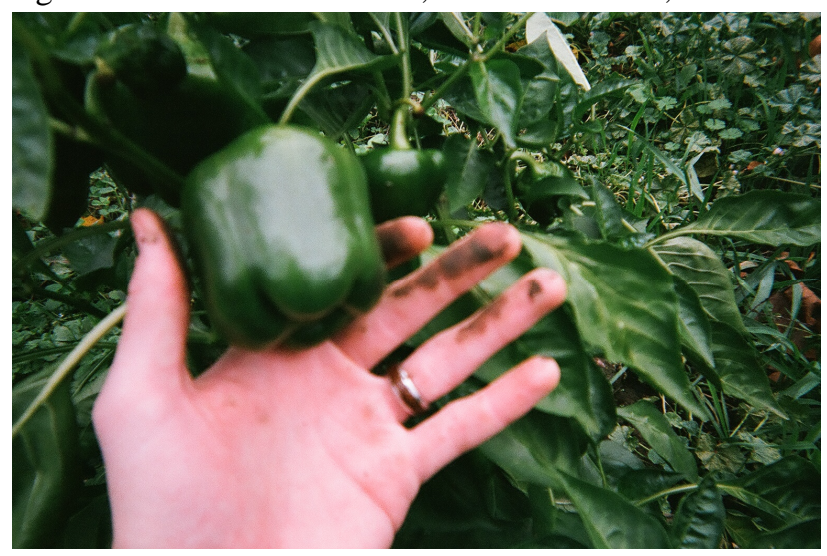

"I was proud of the pepper. I got many good peppers from my plant. I did not know whether it would grow, I did not have expectations, it was a surprise..."

It was first pepper he has ever grown. The picture is proof that he was able to grow vegetables. Learning basic gardening techniques was a big accomplishment. "I learned a lot. I consider myself a garden apprentice..."

\section{Ripening Tomatoes}

The picture shows

"Ripening Tomatoes"

Fig. A. 24.d. Photo: Hawkins, Johns Gardener, 2009

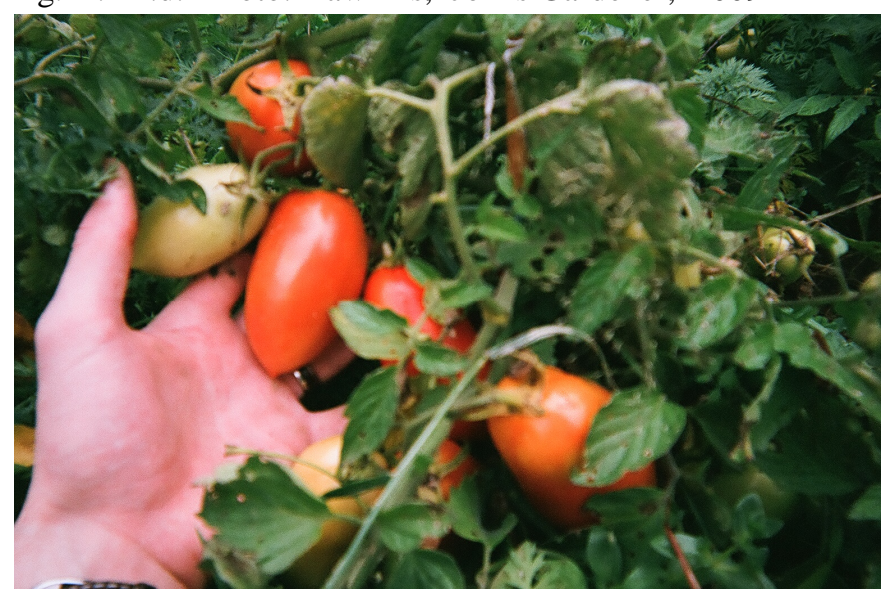

another big accomplishment, a cluster of ripening tomatoes. "I had so many different types of tomatoes; it was a real accomplishment ..."

"The garden experience makes you appreciate what goes into living things. I you are just walking on the street and you never try to plant anything it means

one thing to you, but if you have been nurturing the tree in your backyard trying to nurture it for one reason or another you have more respect for life..." 
APPENDIX A. 25.

\section{EMPOWERMENT IMAGES}

Wendy

\section{Canned Tomatoes: Learning about Food Production}

"Canned Tomatoes: Learning about Food Production" Fig. A. 25.a.

Photo:Wendy, Johns Gardener, 2009

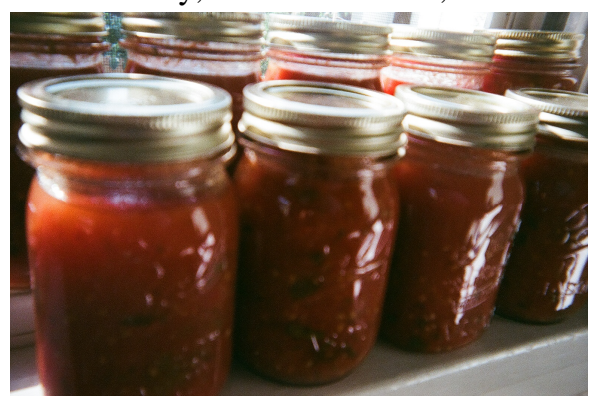

The picture captures several rows of canned tomatoes. It symbolizes the moment of celebration and reflection on Wendy's learning experience in the garden. Wendy's primary objective in the community garden was to meet other gardeners and learn from them. She has her own home garden and her community garden plot provided a complementary space for vegetables and a learning venue.

Gardening, including canning tomatoes,

became a family affair. It was a way Wendy reconnected with her parents. "This is the first time I have canned tomatoes and before I canned jam. I do not the equipment for canning. We had so many tomatoes that when I was out of town, my husband canned with my mom.... Things my mom never taught me I feel I should know by now. It gave me an opportunity to do that..."

2. The Bridge over the Garden

"The Bridge over the Garden"

Fig. A. 25.b. Photo:Wendy, Johns Gardener, 2009

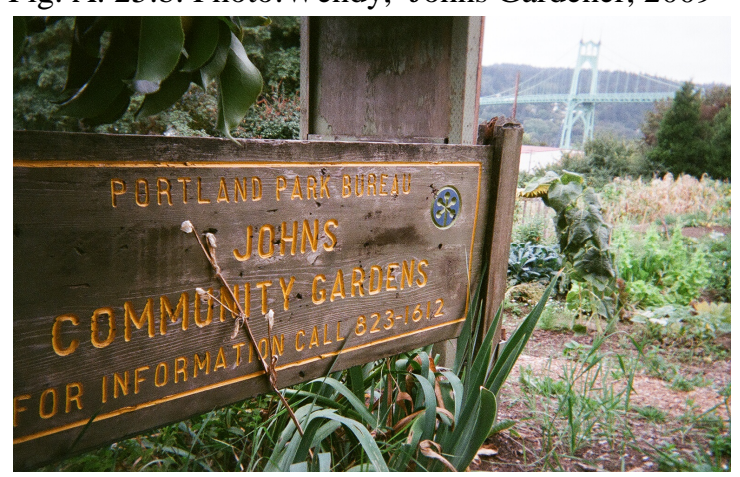

This picture captures the bridge and the garden sign posted in the garden. It is a reminder that the context for the garden is important. The view of the bridge defines Wendy's connection to the garden and the area.

"I want to be able to see where I am. This picture it gives you the idea. It is not beautiful, but you can see where we are and

sense the context for the garden. I like this picture a lot, where we are in the space..." 


\section{The Dog Companion}

"The Dog Companion"

Fig. A. 25.c. Photo:Wendy, Johns Gardener, 2009

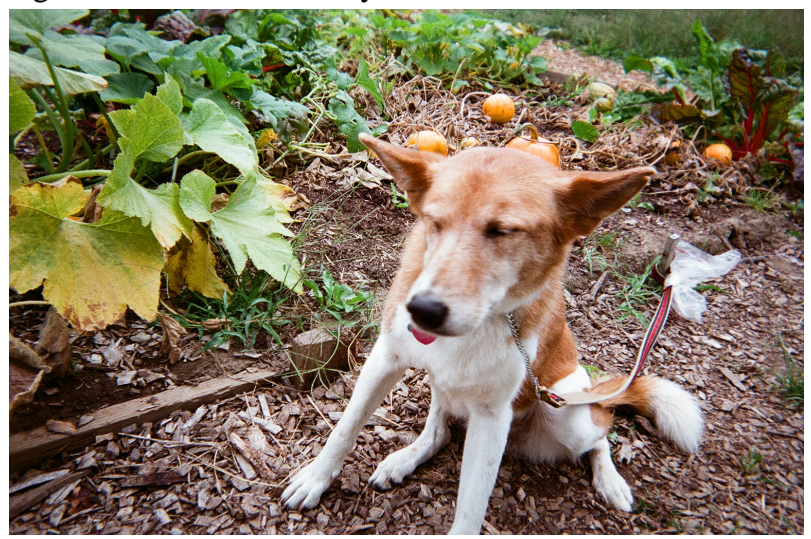

The picture is of an old dog Wendy and her husband adopted from the Humane Society. Wendy lives close to the garden and tries to take her dog to the garden as often as possible to make sure that the dog has a bit of exercise. The picture captures pumpkins in the garden background on Wendy's plot.

"We were glad we could take her with us to the garden. She was on the leash but we still liked to take her with us. I can understand that people do not like dogs in the garden. But whenever I can do something with her, I feel that I am a better caring person and it is important to me..." The picture reminds Wendy of the $t$ the enjoyment of sharing her garden experience with her aging dog. 
4. Community in the Garden: Garden Orchard

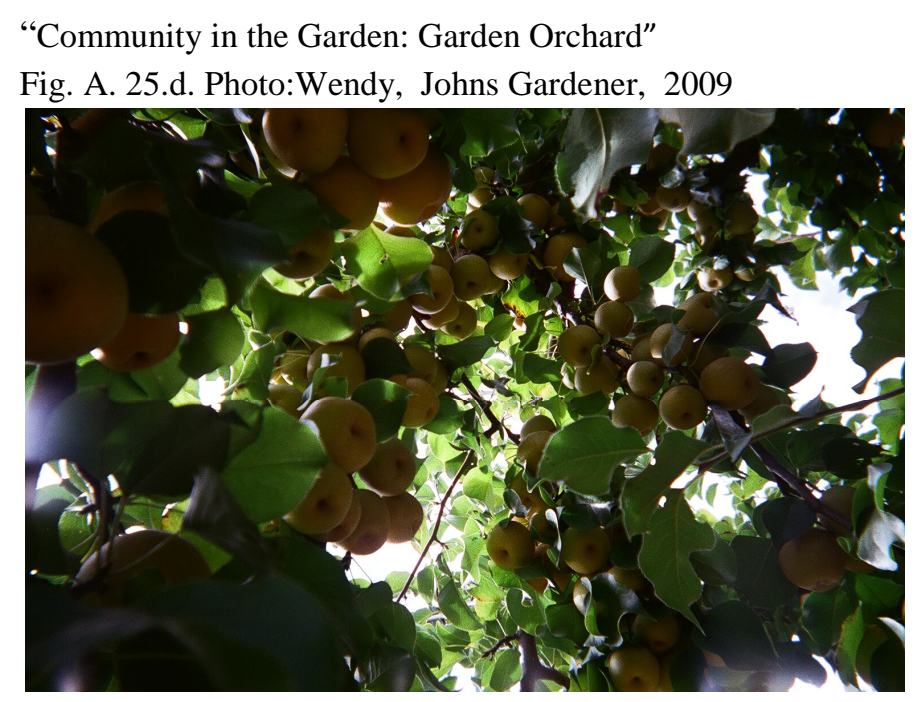

This picture is of ripe Asian pears on one of the trees in the communal areas. It is a reminder that the communications among the gardeners is not perfect and can be improved. The trees are in the corner, communal area of the garden, next to the fence. Despite the abundance of ripe fruit, nobody seemed to be interested in harvesting it. Many pears were wasted.

"These trees up on the top... leaning with a heavy crop of pears; hardly anybody picked the fruit. I wish we could pick some for processing. I would have liked to make something. This is a reminder of wasted food. I am not sure how, but we could improve our interaction in the garden. There are not that many people at the same time in the garden. We cannot really force the communication on the people but we can improve our communication. Maybe some people just do not know that they can pick the pears... "“

"There a lot of us of growing excess food. I would like to donate it. We had an extra chard. I would have been glad to have people come and take it. That aspect of community garden bothers me. We never had a box out in the garden to collect excess food for donations..." 


\section{APPENDIX A.26. EMPOWERMENT IMAGES \\ Mark}

1. The Road to the Garden

"The Road to the Garden"

Fig. A. 26.a. Photo: Mark, Johns Gardener, 2009

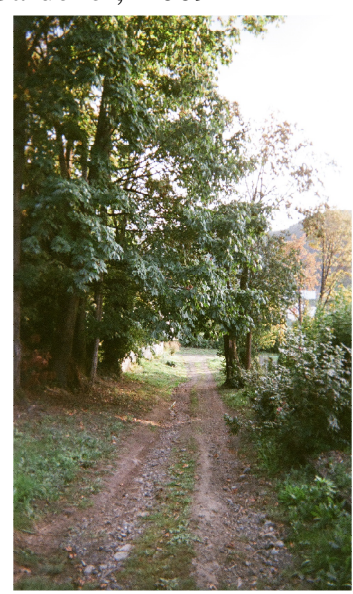

"The Road to the Garden"

Fig.A. 26.b. Photo: Mark, Johns

Gardener, 2009

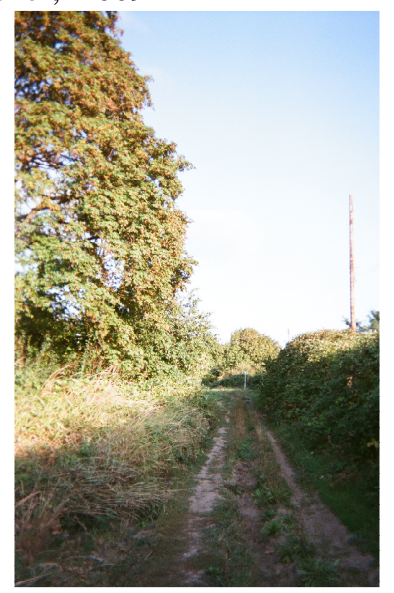

"The Road to the Garden"

Fig. A. 26.c. Photo: Mark, Jol

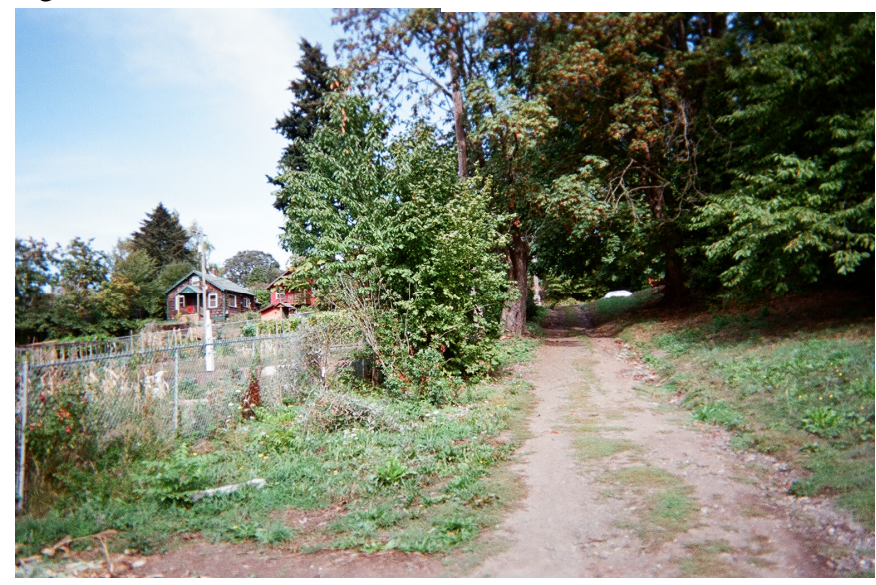

A series of three pictures representing Mark's everyday walk to and by the garden. Mark walks by the garden every day on his way to work. He alters his daily walking routine to see the garden. As he walks by the garden, he either stops by to do some simple maintenance tasks or assesses what needs to be done during the weekend when he has more time.

The first picture marks the transition from the paved street to the gravel road down to the garden. The gravel road symbolizes the community garden connection with the bucolic countryside. The second picture captures a view of the garden from the gravel

road with the surrounding houses in the background. The third picture shows the last segment of the journey, the road that takes Mark from the garden to his office. 
Mark admits that the pictures he took represent a "romanticized" version of country life, with the dirt road leading down to the garden. "Walking down, the old dirt road, even if this picture romanticizes it, even if it seems to be more rural that it really is, it still represents a romantic notion of something pleasant, a green, bucolic life in the city. I see it many times when I go the garden, which is the same way I go to work..."

\section{Green Oasis in Rural Eden}

\section{"Green Oasis in Rural Eden"}

Fig. A. 26.d. Photo: Mark, Johns Gardener, 2009

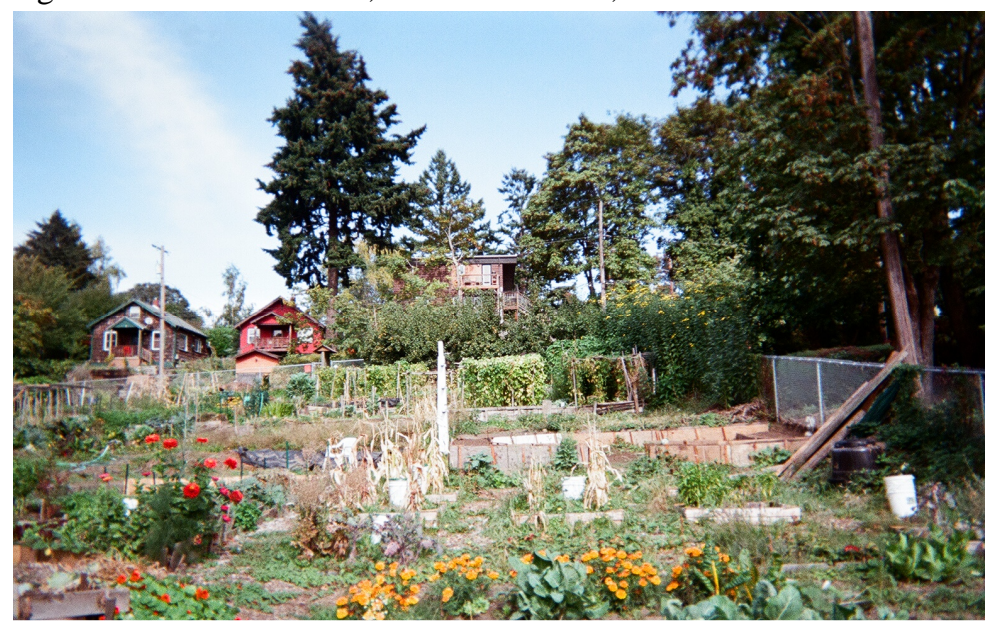

This picture is taken from Mark's plot, with the houses in the background of the garden. Here, the community garden area is a green oasis in the city. The surrounding houses symbolize the city life. The garden area is a reminiscent of bucolic rural life in the city. Typically, community gardens are located on flat areas. In this picture, Mark has tried to capture the slope of the garden, which makes it unique and challenging to design and develop. The surrounding houses appear to be cheerful and pleasant; it evokes an image of happy people living in a happy place overlooking the garden.

"I like this picture because it is representative of the houses and the area I always liked. They sit above the road, they look down the garden. I like the character of the garden that it is on the slope... the overall garden. The majority of gardens are relatively flat, this one is hilly, with the houses above. It is a story you can made up of the people who live there, what they see from their windows. It triggers your imagination of a happy and cheerful life..." 
3. Compost Bin: The Most Important Object in the Garden

"Composting Bin: The Most Important Object in the Garden"

Fig. A. 26.e. Author: Mark, Johns Gardener, 2009

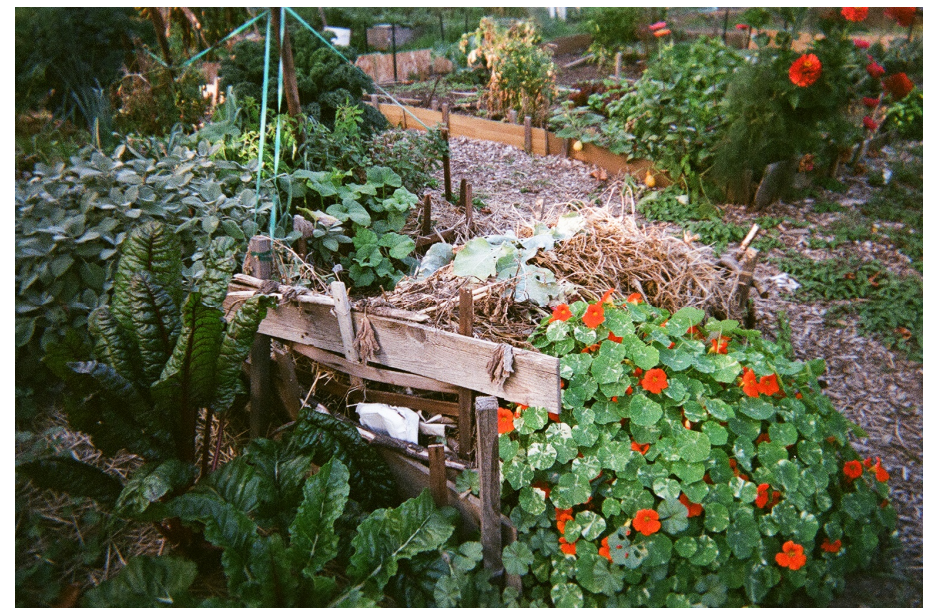

Composting is Mark's favorite gardening activity. He incorporated a composting bin into the overall design of his plot. The composting bin with the cascading flow of nasturtiums is Mark's most important place in the garden.

"I am a compost gardener. I do not use the compost in the end. I like building the pile and watching it break down. I spend more time watering my compost pile that tending the rest of my plot. It became the backbone of my gardening. If I go in the morning, I would take some compost with me...it was like a consistent thing. You would plant things and nothing would come out for a couple of weeks, but I always had my compost pile to attend to..."

The compost pile symbolizes the "active" part of gardening. "I like to have my hands dirty..." 
APPENDIX A.27.

\section{EMPOWERMENT IMAGES}

Marguerite

1. Strawberry Patch

"Strawberry Patch: Everyday Snack and Wellbeing"

Fig. A. 27.a. Photo: Marguerite, Johns Gardener, 2009

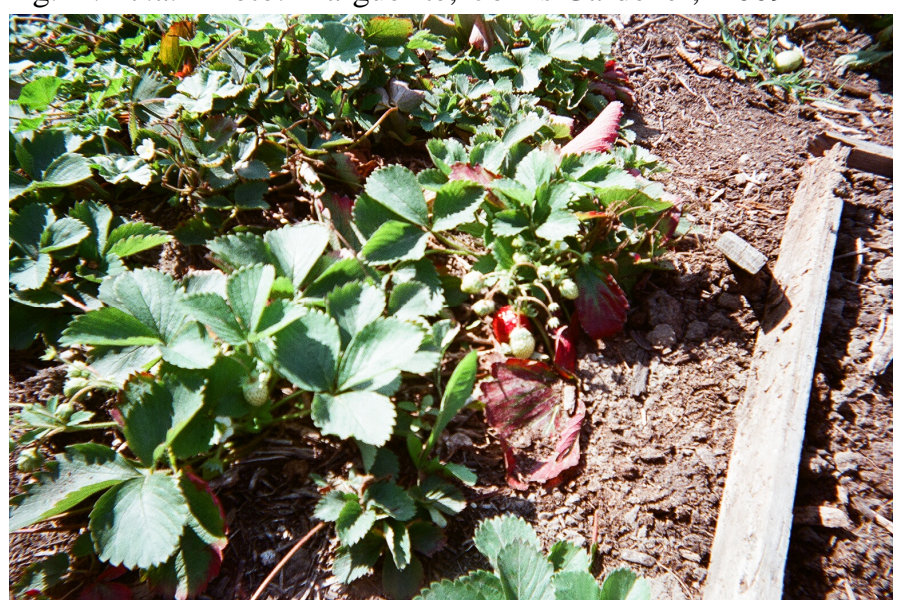

Strawberries are

Marguerite's

everyday snack.

She can pick

strawberries

almost every day.

"They grow all

year, you can

have a strawberry

every single day

you go down

there..."

Gardening has

always been part

of her life. She

loves fresh berries and vegetables. This picture reminds her that she has been interested in gardening all her life. The pleasure of going to the garden to pick a fresh strawberry defines her concept of well-being.

\section{Blueberry Bush}

"Blueberry Bush: Rooted in the Garden"

Photo: Marguerite, Johns Gardener, 2009

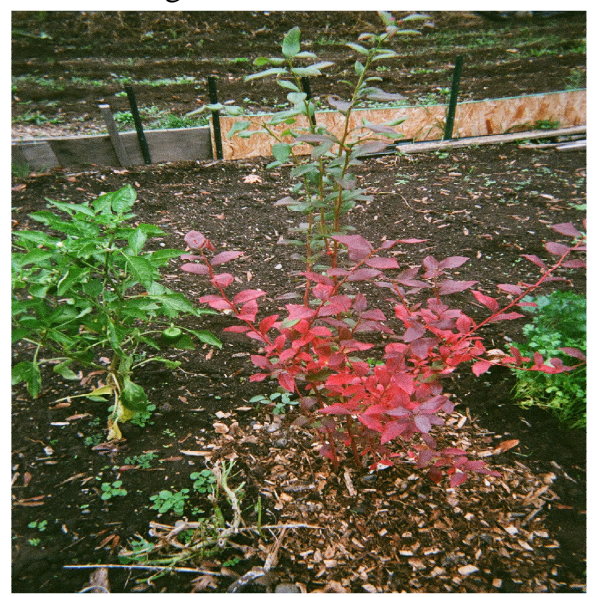

Fig. A. 27.b.

The berry bush is the heart of the garden. Marguerite planted it three years ago when she started gardening in the garden. She has moved the plant a few times but it remains her focal point; it marks her space in the garden. "The blueberry bush... it is the center of my plot. This garden was nothing. It was just clay. I wanted to have something to eat and to nibble when I go there. I like berries to snack. It started in the middle of the 
plot. It took me the whole summer to clear. It started with the blueberry bush..."

"I feel settled with what my plot, I am totally happy with what I have there. This is the center, the heart of my garden..." The blueberry bush is the one permanent object in her plot. She changes her crops frequently and experiments with different plants. "I like to eat strawberries. I like to grow lettuce. I just love fresh lettuce. The garden changes constantly, you never know what you are going to have there. Next year I will have more potatoes..."

\section{Zinnias: Childhood Connection}

"Zinnias: Childhood Connection"

Fig. A. 27.c. Photo: Marguerite, Johns Gardener, 2009

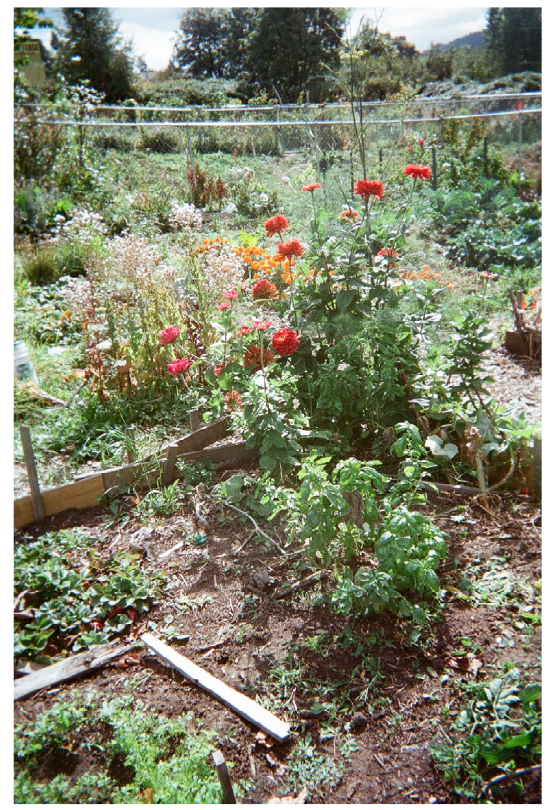

Blooming zinnias connect Marguerite with her childhood memories of cold climates on the East Coast. Zinnias survive even in cold climates. In Oregon, they grow effortlessly.

"Zinnias, you can grow them in the colder climates. People in Oregon think that they garden but they do not have a clue... In cold climates, you have to really work on it hard. Zinnias are flowers that would grow in cold climates, that cold upper great lakes climate I grew up..." 
APPENDIX A.28.

EMPOWERMENT IMAGES

Mary Anne

1. Balance and Beauty: A Garden Composition

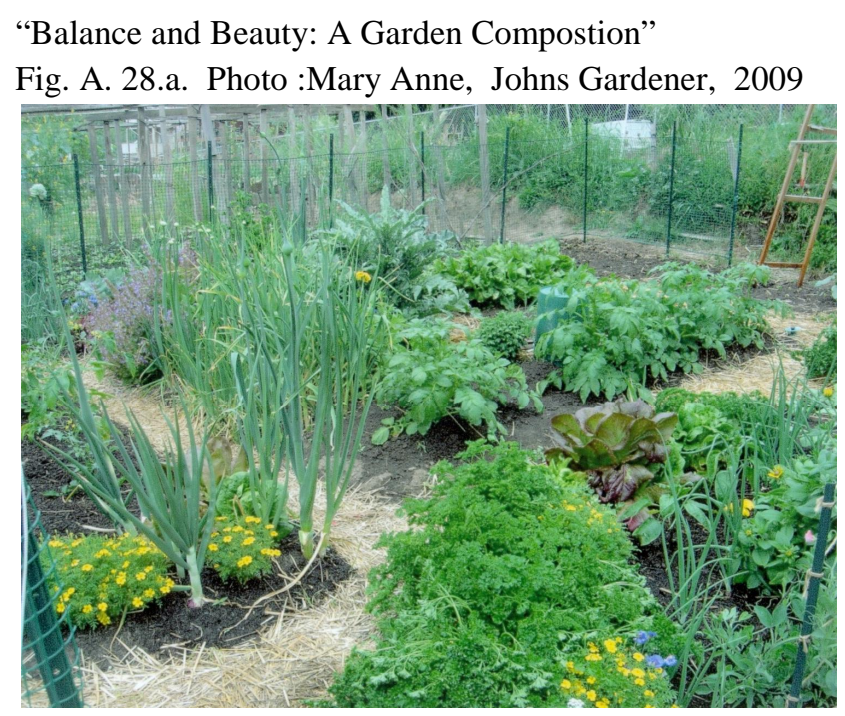

Mary Anne's most important place in the garden is her plot. Mary Anne's garden is an object of admiration for many fellow gardeners. It is a place of beauty and Mary Anne's expression of passion and love for gardening. "My plot is my composition, like a picture. The sage is blooming. The way my herbs grow it is not what I really expected. I like the way they grow together as a patch I never expected or planned but I like it. Individually, they are not that interesting, but, collectively they are very interesting to me. The picture shows the garden and pathways around the garden that define the circle, my plot..."

The garden is also Mary Anne's sanctuary. She goes to the garden in the morning to see the plants in the morning sun. She likes to see the sunset in the garden. "My plot is the most important place in the community garden. I can walk down the street and the closer I get, the better I feel. I open the gate ... and I am not quite there, I walk down the path and I physically step into my garden... and is wonderful. I think about my garden a lot. As I get closer, I can feel it. I go to my space to be there..." 
2. Natural Beauty and Space Making

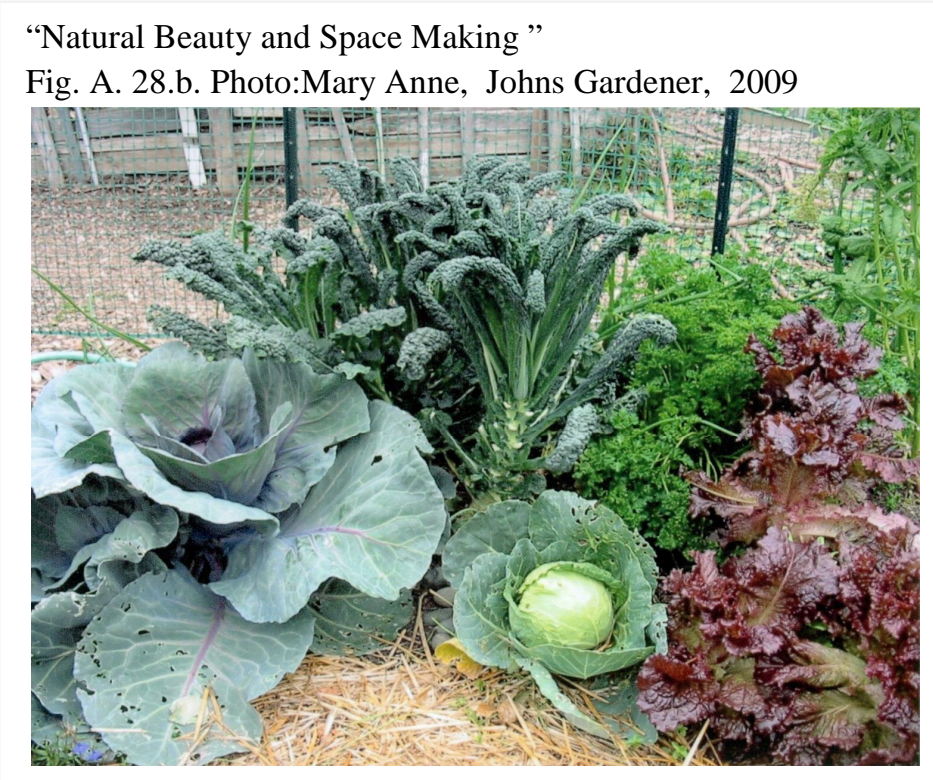

"The composition of this picture and the color in it shows a beautiful day. It is a sense of beauty, of mystery of life, a sense of nature, cycle of life. I have the kale and onions... lots of the stuff going on here. In the corner is the straw path I created in my garden. It is the reminder of my space in the garden..." The picture symbolizes the relationship between human actions and the natural garden cycle. The natural beauty of growing plants in the context of cultivated space, marked by the straw path. The straw path is an attempt to control nature by marking the boundary of one's territory, the private space and enclave of safety. . ."

"I did a lot of therapy in my garden. The going to the garden... being in my little space, something about it makes me feel really good and secure, even though I have not been gardening for that long. I feel I know what I am doing there, just because is my place..." 
3. Control and Change in the Garden and Life

"Control and Change in the Garden and Life"

Fig. A. 28.c. Photo:Mary Anne, Johns Gardener, 2009

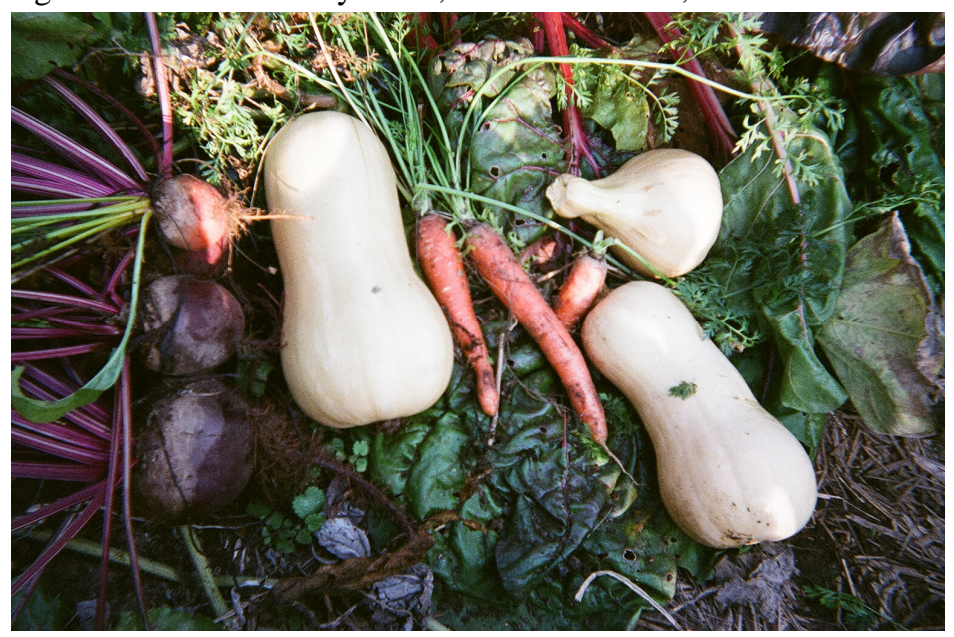

"I had not been to the garden for a while and I was a little surprised. It was a lovely surprise, my butternut squash was ready. I put the ladder, but it did not climb, it was not orderly. I am orderly in my garden, the squash took over the other part of the garden, and not where I wanted it to grow, on the ladder. It just further reminded me of how my life has changed so much this year, with Mark and me opening my shop, one of the best years in my life. Having my squash go everywhere made me smile. The garden was one of the areas that I lost control of and it did not bother me that much.... 


\section{APPENDIX A.29.EMPOWERMENT IMAGES}

Robby

1. Tomatoes and Garden Tools

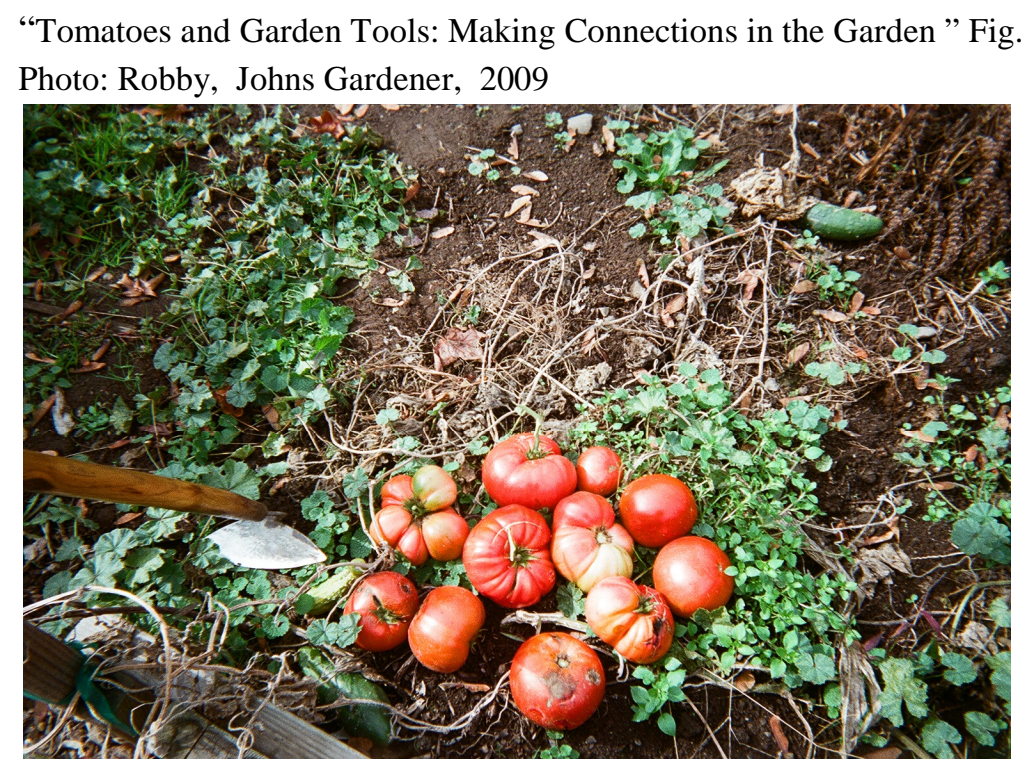

Tomatoes symbolize Robby's primary objective in gardening, food production. A small gardening tool, a hoe, is placed next to the tomato crop. The tool is very important to Robby. It symbolizes the special connections he developed with the Hmong gardeners. The hoe was given to Robby by one of the gardeners. "When I first came there they endeared me. They were kind to me' they saw that I was interested and always came over and took time to talk to them. Some of the ladies asked me whether I want some of their tools and I bought that tool from them. It was a way to be welcomed to the garden by somebody who have been there for a long time. It is a true gift, not just a working tool but also a relationship..." 
2. St. Johns Bridge: How fortunate we are in our garden...

"St. Johns Bridge: How fortunate we are in our garden" Fig.A. 29.b. Photo: Robby, Johns Gardener, 2009

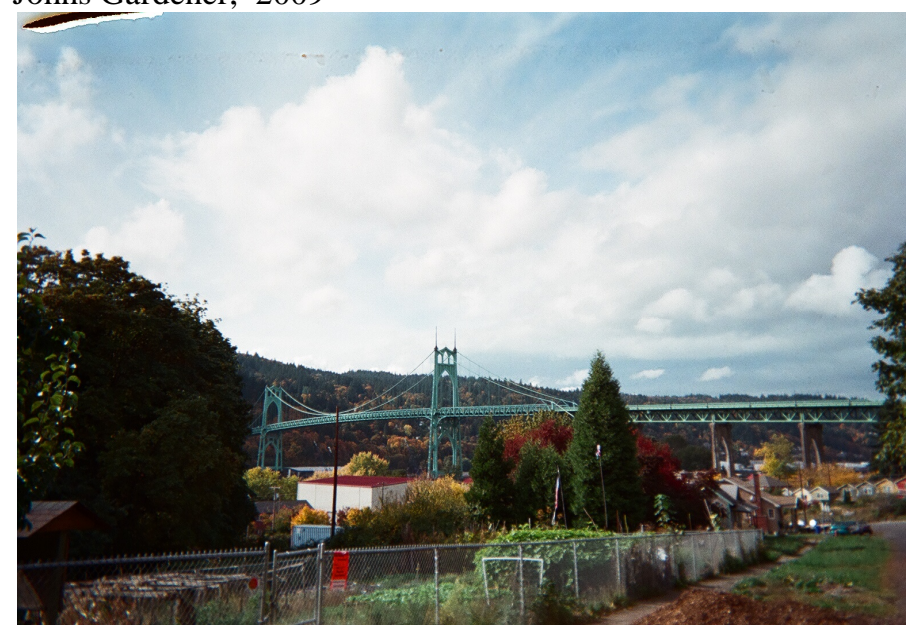

The picture of the St. Johns bridge was taken by Robby in front of the garden. "How fortunate we are in this garden to have such a piece of art. It has been my third year in the garden and I started noticing it... In some point in my second year, I started to be aware of the bridge. I saw it before, but I did not appreciate it. It is the city. It is beautiful..." Robby frequently watches the bridge from his car, parked on the road in front of the garden. 
3. Water in the Garden: "It is something I do not take for granted..."

"Water in the Garden: It is something I do not take for granted..."

Fig. A. 29.c Photo: Robby, Johns Gardener, 2009

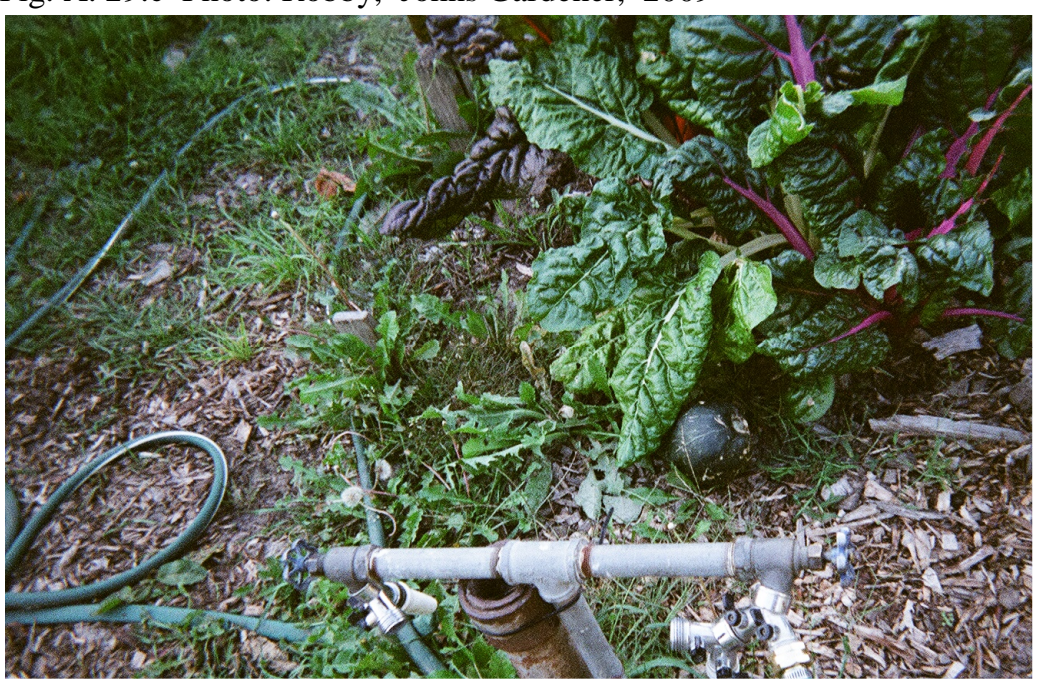

This picture is of the water station in the garden. It symbolizes the availability of water to cultivate plants. This is the place where everybody needs to go to get water. "It is water, the watering station ion above my garden. Without water, nothing is possible. If we did not have water, it would be much different task growing. It is something I do not take for granted. We do not have to pay for it other than our fees for the year. A very important picture for me..." 
APPENDIX A.30.

\section{EMPOWERMENT IMAGES}

Mike

1. Garden View: St. Johns Bridge

"Garden View: St. Johns Bridge"

Fig. A. 30.a. Photo: Mike, Johns Gardener, 2009

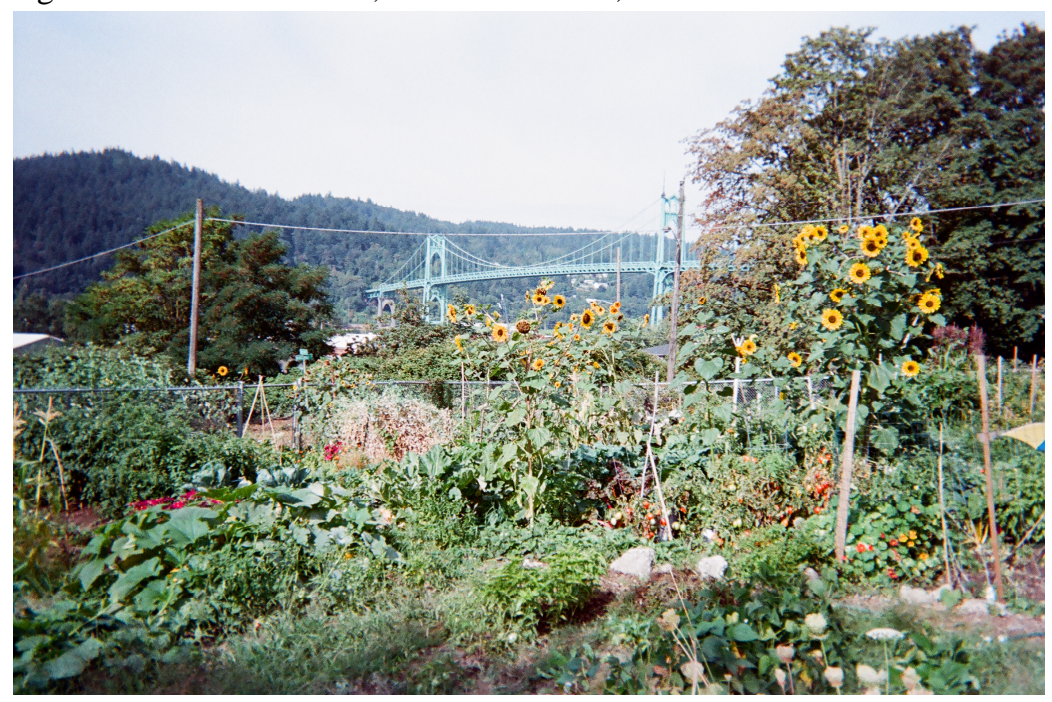

The view

of the St. Johns Bridge with Forest Park in the background is the primary reason Michael chose his plot at St. Johns Community Garden. "Whenever I am in the garden or just going down the road to the garden, it is noticing the bridge. It is so scenic that I feel I am so lucky to have it, the nice of view of the bridge from the garden, and it is the most important thing to me when I am in the garden..."

"I look around and see this beautiful bridge. I like it. It is nice to work and look up. It is pretty. You see barges going on the river..."

"This is one of the major reasons I took a picture of the background, this is the Forest Park in the background. This is pretty and it changes throughout the year. Leaves change during the winter. Trees, change colors. The Forest Park is very pretty. I can see more things during the winter when the trees lose leaves. You will start to see the water... When the leaves drop off, the context changes. You can see the river, the big boats coming down. I can see it from my plot. You hear the river, the boats and welding shops down the river..."

"The garden is close to the residential area on the hill with a little shopping, flower shops, a variety of small restaurants and the diversity of the surrounding areas. You can always take some time off from the garden and walk up to the Safeway. The library is nearby..." 


\section{A View of the Garden}

\section{"A View of the Garden"}

Fig. A. 30.b. Photo: Mike, Johns Gardener, 2009

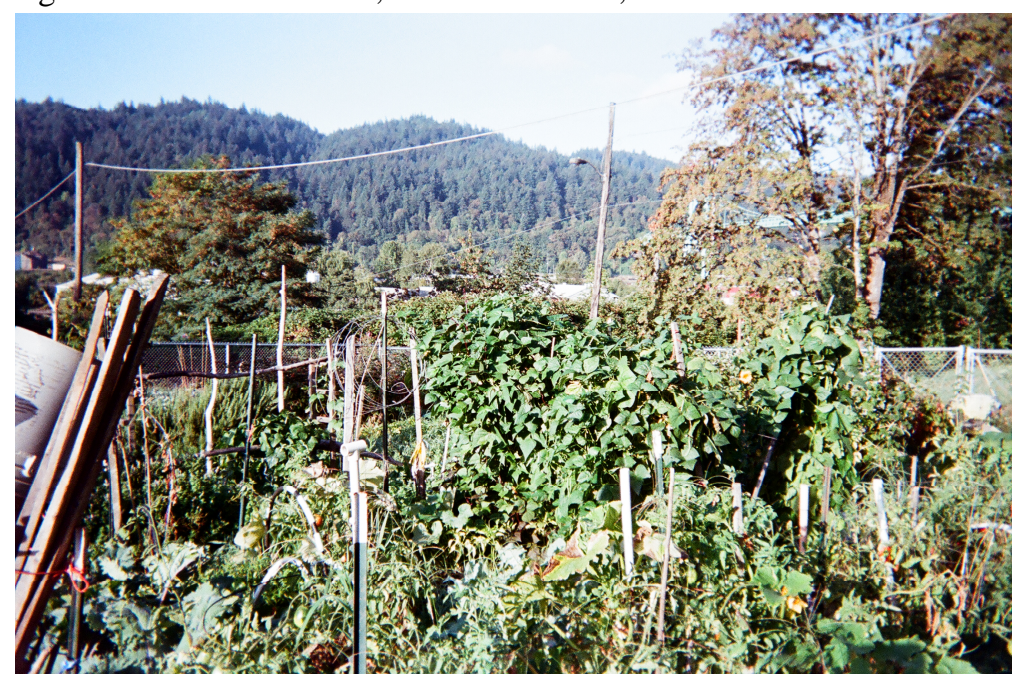

"This is one of the major reasons I took a picture of the background, this is the Forest Park in the background... "“

This picture is centered on Mike's plot at Johns garden. The white stakes for tomatoes mark the place of Mike's plot. The picture captures the bounty and lushness of the garden and its scenic location. From here, Mike can experience the beauty of the surrounding area and cultivate his garden.

Mike's garden is known for its crop diversity and extraordinary number of plants... "Raspberries, black cups, boysenberries, blueberries, lots of intense planning to squeeze it in, the diversity, the bounty of the garden. It takes a high level of rotation and careful and intense planning... Winter squash blooming, green beans, red peppers, green peppers, leaks, for the winter, layers, to keep it going the whole year...parsnips, tomatoes, leeks..." 


\section{Kale: A Friendly Plant}

"Kale: A Friendly Plant"

Fig. A. 30.c. Photo: Mike, Johns Gardener, 2009

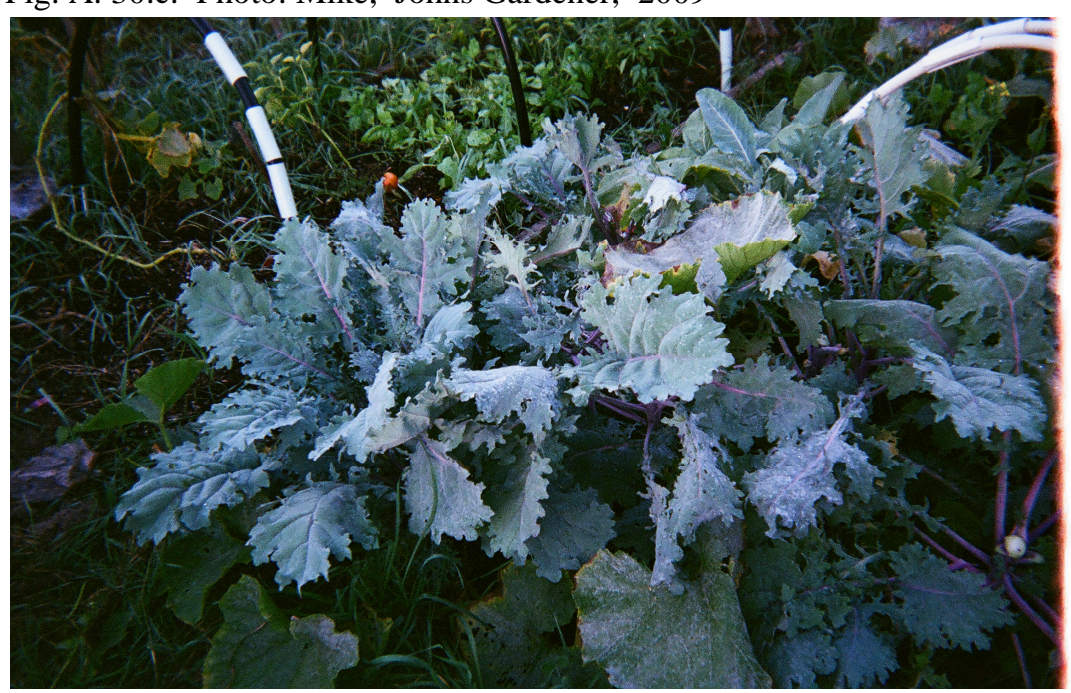

The close up picture of the garden shows how prolific the garden is. "I like to take pictures of kale. It is very prolific. It lasts long. You get four or five months on a plant. You get a lot of food out of kale. It is good. You cook it in a number of ways. You eat it fresh. The leaves are excellent in salads. You keep eating it and it gets bigger...It stays healthy. It shows how prolific the garden is. I was eating kale in February..."

"Kale is not my favorite, but it is always there. It is prolific. You can prepare it, a symbol of garden sustenance...It is friendly. It is always there, as long as you plant it. It is very reliable and goes though the winter. There are times that there is almost nothing in the garden and there would kale. You can cut it and it keeps growing. You cut what you want on the leaf..." 
4. The Prolific Garden: Summer Harvest

"The Prolific Garden: Summer Harvest"

Fig. A. 30.d. Photo: Mike, Johns Gardener, 2009

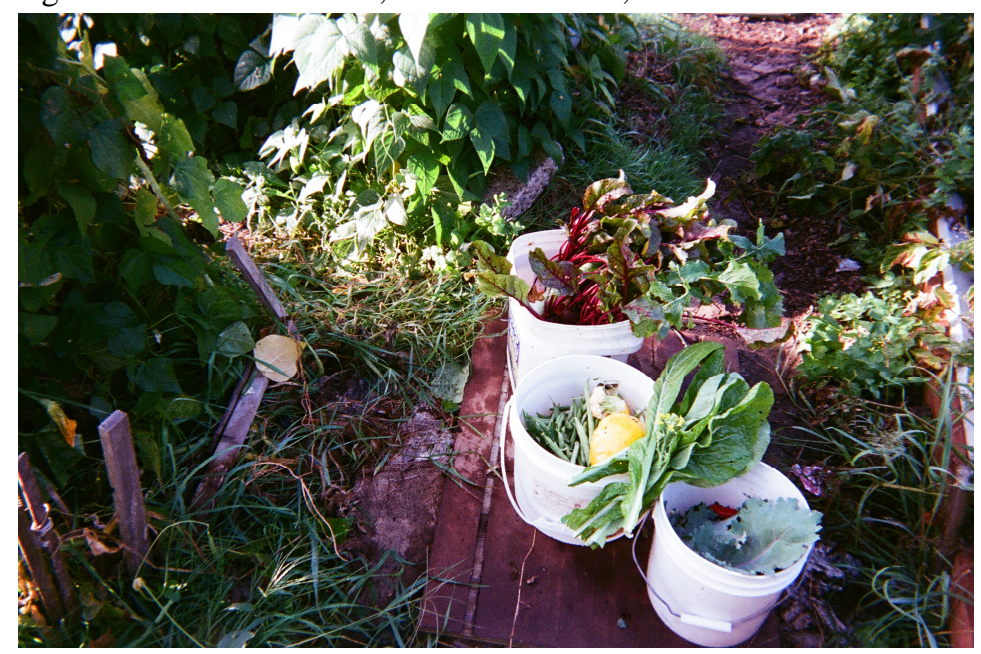

The three white buckets are full of summer vegetables. It represents a typical daily harvest: red beets, yellow squashes, green beans, leaks, and green kale. "A picture of a typical small harvest from my garden; it is lots of food, really, twice per week. Some of that could be frozen or canned, I eat out of my garden the whole year... I can get kale in February, from my winter crop...

"It is growing vegetables. You go out there, looking for some seeds. It is growing, if it does, you plant more. Planting and harvesting time, you get surprised by something that grows well or does not grow... I eat much more vegetables. I feel more compelled to eat them. I give them away to, friends, Food Bank. I try different vegetables...I like to harvest and I like to eat it right on the spot..." 
APPENDIX B. MAPS

B.1. Fulton Community Garden Location

Location: SW 3rd Ave \& Miles St

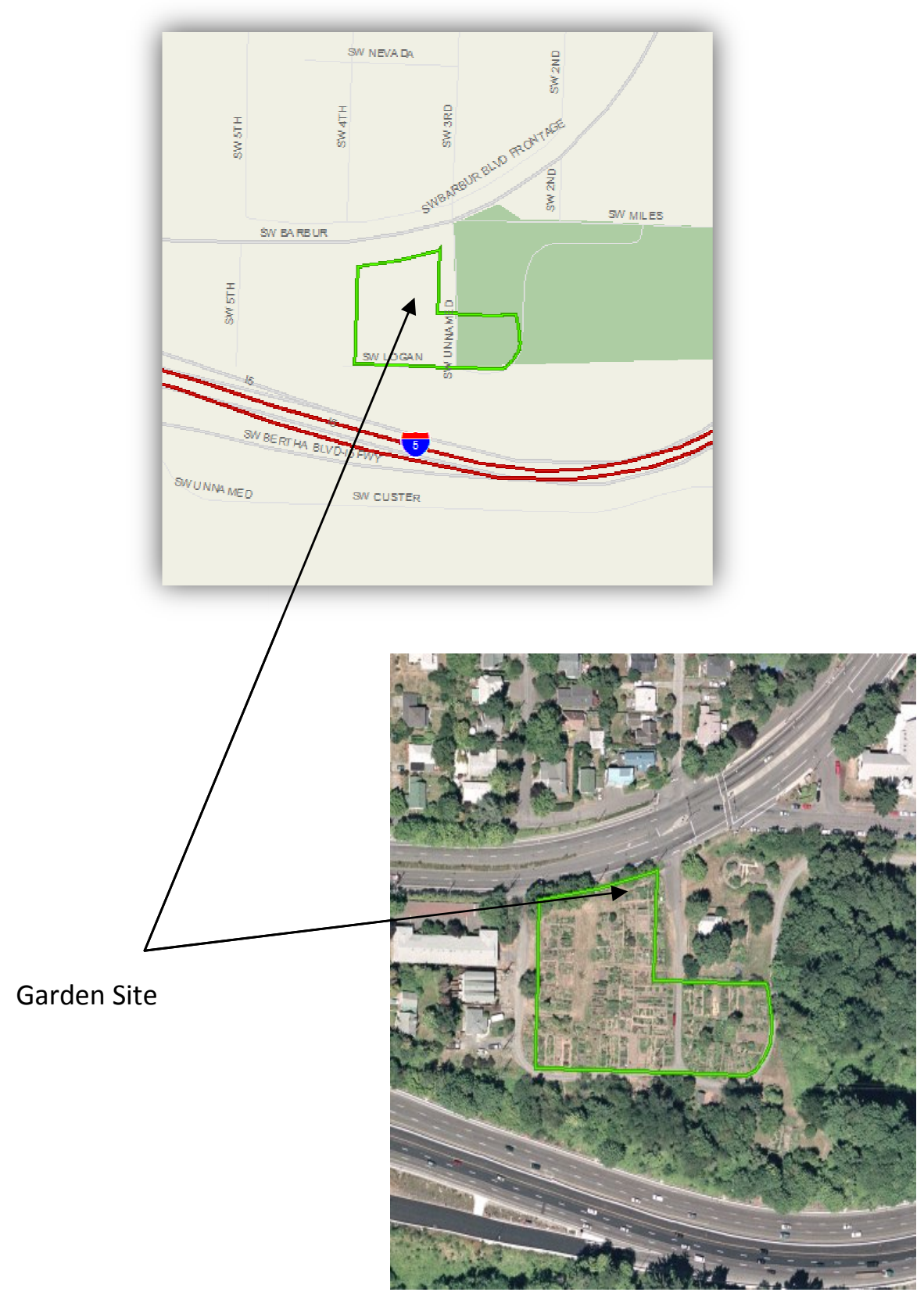




\section{APPENDIX B.MAPS}

B. 1. Brentwood Community Garden Location

Location: SE 57th Ave \& Cooper St

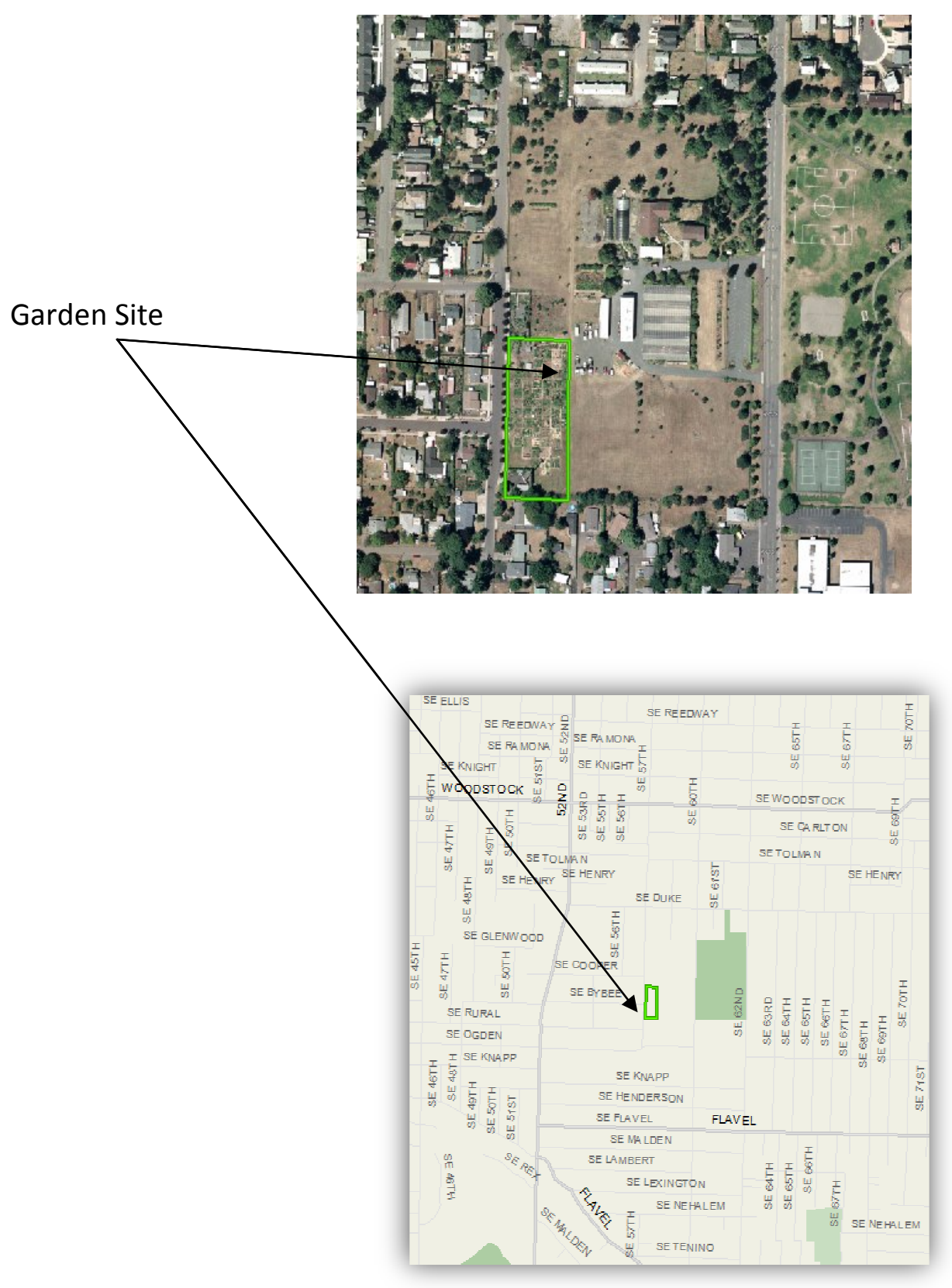




\section{APPENDIX B}

B. 3. Johns Community Garden Location

Location: N Edison St \& John Ave

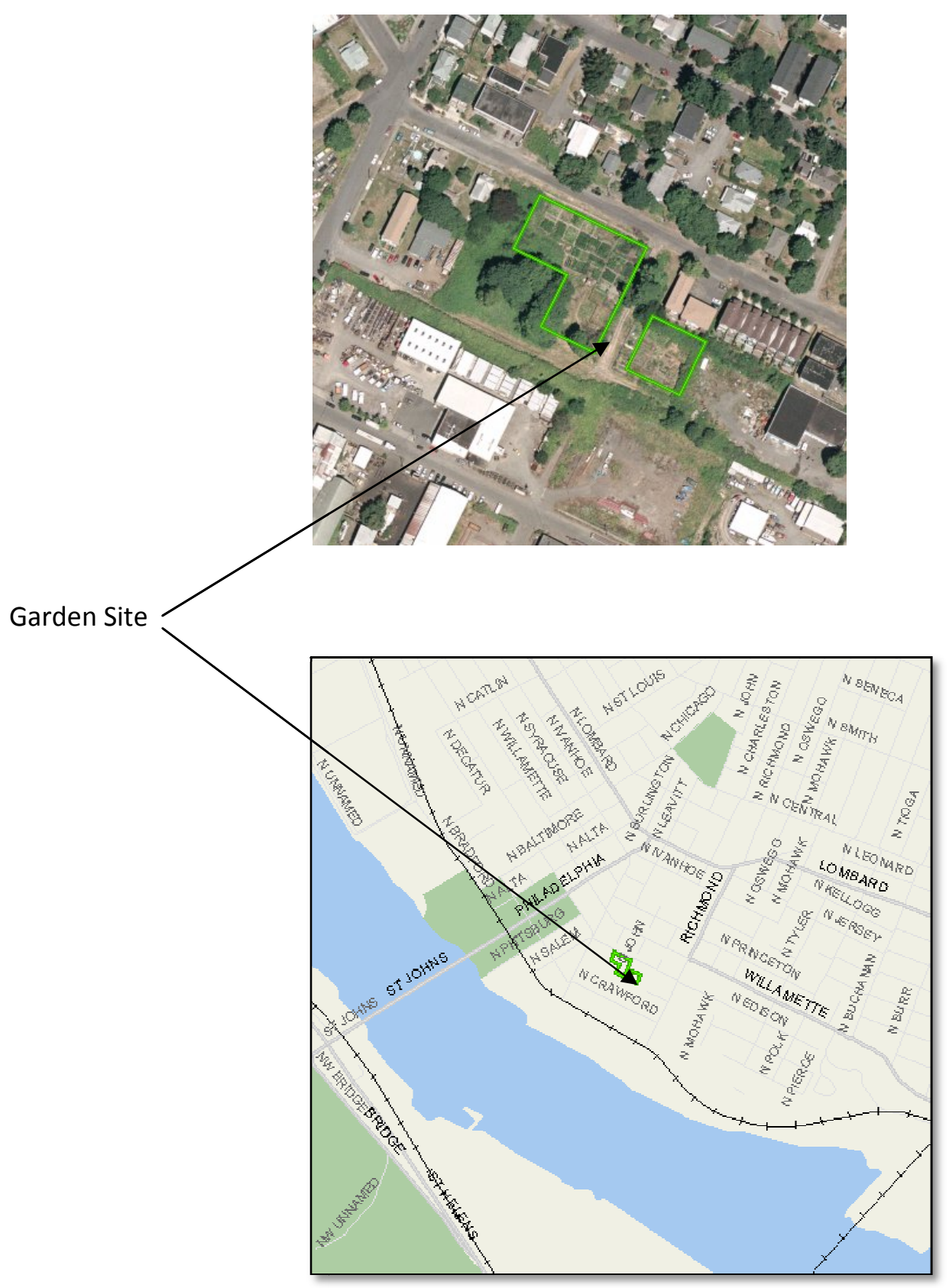


APPENDIX C

C.1.Fulton Community Garden Site Plan

Source: City of Portland Community Garden Office, 2009

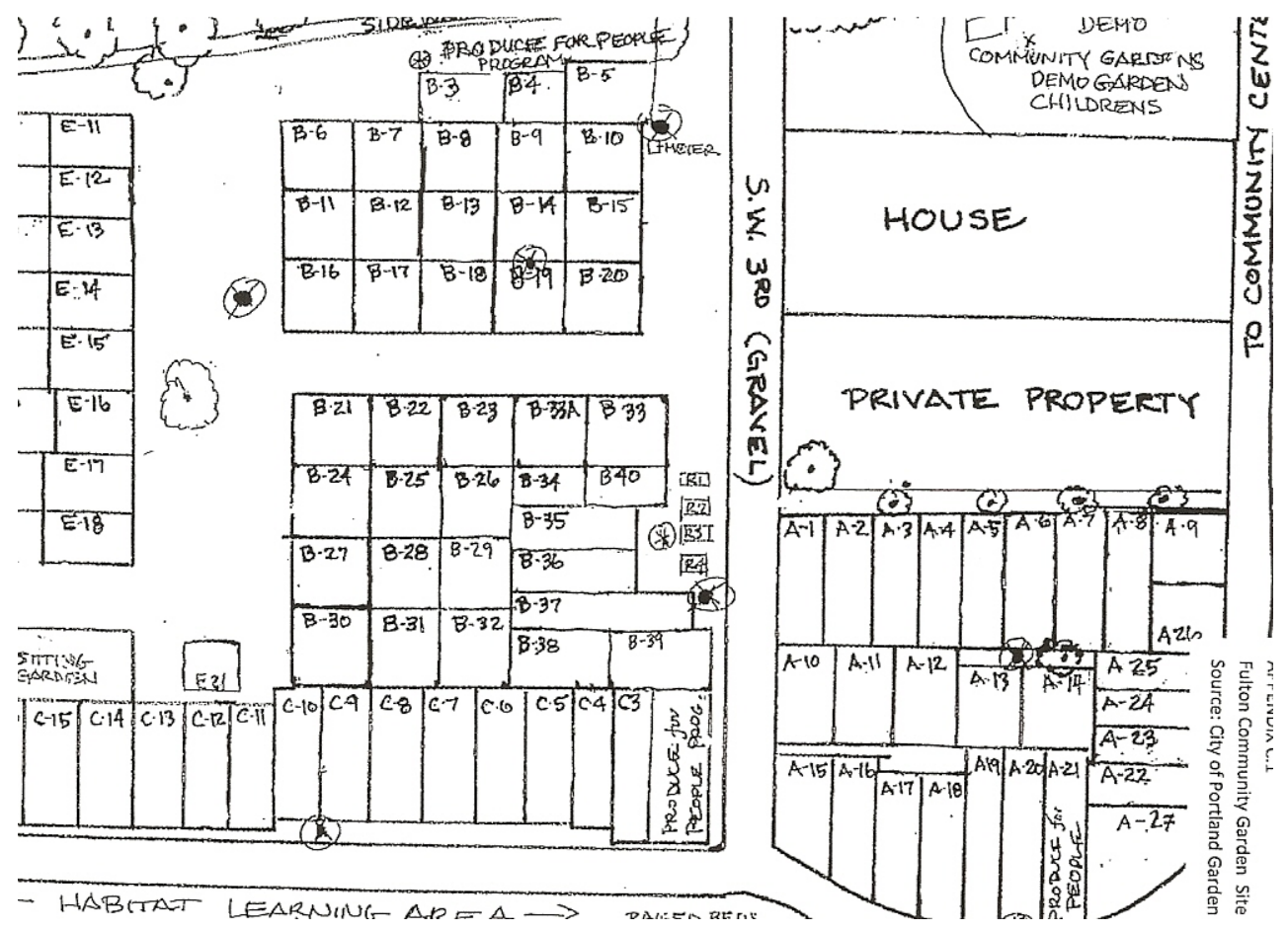




\section{APPENDIX C}

C.2. Brentwood Community Garden Site Plan

Source: City of Portland Community Garden Office , 2009

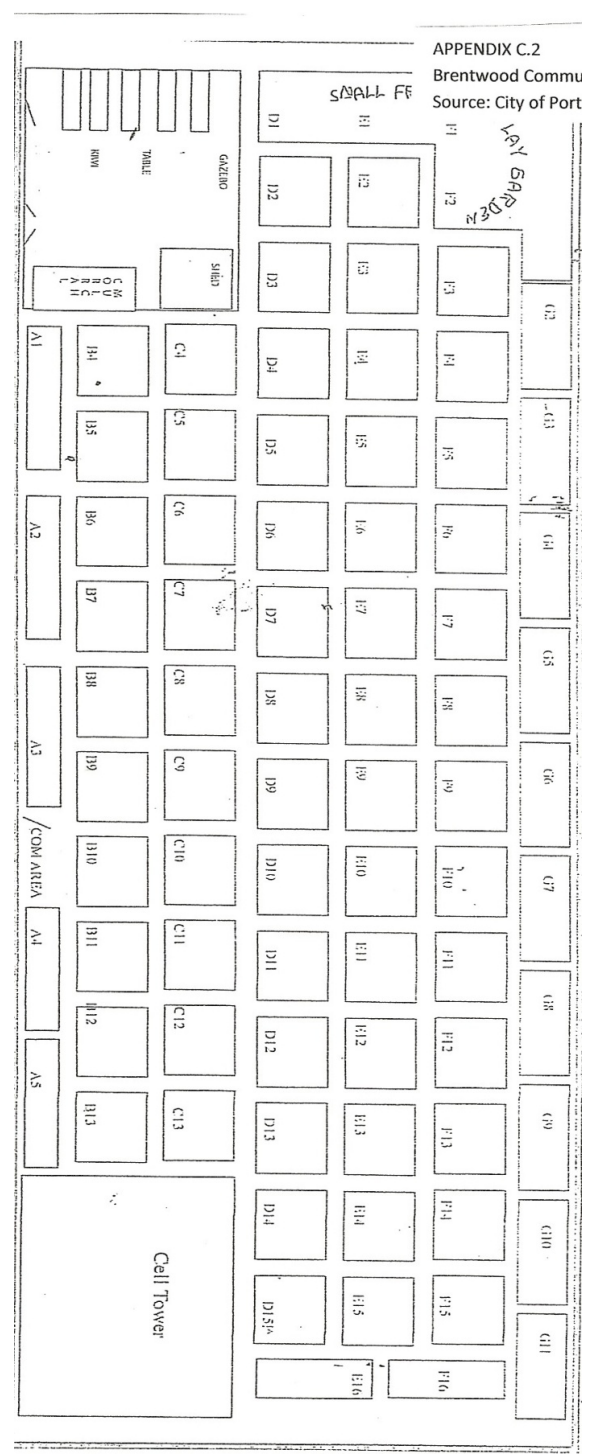


Appendix C

C.3. Johns Community Garden Site Plan

Source: City of Portland Community Garden Office 2009

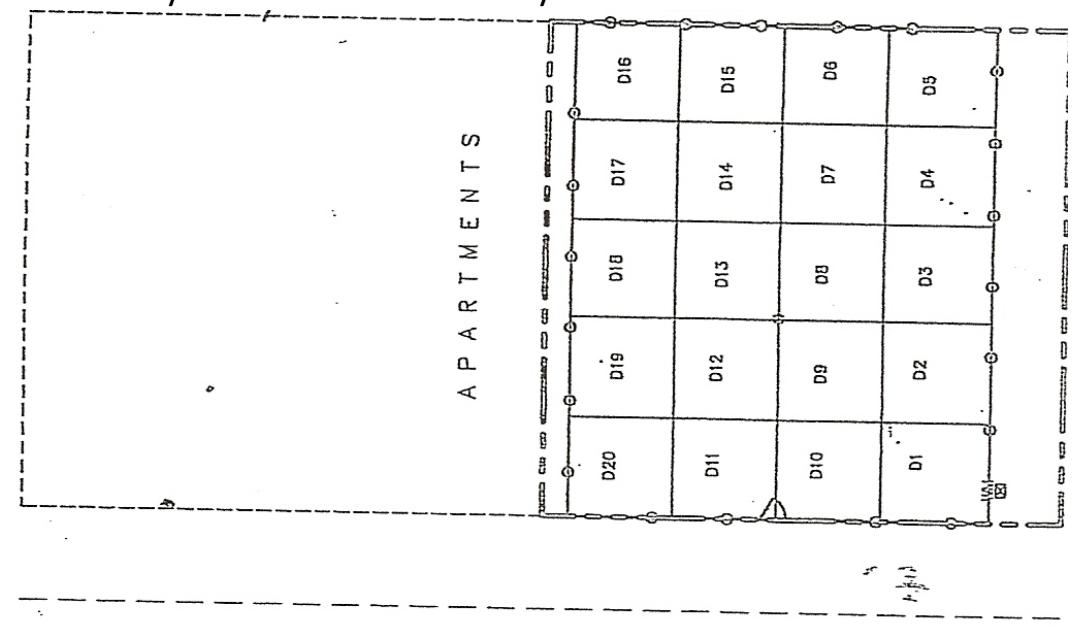

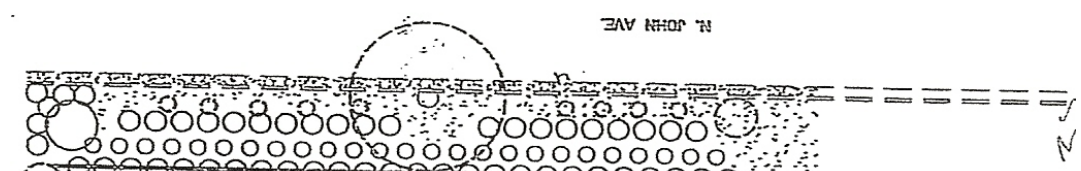

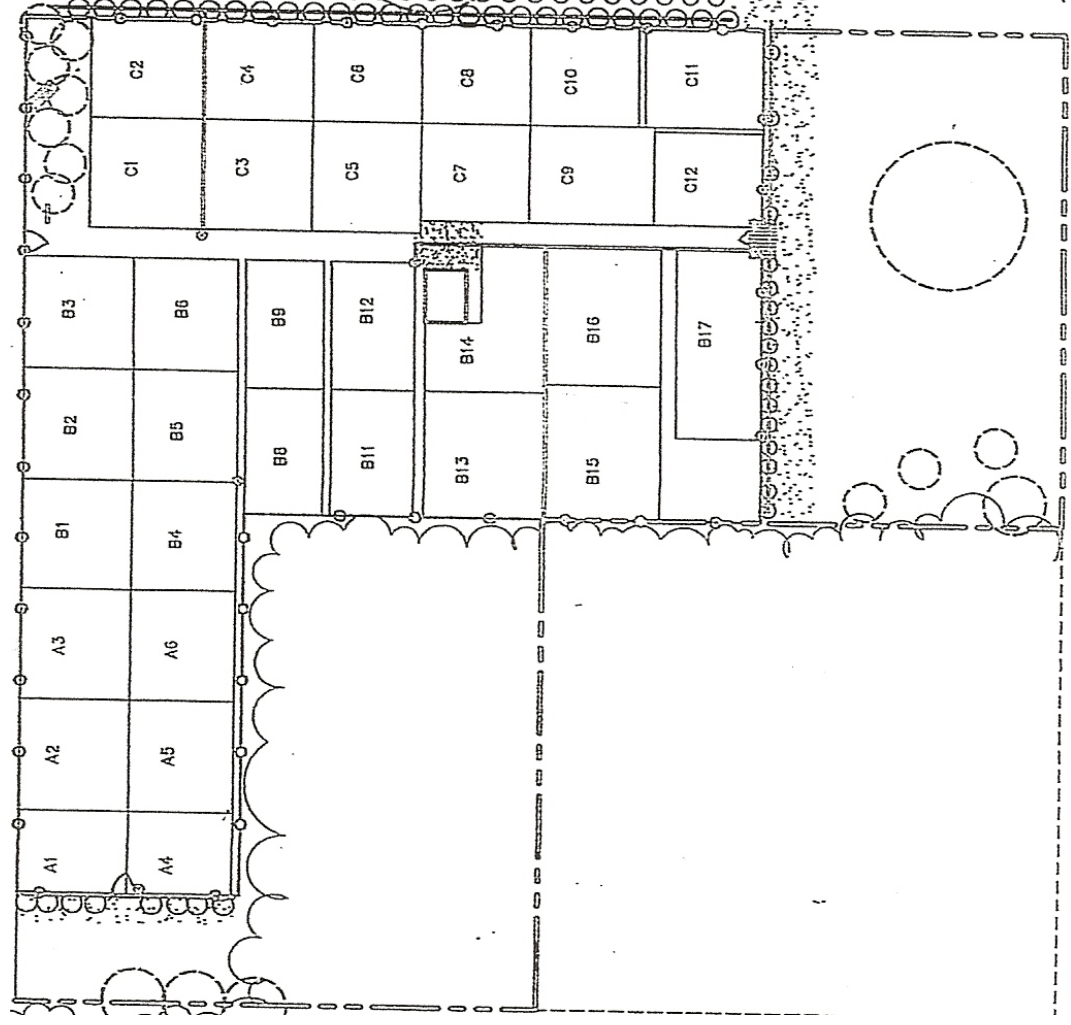


APPENDIX D. FIELD DATA COLLECTION

D.1 Camera Script

\section{Script for Passing out Cameras}

Please take photographs of the following:

1. Your most important place in the garden

2. Your most enjoyable activity in the garden

3. Things that make you feel safe in the garden

4. Things that relax you in the garden

5. Things that you like the least about the garden

6. Things that may be outside the garden area but are still important to you and somehow connect you with the garden

7. Other things that you associate with the garden 
APPENDIX D.2

FIELD DATA COLLECTION

In-Depth Interview Script

\section{$\underline{\text { General Introductory Information }}$}

Total Gardening Experience/Years: Years in the Garden: Years lived in the general area? Distance to garden/Travel to garden; Visits to garden: how many times per week?

\section{Part I. Photo Storytelling}

Please describe your pictures of:

1) Your most important place in the garden

2) Your most enjoyable activity in the garden

3) Things that make you feel safe in the garden

4) Things that relax you in the garden

5) Things that you like the least about the garden

6) Things that may be outside the garden area but are still important to you and somehow connect you with the garden

\section{Part II. Follow Up Questions}

[interview follow up]

1. Please choose your three most important pictures/why are they most important?

2. Is your experience in the garden more about people or place?

3. How did the garden change your life? (assuming it did)?

4. What would you do if the garden were to be developed into something different?

5. Community gardening does not seem to be convenient. What is it worth to you? Why do you do that?

[field observation related follow up questions]

6. How many people do you typically see in the garden/how people form connections in the garden?

7. How can you tell who is a stranger in the garden? 
8. How do people typically use common spaces? Should anything be changed to make it different?

9. Should people who live near the garden be engaged in the garden (even if they are not registered gardeners)? 